\title{
Respiratory tract infections in general practice : enhanced communication skills and C-reactive protein testing to optimise management
}

Citation for published version (APA):

Cals, J. W. L. (2009). Respiratory tract infections in general practice : enhanced communication skills and C-reactive protein testing to optimise management. [Doctoral Thesis, Maastricht University]. Datawyse / Universitaire Pers Maastricht. https://doi.org/10.26481/dis.20091203jc

Document status and date:

Published: 01/01/2009

DOI:

10.26481/dis.20091203jc

Document Version:

Publisher's PDF, also known as Version of record

Please check the document version of this publication:

- A submitted manuscript is the version of the article upon submission and before peer-review. There can be important differences between the submitted version and the official published version of record.

People interested in the research are advised to contact the author for the final version of the publication, or visit the DOI to the publisher's website.

- The final author version and the galley proof are versions of the publication after peer review.

- The final published version features the final layout of the paper including the volume, issue and page numbers.

Link to publication

\footnotetext{
General rights rights.

- You may freely distribute the URL identifying the publication in the public portal. please follow below link for the End User Agreement:

www.umlib.nl/taverne-license

Take down policy

If you believe that this document breaches copyright please contact us at:

repository@maastrichtuniversity.nl

providing details and we will investigate your claim.
}

Copyright and moral rights for the publications made accessible in the public portal are retained by the authors and/or other copyright owners and it is a condition of accessing publications that users recognise and abide by the legal requirements associated with these

- Users may download and print one copy of any publication from the public portal for the purpose of private study or research.

- You may not further distribute the material or use it for any profit-making activity or commercial gain

If the publication is distributed under the terms of Article $25 \mathrm{fa}$ of the Dutch Copyright Act, indicated by the "Taverne" license above, 
Respiratory tract infections in general practice enhanced communication skills and $\mathrm{C}$-reactive protein testing to optimise management 
The studies presented in this dissertation were conducted under the auspices of the School for Public Health and Primary Care (CAPHRI) at Maastricht University, The Netherlands. CAPHRI is part of the Netherlands School of Primary Care Research (CaRe), which has been acknowledged since 1995 by the Royal Netherlands Academy of Art and Sciences (KNAW).

The studies related to the IMPAC ${ }^{3} \mathrm{~T}$ randomised trial were funded by the Netherlands Organisation for Health Research and Development (ZonMW Doelmatigheidsonderzoek, grant 045-04010). Additional funding for the qualitative studies was obtained from Axis Shield PoC AS (Norway). The CAPRESA randomised trial was funded by Orion Diagnostica (Finland).

(C) 2009 J.W.L. Cals, Maastricht

Cover design: Images courtesy of USGS National Center for EROS and NASA Landsat Project Science Office

Front cover: "Lungs of the world" Mississippi river delta, Gulf of Mexico

Back cover: Namibian desert, Coastline Guinea Bissau, Snow-capped peaks of the Himalaya, Araca river in Brazil's Amazon, Volcanoes in Chili (left to right)

Layout: Tiny Wouters

Production: Datawyse | Universitaire Pers Maastricht

ISBN: 9789052788814

Financial support for the printing of this thesis was kindly provided by:

Stichting Gezondheidscentra Eindhoven (www.sge.nl), Zorgverzekeraar CZ,

Orion Diagnostica (Finland), Axis-Shield PoC AS (Oslo, Norway),

Clindia Benelux, Mediphos, ZonMW AGIKO fellowship (grant 92003471). 


\title{
Respiratory tract infections in general practice enhanced communication skills and $\mathrm{C}$-reactive protein testing to optimise management
}

\begin{abstract}
PROEFSCHRIFT
ter verkrijging van de graad van doctor aan de Universiteit Maastricht, op gezag van de Rector Magnificus, Prof. mr. G.P.M.F. Mols

volgens het besluit van het College van Decanen, in het openbaar te verdedigen op donderdag 3 december 2009 om 14.00 uur
\end{abstract}

door

Jochen Willo Lennert Cals

geboren te Stein

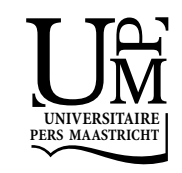


Promotor

Prof. dr. G.J. Dinant

Prof. dr. C.C. Butler (Cardiff University, United Kingdom)

Copromotor

Dr. R.M. Hopstaken

Beoordelingscommissie

Prof. dr. A.J.J.A. Scherpbier (voorzitter)

Prof. dr. J.A. Knottnerus

Prof. dr. T.J.M. Verheij (Universitair Medisch Centrum Utrecht)

Dr. T. van der Weijden 
Voor pap en mam 


\section{Table of contents}

$\begin{array}{lll}\text { Chapter } 1 \text { Introduction } & 9\end{array}$

Chapter 2 Public beliefs on antibiotics and respiratory tract infections: an 27 internet-based questionnaire study

British Journal of General Practice 2007;57:942-7

Huisarts en Wetenschap 2008;51:190-4

Chapter 3 Dose timing and patient compliance with two antibiotic treatment 39 regimens for lower respiratory tract infections in primary care International Journal of Antimicrobial Agents 2008;31:531-6

Chapter 4 Improving management of patients with acute cough by C-reactive protein point of care testing and communication training (IMPAC ${ }^{3} \mathrm{~T}$ ): study protocol of a cluster randomised controlled trial BMC Family Practice 2007;8:15

Chapter 5 Evidence based management of acute bronchitis; sustained competence of enhanced communication skills acquisition in general practice

Patient Education and Counseling 2007;68:270-8

Tijdschrift voor Medisch Onderwijs 2008;27:137-46

Chapter 6 Effect of point of care testing for C-reactive protein and training in communication skills on antibiotic use in lower respiratory tract infections: cluster randomised trial

British Medical Journal 2009;338:b1374

Huisarts en Wetenschap 2009;52:576-83

Huisarts Nu 2009;38:297-305

Chapter 7 Cost-effectiveness of C-reactive protein point of care testing and physician communication skills training in reducing antibiotic prescribing for lower respiratory tract infections in general practice

Submitted 
Chapter 8 Predictors of patient-initiated reconsultation for lower respiratory tract infections in general practice British Journal of General Practice 2009;59:761-4

Chapter 9 C-reactive protein point of care testing for lower respiratory tract infections; a qualitative evaluation of experiences in general practice

Submitted

Chapter 10 Testing C-reactive protein at the point of care to assist 161 antibiotic prescribing for respiratory tract infections: a randomized controlled trial in family practice Accepted for publication in Annals of Family Medicine

Chapter 11 'Experience talks': physician prioritisation of two contrasting 183 interventions to optimise management of acute cough in general practice

Implementation Science 2009;4:57

Chapter 12 General discussion

Chapter 13 Wrapping it up and bringing these findings back to practice: 215 a 10-minute consultation for acute cough

Submitted

Summary

Samenvatting

Dankwoord

Publications 

.

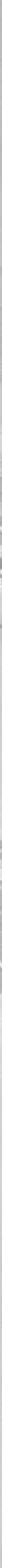

"Antibiotic therapy, if indiscriminately used, may turn out to be a medicinal flood that temporarily cleans and heals, but ultimately destroys life itself"

Felix Marti-Ibanez, 1955 
10 Chapter 1 


\section{Respiratory tract infections and antibiotics in general practice}

In the Netherlands and most other countries, most antibiotics are prescribed in general practice. Of these, the majority are prescribed to patients consulting for common respiratory tract infections (RTI). This is surprising, as antibiotics are shown to be of hardly any benefit to patients with the common cold $^{1}$, sore throat, otitis media, rhinosinusitis ${ }^{2}$ and acute bronchitis. ${ }^{3}$ Patients consulting for these conditions account for a vast amount of the daily workload in general practice with an estimated $15 \%$ of all contacts and approximately one million RTI related patient encounters annually in The Netherlands alone. ${ }^{4,5}$ Antimicrobial resistance, mainly driven by inappropriate use of antibiotics, is a growing problem worldwide with considerable costs. ${ }^{6,7}$ Yet globally, the Netherlands range among the countries with lowest antibiotic expenditure with particular low prescribing rates for most upper respiratory tract infections. ${ }^{8-10}$ Nonetheless, antibiotic prescribing rates for lower respiratory tract infections (LRTI) and rhinosinusitis are at a comparable rate to primary care settings of high-prescribing countries. ${ }^{9,11}$ Another undesirable development is the increased use of broad-spectrum antibiotics. Although this increase is more prominent in the $\mathrm{US}^{12}$ and some other European countries ${ }^{13}$, data from The Netherlands also show an increase in the use of these substances, particularly for LRTI. ${ }^{14,15}$ Everyday decisions about when to prescribe antibiotics for LRTI constitute a significant part of the burden of antibiotic use that drives antibiotic resistance. ${ }^{16,17}$ Because the pharmaceutical industry pipeline for new antibiotics has been curtailed in recent years, and it may be more than 10 years before important new antibiotics find their way to the market, maintaining the effectiveness of the currently available agents is crucial. $^{18}$ Improving antimicrobial stewardship is therefore of utmost importance and primary care has been and will be the area to gain most. ${ }^{19,20}$ The previously suggested $4 \times 80 \%$ rule emphasises the need for effective interventions in this field. ${ }^{21}$

- $80 \%$ of all antibiotics are prescribed in primary care. ${ }^{1422}$

- $80 \%$ of these prescriptions are for respiratory tract infections. ${ }^{1423}$

- $80 \%$ of all LRTI patients in primary care are treated with antibiotics, despite evidence of benefit in only a small minority of cases. ${ }^{14} 24$

- $\quad 80 \%$ of all LRTI patients have acute bronchitis, which is typically self-limiting and rarely requires antibiotic treatment. ${ }^{3}$

In this general introduction and throughout this thesis I will first consider and build upon the available evidence on why antibiotics are over prescribed for RTI. I will then propose and investigate how prescribing behaviour may be changed using tailored interventions specifically aimed at these factors before evaluating why certain possible changes occurred. In the discussion a further 
elaboration on how these processes may be further improved and implemented will also be presented. The main part of this thesis, and this underlying introduction, will focus on LRTI, but some parts also cover rhinosinusitis and RTIs in general.

\section{Antibiotic over prescribing for lower respiratory tract infections - Why?}

In general, antibiotic over prescribing for LRTI in general practice can broadly be related to two distinct factors within the RTI consultation. Clinicians' diagnostic uncertainty in differentiating serious from self-limiting disease and patient related factors during the time-pressured RTI consultation.

\section{Diagnostic uncertainty}

While most respiratory tract infections are self-limiting, some are potentially lifethreatening, such as cases of pneumonia, which constitute a small but clinically meaningful part of all LRTI in general practice. However, acute bronchitis accounts for most LRTI episodes, which is usually self-limiting. Accurately differentiating pneumonia from acute bronchitis based on clinical findings from medical history and physical examination is near to impossible, with a large discrepancy between clinical findings and radiographic pneumonia. ${ }^{25-27}$ The supposed gold-standard for diagnosing pneumonia, chest $X$-rays, are not routinely used in the Netherlands for economic and logistic reasons. ${ }^{28}$ Furthermore, radiographic examination of chest X-rays in LRTI patients from general practice show considerable variation, questioning its reliability. ${ }^{29}$ The superior gold-standard, high resolution computed tomography is far from feasible in primary care LRTI patients. ${ }^{30}$ However in the light of possible pneumonia and with no readily available diagnostic test to rule out this condition, many general practitioners (GPs) empirically prescribe antibiotics to most LRTI patients, both pneumonia and acute bronchitis. Antibiotic prescribing is often initiated upon detecting non evidence-based factors suggestive of pneumonia such as auscultation abnormalities. ${ }^{31,32}$ Moreover, physicians sometimes tend to use the diagnostic label acute bronchitis as an indication for antibiotic treatment. ${ }^{33}$ Several studies have indicated that to practicing GPs the needs of individuals with potential infections and maintaining good relationships with patients outweigh the perceived risk of bacterial resistance. ${ }^{34-36}$ Yet despite this, many GPs do acknowledge that many prescriptions are unnecessary ${ }^{37}$, and admit feeling uncomfortable in that particular situation. ${ }^{36}$

Treatment recommendations in guidelines are mainly based on clinical diagnoses. $^{38,39}$ Yet with the obvious inability to accurately make these 
diagnoses in general practice, recommendations are hard to follow. From a disease perspective therefore, there is a need to have additional guidance on diagnosis in LRTI.

\section{Patient related factors}

When consulting for RTI patient motivations include the desire for a tangible product of the clinical encounter. Antibiotics are perceived as strong, efficient drugs by patients, and many patients, more than their treating GPs, endorse the severity of respiratory tract symptoms and the ability of antibiotics to speed up recovery. ${ }^{40,41}$ Patient demand and expectations have also been shown to affect antibiotic prescribing. Perceived pressure from patients in general is a strong predictor of whether clinicians examine, prescribe or refer. ${ }^{42}$ Yet, the explanation of patients' expectations as driver of unnecessary antibiotic use lies not in those expectations themselves, but in clinicians misperceptions of these needs and expectations of the consultation. ${ }^{43}$ In prescribing decision in general, patients in which the GP thought that they wanted medication, were ten times more likely to be prescribed medication. ${ }^{44}$ When solely focusing on antibiotic prescribing decisions, the effect of perceived patient demand was significantly associated with the decision to prescribe, even when controlling for case-mix and GP characteristics, with a likelihood of five and higher being reported when patient demand was perceived. ${ }^{45}$ Strikingly, GPs are poor at predicting which patients expect medication. ${ }^{46}$ Furthermore, patient satisfaction is hardly related to antibiotic prescribing, although this is often believed by practicing clinicians. The time spent listening or performing physical examination on the other hand, is significantly associated with satisfaction. ${ }^{47,48}$ As the ultimate consumers, patients play a pivotal role in the emergence of bacterial resistance. Improved understanding of beliefs, concerns and expectations, from both the patients' and clinicians' point of view, are crucial steps in restricting antibiotic use in general practice. ${ }^{43}$ When we know that GPs' perceptions of patients' expectations predict antibiotic prescribing, eliciting these patients' agenda's during RTI consultations is of utmost importance. There is growing evidence that implementation of patient-centered strategies, in conjunction with educational strategies, help to change behaviour and improve appropriate antibiotic prescribing. ${ }^{43,49,50}$ In the end, it is antibiotic over prescribing driving antibiotic over use, which then creates the desire and expectation for another antibiotic prescription when suffering from similar symptoms in the future, putting pressure on antibiotic prescribing. Crucially, when developing the interventions to combat this cycle with a focus on changing prescribing behaviour, barriers to change need to be addressed, and their results should be evaluated in prospective randomised trials. ${ }^{51,52}$ 


\section{Improving management of lower respiratory tract infections - How?}

Based on theory from patient centred methods in medicine two conceptualisations of ill health need to be distinguished: disease and illness. Effective patient care - and improving management of RTls for that matter requires attending to patients' personal experience of illness as well as their disease. Disease is diagnosed by objective observation, by which physicians try to explain patients' problems in terms of abnormalities of structure or function of body organs and systems. Illness, on the other hand, is the patient's personal and subjective experience of sickness; the feelings, thoughts, and altered behaviour of someone who feels sick. ${ }^{53}$

The previously described driving factors of inappropriate antibiotic prescribing can be seen from the disease perspective (clinicians' diagnostic uncertainty) and the illness perspective (patient related factors, including (perceived) patients' expectations, validating concerns, understanding how the illness is impacting on the patients life, information exchange and conveying an accurate idea of prognosis by setting realistic expectations) and the possible solution may lie in targeting these factors based on a framework addressing both the GPs' and patients' agenda. ${ }^{50}$

When trying to change behaviour - changing physician antibiotic prescribing behaviour in this thesis - the concept of readiness to change derived from health behaviour counselling may be relevant to keep in mind. ${ }^{54}$ Readiness to change in this model is driven by the 'importance of change' (the "why" of changing) and 'confidence in changing' (the "how" of changing) (Figure 1.1). In this introduction, we have outlined the importance of change and provided evidence that GPs see the importance of changing antibiotic prescribing. The interventions are means of providing them with the "how" of changing, giving them feasible interventions to facilitate readiness to change and subsequently achieve a change in antibiotic prescribing behaviour. 


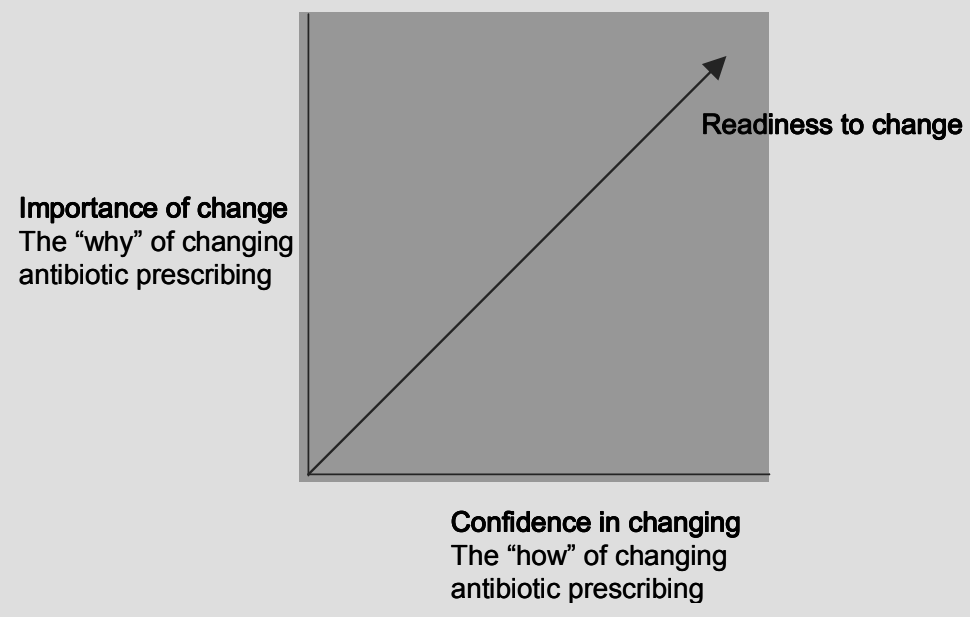

Figure 1.1 Readiness to change antibiotic prescribing: considering "why" and "how".

\section{The interventions in this thesis}

In this thesis we study two distinct interventions to improve management of LRTI; point of care testing for C-reactive protein as a disease focused approach and enhanced communication skills training as an illness focused approach.

\section{Addressing diagnostic uncertainty: C-reactive protein point of care testing - the disease focused intervention}

C-reactive protein, originally named for its capacity to precipitate the Cpolysaccharide of Streptococcus pneumoniae, was the first acute-phase protein to be described. ${ }^{55}$ The acute phase response comprises the non-specific physiological and biochemical response to most forms of tissue damage, infection and inflammation. ${ }^{56}$ C-reactive protein is a widely used and acknowledged marker to diagnose and monitor infections in secondary care. With the emerge of point of care devices in the 1980's Melbye et al. were the first to evaluate the diagnostic value of the test in LRTI in primary care. ${ }^{57}$ Unfortunately, the widespread introduction of point of care CRP testing in the Scandinavian countries was not accompanied by appropriate training for clinicians. Hence, in some settings this has sometimes led to an overuse of CRP testing in mostly mild respiratory tract infections, often followed by an unnecessary antibiotic course. ${ }^{58,59}$

Robustness for the CRP point of care tests is now firmly established with three studies showing reliability and accuracy of test results obtained from point of 
care devices when compared to laboratory standards. ${ }^{60-62}$ Diagnostic studies supporting its role as an additional diagnostic marker in LRTI gradually also emerged. ${ }^{26,63,64}$ A systematic review on the diagnostic role of CRP in LRTI in primary care showed that CRP was a strong predictor in differentiating pneumonia from acute bronchitis. ${ }^{65}$ Leading on from his diagnostic study in LRTI Hopstaken mentioned several barriers for the implementation of CRP as part of routine diagnostic work-up in LRTI, which included the hesitation of GPS to alter existing clinical procedures and the absence of strong randomised evidence that using point of care CRP could decrease antibiotic prescribing. ${ }^{21}$

Secondary care clinicians could argue that an additional diagnostic test should differentiate between bacterial and viral infections. Yet, based on large aetiological LRTI cohorts we know that causative organisms can only by found in the minority of RTI cases in general practice. ${ }^{25-27,66-69}$ So although this aim holds for targeting appropriate antibiotic treatment in secondary care, a diagnostic test in primary care should not necessarily differentiate between bacterial and viral origin of the RTI. The ultimate aim of such a test would be to assist GPs to differentiate serious from self-limiting infections and as a result assist them in withholding antibiotics in the group of patients with the latter. Taking this assumption as a starting point we define criteria for a successful point of care test for RTI in general practice:

1 The test needs to have a valuable role in differentiating serious from selflimiting RTI

2 Results of the test - that is easy to use, robust and reliable ${ }^{70}$ - need to be available within the standard 10-minute consultation

3 The test needs to be accompanied by evidence-based information on how to interpret results

4 The test needs to be effective in reducing inappropriate antibiotic prescribing compared to current usual practice without compromising patient recovery

5 The test needs to be cost-effective

Based on extensive Scandinavian research and the available range of diagnostic studies we know that criteria 1 and 2 are present for CRP point of care testing. However, conditions 4 and 5 form the gap in de evidence-base of this disease focused intervention. In order to guide health policy decisions and promote efficient uptake of research findings into routine practice we planned to obtain pragmatic randomised evidence of the introduction of CRP point of care testing in the management of RTI, with the emphasis on LRTI. To ascertain condition 3, the introduction of the test was accompanied by an evidence-based training on the role of CRP in LRTI and guidance on interpretation. 


\section{Addressing patient related factors: enhanced communication skills training - the illness focused intervention}

Changing physicians' communication skills is challenging. Communication skills components applied in the field of RTI were variably successful in decreasing inappropriate antibiotic prescribing. ${ }^{49,71}$ Sanson Fisher stated that in order for communication skills to be effective in post-training medical practice, they must be taught within an appropriate clinical context, while providing rationale for seven criteria by which to select clinical issues which are appropriate foci for communication skills training. ${ }^{72}$ These criteria are:

1 The issue must be one which is encountered frequently in clinical practice

2 The issue must be associated with a high burden of illness

3 There must be evidence that practitioners need to improve skills for dealing with the issue

4 There must be an intervention, of which communication skills are an integral component, that is demonstrably effective for dealing with the clinical issue

5 The intervention must represent a cost-effective means of dealing with the issue

6 The intervention must be acceptable to doctors and be able to be incorporated into routine medical practice

7 The intervention must be acceptable to patients

As an extension to the fourth criterion, and specifically when attempting to optimise management of LRTI by communication skills training, I would like to add that the communication training method needs to be effective in reducing inappropriate antibiotic prescribing. Based on the previous outline in this introduction it can be concluded that within the field of prescribing decisions in LRTI the first three criteria very much apply. However, conditions 4 and 5 form the gap in de evidence-base of this illness focused approach.

We set out to develop an evidence-based context-bound communication skills training, specifically drafted to assist GPs in dealing with LRTI patients with the aim to achieve 4 and 5 , while facilitating criteria 6 and 7 . We took the method introduced by Rollnick et al., which proved to be acceptable and applicable to GPs and adaptable to a range of scenarios ${ }^{54,73}$, and further developed it for use in LRTI consultations. The communication skills and the illness focused approach is not just about assessing expectations about treatment. It is also about validating concerns, understanding how the illness is impacting on the patients life, information exchange (the evidence for and against antibiotic use for example) and conveying an accurate idea of prognosis (setting realistic expectations). Based on Rollnick's findings in a pilot study of the method, we could assume that criteria 4 and 5 were feasible to be achieved. ${ }^{74}$

We therefore planned to collect pragmatic randomised evidence of enhanced physician communication skills in the management of LRTI. 


\section{Aim of this thesis - bridging the evidence gaps}

To study the effectiveness and cost-effectiveness of CRP point of care testing and physician communication skills training on antibiotic use and clinical recovery in LRTI in general practice. To achieve a deeper understanding of the acceptability, applicability and adaptability of CRP point of care testing and physician communication skills training in the management of RTI in general practice.

\section{Main research questions}

With the specific aim of this thesis in mind, the following main research questions were formulated:

1 What is the effect of GP use of CRP point of care testing on antibiotic use and clinical recovery in LRTI?

2 What is the effect of physician communication skills training on antibiotic use and clinical recovery in LRTI?

3 What is the cost-effectiveness of these approaches from the health care perspective? 


\section{Outline of thesis}

While these research questions form the backbone of this thesis, other secondary research questions and projects were formulated and undertaken along the way. All the chapters in this thesis have one key aim in common; in each chapter we try to bridge evidence gaps in the management of respiratory tract infections in general practice.

We know that patients' expectations and pressure influence the RTI consultation. However, only little is known on the assumptions and beliefs in the general population. As patients' expectations at the point of care for an acute RTI may be shaped by these beliefs we investigated public beliefs on antibiotic use and respiratory tract infections in a cross-sectional internet-based questionnaire study with a sample of 935 respondents representative for the Dutch population (Chapter 2).

Most studies investigating the effect of antibiotics for LRTI were done without appropriate compliance measurements. ${ }^{3}$ So we have no evidence on overall adherence with antibiotics, consisting of compliance (dose intakes) and persistence (number of days for which patients continue to take medication). Moreover, physicians are particular poor at predicting compliance in their patients. ${ }^{41}$ Electronic monitoring is the current state-of-the-art method of measuring compliance. ${ }^{75,76}$ With the varying duration and regimens of antibiotics courses in Europe $^{77}$, it is relevant to gain knowledge on compliance and persistence in short-term antibiotic treatment. In the Netherlands, a once-daily or three-times daily regimen are currently recommended as the first choices of treatment in the national guideline on acute cough. ${ }^{38}$ We used data from an existing cohort of 155 LRTI patients with electronically monitored compliance, previously enrolled in a diagnostic and therapeutic LRTI study. ${ }^{78}$ The objective of this analysis was to assess compliance with a 10-day treatment of antibiotics and placebo once-daily and three-times-daily for LRTI using electronic monitoring, and to evaluate whether compliance depends on time since start of treatment and weekday by assessing taking compliance, timing compliance, correct dosing compliance and mean interdose intervals (Chapter 3 ).

With the recent requirement of submitting trial protocols to clinical trial registries before start of patient recruitment, transparency in trial procedures and appropriate reporting of outcomes has dramatically improved. ${ }^{79} 80$ Publication of a trial protocol has similar advantages. It forces researchers to predefine analysing strategies and it allows discussing methodological considerations prior to recruitment and reporting. In chapter 4 we present the trial protocol of the IMPAC ${ }^{3} T$ cluster randomised factorial trial in general practice. Besides extensive description of the interventions and background, specific choices in randomisation, sample size calculation and planned analysis are elaborated upon. 
Competency based assessments measure what doctors can do in controlled representations of professional practice; performance based assessments measure what doctors actually do in professional practice. Competence, therefore, is a prerequisite for performance. ${ }^{81}$ Before assessing the effects of our communication skills training method on clinical outcomes, GPs' competence of implementing the used method needed to be established. Chapter 5 describes the key features of the program, involving simulated patients and peer-review of transcripts, and presents data on the competence of 20 GPs in communicating with LRTI simulated patients shortly before and six months after the workshop-based training. The participating GPs in this study had been randomised and allocated to the enhanced communication skills training, as participants in the IMPAC ${ }^{3} T$ trial.

Chapter 6 describes the clinical outcomes of the IMPAC ${ }^{3} T$ cluster randomised trial evaluating the effect of CRP point of care testing and enhanced physician communication skills training on antibiotic use and clinical recovery in LRTI in general practice. The trial involved $40 \mathrm{GPs}$ and $431 \mathrm{LRTI}$ patients and can be regarded as the backbone of this thesis.

There have been few studies on the cost-effectiveness of interventions aimed at improving antimicrobial stewardship. Such studies are urgently needed to guide investment in strategies to reduce inappropriate antibiotic prescribing, considering increasing antibiotic resistance and lack of development of new antibiotics. ${ }^{18}$ We therefore performed a cost effectiveness analysis alongside our trial to determine the incremental cost-effectiveness of three strategies - GP use of CRP, GP communication skills training, and GP use of both CRP and communication training - compared to usual care from a health care perspective. These finding are presented in chapter 7.

LRTI constitutes a fair amount of workload in general practice and reconsultation is common, yet mostly unnecessary, as evidence indicates that new treatment is rarely indicated at the point of reconsultation. ${ }^{82}$ Reconsultation can either be GP-requested or patient-initiated. There is no information on predictors of the latter, but knowing determinants of patient-initiated reconsultation could guide GPs in trying to detect and address these factors at the initial consultation. We used data from the IMPAC ${ }^{3} T$ trial to investigate independent predictors of patient-initiated reconsultation for LRTI within 28-days follow-up in chapter 8.

Following completion of the IMPAC ${ }^{3} \mathrm{~T}$ trial we semi-structured interviewed all participating GPs to elicit their experiences with and attitudes towards the CRP point of care test in the management of LRTI. In chapter 9 we present qualitative data on the GPs' attitudes to and experiences with using the test for LRTI and other common infections in general practice. We identified perceptions of barriers and opportunities to uptake among those who had 
recently started using the test in order to possibly develop plans for successful wider implementation into routine clinical care.

Based on findings from the studies presented in chapter 6 and 8 and based upon the reflections of GPs in chapter 9, we designed a second randomised controlled trial. As GPs expressed difficulties in dealing with intermediately elevated CRP test results and explaining these to their patients, and as intermediately elevated CRP results were independently associated with reconsultation, we set out to investigate if delayed prescriptions could be a suitable prescribing strategy for these patients. Furthermore, we decided to extend our inclusion criteria to rhinosinusitis patients. Previous research has shown a possible role of CRP in rhinosinusitis and prescribing figures for this condition are comparably high compared to LRTI in the Netherlands, despite evidence of hardly any benefit for the patient. ${ }^{2,9,83,84}$ Chapter 10 therefore presents findings from the CAPRESA trial. This study involved 31 GPs and 258 patients with LRTI or rhinosinusitis and studied the effect of CRP assistance in antibiotic prescribing strategies - including delayed prescribing - in LRTI and rhinosinusitis consultations in general practice.

In chapter 11, we present a thematic analysis of semi-structured interviews exploring views and GPs' prioritisation of the illness-focused intervention (communication skills training) and the disease-focused intervention (CRP point of care testing) to optimise management of LRTI among 10 GPs who had used both interventions for two years in the IMPAC ${ }^{3} \mathrm{~T}$ randomised trial (exposed GPs), and 10 GPs without experience of either intervention (non-exposed GPs) in order to display the role of experiences with and attitudes towards interventions when possibly planning rollout of interventions aimed at changing clinical practice.

In the general discussion in chapter 12 , we discuss the overall methodological considerations of the presented studies and elaborate on possible implications for clinical practice and future research.

Finally, chapter 13 aims to bring these findings back to practice. It gives an outline of what can be said and done in a 10-minute consultation for acute cough and it suggests an approach to a first consultation in a time-pressured primary care setting. 


\section{References}

1. Arroll B, Kenealy T. Antibiotics for the common cold and acute purulent rhinitis. Cochrane Database Syst Rev 2005:CD000247.

2. Arroll B. Antibiotics for upper respiratory tract infections: an overview of Cochrane reviews. Respir Med 2005;99:255-61.

3. Smucny J, Fahey T, Becker L, Glazier R. Antibiotics for acute bronchitis. Cochrane Database Syst Rev 2004.

4. Hak E, Rovers MM, Kuyvenhoven MM, Schellevis FG, Verheij TJ. Incidence of GP-diagnosed respiratory tract infections according to age, gender and high-risk co-morbidity: the Second Dutch National Survey of General Practice. Fam Pract 2006;23:291-4.

5. Gageldonk-Lafeber ABv, Heijnen M-LA, Bartelds AIM, Peters MF, Plas SMvd, Wilbrink B. A Case-Control Study of Acute Respiratory Tract Infection in General Practice Patients in The Netherlands. Clin Infect Dis 2005;41:490-7.

6. Levy SB. Factors impacting on the problem of antibiotic resistance. J. Antimicrob. Chemother. 2002;49:25-30.

7. Metlay JP, Powers JH, Dudley MN, Christiansen K, Finch RG. Antimicrobial drug resistance, regulation, and research. Emerg Infect Dis 2006;12:183-90.

8. Goossens H, Ferech M, Vander Stichele R, Elseviers M. Outpatient antibiotic use in Europe and association with resistance: a cross-national database study. Lancet 2005;365:579-87.

9. Akkerman AE, Kuyvenhoven MM, van der Wouden JC, Verheij TJ. Prescribing antibiotics for respiratory tract infections by GPs: management and prescriber characteristics. $\mathrm{Br} \mathrm{J}$ Gen Pract 2005;55:114-8.

10. Goossens H, Ferech M, Coenen S, Stephens P. Comparison of outpatient systemic antibacterial use in 2004 in the United States and 27 European countries. Clin Infect Dis 2007; 44:1091-5.

11. Gonzales R, Steiner JF, Sande MA. Antibiotic prescribing for adults with colds, upper respiratory tract infections, and bronchitis by ambulatory care physicians JAMA 1997;278: 901-4.

12. Steinman MA, Gonzales R, Linder JA, Landefeld CS. Changing Use of Antibiotics in Community-Based Outpatient Practice, 1991-1999. Ann Intern Med 2003;138:525-533.

13. Ferech M, Coenen S, Malhotra-Kumar S, Dvorakova K, Hendrickx E, Suetens C, Goossens H; ESAC Project Group. European Surveillance of Antimicrobial Consumption (ESAC): outpatient antibiotic use in Europe. J. Antimicrob. Chemother. 2006;58:401-7.

14. Kuyvenhoven MM, Van Balen FA, Verheij TJ. Outpatient antibiotic prescriptions from 1992 to 2001 in The Netherlands. J Antimicrob Chemother 2003;52:675-8.

15. van Duijn HJ, Kuyvenhoven MM, Schellevis FG, Verheij TJM. Determinants of prescribing of second-choice antibiotics for upper and lower respiratory tract episodes in Dutch general practice J. Antimicrob. Chemother. 2005;56:420-2.

16. Bradley JS, Guidos R, Baragona S, Bartlett JG, Rubinstein E, Zhanel GG, Tino MD, Pompliano DL, Tally F, Tipirneni P, Tillotson GS, Powers JH, Tillotson GS. Anti-infective research and development--problems, challenges, and solutions. Lancet Infect Dis 2007;7: 68-78.

17. Nordberg P, Monnet DL, Cars O. Antibacterial drug resistance: options for concerted action. World Health Organization Department of Medicines Policy and Standards. Geneva, 2005: 1-48.

18. Wenzel RP. The antibiotic pipeline--challenges, costs, and values. N Engl J Med 2004;351: 523-6.

19. Fishman N. Antimicrobial Stewardship. The American Journal of Medicine Antimicrobial Resistance Prevention Initiative: Proceedings of an Expert Panel on Resistance 2006;119(S1): S53-S61.

20. Cosby JL, Francis N, Butler CC. The role of evidence in the decline of antibiotic use for common respiratory infections in primary care. Lancet Infect Dis 2007;7:749-56. 
21. Hopstaken RM. Lower respiratory tract infections in general practice; aetiology, diagnosis, management and prognosis. Maastricht University, 2005.

22. Wise R, Hart T, Cars O, Streulens M, Helmuth R, Huovinen P, Sprenger M. Antimicrobial resistance. BMJ 1998;317:609-10.

23. Gonzales R, Steiner JF, Lum A, Barrett PH, Jr. Decreasing antibiotic use in ambulatory practice: impact of a multidimensional intervention on the treatment of uncomplicated acute bronchitis in adults. JAMA 1999;281:1512-9.

24. Holmes WF, Macfarlane JT, Macfarlane RM, Hubbard R. Symptoms, signs, and prescribing for acute lower respiratory tract illness. Br J Gen Pract 2001;51:177-81.

25. Holm A, Nexoe J, Bistrup LA, Pedersen SS, Obel N, Nielsen LP, Pedersen C. Aetiology and prediction of pneumonia in lower respiratory tract infection in primary care. $\mathrm{Br} \mathrm{J}$ Gen Pract 2007;57: 547-54.

26. Hopstaken RM, Muris JWM, Knottnerus JA, Kester ADM, Rinkens PELM, Dinant GJ. Contributions of symptoms, signs, erythrocyte sedimentation rate and C-reactive protein to a diagnosis of pneumonia in acute lower respiratory tract infection. $\mathrm{Br} J$ Gen Pract 2003;53: 358-64.

27. Melbye H, Straume B, Aasebo U, Dale K. Diagnosis of pneumonia in adults in general practice. Relative importance of typical symptoms and abnormal chest signs evaluated against a radiographic reference standard. Scand J Prim Health Care 1992;10:226-33.

28. Cals J, Hopstaken R. Lower respiratory tract infections: treating patients or diagnoses? J Fam Pract 2006;55:545-6; author reply 546-7.

29. Hopstaken RM, Witbraad T, van Engelshoven JMA, Dinant GJ. Interobserver variation in the interpretation of chest radiographs for pneumonia in community-acquired lower respiratory tract infections. Clin Radiol 2004;59:743-52.

30. Syrjala H, Broas M, Suramo I, Ojala A, Lahde S. High-resolution computed tomography for the diagnosis of community-acquired pneumonia. Clin Infect Dis 1998;27:358-63.

31. Fischer T, Fischer S, Kochen MM, Hummers Pradier E. Influence of patient symptoms and physical findings on general practitioners' treatment of respiratory tract infections: a direct observation study. BMC Fam Pract 2005;6:6.

32. Hopstaken RM, Butler CC, Muris JW, Knottnerus JA, Kester AD, Rinkens PE, Dinant GJ. Do clinical findings in lower respiratory tract infection help general practitioners prescribe antibiotics appropriately? An observational cohort study in general practice. Fam. Pract. 2006; 23:180-7.

33. Gonzales R, Barrett PH, Jr., Crane LA, Steiner JF. Factors associated with antibiotic use for acute bronchitis. J Gen Intern Med 1998;13:541-8.

34. Simpson SA, Wood F, Butler CC. General practitioners' perceptions of antimicrobial resistance: a qualitative study. J Antimicrob Chemother 2007;59:292-6.

35. Wood F, Simpson S, Butler CC. Socially responsible antibiotic choices in primary care: a qualitative study of GPs' decisions to prescribe broad-spectrum and fluroquinolone antibiotics. Fam Pract 2007;24:427-34.

36. Butler CC, Rollnick S, Pill R, Maggs Rapport F, Stott N. Understanding the culture of prescribing: qualitative study of general practitioners' and patients' perceptions of antibiotics for sore throats. BMJ 1998;317:637-42.

37. Macfarlane J, Lewis SA, Macfarlane R, Holmes W. Contemporary use of antibiotics in 1089 adults presenting with acute lower respiratory tract illness in general practice in the U.K.: implications for developing management guidelines. Respir Med 1997;91:427-34.

38. Verheij TJM, Salomé PL, Bindels PJ, Chavannes AW, Ponsioen BP, Sachs APE, et al. NHGStandaard Acuut hoesten. Dutch College of General Practitioners Guidelines on Acute Cough. Huisarts Wet 2003;46:496-506.

39. Woodhead M, Blasi F, Ewig S, Huchon G, leven M, Ortqvist A, Schaberg T, Torres A, van der Heijden G, Verheij TJ; European Respiratory Society; European Society of Clinical Microbiology and Infectious Diseases. Guidelines for the management of adult lower respiratory tract infections. Eur Respir J 2005;26:1138-80. 
40. van Duijn HJ, Kuyvenhoven MM, Schellevis FG, Verheij TJ. Views on respiratory tract symptoms and antibiotics of Dutch general practitioners, practice staff and patients. Patient Educ Couns 2006;61:342-7.

41. Pechere JC. Patients' interviews and misuse of antibiotics. Clin Infect Dis 2001;33(S3): S170-3.

42. Little P, Dorward M, Warner G, Stephens K, Senior J, Moore M. Importance of patient pressure and perceived pressure and perceived medical need for investigations, referral, and prescribing in primary care: nested observational study. BMJ 2004;328:444-.

43. Davey $P$, Pagliari $C$, Hayes $A$. The patient's role in the spread and control of bacterial resistance to antibiotics. Clin Microbiol Infect 2002;8(S2):43-68.

44. Cockburn J, Pit S. Prescribing behaviour in clinical practice: patients' expectations and doctors' perceptions of patients' expectations-a questionnaire study BMJ 1997;315:520-3.

45. Coenen S, Michiels B, Renard D, Denekens J, Van Royen P. Antibiotic prescribing for acute cough: the effect of perceived patient demand. Br J Gen Pract 2006;56:183-90.

46. Hamm RM, Hicks RJ, Bemben DA. Antibiotics and respiratory infections: are patients more satisfied when expectations are met? J Fam Pract 1996;43:56-62.

47. Lundkvist J, Akerlind I, Borgquist L, Molstad S. The more time spent on listening, the less time spent on prescribing antibiotics in general practice. Fam Pract 2002;19:638-40.

48. Shapiro E. Injudicious antibiotic use: an unforeseen consequence of the emphasis on patient satisfaction? Clin Ther 2002;24:197-204.

49. Welschen I, Kuyvenhoven MM, Hoes AW, Verheij TJM. Effectiveness of a multiple intervention to reduce antibiotic prescribing for respiratory tract symptoms in primary care: randomised controlled trial. BMJ 2004;329:431.

50. Butler CC, Kinnersley P, Prout H, Rollnick S, Edwards A, Elwyn G. Antibiotics and shared decision-making in primary care. J Antimicrob Chemother 2001;48:435-40.

51. Arnold SR, Straus SE. Interventions to improve antibiotic prescribing practices in ambulatory care. Cochrane Database Syst Rev 2005.

52. Raebel MA. Interventions to improve treatment of respiratory infections in ambulatory managed-care patients. Ann Pharmacother 2005;39:699-705.

53. Stewart M. Patient-centered medicine : transforming the clinical method. 2nd ed. ed. Abingdon: Radcliffe Medical, 2003.

54. Rollnick S, Mason P, Butler C. Health Behavior Change; a guide for practitioners: Churchill Livingston, 1999.

55. Pepys MB, Baltz ML. Acute phase proteins with special reference to C-reactive protein and related proteins (pentaxins) and serum amyloid A protein. Adv Immunol 1983;34:141-212.

56. Pepys MB, Hirschfield GM. C-reactive protein: a critical update. J. Clin. Invest. 2003;111: 1805-12.

57. Melbye H, Straume B, Aasebo U, Brox J. The diagnosis of adult pneumonia in general practice. The diagnostic value of history, physical examination and some blood tests. Scand J Prim Health Care 1988;6:111-7.

58. Andre M, Schwan A, Odenholt I. The use of CRP tests in patients with respiratory tract infections in primary care in Sweden can be questioned. Scand J Infect Dis 2004;36:192-7.

59. Engstrom S, Molstad S, Lindstrom K, Nilsson G, Borgquist L. Excessive use of rapid tests in respiratory tract infections in Swedish primary health care. Scand J Infect Dis 2004;36:213-8.

60. Esposito S, Tremolati E, Begliatti E, Bosis S, Gualtieri L, Principi N. Evaluation of a rapid bedside test for the quantitative determination of C-reactive protein. Clin Chem Lab Med 2005;43:438-40.

61. Dahler Eriksen BS, Lassen JF, Petersen PH, Lund ED, Lauritzen T, Brandslund I. Evaluation of a near-patient test for C-reactive protein used in daily routine in primary healthcare by use of difference plots. Clin Chem 1997;43:2064-75.

62. Seamark DA, Backhouse SN, Powell R. Field-testing and validation in a primary care setting of a point-of-care test for C-reactive protein. Ann Clin Biochem 2003;40:178-80.

63. Flanders SA, Stein J, Shochat G, Sellers K, Holland M, Maselli J, Drew WL, Reingold AL, Gonzales R. Performance of a bedside C-reactive protein test in the diagnosis of communityacquired pneumonia in adults with acute cough. Am J Med 2004;116:529-35. 
64. Melbye H, Straume B, Brox J. Laboratory tests for pneumonia in general practice: the diagnostic values depend on the duration of illness. Scand J Prim Health Care 1992;10: 234-40.

65. van der Meer V, Neven AK, Broek PJvd, Assendelft WJJ. Diagnostic value of C reactive protein in infections of the lower respiratory tract: systematic review. BMJ 2005;331:26-9.

66. Creer DD, Dilworth JP, Gillespie SH, Johnston AR, Johnston SL, Ling C, Patel S, Sanderson G, Wallace PG, McHugh TD. Aetiological role of viral and bacterial infections in acute adult lower respiratory tract infection (LRTI) in primary care. Thorax 2006;61:75-9.

67. Graffelman AW, Knuistingh Neven A, le Cessie S, Kroes ACM, Springer MP, van den Broek $\mathrm{PJ}$. Pathogens involved in lower respiratory tract infections in general practice. $\mathrm{Br} \mathrm{J}$ Gen Pract 2004;54:15-9.

68. Macfarlane J, Holmes W, Gard P, Macfarlane R, Rose D, Weston V, Leinonen M, Saikku P, Myint S. Prospective study of the incidence, aetiology and outcome of adult lower respiratory tract illness in the community. Thorax 2001;56:109-14.

69. Hopstaken RM, Stobberingh EE, Knottnerus JA, Muris JW, Nelemans P, Rinkens PE, Dinant GJ. Clinical items not helpful in differentiating viral from bacterial lower respiratory tract infections in general practice. Journal of Clinical Epidemiology 2005;58:175-83.

70. Price CP. Point of care testing. BMJ 2001;322:1285-8.

71. Briel M, Langewitz W, Tschudi P, Young J, Hugenschmidt C, Bucher HC. Communication training and antibiotic use in acute respiratory tract infections. A cluster randomised controlled trial in general practice. Swiss Med Wkly 2006;136:241-7.

72. Sanson Fisher R, Cockburn J. Effective teaching of communication skills for medical practice: selecting an appropriate clinical context. Medical education 1997;31:52-7.

73. Rollnick S, Kinnersley P, Butler C. Context-bound communication skills training: development of a new method. Med Educ 2002;36:377-83.

74. Rollnick S, Seale C, Kinnersley P, Rees M, Butler C, Hood K. Developing a new line of patter: can doctors change their consultations for sore throat? Med Educ 2002;36:678-81.

75. Cramer JA. Microelectronic systems for monitoring and enhancing patient compliance with medication regimens. Drugs 1995;49:321-7.

76. Garber MC, Nau DP, Erickson SR, Aikens JE, Lawrence JB. The concordance of self-report with other measures of medication adherence: a summary of the literature. Med Care 2004;42: 649-52.

77. Coenen S, Molstad S. Preferred antibiotics, dosages and length of treatments in general practice--a comparison between ten European countries. Eur J Gen Pract 2004;10:166-8.

78. Hopstaken RM, Nelemans P, Stobberingh EE, Muris JWM, Rinkens PELM, Dinant GJ. Is roxithromycin better than amoxicillin in the treatment of acute lower respiratory tract infections in primary care? A double-blind randomized controlled trial. J Fam Pract 2002;51:329-36.

79. Laine C, Horton R, Deangelis CD, Drazen JM, Frizelle FA, Godlee F, Haug C, Hébert PC, Kotzin S, Marusic A, Sahni P, Schroeder TV, Sox HC, Van der Weyden MB, Verheugt FW. Clinical Trial Registration: Looking Back and Moving Ahead. N Engl J Med 2007;356:2734-6.

80. De Angelis CD, Drazen JM, Frizelle FA, Haug C, Hoey J, Horton R, Kotzin S, Laine C, Marusic A, Overbeke AJ, Schroeder TV, Sox HC, Van Der Weyden MB; International Committee of Medical Journal Editors. Is this clinical trial fully registered?--A statement from the International Committee of Medical Journal Editors. N Engl J Med 2005;352:2436-8.

81. Rethans JJ, Norcini JJ, Barón-Maldonado M, Blackmore D, Jolly BC, LaDuca T, Lew S, Page GG, Southgate LH. The relationship between competence and performance: implications for assessing practice performance. Medical education 2002;36:901-9.

82. Macfarlane J, Prewett J, Rose D, Gard P, Cunningham R, Saikku P, Euden S, Myint S. Prospective case-control study of role of infection in patients who reconsult after initial antibiotic treatment for lower respiratory tract infection in primary care. BMJ 1997;315: 1206-10.

83. Bjerrum L, Gahrn Hansen B, Munck AP. C-reactive protein measurement in general practice may lead to lower antibiotic prescribing for sinusitis. Br J Gen Pract 2004;54:659-62.

84. Hickner JM, Bartlett JG, Besser RE, Gonzales R, Hoffman JR, Sande MA. Principles of appropriate antibiotic use for acute rhinosinusitis in adults: background. Ann Intern Med 2001;134:498-505. 




\section{Abstract}

Background

Patient expectations are among the strongest predictors of clinicians' antibiotic prescribing decisions. Although public knowledge, beliefs, and experiences of antibiotics contribute to these expectations, little is known about these public views.

\section{Aim}

To gain insight into public knowledge, beliefs, and experiences of antibiotics and respiratory tract infections.

Design of study

Cross-sectional, internet-based questionnaire study.

\section{Setting}

Members of the general public aged 16 years and over in the Netherlands.

\section{Methods}

Public knowledge, beliefs, and experiences of antibiotics and respiratory tract infections, as well as predictors of accurate knowledge of antibiotic effectiveness, were measured using 20 questions with sub-items. The questionnaire was given to a Dutch community-based nationwide internet panel of 15673 individuals. Of these, 1248 eligible responders were invited to participate; 935 responders $(75 \%)$ completed the questionnaire.

\section{Results}

Of the participants, $44.6 \%$ accurately identified antibiotics as being effective against bacteria and not viruses. Acute bronchitis was considered to require treatment with antibiotics by nearly $60 \%$ of responders. The perceived need for antibiotics for respiratory tract infection-related symptoms ranged from $6.5 \%$ for cough with transparent phlegm, to $46.2 \%$ for a cough lasting for more than two weeks.

\section{Conclusion}

Public misconceptions on the effectiveness of, and indications for, antibiotics exist. Nearly half of all responders $(47.8 \%)$ incorrectly identified antibiotics as being effective in treating viral infections. Doctors should be aware that unnecessary prescribing could facilitate misconceptions regarding antibiotics and respiratory tract infections. Expectations of receiving antibiotics were higher for the disease label 'acute bronchitis' than for any of the separate or combined symptoms prominently present in respiratory tract infection. Public beliefs and expectations should be taken into account when developing interventions targeting the public, patients, and physicians to reduce unnecessary prescribing of antibiotics for respiratory tract infections.

\section{How this fits in?}

Clinicians' decisions regarding prescribing antibiotics are often influenced and can be predicted by patient expectations. The knowledge that members of the public have of antibiotics, together with their beliefs and experiences of them, will shape these expectations. However, important misconceptions exist among the public about the effectiveness and the appropriate indications for antibiotics. Focusing on symptoms may be preferable to mentioning microbiological distinctions and disease labels when communicating with patients on antibiotics for respiratory tract infections. 


\section{Introduction}

In an era of increasing antimicrobial resistance, reducing overprescribing of antibiotics for respiratory tract infections is considered a priority for general medical practice. ${ }^{1}$ Respiratory tract infections comprise upper respiratory tract infections, such as the common cold, and lower respiratory tract infections, such as acute bronchitis and pneumonia. Most respiratory tract infections are viral in origin and self-limiting; therefore, antibiotics are seldom warranted. The probable exception is pneumonia which, regardless of aetiology, is usually treated with antibiotics. ${ }^{2,3}$ Important factors influencing over prescription of antibiotics for respiratory tract infections are physicians' diagnostic uncertainty, patients' expectations of antibiotics, and physicians' assumptions regarding these expectations..$^{4-7}$ Patient expectations are among the strongest predictors of clinicians' decisions regarding prescribing antibiotics; patients' knowledge, beliefs, and experiences of antibiotics are likely mediators of these expectations. ${ }^{8}$ For example, it has been recognised that a large proportion of people believe that antibiotics improve outcomes for bacterial as well as viral respiratory infections, ${ }^{9-12}$ and previous studies have described patients' beliefs and expectations at the point of care for respiratory tract complaints. ${ }^{13-15}$ This study aimed to gain insight into the general public's knowledge, beliefs, and experiences of antibiotics and respiratory tract infections to determine predictors of accurate knowledge on antibiotic effectiveness.

\section{Method}

A cross-sectional survey among a sample of the general Dutch population was conducted during a 2-week period in October and November 2006, using an internet-based questionnaire. Approximately 800 responders were considered an adequate sample target to ensure generalisability of answers. Expecting a response rate of $60 \%, 1300$ adult responders (aged $\geq 16$ years) were invited to participate. These responders were randomly selected from a community-based nationwide internet panel of 15673 individuals (Flycatcher Internet Research BV, Maastricht, the Netherlands) after stratification for sex, age, level of education (low/medium/high), and region of residence, based on national figures from Statistics Netherlands.

The questionnaire was developed by experts initially deciding which domains they considered most important. Questions to tap these domains were derived from previous international qualitative and quantitative scientific publications and further expert opinion., ${ }^{6,9-12}$ Two pilot studies were performed in general practice to check face validity, and the wording of some items was modified in light of this. Twenty questions with subitems within the domains of the questions 
were included in the final instrument (for example, 'How often do you think the following complaints require antibiotic treatment ...' [question], '... if coughing up phlegm?' [sub-item]). Response options, including yes/no, agree/disagree, and Likert-type scale response items, were used as appropriate for each question.

Biomedically accepted knowledge of antibiotic effectiveness (that is, knowing that antibiotics are effective against bacteria but not viruses) was assessed by combining true/false answers to two separate questions regarding bacteria and viruses: 'Antibiotics are effective in treating infections caused by bacteria/ viruses'. Respiratory tract infection was defined by means of diagnoses (for example, sinusitis, tonsillitis, and acute bronchitis) and associated symptoms. Explanation boxes accompanied most questions. This proved helpful when explaining commonly used medical terms, such as acute bronchitis.

The internet-based questionnaire software required responders to answer a question with subitems before being able to continue to the next question; the automatic routing of questions prevented responders returning to and altering responses to questions already completed. Total time taken to complete the questionnaire was recorded and stored to detect possible errors (for example, responders who completed the questionnaire quickly and perhaps did not read everything properly).

All responders' answers were automatically entered into a data file which was checked for accuracy by two independent researchers. Data were analysed using SPSS (version 13.0). Frequencies and cross tables of pre-selected variables were calculated and $\chi^{2}$ tests were performed to identify variables associated with the dependent variable 'accurate knowledge of antibiotic effectiveness' (that is, knowing that antibiotics are effective against bacteria but not viruses). Variables with $P \leq 0.10$ were selected for the multivariate logistic regression model for the dependent variable to examine independence of associations $(P \leq 0.05)$. Odds ratios (ORs) with corresponding $95 \%$ confidence intervals (Cls) were calculated. Sex, age, and level of education were eligible variables for the multivariate model.

\section{Results}

\section{Demographics}

Of the 1300 adults invited to participate, 52 individuals could not be contacted as a result of undeliverable invitational e-mails. Of the 1248 eligible responders, 935 completed the online questionnaire (response rate $75 \%$ ) within a set period of two weeks (19 responders did not fully complete the questionnaire). In total, 467 responders (49.9\%) were male, and 372 (39.8\%) and 249 (26.6\%) had a medium and high level of education respectively. Responders were 
representative of the general Dutch population with regard to sex, level of education, and experienced state of health, but older people (aged over 60 years) were underrepresented. Other characteristics of the study population, including having a chronic disease and parenthood, are detailed in Table 2.1. There was no notable difference between characteristics of responders and nonresponders.

Table 2.1 Characteristics of the study population ( $n=935)$ compared with national figures for the Netherlands.

\begin{tabular}{|c|c|c|c|}
\hline \multicolumn{2}{|l|}{ Characteristic } & \multirow{2}{*}{$\begin{array}{c}\text { Respondents } \\
\text { n (\%) } \\
467(49.9)\end{array}$} & \multirow{2}{*}{$\begin{array}{c}\text { Netherlands }{ }^{\mathrm{a}} \\
\% \\
49.0\end{array}$} \\
\hline Gender & Male & & \\
\hline \multirow[t]{4}{*}{ Age (years) } & $16-29$ & $164(17.5)$ & 20.8 \\
\hline & $30-44$ & $283(30.3)$ & 28.6 \\
\hline & $45-59$ & $303(32.4)$ & 26.5 \\
\hline & $60^{+}$ & $185(19.8)$ & 24.1 \\
\hline \multirow[t]{3}{*}{ Level of education } & Low & $314(33.6)$ & 33.6 \\
\hline & Medium & $372(39.8)$ & 41.2 \\
\hline & High & 249 (26.6) & 25.2 \\
\hline \multirow[t]{2}{*}{ Experienced state of health } & Very good-good & 708 (75.7) & 79.9 \\
\hline & Poor (Less than good) & $227(24.3)$ & 20.1 \\
\hline \multirow[t]{2}{*}{ Parenthood } & Child(ren) $\leq 12$ years old & $234(25.0)$ & $\mathrm{b}$ \\
\hline & Child(ren) $\leq 5$ years old & $122(13.0)$ & b \\
\hline Chronic pulmonary disease & & $105(11.2)$ & b \\
\hline Chronic disease in general & & $228(24.4)$ & b \\
\hline
\end{tabular}

${ }^{a}$ Data derived from Statistics Netherlands 2006 (www.cbs.nl); ${ }^{\text {b }}$ Data not available

\section{Knowledge, beliefs, and experiences}

The majority of responders (83.7\%) endorsed the view that antibiotics are effective in treating infections caused by bacteria (Table 2.2). However, almost half of responders (47.8\%) believed that antibiotics are effective in treating viral infections. The results for these two questions were combined to assess overall knowledge of antibiotic effectiveness and $44.6 \%$ of responders accurately identified antibiotics as effective against bacterial and not viral infections.

Of the responders, $93.1 \%$ correctly identified penicillin as an antibiotic. Most $(n=806,86 \%)$ had used antibiotics at some point in the past: $236(25.2 \%)$ during the past 12 months for any reason, and $92(9.8 \%)$ in the past year for a respiratory tract infection. Almost a third $(31.3 \%)$ had obtained information on antibiotics in the past 12 months, mostly from a doctor (53.6\%). The perceived need for antibiotic treatment for respiratory tract infection related symptoms ranged from $6.5 \%$ for a cough with transparent phlegm to $46.2 \%$ for a cough lasting more than two weeks. Similar frequencies to those for the perceived need for antibiotic treatment were found for the perceived need to consult a doctor with these symptoms (Table 2.3). 
Table 2.2. Responders' knowledge, beliefs, and experiences of antibiotics and respiratory tract infections $(n=935)$.

\begin{tabular}{lc} 
Knowledge & True \\
& $\mathrm{n}(\%)$ \\
\hline Antibiotics are effective in treating bacterial but not viral infections & $417(44.6)$ \\
Antibiotics are effective in treating infections caused by bacteria & $783(83.7)$ \\
Antibiotics are effective in treating infections caused by viruses & $447(47.8)$ \\
\hline Beliefs and experiences & Agree \\
& $\mathrm{n}(\%)$ \\
\hline I usually know when I need antibiotics & $349(37.3)$ \\
Decisions regarding the prescription of antibiotics have to be taken by a doctor & $869(92.9)$ \\
I find being given a delayed prescription of antibiotics acceptable & $371(39.7)$ \\
Bacteria can become less susceptible (resistant) to antibiotics & $859(91.9)$ \\
If antibiotics have been prescribed before they will be required again for similar & $350(37.4)$ \\
symptoms in the future & \\
If antibiotics have cured me before they will be required again for similar & $233(24.9)$ \\
symptoms in the future & \\
Taking antibiotics helps a patient feel better sooner in case of & \\
Common cold & $177(18.9)$ \\
Acute bronchitis & $635(67.9)$ \\
Pneumonia & $806(86.2)$
\end{tabular}

Table 2.3 Responders' perceived need for antibiotic treatment and need to consult for respiratory tract symptoms and infections $(n=935)$.

$\begin{array}{lcc}\text { Symptom } & \begin{array}{c}\text { Perceived need for antibiotic } \\ \text { treatment (always-often) } \mathrm{n}(\%)\end{array} & \begin{array}{c}\text { Perceived need to consult } \\ \text { (always-often) } \mathrm{n}(\%)\end{array} \\ \text { Sore throat } & 65(7.0) & 19(2.0) \\ \text { Cough with transparent phlegm } & 61(6.5) & 57(6.1) \\ \text { Cough with yellow/green phlegm } & 264(28.2) & 264(28.2) \\ \text { Cough with fever } & 243(26.0) & 145(15.5) \\ \text { Cough lasting more than two weeks } & 432(46.2) & 438(46.8) \\ \text { RTI } & \text { Perceived need for antibiotic } \\ & \text { treatment (always-often) } \mathrm{n}(\%) \\ \text { Common cold } & 11(1.2) \\ \text { Acute bronchitis } & 557(59.6) \\ \text { Pneumonia } & 850(90.9)\end{array}$

\section{Predictors of accurate knowledge of antibiotic effectiveness}

Acknowledgement of developing antimicrobial resistance (OR 3.18, 95\% $\mathrm{Cl}=1.75$ to 5.79 ) and high level of education (OR $3.03,95 \% \mathrm{Cl}=2.11$ to 4.36 ) were the strongest predictors of accurate knowledge of antibiotic effectiveness (Table 2.4). Female sex was also significantly associated with accurate knowledge (OR $1.54,95 \% \mathrm{Cl}=1.17$ to 2.04$)$. No significant association was observed for having a chronic pulmonary disease $\left(\chi^{2}=1.16\right.$, degrees of freedom $(\mathrm{df})=1, P=0.28)$ or being a parent of at least one child aged $\leq 12$ years $\left(\chi^{2}=1.72\right.$, $\mathrm{df}=1, P=0.19)$. 
Table 2.4 Factors independently associated with accurate knowledge of antibiotic effectiveness.

$\begin{array}{lrr}\text { Factor } & & \text { Odds Ratio }(95 \% \mathrm{Cl}) \\ \text { Female sex } & & 1.54(1.17-2.04) \\ \text { Level of education } & \text { Low } & 1.00(\text { reference) } \\ & \text { Medium } & 1.79(1.30-2.47) \\ & \text { High } & 3.03(2.11-4.36) \\ \text { Acknowledgement of developing bacterial resistance } & 3.18(1.75-5.79) \\ \text { Use of antibiotics at some point in life } & 2.12(1.38-3.25) \\ \text { Received or searched information on antibiotics during the past 12 months }{ }^{a} & 1.50(1.12-2.01) \\ \text { a }^{a} \text { Information obtained from doctor, pharmacist, drug store, patient leaflet, the Internet, media }\end{array}$

\section{Discussion}

\section{Summary of main findings}

These data reveal important misconceptions that members of the general public have about the effectiveness of, and the appropriate indications for using, antibiotics. Only $44.6 \%$ of responders accurately identified antibiotics as being effective against bacteria but not viruses. Expectations for antibiotics were higher for the disease label 'acute bronchitis' than for any of the separate or combined respiratory tract symptoms prominently present in respiratory tract infections.

Female sex, use of antibiotics at any time previously, and recent information on antibiotics were independently associated with accurate knowledge of antibiotic effectiveness. One possible explanation is that women consult more frequently, often with their children, and therefore receive more accurate information on antibiotics; however, the finding that women had more accurate knowledge was independent of having children in the household. GPs usually apply a low threshold to prescribe for lower respiratory tract infection in patients with chronic pulmonary disease based, for instance, on evidence of some beneficial effects of antibiotics for acute exacerbations in patients with severe chronic obstructive pulmonary disease or specific symptomatology. ${ }^{3}$ Yet, surprisingly, patients with chronic pulmonary disease did not have more accurate knowledge of antibiotics, despite that they generally are high consulters and receive frequent antibiotic treatment.

\section{Strengths and limitations of the study}

To date, this is one of the largest studies on public views of antibiotics and respiratory tract infections in Europe. This study was community-based, while most other research has studied patient populations. ${ }^{13-16}$ Performing this study among the general population allowed the researchers to gain more insight into views on antibiotics and respiratory tract infections before people become 
unwell and consult. A high response rate was achieved and the study sample was representative of the general Dutch population for most baseline characteristics; the only limitation in this regard was that older people were underrepresented.

A limitation of any survey is the potential for recall and response bias. The internet-based questionnaire may have introduced selection bias, as only internet users were invited to participate in the study. The assumption that internet users were better educated did not hold in this regard, given that the level of education of the study sample was similar to that of the Dutch population. However, it may partly explain the underrepresentation of older people in the study.

\section{Comparison with existing literature}

Although many people correctly endorsed the view that antibiotics are generally effective against bacterial infections, nearly half of the responders also endorsed the view that antibiotics are effective in treating viruses. This was surprising, as the Netherlands has low prescribing figures for respiratory tract infections which are mostly viral and self-limiting in origin; ${ }^{17}$ therefore, it was expected that the Dutch public would have been better informed. A study investigating public views on antibiotics in the US exposed a similar percentage of responders as the current study, who incorrectly identified antibiotics as being effective against viral infections. ${ }^{11}$

Public misconceptions on antibiotic effectiveness are most likely facilitated by unnecessary antibiotic prescriptions for self-limiting respiratory illnesses. Other research has shown that previous antibiotic treatment was the strongest predictor for patients expecting antibiotics in the future. ${ }^{18-19}$ Given this, it is not unusual that a general population might lack some knowledge of antibiotic efficacy.

\section{Implications for clinical practice and future research}

The most important step in enhancing public knowledge on antibiotics is to restrict unnecessary prescriptions of them, thereby establishing evidence-based expectations about antibiotic treatment. More effective education about appropriate antibiotic use, focusing on the treatment of cough and acute bronchitis, could help in this regard. Dutch prescription rates for acute bronchitis are comparable to the US and the UK, where approximately $80 \%$ of patients consulting with this diagnosis are prescribed antibiotics. ${ }^{20-21}$

The majority of this study's responders considered antibiotic treatment necessary for acute bronchitis. This misconception was independent of age, sex, or level of education. The proportion of responders who endorsed the view that antibiotics helped the symptoms of acute bronchitis resolve more quickly 
than recovery without antibiotics was much higher than for any of the separate respiratory tract symptoms. In other words, expectations for antibiotics were highest when mentioning the disease label 'acute bronchitis' (Table 2.3), compared with when mentioning separate or combined symptoms commonly used in the definition of acute bronchitis (prominent cough with phlegm occurring for any duration).

Although antibiotics do not meaningfully alter the course of uncomplicated acute bronchitis for most people, ${ }^{3}$ up to $50 \%$ of the public expect a prescription for antibiotics when consulting with an ongoing cough. This expectation exists regardless of country or continent, as found by Pechere in an intercontinental study.$^{16}$ GPs are often in time pressured consultations with limited options for dealing with these expectations. Steering clear of disease labels and microbiological distinctions, and focusing on symptoms may help GPs to restrict their prescribing of antibiotics while providing patients with accurate information on the necessity of antibiotics for specific symptoms.

Several interventions that involve giving patients accurate information can improve the appropriateness of prescribing antibiotics. That some $40 \%$ of the study population considered a delayed prescription acceptable, despite the rarity of this prescribing strategy in the Netherlands, merits further research. Even when using this strategy of delayed prescription, setting realistic goals about the likely clinical course - and its long duration in particular, both with and without treatment with antibiotics - is crucial to changing incorrect assumptions about treatment using antibiotics. Training physicians in communication skills could be an additional means to achieving this, ${ }^{22,23}$ as could educational interventions aimed at informing doctors and patients. Multifaceted educational interventions have proven to be most effective in this regard. ${ }^{24-27}$

Possible future interventions involving information on antibiotics and respiratory tract infections aimed at the general public should consider focusing on educating younger generations. They will be the ones consulting with respiratory tract infections for many years to come, especially when consulting with their children. For many people suffering from a non-resolving severe cough, treatment using antibiotics appears to be the obvious solution. Such inappropriate expectations persist irrespective of national prescribing figures or international borders. Hence working towards a more appropriate management of respiratory tract infections using antibiotics requires an international effort. Acknowledging the public's views on antibiotics and respiratory tract infections remains crucial to this endeavour for both researchers and physicians. 


\section{References}

1. Nordberg P, Monnet DL, Cars O. Antibacterial drug resistance: options for concerted action. Geneva; 2005 february 2005.

2. Arroll B, Kenealy T. Antibiotics for the common cold and acute purulent rhinitis. Cochrane Database Syst Rev. 2005(3):CD000247.

3. Woodhead M, Blasi F, Ewig S, Huchon G, leven M, Ortqvist A, Schaberg T, Torres A, van der Heijden G, Verheij TJ; European Respiratory Society; European Society of Clinical Microbiology and Infectious Diseases. Guidelines for the management of adult lower respiratory tract infections. Eur Respir J. 2005;26:1138-80.

4. Cockburn J, Pit S. Prescribing behaviour in clinical practice: patients' expectations and doctors' perceptions of patients' expectations - a questionnaire study. BMJ. 1997;315:520-3.

5. Coenen S, Michiels B, Renard D, Denekens J, Van Royen P. Antibiotic prescribing for acute cough: the effect of perceived patient demand. Br J Gen Pract. 2006;56:183-90.

6. Davey P, Pagliari C, Hayes A. The patient's role in the spread and control of bacterial resistance to antibiotics. Clin Microbiol Infect. 2002;8(S2):43-68.

7. Butler CC, Rollnick S, Pill R, Maggs Rapport F, Stott N. Understanding the culture of prescribing: qualitative study of general practitioners' and patients' perceptions of antibiotics for sore throats. BMJ. 1998;317:637-42.

8. Butler CC, Rollnick S, Kinnersley $\mathrm{P}$, Jones A, Stott N. Reducing antibiotics for respiratory tract symptoms in primary care: consolidating 'why' and considering 'how'. $\mathrm{Br} J$ Gen Pract. 1998;48: 1865-70.

9. Emslie MJ, Bond CM. Public knowledge, attitudes and behaviour regarding antibiotics--a survey of patients in general practice. Eur J Gen Pract. 2003;9:84-90.

10. Belongia EA, Naimi TS, Gale CM, Besser RE. Antibiotic use and upper respiratory infections: a survey of knowledge, attitudes, and experience in Wisconsin and Minnesota. Prev Med. 2002;34:346-52.

11. Wilson AA, Crane LA, Barrett PH, Gonzales R. Public beliefs and use of antibiotics for acute respiratory illness. J Gen Intern Med. 1999;14:658-62.

12. Corbett KK, Gonzales R, Leeman-Castillo BA, Flores E, Maselli J, Kafadar K. Appropriate antibiotic use: variation in knowledge and awareness by Hispanic ethnicity and language. Prev Med. 2005 2005/2;40:162-9.

13. Little P, Dorward M, Warner G, Stephens K, Senior J, Moore M. Importance of patient pressure and perceived pressure and perceived medical need for investigations, referral, and prescribing in primary care: nested observational study. BMJ. 2004;328:444.

14. Macfarlane J, Holmes W, Macfarlane R, Britten N. Influence of patients' expectations on antibiotic management of acute lower respiratory tract illness in general practice: questionnaire study. BMJ. 1997;315:1211-4.

15. Welschen I, Kuyvenhoven M, Hoes A, Verheij T. Antibiotics for acute respiratory tract symptoms: patients' expectations, GPs' management and patient satisfaction. Fam Pract. 2004;21:234-7.

16. Pechere JC. Patients' interviews and misuse of antibiotics. Clin Infect Dis. 2001;33(S3): S170-3.

17. Goossens H, Ferech M, Vander Stichele R, Elseviers M. Outpatient antibiotic use in Europe and association with resistance: a cross-national database study. Lancet. 2005;365:579-87.

18. Gonzales R, Corbett K. The culture of antibiotics. Am J Med. 1999;107:525-6.

19. Hong JS, Philbrick JT, Schorling JB. Treatment of upper respiratory infections: do patients really want antibiotics? Am J Med. 1999;107:511-5.

20. Gonzales R, Steiner JF, Sande MA. Antibiotic prescribing for adults with colds, upper respiratory tract infections, and bronchitis by ambulatory care physicians. JAMA. 1997; 278: 901-4.

21. Kuyvenhoven MM, Verheij TJ, de Melker RA, van der Velden J. Antimicrobial agents in lower respiratory tract infections in Dutch general practice. Br J Gen Pract. 2000;50:133-4. 
22. Briel M, Langewitz W, Tschudi P, Young J, Hugenschmidt C, Bucher HC. Communication training and antibiotic use in acute respiratory tract infections. A cluster randomised controlled trial in general practice. Swiss Med Wkly. 2006;136:241-7.

23. Altiner A, Brockmann S, Sielk M, Wilm S, Wegscheider K, Abholz HH. Reducing antibiotic prescriptions for acute cough by motivating GPs to change their attitudes to communication and empowering patients: a cluster-randomized intervention study. J Antimicrob Chemother. 2007;60:638-44.

24. Little P, Rumsby K, Kelly J, Watson L, Moore M, Warner G, Fahey T, Williamson I. Information Leaflet and Antibiotic Prescribing Strategies for Acute Lower Respiratory Tract Infection: A Randomized Controlled Trial. JAMA. 2005;293:3029-35.

25. Arnold SR, Straus SE. Interventions to improve antibiotic prescribing practices in ambulatory care. Cochrane Database Syst Rev. 2005:CD003539.

26. Gonzales R, Steiner JF, Lum A, Barrett PH, Jr. Decreasing antibiotic use in ambulatory practice: impact of a multidimensional intervention on the treatment of uncomplicated acute bronchitis in adults. JAMA. 1999;281:1512-9.

27. Welschen I, Kuyvenhoven MM, Hoes AW, Verheij TJ. Effectiveness of a multiple intervention to reduce antibiotic prescribing for respiratory tract symptoms in primary care: randomised controlled trial. BMJ. 2004;329:431. 



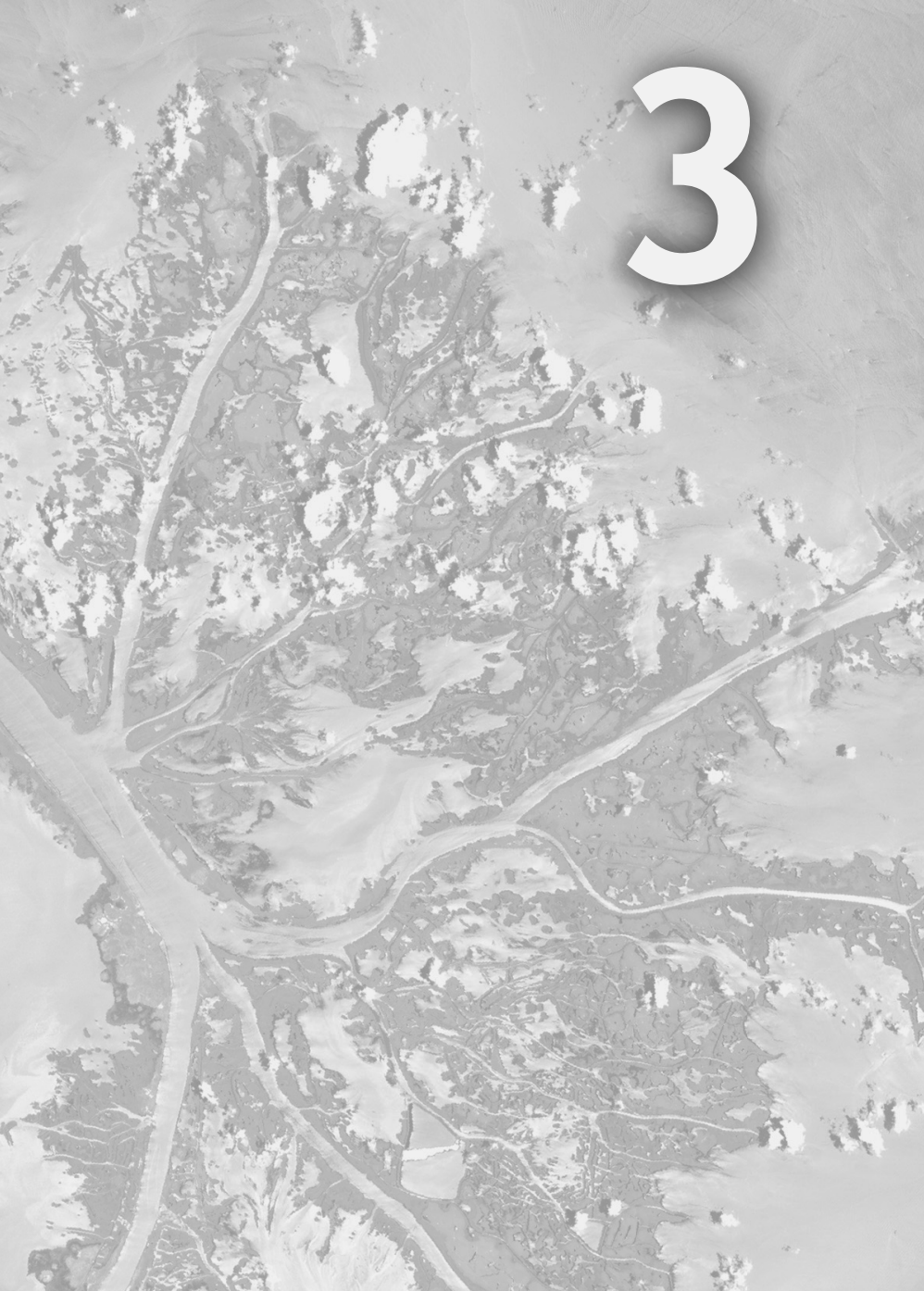

Dose timing and patient compliance with two antibiotic treatment regimens for lower respiratory tract infections in primary care

Jochen Cals, Rogier Hopstaken, Philippe Le Doux, Ger Driessen, Patricia Nelemans, Geert-Jan Dinant

International Journal of Antimicrobial Agents 2008;31:531-6 


\section{Abstract}

\section{Objective}

To assess compliance with a 10-day treatment of antibiotics or placebo once-daily (OD) and three times daily (TD) for lower respiratory tract infections (LRTI) using electronic monitoring. To evaluate whether compliance depends on time since the start of treatment and weekday.

\section{Methods}

Taking compliance, timing compliance, correct dosing compliance and mean interdose intervals were assessed by using data from 155 LRTI patients who received either a 10-day treatment of amoxicillin TD and placebo OD or roxithromycin OD and placebo TD using a double dummy technique. Compliance was assessed by electronic monitoring (MEMS, Aardex, Switzerland).

\section{Results}

Taking compliance was $98.0 \%$ for the OD regimen and $91.0 \%$ for the TD regimen. Correct dosing was $98.1 \%$ (OD) and $91.1 \%$ (TD) and timing compliance $48.2 \%$ and $10.9 \%$, respectively. The mean interdose interval before the first daily dose for the TD group was particularly prolonged to more than 13 hours. Correct dosing over time showed fewer patients with correct dosing compliance to a low of $79 \%$ for the TD group towards the end of 10-day treatment. Compliance was not influenced by weekday.

\section{Conclusion}

This study adds important information to the limited evidence on compliance with antibiotics for LRTI, one of the most common reason for consultation in primary care. Taking compliance was high for both regimens, yet timing compliance was poor. The prolonged mean interdose intervals provide striking new insights in understanding non-compliance with more-than-once-daily regimens. These findings require consideration when exploring means to improve future compliance in short term antibiotic treatment for RTI. 


\section{Introduction}

Patient compliance is a key factor for successful clinical recovery. Compliance can be best described as the correspondence between the physician's instructions with the prescribed medication and the actual time history of the patient's dosing during the prescribed regimen. Mistakes in dosing regimens such as unintentional omissions of doses, change in frequency of doses and delayed time intervals are common in patients taking antimicrobials for respiratory tract infections. ${ }^{1}$ An important issue in compliance studies is the extent to which compliance is needed for good therapeutic outcome. Some drugs remain therapeutically active after certain lapses in dosing, the so-called forgiving drugs, whereas others demand punctual dosing. ${ }^{2}$ A typical antimicrobial prescription comprises both quantity and timing of doses. The latter is particularly relevant since prolonged intervals between doses decreases the antibiotic's micro organism inhibitory mechanism and may decrease the efficacy of treatment. ${ }^{3}$ Dosing regimen has proven to be an important influence on compliance, as an increase in the complexity of dosing regime in antibiotic agents has shown to significantly raise the probability of missing doses during the prescribed course. ${ }^{4}$

With the emergence of electronic drug monitoring devices new possibilities have become available to study dose interval compliance, as the exact date and time of vial opening can be determined. This facilitates accurate monitoring of timing effects. ${ }^{5}$ Of the indirect methods to measure compliance, including self report, interviews, and pill counts, electronic monitoring is now regarded the most objective method to determine compliance. ${ }^{5-7}$ Taking compliance rates of $79 \%$ for once-daily regimens to as low as $51 \%$ for four-times-daily regimens have been reported in a systematic review involving studies using electronic monitoring devices. ${ }^{6}$ Surprisingly, only two studies have assessed antibiotic compliance for respiratory tract infections (RTI) using electronic monitoring., Kardas was the first to visualise the subject of compliance over time in antimicrobial treatment of RTIs by showing a maximum compliance on day three and a subsequent gradual daily decline in compliance. ${ }^{8}$ Dose timing has not been extensively studied in antimicrobial treatment for respiratory tract infections. Yet again information on actual dose timing of patients is crucial for physicians when deciding what information should be given to patients to achieve optimal compliance for different regimens.

The aim of this study was to assess compliance with a 10-day once-daily treatment and with a 10-day treatment three times a day for lower respiratory tract infections (LRTI) using electronic monitoring. Moreover, we aimed to perform a more in-depth investigation of specific compliance measures, including mean dosing intervals, and to evaluate whether compliance depends on time since the start of treatment and day of the week(end). 


\section{Method}

\section{Study design}

This study was part of a randomised clinical trial comparing the effectiveness of a 10 day treatment with amoxicillin to roxithromycin for the treatment of LRTI. ${ }^{10}$ Consecutive patients consulting their general practitioner (GP) with signs and symptoms of an acute lower respiratory tract infection were asked to participate in this trial.

Eligible patients were randomly assigned to either oral treatment with roxithromycin (300 mg once-daily (OD)) or amoxicillin (500 mg three times daily (TD)) for ten days. A double-dummy technique was used for blinding as the antibiotics had different dose schedules and different appearance. Patients assigned to amoxicillin received two vials, one vial containing 30 real amoxicillin capsules and one vial containing ten placebo tablets. Patients assigned to roxithromycin received two vials as well, one vial containing ten real roxithromycin tablets and one vial containing 30 placebo capsules. All capsules had identical appearance and taste, so had all tablets.

\section{Electronic monitoring}

Patients received their medication in electronic monitoring packages (MEMS containers, Medication Event Monitoring System, Aardex Ltd, Zug, Switzerland) to collect data on compliance. MEMS vials contain a microprocessor in the cap that records every removal of the cap as a presumptive dose taken and registers date and time of cap removal. Both antibiotics and placebo were handed out to patients in MEMS containers.

All patients were instructed to take one tablet a day from the vial containing tablets with an interval of 24 hours and three capsules a day with intervals of eight hours from the vial containing capsules. These instructions were given to patients by the GP both orally as well as in writing. Patients were also informed of the monitoring device in the vial cap and were asked to open the vial only when taking medication and to take out only one tablet or capsule per vial opening. All patients consented to participate.

\section{Data processing and analysis}

Patients returned MEMS containers to the research team after the treatment period. Data from the vials was transmitted into a computer using Powerview software program. Dose event data were then transferred to SPSS 13.0 for computation of outcome measures. Multiple openings within a period shorter than 15 minutes were identified and counted as a single dose event. All other recorded container openings were considered to represent a single dose event. 
As all patients received two vials, taking compliance and dose interval compliance for both treatment regimens could be evaluated in all patients. Compliance analyses were performed for all patients with complete data.

\section{Compliance measures}

MEMS-recorded data were assessed for three different measures of compliance:

A. Taking compliance, calculated as (the number of vial openings/ the total number of prescribed doses during the monitoring period) ${ }^{*} 100 \%$.

B. Correct dosing, calculated as (the number of days on which the patient opened the vial at least the prescribed number of times/ the total number of days during the monitoring period) * $100 \%$

C. Timing compliance, calculated as (the number of doses taken within the $8 \pm 1$ hour interval for the TD group and $24 \pm 2$ hours for the OD group)/ the total number of prescribed doses during monitoring period) * $100 \%$.

Furthermore, we studied mean interdose intervals, defined as the mean interval between doses in hours (D). In order to study whether compliance decreases over time or depends on the day of the week, compliance percentages (defined as correct dosing) were plotted according to time since the start of treatment and according to weekday. Day one was omitted from the compliance over time graph as for the TD regimen late start of treatment on day one (e.g. in the afternoon or evening after visiting the GP) would result in a first treatment day with an unintentional dosing of less than three capsules. Explorative analysis of comparison of the outcome measures for the two regimens were assessed by Wilcoxon matched pairs signed ranks test.

\section{Results}

MEMS containers for the study medication were available for 167 patients enrolled in the randomised trial (Figure 3.1). Data of 12 patients were not available due to reasons displayed in Figure 3.1. Hence, compliance data of 155 patients, of which 78 received amoxicillin (and placebo) and 77 received roxithromycin (and placebo), were evaluated. Baseline characteristics of patients included in the analyses are shown in Table 3.1. One set of multiple openings within 15 minutes was identified and counted as a single dose event. 


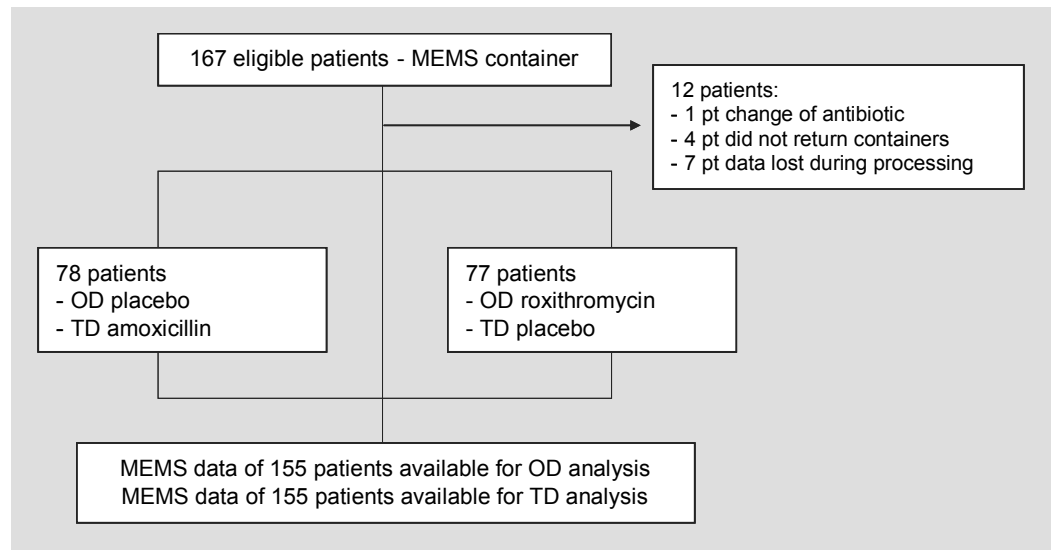

Figure 3.1 Study flowchart.

LRTI: Lower respiratory tract infection; MEMS: Medical event monitoring system; OD: Once-daily; TD: Three-times-daily.

Table 3.1 Baseline characteristics of patients with electronic compliance monitoring. Values are numbers (percentages) unless stated otherwise.

$\begin{array}{lc}\text { Number of patients } & 155 \\ \text { Mean age in years (SD) } & 52.6(16.0) \\ \text { Male sex } & 74(48) \\ \text { Smoking cigarettes } & 55(34) \\ \text { Comorbidity: } & 76(47) \\ \text { Asthma } & 32(20) \\ \text { COPD } & 25(15) \\ \text { Other lung diseases } & 9(6) \\ \text { Heartfailure } & 6(4) \\ \text { Diabetes mellitus } & 3(2) \\ \text { Other } & 22(14) \\ \text { Antibiotic: } & 155(100) \\ \quad \text { Rmoxicillin } & 78(50.4) \\ \text { Roxithromycin } & 77(49.6)\end{array}$

Mean taking compliance (A, Table 3.2) was $98.0 \%$ for the once-daily regimen and $91.0 \%$ for the three times daily regimen. Correct dosing (B) was $98.1 \%$ in the OD group and 91.1 for the TD group. Timing compliance (C) calculations showed that $48.2 \%$ of all tablets in the OD group were taken within the $22-26$ hours interval to the previous dose whereas only $10.9 \%$ of all capsules were taken within the 7-9 hours interval for the TD group. The mean interdose interval (D) for all doses in the TD regimen was within normal range (8.6 hours) but varied widely for individual daily doses from 6.1 hours before the second daily dose to 13.4 hours before the first daily dose (Table 3.2). 
Table 3.2 Means, medians and 25-75 interquartiles (25-75IQ) for compliance outcome measures of once-daily (OD) and three times daily (TD) antibiotic regimens. Differences assessed by Wilcoxon signed ranks test in an explorative analysis.

\begin{tabular}{|c|c|c|c|c|c|c|c|}
\hline & \multicolumn{3}{|c|}{$\begin{array}{l}\text { Once-daily (OD) } \\
\quad n=155\end{array}$} & \multicolumn{3}{|c|}{$\begin{array}{l}\text { Three times daily (TD)* } \\
\qquad n=155\end{array}$} & \multirow[b]{2}{*}{ P-value } \\
\hline & Mean & Median & $25-75 I Q$ & Mean & Median & $25-75 \mathrm{IQ}$ & \\
\hline A Taking compliance (\%) & 98.0 & 100 & $100-100$ & 91.0 & 100 & $88.8-100$ & $<0.001$ \\
\hline B Correct dosing (\%) & 98.1 & 99.0 & $97.0-99.5$ & 91.1 & 94.0 & $86.0-95.5$ & 50.011 \\
\hline C Timing compliance (\%) & 48.2 & 66.7 & $0.00-88.9$ & 10.9 & 0.00 & $0.00-18.8$ & $8<0.001$ \\
\hline D Mean interdose intervals (hours) & Mean & SD & & Mean & SD & & \\
\hline - all doses & 23.2 & 5.9 & & 8.6 & 4.2 & & \\
\hline - before $1^{\text {st }}$ daily dose & 23.2 & 5.9 & & 13.4 & 2.8 & & \\
\hline - before $2^{\text {nd }}$ daily dose & N/A & N/A & & 6.1 & 2.5 & & \\
\hline - before $3^{\text {rd }}$ daily dose & N/A & N/A & & 6.3 & 1.9 & & \\
\hline
\end{tabular}

"Due to the study design there are three times more observations in the TD group

Additional analysis of TD regimen data revealed a total of 613 missed doses. If a dose was omitted, this was most likely the $2^{\text {nd }}$ daily dose $(46.5 \%)$, which may be more sensitive to changes in daily routine. The $1^{\text {st }}$ and $3^{\text {rd }}$ doses, which are often combined with routine activities like breakfast and dinner, were less frequently missed $(25.1 \%$ and $28.4 \%$ respectively).

Over the ten days in the OD group, $93 \%$ to $100 \%$ of patients showed correct dosing on individual days, staying reasonably stable at first, but with more patients failing to have sufficient openings per day towards the end of the 10day treatment period. In the TD group nearly all patients also started with correct dosing. Nonetheless, an obvious decline could be noted from day 7 onwards with only $79 \%$ of patients having correct dosing on day 10 (Figure 3.2 ).

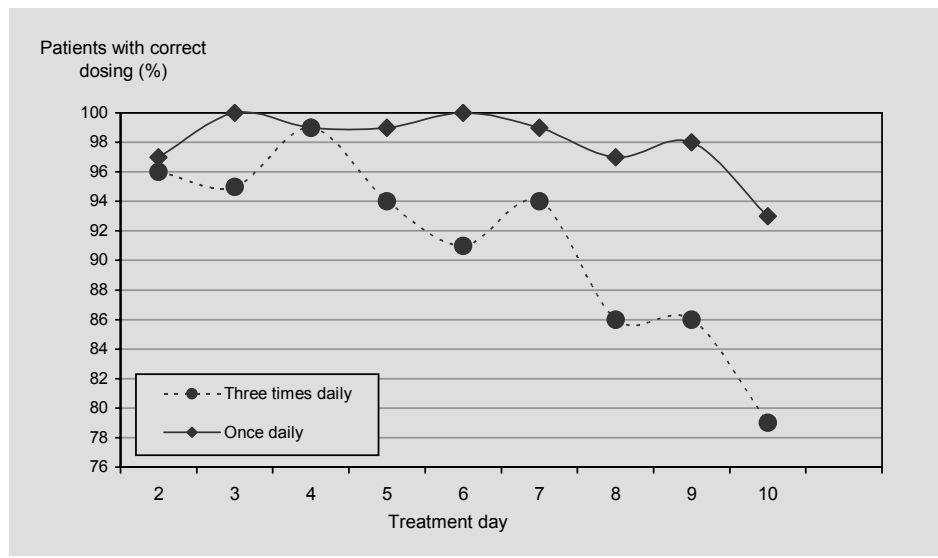

Figure 3.2 Correct dosing over time, percentage of patients opening the electronic container at least the prescribed number of times per day. 
Figure 3.3 shows the number of patients having correct dosing compliance per weekday. It does not show the presence of so called drug holidays during weekend days.

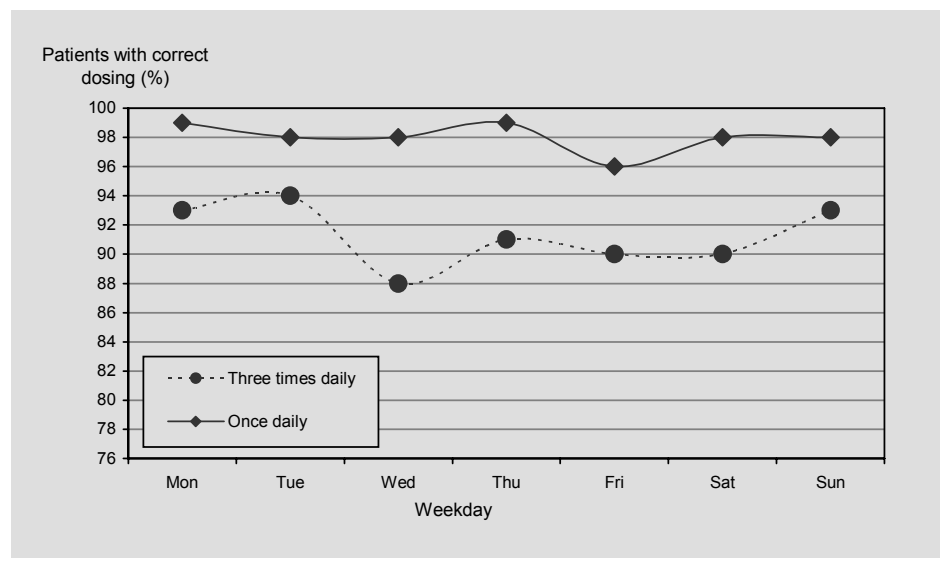

Figure 3.3 Correct dosing per weekday, percentage of patients opening the electronic container at least the prescribed number of times per weekday.

\section{Discussion}

\section{Main findings}

Dosing interval measures provided striking results. Only $10 \%$ of capsules in the three times daily regimen were taken within the pre-defined interval and the mean interdose interval before the first daily dose was particularly prolonged to more than 13 hours. Moreover, patient compliance over time decreased noticeably after day 7 of treatment in the TD regimen.

\section{Comparison with existing literature}

Overall, taking compliance was high for both regimens in our study. The other two previous studies investigating compliance with antibiotic therapy for acute respiratory tract infections using electronic monitoring have reported similar findings regarding taking compliance. ${ }^{8,9}$ Taking compliance however holds no information on the correctness of dosing intervals, and can theoretically be $100 \%$ without any correct dosing intervals being present.

A review of studies across various therapeutic classes that measured compliance using electronic monitoring confirmed that the prescribed number of doses per day is inversely related to compliance. ${ }^{6}$ Our findings confirm this well known fact. However, findings from this study can add to the existing literature 
on mean interdose intervals of antibiotic regimens. The longest mean dosing interval in the TD group (13.4 hours) was between $3^{\text {rd }}$ and $1^{\text {st }}$ daily dose, which represents night time. This finding exposes a potential problem for effectiveness of the antibiotic. One effect of this protracted mean interdose interval is a remarkably low number of correct dosing intervals for the TD group. In the two previous studies $32.6-56.4 \%$ correct dosing intervals in twice-daily regimens have been reported, whilst the number of correct dosing intervals for the oncedaily regimen was similar to the results obtained in our study. ${ }^{8,9}$ We chose to adopt the timing compliance definition $(24+/-2$ hours) for the OD regimen based on Kardas et al. ${ }^{8}$ As a consequence, our chosen definition of $8+/-1$ hour for the TD regimen does allow for a broader range of accepted interval (87.5-112.5\% for the TD regimen vs. $91.7-108.3 \%$ of the normal interval for OD dosing). Yet, to sustain transparancy of the results we chose to use full hours in the definition of timing compliance. Analysis of the $91.7-108.3 \%$ range on the TD data did not yield different results.

We found a maximum compliance on the first seven days in the OD group with a gradual decline thereafter. However, a sharp subsequent decline as described previously, remained absent. ${ }^{8}$ In the TD group however, we did notice an evident decline from day 7 onwards to a minimum percentage of $79 \%$ of patients having correct dosing on day 10.

\section{Strengths and limitations of the study}

To our knowledge this is the first study that evaluates the influence of weekdays on compliance in antibiotic treatment for RTIs. A disturbance in daily routine may cause difficulties for patients trying to fit a three times daily regimen into their lives, especially during non-working days Nevertheless, we could not confirm the prior hypothesis that correct dosing was lower during weekends.

In the end, both doctors and patients are mainly interested in treatment outcome. The effect of the two antibiotics studied in this trial, roxithromycin and amoxicillin, was similar with respect to outcomes at day 10 and $28 .{ }^{10}$ After 28 days $88 \%$ of patients having received amoxicillin had recovered, versus $91 \%$ of patients on roxithromycin. The duration of treatment was quite long in this study, as patients with LRTI are usually prescribed a course of antibiotics not exceeding seven days in the Netherlands. Many countries in Europe however apply an antibiotic strategy of at least ten days. ${ }^{11}$

Electronically monitored compliance assessment is an indirect method that does not prove actual intake of the prescribed medication. Yet, when the time for a scheduled dose passes without a dosing administration, one can be sure that medication has not been taken. The use of other medication vials was prohibited in our trial. Adverse effects of either of the antibiotics could of course 
influence compliance, yet no differences in adverse effects were found in the clinical trial. $^{10}$

The use of a double dummy technique has both limitations as well as strengths. As this is a secondary analysis of data collected within a RCT, this double dummy strategy was originally applied to avoid potential bias due to the different dosing schemes of the tested antibiotics. Consequently, in this analysis the design did not allow us to compare separate groups of patients, who were prescribed three capsules a day or one tablet a day; all patients had to take both. Hence, the total compliance burden of four intakes per day was the same for all patients. Yet, this also meant that patients were required to remember taking medication four times a day, which should be taking into account when interpreting our results. However, the chosen design did enable us to compare compliance with an OD and TD regimen of either antibiotics or placebo within a large group of 155 patients. Statistical testing to compare both regimens were only performed as an explorative analysis. Decisively, we took the paired nature of observations into account by selecting the appropriate statistical tests (Wilcoxon signed ranks test for paired observations) to assess differences. For this reason, our data provide an overview of compliance measures for oncedaily and three times daily regimens in a large population without aiming to simulate a head-to-head randomized comparison.

Patients were informed about the monitoring mechanism for both ethical and practical reasons. Their awareness about monitoring and the aim of the trial may have slightly increased compliance as compared to daily practice. Studies investigating this assumptions have shown conflicting results. ${ }^{12-14}$ Nevertheless, this study provides additional insight into dose timing in antibiotic therapy for acute LRTI in primary care.

\section{Implications for future research and clinical practice}

This study raises important issues for clinical practice. Firstly, a once-daily formulation may be favourable with respect to improving compliance. Yet, the most important criterion in choosing antibiotics should remain the method of action against the target bacteria, as resistance to antibiotics is an ever-growing problem. In most decisions on antibiotics for RTIs in primary care, narrowspectrum antibiotics should be used irrespective of dosing schedule. Still, involving the forgiveness of specific agents, which is a crucial factor in case of dose omissions, in these decisions remains difficult. ${ }^{3}$ Only if similar appropriate antibiotics according to national guidelines are available, the least complex treatment may be chosen to enhance compliance. This may also better meet patients' expectations. ${ }^{15}$

Secondly, we suggest that instructions on dose timing should be given in detail, thereby stressing the importance of taking the medication at the same time 
every day. Specifically, in three times daily regimens one should inform patients to take the third dose directly before bedtime and not during diner to minimise chances of protracted interdose intervals because this may facilitate the development of resistance. ${ }^{2}$ Specific rather than general advice on dose timing is associated with better compliance ${ }^{16}$ however correct information is provided in a minority of cases. ${ }^{9}$ Combined with the fact that GPs are bad at guessing which patient is compliant, ${ }^{4}$ this stresses the need for interventions. A variety of intervention have proven successful in enhancing compliance for short-term treatment. $^{1,17}$

Considering 28 million primary care consultations for LRTI in the US and the EU annually ${ }^{18,19}$ and antibiotics ranging among the most common prescribed drugs globally, compliance research in this field deserves more attention. This study is only the third study worldwide to present compliance data of antibiotics for RTI using electronic monitoring, and only the second ever in LRTI. It can therefore add valuable information to the extremely limited evidence available. Our data show that the more complex regimen showed a wide range of dosing intervals and declining compliance towards the end of treatment. These findings are even more surprising when considering that the Dutch population proved to be particularly conscious about antibiotic leftovers and had the lowest level of admitted non-compliance in two recent large global surveys. ${ }^{20,21}$ Crucially, the prolonged mean interdose intervals provide striking new insights in understanding non-compliance with more-than-once-daily regimens. These findings merit further research and require consideration when exploring means to improve and study compliance in short term antibiotic treatment for RTI in the future. 


\section{References}

1. Kardas P. Patient compliance with antibiotic treatment for respiratory tract infections. J Antimicrob Chemother 2002;49:897-903.

2. Urquhart J. Ascertaining how much compliance is enough with outpatient antibiotic regimens. Postgrad Med J 1992;68 Suppl 3:S49-58; discussion S59.

3. Vrijens B, Urquhart J. Patient adherence to prescribed antimicrobial drug dosing regimens. J Antimicrob Chemother 2005;55:616-27.

4. Cockburn J, Reid AL, Bowman JA, Sanson-Fisher RW. Effects of intervention on antibiotic compliance in patients in general practice. Med J Aust 1987;147:324-8.

5. Cramer JA. Microelectronic systems for monitoring and enhancing patient compliance with medication regimens. Drugs 1995;49:321-7.

6. Claxton AJ, Cramer J, Pierce C. A systematic review of the associations between dose regimens and medication compliance. Clin Ther 2001;23:1296-310.

7. Cramer JA, Mattson RH, Prevey ML, Scheyer RD, Ouellette VL. How often is medication taken as prescribed? A novel assessment technique. JAMA 1989;261:3273-7.

8. Kardas P. Comparison of patient compliance with once-daily and twice-daily antibiotic regimens in respiratory tract infections: results of a randomized trial. J Antimicrob Chemother 2007;59:531-6.

9. Favre O, Delacretaz E, Badan M, Glauser M, Waeber B. Relationship between the prescriber's instructions and compliance with antibiotherapy in outpatients treated for an acute infectious disease. J Clin Pharmacol 1997;37:175-8.

10. Hopstaken RM, Nelemans P, Stobberingh EE, Muris JW, Rinkens PE, Dinant GJ. Is roxithromycin better than amoxicillin in the treatment of acute lower respiratory tract infections in primary care? A double-blind randomized controlled trial. J Fam Pract 2002;51:329-36.

11. Coenen S, Molstad S. Preferred antibiotics, dosages and length of treatments in general practice--a comparison between ten European countries. Eur J Gen Pract 2004;10:166-8.

12. Kruse W, Weber E. Dynamics of drug regimen compliance--its assessment by microprocessor-based monitoring. Eur J Clin Pharmacol 1990;38:561-5.

13. Cramer JA, Ouelette VL, Mattson RH. Effect of microelectronic observation on compliance. Epilepsia 1990;31:617-8.

14. Urquhart J. Partial compliance in cardiovascular disease: risk implications. $\mathrm{Br} \mathrm{J}$ Clin Pract Suppl 1994;73:2-12.

15. Perez-Gorricho B, Ripoll M. Does short-course antibiotic therapy better meet patient expectations? Int J Antimicrob Agents 2003;21:222-8.

16. Cockburn J, Gibberd RW, Reid AL, Sanson-Fisher RW. Determinants of non-compliance with short term antibiotic regimens. BMJ 1987;295:814-8.

17. Haynes RB, Yao X, Degani A, Kripalani S, Garg A, McDonald HP. Interventions to enhance medication adherence. Cochrane Database Syst Rev 2005(4):CD000011.

18. Macfarlane J, Holmes W, Gard P, Macfarlane R, Rose D, Weston V, Leinonen M, Saikku P, Myint S. Prospective study of the incidence, aetiology and outcome of adult lower respiratory tract illness in the community. Thorax 2001;56:109-14.

19. Schappert SM, Burt CW. Ambulatory care visits to physician offices, hospital outpatient departments, and emergency departments: United States, 2001-02. Vital Health Stat 13 2006:1-66.

20. Kardas P, Pechere JC, Hughes DA, Cornaglia G. A global survey of antibiotic leftovers in the outpatient setting. Int J Antimicrob Agents 2007;30:530-6.

21. Pechere JC, Hughes D, Kardas P, Cornaglia G. Non-compliance with antibiotic therapy for acute community infections: a global survey. Int J Antimicrob Agents 2007;29:245-53. 


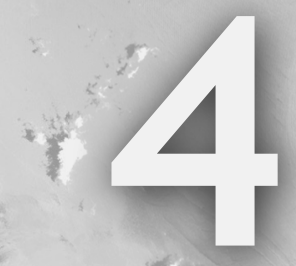

Improving management of patients with acute cough by $\mathrm{C}$-reactive protein point of care testing and communication training (IMPAC ${ }^{3} \mathrm{~T}$ ): study protocol of a cluster randomised controlled trial

Jochen Cals, Rogier Hopstaken, Christopher Butler, Kerenza Hood, Johan Severens, Geert-Jan Dinant

BMC Family Practice 2007;8:15 


\section{Abstract}

\section{Background}

Most antibiotic prescriptions for acute cough due to lower respiratory tract infections (LRTI) in primary care are not warranted. Diagnostic uncertainty and patient expectations and worries are major drivers of unnecessary antibiotic prescribing. A C-reactive protein (CRP) point of care test may help GPs to better guide antibiotic treatment by ruling out pneumonia in cases of low test results. Alternatively, enhanced communication skills training to help clinicians address patients' expectations and worries could lead to a decrease in antibiotic prescribing, without compromising clinical recovery, while enhancing patient enablement. The aim of this paper is to describe the design and methods of a study to assess two interventions for improving LRTI management in general practice.

\section{Methods. and design}

This cluster randomised controlled, factorial trial will introduce two interventions in general practice; point of care CRP testing and enhanced communication skills training for LRTI. Twenty general practices with two participating GPs per practice will recruit 400 patients with LRTI during two winter periods. Patients will be followed up for at least 28 days. The primary outcome measure is the antibiotic prescribing rate. Secondary outcomes are clinical recovery, cost-effectiveness, use of other diagnostic tests and medical services (including reconsultation), and patient enablement.

\section{Discussion}

This trial is the first cluster randomised trial to evaluate the influence of point of care CRP testing in the hands of the general practitioner and enhanced communication skills, on the management of LRTI in primary care. The pragmatic nature of the study, which leaves treatment decisions up to the responsible clinicians, will enhance the applicability and generalisability of findings. The factorial design will allow conclusion to be made about the value of CRP testing on its own, communication skills training on its own, and the two combined. Evaluating a biomedical and communication based intervention ('hard' and 'soft' technologies) together in this way makes this trial unique in its field. 


\section{Background}

This article describes the design of a cluster randomised clinical trial (RCT) evaluating the clinical efficacy and cost-effectiveness of a point of care C-reactive protein (CRP) test and enhanced communication skills in the management of lower respiratory tract infections (LRTI) in general practice.

About $80 \%$ of all antimicrobials are prescribed in primary care, and up to $80 \%$ of these are for respiratory tract indications, including acute cough. Respiratory tract infections are by far the most common cause of cough in primary care. ${ }^{1,2}$ Broad spectrum antibiotics are often prescribed for cough, including acute bronchitis ${ }^{3,4}$, and many of these prescriptions will benefit patients only marginally if at all (Number Needed to Treat $=17)^{5}$, and may cause side effects (Number Needed to Harm $=33$ ). ${ }^{5}$ Unnecessary prescribing, especially of broad spectrum antibiotics, drives antimicrobial resistance, wastes money and raises wrong expectations for patients. Microbial resistance topped the list of priority intervention needs in the World Health Organization report on Priority Medicines. Although the Netherlands is one of the lowest antibiotic prescribing countries worldwide, unnecessary prescribing for LRTI remains of great concern. ${ }^{6}$ While unnecessary prescribing is a highly complex phenomenon, much of it relates to two factors, diagnostic uncertainty and patients' expectations. Interventions therefore should be aimed at clinicians to address these two factors. Previous studies with interventions aimed at general practitioners have resulted in less antibiotic prescribing. ${ }^{7,8}$

\section{Diagnostic uncertainty and C-reactive protein}

LRTI represents a source of considerable diagnostic uncertainty for clinicians. Only a small number of patients with signs and symptoms of LRTI have pneumonia. Differentiating pneumonia from acute bronchitis on clinical grounds is often impossible and so clinicians frequently prescribe antibiotics empirically. However, as acute bronchitis is generally self-limiting, and benefits do not generally outweigh possible side effects from antibiotic treatment ${ }^{5,9}$, rapid diagnostic tools to determine which patients will benefit from antibiotic treatment are urgently needed. ${ }^{10}$

C-reactive protein is a marker of an acute inflammatory response. Several studies have indicated that CRP is probably the most feasible and accurate investigation to differentiate pneumonia from acute bronchitis in patients with LRTI in general practice. ${ }^{11-14}$ We demonstrated in an earlier diagnostic study that for patients with a CRP less than $20 \mathrm{mg} / \mathrm{l}$ and who had no more than one of the three clinical predictors of pneumonia (dry cough, fever, diarrhoea), the absolute risk of pneumonia was reduced from $13 \%$ to less than $3 \% .{ }^{11}$ In daily practice a CRP value will only be useful when available during the initial 
consultation. CRP is available as a feasible point of care test for primary care and the test result can be available within three minutes. A low CRP test result is especially useful for reassuring both the doctor and the patient that further diagnostic testing and antibiotic treatment are not necessary. CRP tests can be done quickly, cheaply and with good reliability in everyday general practice using a finger prick blood sample. ${ }^{15}$ In Scandinavia, point of care CRP testing is part of the routine evaluation of patients with LRTI in general practice, and its use has proved cost-effective. ${ }^{16,17}$ In other countries including the Netherlands, however, GPs are still relatively unfamiliar with point of care CRP testing. The widespread introduction of point of care CRP testing in the Scandinavian countries was not accompanied by appropriate training for clinicians. This has led to an overuse of CRP testing in often mild respiratory tract infections. Slightly elevated CRP levels were too often followed by an unnecessary antibiotic course. ${ }^{18}$ Therefore, thorough training in use and interpretation of test results is needed for a fair chance of success. This should include information about the diagnostic value of the test in addition to a focus on the fact that pneumonia can be excluded by a low test result.

\section{Patient expectations and enhanced communication within the consultation}

Apart from diagnostic uncertainty, a range of other, 'non medical' influences come to bear on the decision to prescribe antibiotics. ${ }^{19}$ Perceived patient pressure for an antibiotic, patient expectations and satisfaction are major factors influencing the decision whether to prescribe antibiotics. ${ }^{20-25}$ Therefore, GPs need adequate communication skills to efficiently explain the pros and cons of antibiotic treatment, natural course and when to reconsult for this condition. Training GPs in enhanced consultations may therefore lead to easier and more acceptable non-antibiotic management. ${ }^{26}$ Clinicians' communication skills in managing common infections are often sub-optimal. ${ }^{27,28}$ In one of our studies, for example, carers' views/expectations on antibiotic treatment were elicited in only one of 39 audio taped consultations for children with respiratory tract infections. ${ }^{28}$ Many GPs therefore do not routinely use optimal communication skills to efficiently implement a non-antibiotic management strategy that patients would find acceptable and is time efficient in time pressured consultations. ${ }^{29}$ Although GPs perceive high patient expectations for antibiotics, evidence suggests that GPs are not good at estimating which patients expect antibiotics. Patient satisfaction is determined more by the quality of explanation and physical examination than whether or not they receive a prescription for an antibiotic. $^{20,30}$ Rollnick et al. developed an innovative communication skills training method which proved to be practical and acceptable to experienced clinicians. ${ }^{26}$ With everyday clinical experience in the foreground and 
communication skills in the background this context-bound method proved successful in sore throat consultations and was well received by GPs. ${ }^{31} \mathrm{We}$ have shown that training clinicians using these methods was associated with changes in the behavior of clinicians and patients in consultations for common infections. In an interrupted time series pilot study, before training in our enhanced consultation skills, GPs in 10 consultations elicited patients concerns on two occasions and empathized three times in total. ${ }^{31}$ No evidence was found of eliciting expectations of the consultation in general, or about antibiotics. After training, the same clinicians elicited patients concerns in 14 out of 15 consultations, elicited general expectations eight times, elicited expectations about antibiotics in all 15 consultations, and empathized a total of 38 times. Before clinician training, patients expressed their expectations only once in 10 consultations and asked questions a total of 12 times. After clinician training, patients expressed expectations in 14 out of 15 consultations and asked questions a total of 33 times. Although the importance of studying an intervention like this in a large trial is obvious ${ }^{32}$, as far as we know a full costeffectiveness analysis has never been performed, to evaluate the efficacy of any intervention to improve health care providers' behaviour regarding antibiotics prescribing.

\section{Opportunities in LRTI}

These studies on the potential for CRP and enhanced communication skills indicate that these interventions, either separately or combined, are able to have a positive effect on the prevention of misuse of antibiotics in LRTI. No point of care test has been evaluated together with context-bound training in enhanced communication skills.

Effective management of LRTI, we hypothesize, will involve a point of care test that performs well in primary care. It will also involve providing clinicians with the skills to efficiently and effectively communicate about the condition, its duration and implications to patients in a way that might make them accept a potential non-antibiotic management and facilitate patient enablement. However, some may argue that one of these interventions alone or indeed both together is required to enhance care. The factorial design of this study allows us to answer these questions.

\section{Research questions and outcome measures}

This study will investigate the following research questions:

To what extent does the introduction of the C-reactive Protein (CRP) point of care test and enhanced communication skills for managing LRTI in general practice, either separately or combined, have effect on: 


\section{Primary outcome measure}

1. Immediate antibiotic prescribing rates

\section{Secondary outcome measures}

1. Clinical recovery and return to usual activities

2. Cost-effectiveness of point of care CRP and communication training

3. Patient enablement, satisfaction and future consulting intention

4. Diagnostic testing other than point of care CRP

5. Use of health services, including reconsultation

6. Subsequent antibiotic prescribing rates within 28 days of the initial consultation

\section{Ethical approval}

The Ethics Committee of Catharina Hospital in Eindhoven, the Netherlands, approved the study protocol under number M05-1529, in compliance with the Helsinki Declaration.

\section{Methods}

This study is an open randomised controlled trial in general practice with randomisation at the practice level. The practices will be allocated to one of four groups (Table 4.1):

1. Access to and training in point of care CRP

2. Context-bound training in enhanced communication skills for acute cough

3. Access to and training in the use of point of care CRP plus context-bound training in enhanced communication skills for acute cough

4. Usual care.

The GPs in groups 1 and 3 will be trained to use and interpret point of care CRP and those in 2 and 3 in enhanced communication with patients.

Table 4.1 Intervention allocation.

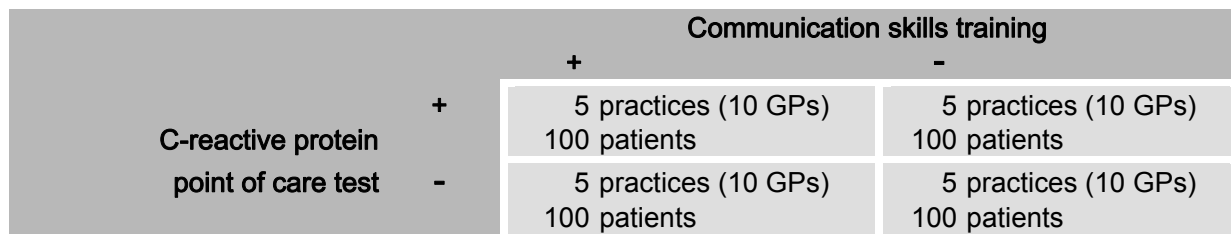




\section{Randomisation}

A cluster randomised design has been chosen to avoid contamination. In order to allow assessment of the effects of each individual intervention and of combinations of interventions, compared with a control group, a factorial design for randomisation by practice will be used. Two randomisation procedures will be undertaken, one to create two groups for CRP/no CRP and a second for communication skills training/no communication skills training. The process will be stratified by the classification of the practices as above/below average for their ability to recruit patients (total number of practitioner clinics per practice per week). This will ensure a balance in recruitment potential between the two arms. Random permuted blocks of four will be generated for each randomization process. This will create two groups of ten practices and balance at the margins for the stratification variable.

\section{Sample size calculation}

In order to detect a reduction in antibiotic prescribing from $80 \%$ to $60 \%$, with $80 \%$ power at a $5 \%$ significance level, an individually randomised study would require 175 patients. If we randomise 20 practices with an intra-cluster correlation coefficient (icc) of 0.06 this increases to 350 patients. In order to allow for a $90 \%$ follow-up rate for the primary outcome measure of antibiotic prescribing we intend to recruit 400 patients (20 per practice and 100 in each cell). We have previously demonstrated that 40 GPs can recruit over 400 patients suspected of having a LRTI in two winter seasons. ${ }^{11}$

\section{General practices}

A total of 20 general practices will be recruited, with a fixed number of two GPs per practice participating in the study. The practices are located in the Southeastern part of the province of Noord-Brabant in the Netherlands. This region compromises both urban and rural areas. Recruited practices will be geographically spread throughout this region.

\section{Patients}

The GPs will approach sequential eligible adult patients during regular consultation hours. Patients are eligible if they present in general practice with an acute cough, lasting no more than four weeks, considered to be caused by LRTI according to the GP. In addition, the patient needs to have at least one focal and one systemic sign/symptom. ${ }^{33}$ (Figure 4.1) Children will not eligible, since the diagnostic value of CRP has not been investigated for LRTI in children, consultations with children and their parents will be different with respect to communication styles and strategies, and diagnostic and prognostic 
factors are not automatically applicable in infants. Exclusion criteria are described in Figure 4.1.

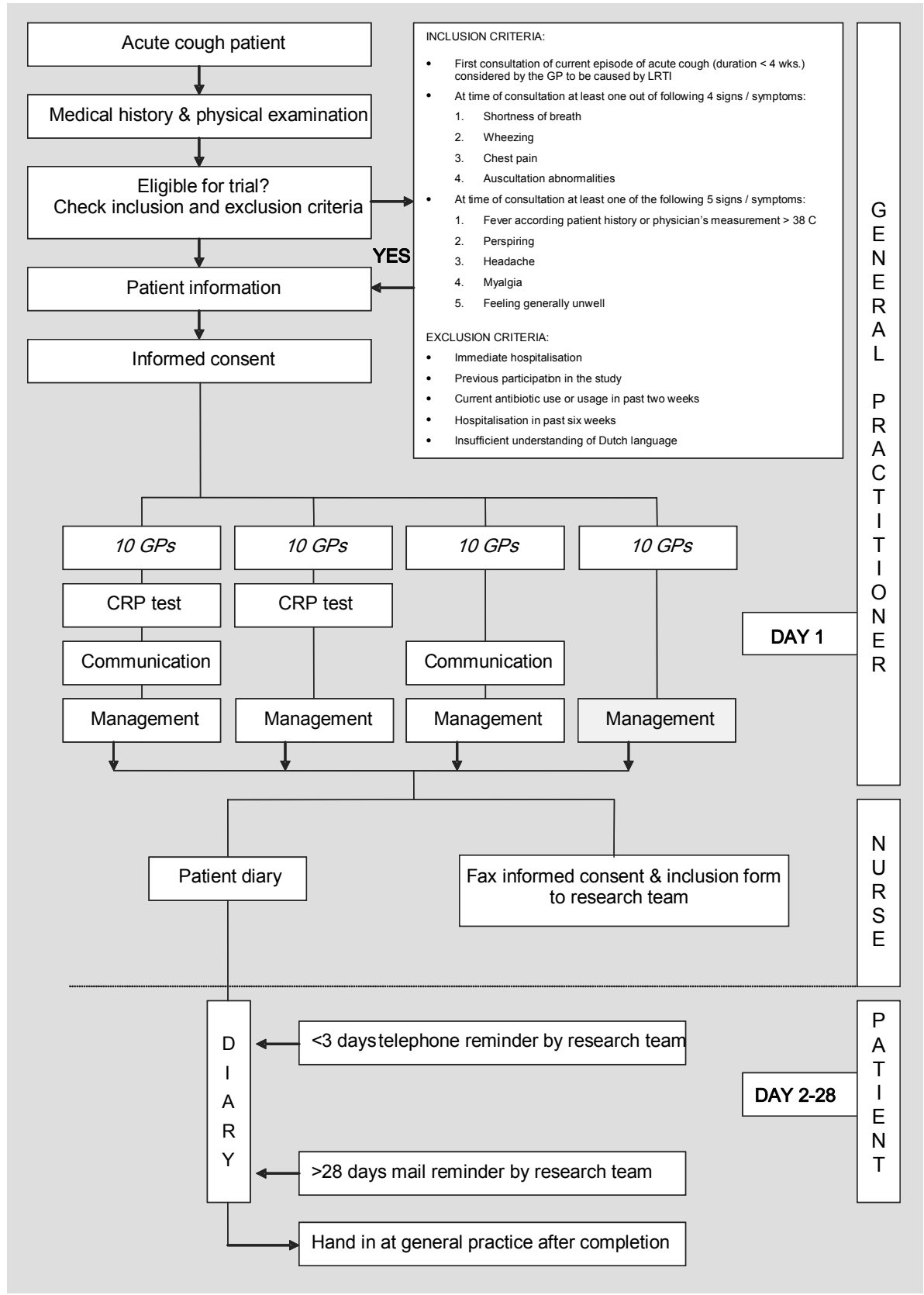

Figure 4.1 Flow chart inclusion and data collection. 


\section{CRP point of care test}

Twenty GPs will have a CRP test device in their practice. CRP analysis will be carried out during the consultation. The NycoCard ${ }^{\circledR}$ II Reader, product of AxisShield, will be used, in accordance with the manufacturer's instructions. The test system is based on an immunometric principle and consists of 1) a liquid for sample dilution and lysis of cells, 2) a test card with CRP-specific monoclonal antibodies coated to a membrane, 3) a conjugate solution with monoclonal antibodies coupled to ultra small gold particles and 4) a washing solution. One single drop of blood from a finger prick is needed to perform the test. A capillary collects $5 \mu \mathrm{l}$ blood which is diluted in the $0,4 \mathrm{ml}$ dilution liquid. $50 \mu \mathrm{l}$ of this diluted sample is applied to the test well of the device. When the sample flows through the antibody-coated membrane, C-reactive proteins are forced to react and bind to the antibodies on the membrane. CRP trapped on the membrane will bind the antibody gold conjugate. Unbound conjugate is removed by one drop of washing solution. In the presence of pathological levels of CRP in the sample, the membrane appears red-brown with color intensity proportionally to the CRP concentration. The color intensity is measured quantitatively with the color densitometer NycoCard $\AA$ Reader II. The measuring range for whole blood samples is 8 to $250 \mathrm{mg} / \mathrm{l}$. In the measuring range the test response is directly proportional to the concentration of CRP in the sample. For internal quality a control positive will be measured to confirm the efficacy and correct performance of the test. The control liquid is supplied with every test kit and will be run after opening of a new kit, which is once in every 24 regular tests. CRP measurements with $\mathrm{Nycocard} \circledast$ have proven to be valid and robust in general practice ${ }^{34}$. The result will be available within three minutes. This means that GPs can use the test result within the consultation. The $20 \mathrm{GPs}$ who are allocated to the CRP intervention will be given guidance about the interpretation of CRP results. This information will include a comprehensive summary of the literature on LRTI and the role of CRP. We will not instruct the GPs in a prescription style fashion. Focus will be on informing them on the additional diagnostic value of CRP in ruling out pneumonia. GPs will decide on management including possible antibiotic treatment in every patient. CRP may complement their clinical findings and help in deciding upon diagnosis and treatment. The desk reminder for CRP interpretation in LRTI can be seen in Figure 4.2. Practice assistants will be trained to use the NycoCard ${ }^{\circledR}$ II Reader by the Dutch distributor who has over ten years of training experience. GPs and assistants will be able to consult a 24-hour helpdesk for technical assistance. Questions on interpretive issues can be submitted to the research team. For specific test handling questions, we will also create a direct telephone number connecting the assistant with a clinic where assistants have extensive experience with handling point of care CRP testing. Once the CRP devices have been installed and training sessions have been performed, practices will 
get a 8-week run-in period before inclusion starts for familiarisation with the device and interpretation of the results.

\section{IMPAC ${ }^{3} T$ \\ LOWER RESPIRATORY TRACT INFECTIONS}

C-Reactive Protein test:

- Rule out pneumonia

- Combine clinical findings with $\mathrm{CRP}$

CRP $<20$

Pneumonia extremely unlikely

CRP 20 - 50

Pneumonia very unlikely

CRP $50-100$

Clear infection

Most likely acute bronchitis

Possibly pneumonia

Combination clinical findings \& CRP very important

CRP $>100$

Severe infection

Pneumonia more likely

IMPAC ${ }^{3} T$

LOWER RESPIRATORY TRACT INFECTIONS

\section{Communication items:}

\section{Elicit worries / expectations}

\section{Actively ask opinion on antibiotics}

Essential information:

Duration cough $>4$ weeks

Acute bronchitis is self-limiting (regardless of virus/bacteria)

Body will fight it, but it needs time

Antibiotica: benifits $=$ harms

Eat \& drink well, limit activities

Summarise and elicit understanding of information

Alarm symptoms

When to reconsult

Figure 4.2 Desk reminders for GPs allocated to the CRP and/or communication skills interventions. 


\section{Communication training}

The communication training is based upon a patient-centred strategy to achieve shared decisions about investigation and treatment of acute infections. The intervention is based on the elicit-provide-elicit framework, which has its background in motivational interviewing and which has been refined for use in primary care. ${ }^{26}$ The context-bound training for acquiring these communicating skills involves one two-hour training seminar at a central location, preceded and followed by consulting with simulated patients in routine surgeries. It involves the following specific elements:

\section{Simulated patient in clinical encounter, part 1}

Two experienced simulated patients will be trained to simulate a patient with acute bronchitis persisting for two weeks. The patient is worried about the duration of the cough and has distinct sleeping problems and impaired daily activities due to the cough. The simulated patients will consult with participating GPs at their own surgeries during regular surgery hours. The simulated patients will carry an audiotape device to record the conversation, which will be transcribed by trained typists.

\section{Seminar on shared decision making}

Within one week after their first simulated patient consultation, all 20 GPs will gather for a training seminar on enhanced communication skills. Three seminars will be held, with 5-8 GPs participating per session. All session will have the same format and content (see below). An experienced moderator from the Department of Vocational Training in General Practice will lead the seminar. The GPs will be encouraged to actively participate in all sections of the training. After a brief introduction, the GPs will receive transcripts of their first simulated patient contact. They will be asked to read their own transcript and make notes. Subsequently, the moderator will invite them to share their reactions to their transcripts and to identify noteworthy aspects. These can be of any kind; structure, vocabulary or occurring difficulties in management. The focus will be on the acute cough patient. This will be followed by a short presentation on current views and insights on LRTI. The contrast between evidence from research and figures from daily practice will be highlighted to stress the importance of enhancing LRTI consultations. GPs will be given the opportunity to contribute their own suggestions for enhancing LRTI consultations. The elicitprovide-elicit framework will be outlined ${ }^{26}$, where the GP first elicits what the patient knows about his condition and what the patient's main worries and expectations are. Crucially, the GP actively asks how the patient feels about antibiotics. This serves two purposes; firstly, to provide the GP with the patient's expectation and hope for antimicrobial treatment (making patients' expectations 
explicit). Secondly, it enables the GP to openly discuss his opinion on antibiotic treatment, mentioning the balance of possible benefits and harms of antibiotic treatment. Secondly, the GP provides information relevant to the patients' individual understanding and interest. This includes findings from the medical history and physical examination. Then the GP elicits the patients' interpretation about what has been said and done, and discusses implications for help seeking behaviour. Specific alarm symptoms should be mentioned to provide exact information to the patient about when to reconsult. All communication is based on an assessment of patients' information needs, thus achieving efficiency by targeting information to individual needs. Practice-based examples will be presented in video clips. Finally, GPs will be asked to attempt to identify the specific aspects, which need most attention during their consultations. Supported by a desk reminder (Figure 4.2) we will ask the GPs to implement the specific steps of the communication training in their routine acute cough consultations.

\section{Simulated patient in clinical encounter, part 2}

The GPs will get the opportunity to use the enhanced communication skills in daily practice during eight weeks before inclusion start. The two simulated patients will now switch practices, visiting the practices they did not visit, while playing a similar acute bronchitis role. Trained typists will once again transcribe the audio-recorded consultations. These transcripts will be copied and made anonymous, after which they are sent to a colleague participating in the study. This GP will be asked to write comments on the transcript based on the enhanced communication method and to add possible suggestions for improvement. The project team will edit or add comments if needed. Finally, the peer-reviewed transcript will be returned to the GP who conducted the consultation. Commenting on a colleague's transcript may promote GPs' critical reflection on their own peer-reviewed transcripts. Thus, participating GPs will benefit from reading and feeding on a colleague's transcript and from reflection on their own transcript.

\section{Data collection}

Sequential elegible patients will be asked by their GP to participate. During this consultation, the GP will take written consent and note the inclusion criteria on the trial inclusion form. The practice nurse will give each participant a simple self-complete symptom diary after the consultation. After general questions on cough and the consultation, patients will be asked each day to complete a 6 item scale, with responses to statements ranging from 0 to 6 . A total symptom score will be derived from this scale. Items relate to coughing, phlegm, shortness of breath, sleep disturbance, impairment of normal daily activities, 
and generally feeling unwell. This symptom diary has previously been used in a large LRTI study ${ }^{35}$. Patients will then be followed-up for 28 days, or if still unwell, until recovered with a maximum follow up of ten weeks. Furthermore, weekly questions will record time off work, medication use and reconsultation. The recruiting GP will fax the informed consent form and inclusion form to the research team in Maastricht on the day of inclusion. The clinical effectiveness analysis will be based on diary responses. A single Likert type scale response item will assess satisfaction with the consultation. Patient enablement will be measured using the Patient Enablement Instrument ${ }^{36}$ translated into Dutch. Concurrent validation will be undertaken. In addition, the research team will retrieve data on diagnosis, antibiotic prescription, reconsultation, diagnostic testing other than CRP and related medical consumption from participating patients' electronic medical records over 28 days follow-up. A societal perspective will be used for the economic evaluation. Thus, for all four groups, in addition to costs to the health care system, we will take into account medical costs borne by patients and production costs due to illness related absence from work. Use of health care facilities will be prospectively recorded in a standardised way including all reconsultations, telephone consultations, out-ofhours consultations, and hospital admissions, (repeat) prescription of antibiotics (type, dosage, duration) and additional diagnostic tests, including bacteriological culture and X-ray. A patient diary will be the basis for assessing actual medication use, other medical costs to the patient, and absence from work. ${ }^{37}$

The research team will retain transcripts of simulated patient consultations. Transcripts before the seminar will be compared with those afterwards for evidence of acquisition of the enhanced communication skills (competence).

\section{Patient follow-up}

The respondent burden will be kept to a minimum. The research team will contact patients by telephone within four days to offer further information about study participation and to iron out eventual problems concerning study materials. Reminders to complete study documents will be sent by post to patients after 14 days, and patients will receive a reminder postcard at the end of the follow up period.

\section{Analysis}

Statistical analyses will be performed with the aid of the SPSS and STATA statistical packages. The primary analysis will be intention to treat and will compare the marginal effects of the two interventions on antibiotic prescribing at the index consultation and incorporate an interaction effect. The interaction term will be included to test for a synergistic or antagonistic relationship between the two interventions. This will be tested using a three level logistic regression 
model to account for variation at the practice/GP/patient. If there is no indication of random effects at a GP level, then this will be reduced to a two level model with GP seen acting as a patient level covariate.

A four level linear regression model will be fitted to the symptom scores (logged) to account for practice, GP, patient and repeated assessments over time. The correlation between repeated assessments within individual patients will be modelled to allow for greater correlation between assessments, which are closer in time. The effect of interventions would be seen in the comparison of the slopes of symptom scores over time in the groups, i.e. having faster (or slower) recovery rates. ${ }^{38}$ Sensitivity analyses on the symptom scores will be undertaken to assess the impact of loss to follow-up by either interpolating from available data using the estimated slope of symptoms from the model or using last value carried forward. The later is unlikely to arise in practice for an acute infection, however provides a useful extreme bound in which to interpret results. Secondary outcomes (satisfaction, enablement, reconsultation and other investigations) will be compared between the two groups using three level regression models (linear and logistic where appropriate). No formal sub-group analyses are planned. However, exploratory analyses will investigate the influence of patient and practitioner demographics on outcomes. The statistical uncertainty regarding the cost-effectiveness of the different strategies will be assessed using non-parametric bootstrap resampling techniques and result in estimates of net monetary benefit values. For the groups of GPs trained in enhanced communication skills and/or CRP testing, the cost analysis will be extended beyond patient level data. Training will lead to additional costs (organising and giving the training and GPs' time investment) which will be included in the analysis. ${ }^{39}$ Such overhead costs are basically one-time costs and can therefore be regarded as fixed costs that will be measured at the level of the trained GPs and attributed to an individual patient, which will be done on the basis of a division calculation as proposed by Mason et al. ${ }^{40}$ The trial will be reported following CONSORT guidelines, extended for cluster randomised trials. $^{41}$

\section{Discussion}

This trial will be the first randomised controlled trial to evaluate the use of point of care CRP testing and enhanced communication skills training, on the management of acute cough due to LRTI in primary care. Both are promising interventions in reducing unnecessary antibiotic prescribing. A systematic evaluation in daily general practice is required to assess effectiveness. Our inclusion criteria are quite broad as a reflection of daily practice. LRTI is such a commonly seen illness among the full range of patients in primary care that we 
think the inclusion criteria should enable us to investigate all these patients. Primary inclusion criterion is the GP's suspicion of LRTI being the primary cause of the acute cough episode. GPs are daily facing difficulty in deciding upon management for these patients. The pragmatic approach of this trial leaves them very close to daily practice when considering recruiting the patient for this study. We did however define a group of focal and a group of systemic signs and symptoms in the inclusion criteria, which indicate that this patient has signs and symptoms of an infection of the lower respiratory tract.

A low CRP test result, expected to occur in at least half of these patients with LRTI, will be reassuring for both the GP and the patient that the illness is mild and most probably self-limiting. On the other end of the spectrum, very high test results will help the GP in considering antibiotic treatment or referral to a hospital. To achieve this GPs must be aware of the usefulness of the test and they should be able to properly interpret results. These are crucial conditions for a positive effect of the CRP intervention. If GPs are not aware of the value of the test, other important influences such as time pressure and patients' expectations may dilute any possible effect on antibiotic prescribing. If GPs are able to build the communication skills, which take the latter influences into account, into their routine consultations, long term competence and performance have to be monitored, since maintenance of acquired communication skills is difficult. So even when GPs understand the theory of the test and the principle of the enhanced communication, the question remains whether they will use it to adjust the management of LRTI patients.

We chose a factorial design, as it will enable us to efficiently investigate the interventions by including all participants in both analyses. Furthermore it will give us the opportunity to consider both the individual effects of both interventions and the benefits of receiving both interventions together. Factorials trials do require special considerations at the analysis stage. Interaction between the interventions needs to be investigated, since this can have effect on the power of the study. ${ }^{42}$

In this trial both interventions are targeted at the GPs with impact on patient outcomes. Randomisation at practice level has been chosen in this trial, because there is less risk of contamination by GPs concurrently managing usual care patients, while other GPs manage their patients under the experimental regimen in the same practice. However, since patients yet have to be recruited after randomisation post-randomisation recruitment bias deserves special attention. One may expect that practices not receiving a desired intervention may gradually loose enthusiasm to recruit. As a strategy to prevent this, those practices allocated to the usual care arm, as well as those allocated to one of the arms to which only one intervention will be allocated, will be informed that they will receive a CRP device and/or the communication training after the study period. Recruitment rates across the four groups have to be 
monitored and baseline characteristics will be described to ensure comparability. Because of the small number of practices involved, randomisation will be restricted carefully with regard to recruitment ability. With a small number of clusters and a large number of patients this trial may be difficult to analyse and risk of loss of power exists if one practice should drop out. In cluster randomised trials the outcome for each patient cannot be assumed to be independent of that of any other patient since the patients within one cluster (practice) are more likely to have similar outcomes. Therefore multilevel analysis will be performed.

Prediction of sample size in cluster randomised trials is difficult given the fact that not only the expected effect size has to be estimated, but also the anticipated cluster size and intra-cluster correlation coefficient. ${ }^{43}$ Despite these limitations analysis on both cluster level as well as individual level will provide us the best information on the outcome of this study. ${ }^{44}$ Results will be reported with full transparency with regard to the factorial and cluster design. ${ }^{41,42}$

The study will allow us to get more insight into the natural course of this common but still under-researched illness. The long follow-up of 28 days and the daily patients' evaluation of number and extent of their symptoms will provide crucial information on natural course, burden and impact on daily activities.

To our knowledge, both from the point of view of interventions and study design, this is a unique study. It will be the first to evaluate complex interventions separately and combined, that focus on the biomedical evaluation of the illness and patient centered communication. The pragmatic nature of the study, which leaves treatment decisions up to the responsible clinicians, will enhance the applicability and generalisability of findings. If these interventions decrease antibiotic prescribing and enhance patient satisfaction with favourable clinical outcomes, they could be used to enhance the quality of a large number of consultations in primary care, both for common infections and for other conditions. A full cost-effectiveness analysis to evaluate the efficiency of the interventions is needed in this regard as well and will therefore be performed. This has never been done before for an intervention to improve health care providers' communication regarding antibiotics prescribing.

If these complex interventions are shown to be effective and cost-effective, they may be refined as a result of the research and we will promote uptake in everyday care. 


\section{References}

1. Van der Velden J. Basisrapport morbiditeit in de huisartspraktijk: NIVEL, 1991.

2. Verheij TJM, Salomé PL, Bindels PJ, Chavannes AW, Ponsioen BP, Sachs APE, et al. NHGStandaard Acuut hoesten. Dutch College of General Practitioners Guidelines on Acute Cough. Huisarts Wet 2003;46:496-506.

3. Steinman MA, Gonzales R, Linder JA, Landefeld CS. Changing Use of Antibiotics in Community-Based Outpatient Practice, 1991-1999. Ann Intern Med 2003;138:525-33.

4. van Duijn HJ, Kuyvenhoven MM, Schellevis FG, Verheij TJM. Determinants of prescribing of second-choice antibiotics for upper and lower respiratory tract episodes in Dutch general practice. J. Antimicrob. Chemother. 2005;56:420-2.

5. Smucny J, Fahey T, Becker L, Glazier R. Antibiotics for acute bronchitis. Cochrane Database Syst Rev 2004.

6. Goossens H, Ferech M, Vander Stichele R, Elseviers M. Outpatient antibiotic use in Europe and association with resistance: a cross-national database study. Lancet 2005;365:579-87.

7. Welschen I, Kuyvenhoven MM, Hoes AW, Verheij TJM. Effectiveness of a multiple intervention to reduce antibiotic prescribing for respiratory tract symptoms in primary care: randomised controlled trial. BMJ 2004;329:431.

8. Coenen S, Van Royen P, Michiels B, Denekens J. Optimizing antibiotic prescribing for acute cough in general practice: a cluster-randomized controlled trial. J Antimicrob Chemother 2004; 54:661-72.

9. Gonzales R, Sande M. What will it take to stop physicians from prescribing antibiotics in acute bronchitis? Lancet 1995;345:665-6.

10. Nordberg P, Monnet DL, Cars O. Antibacterial drug resistance: options for concerted action. World Health Organization Department of Medicines Policy and Standards. Geneva, 2005: $1-48$.

11. Hopstaken RM, Muris JWM, Knottnerus JA, Kester ADM, Rinkens PELM, Dinant GJ. Contributions of symptoms, signs, erythrocyte sedimentation rate and C-reactive protein to a diagnosis of pneumonia in acute lower respiratory tract infection. $\mathrm{Br} J$ Gen Pract 2003;53: 358-64.

12. Melbye H, Straume B, Aasebo U, Dale K. Diagnosis of pneumonia in adults in general practice. Relative importance of typical symptoms and abnormal chest signs evaluated against a radiographic reference standard. Scand J Prim Health Care 1992;10:226-33.

13. Flanders SA, Stein J, Shochat G, Sellers K, Holland M, Maselli J, Drew WL, Reingold AL, Gonzales R. Performance of a bedside C-reactive protein test in the diagnosis of communityacquired pneumonia in adults with acute cough. Am J Med 2004;116:529-35.

14. van der Meer V, Neven AK, Broek PJvd, Assendelft WJJ. Diagnostic value of C reactive protein in infections of the lower respiratory tract: systematic review. BMJ 2005;331:26-9.

15. Hobbs FD, Kenkre JE, Carter YH, Thorpe GH, Holder RL. Reliability and feasibility of a near patient test for C-reactive protein in primary care. BMJ 1996;46:395-400.

16. Diederichsen HZ, Skamling M, Diederichsen A, Grinsted P, Antonsen S, Petersen PH, Munck AP, Kragstrup J. Randomised controlled trial of CRP rapid test as a guide to treatment of respiratory infections in general practice. Scand J Prim Health Care 2000;18:39-43.

17. Dahler Eriksen BS, Lauritzen T, Lassen JF, Lund ED, Brandslund I. Near-patient test for Creactive protein in general practice: assessment of clinical, organizational, and economic outcomes. Clin Chem 1999;45:478-85.

18. Andre M, Schwan A, Odenholt I. The use of CRP tests in patients with respiratory tract infections in primary care in Sweden can be questioned. Scand J Infect Dis 2004;36:192-7.

19. Coenen S, Michiels B, Van Royen P, Van der Auwera JC, Denekens J. Antibiotics for coughing in general practice: a questionnaire study to quantify and condense the reasons for prescribing. BMC Fam Pract 2002;3:16.

20. Hamm RM, Hicks RJ, Bemben DA. Antibiotics and respiratory infections: are patients more satisfied when expectations are met? J Fam Pract 1996;43:56-62. 
21. Fischer $\mathrm{T}$, Fischer $\mathrm{S}$, Kochen MM, Hummers Pradier E. Influence of patient symptoms and physical findings on general practitioners' treatment of respiratory tract infections: a direct observation study. BMC Fam Pract 2005;6:6.

22. Macfarlane $J$, Holmes $W$, Macfarlane R, Britten $N$. Influence of patients' expectations on antibiotic management of acute lower respiratory tract illness in general practice: questionnaire study. BMJ 1997;315:1211-4.

23. Little P, Dorward M, Warner G, Stephens K, Senior J, Moore M. Importance of patient pressure and perceived pressure and perceived medical need for investigations, referral, and prescribing in primary care: nested observational study. BMJ 2004;328:444.

24. Petursson P. GPs' reasons for "non-pharmacological" prescribing of antibiotics. A phenomenological study. Scand J Prim Health Care 2005;23:120-5.

25. Cockburn J, Pit S. Prescribing behaviour in clinical practice: patients' expectations and doctors' perceptions of patients' expectations-a questionnaire study. BMJ 1997;315:520-3.

26. Rollnick $S$, Kinnersley $P$, Butler $C$. Context-bound communication skills training: development of a new method. Med Educ 2002;36:377-83.

27. Little P, Gould C, Williamson I, Warner G, Gantley M, Kinmonth AL. Reattendance and complications in a randomised trial of prescribing strategies for sore throat: the medicalising effect of prescribing antibiotics. BMJ 1997;315:350-2.

28. Butler CC, Rollnick S, Kinnersley P, Tapper Jones L, Houston H. Communicating about expected course and re-consultation for respiratory tract infections in children: an exploratory study. Br J Gen Pract 2004;54:536-8.

29. Butler CC, Rollnick S, Kinnersley P, Jones A, Stott N. Reducing antibiotics for respiratory tract symptoms in primary care: consolidating 'why' and considering 'how'. Br J Gen Pract 1998;48: 1865-70.

30. Butler CC, Rollnick S, Pill R, Maggs Rapport F, Stott N. Understanding the culture of prescribing: qualitative study of general practitioners' and patients' perceptions of antibiotics for sore throats. BMJ 1998;317:637-42.

31. Rollnick S, Seale C, Kinnersley P, Rees M, Butler C, Hood K. Developing a new line of patter: can doctors change their consultations for sore throat? Med Educ 2002;36:678-81.

32. Severens JL. Value for money of changing healthcare services? Economic evaluation of quality improvement. Qual Saf Health Care 2003;12:366-71.

33. Hopstaken RM. Lower respiratory tract infections in general practice; aetiology, diagnosis, management and prognosis. Maastricht University, 2005.

34. Dahler Eriksen BS, Lassen JF, Petersen PH, Lund ED, Lauritzen T, Brandslund I. Evaluation of a near-patient test for C-reactive protein used in daily routine in primary healthcare by use of difference plots. Clin Chem 1997;43:2064-75.

35. Little P, Rumsby K, Kelly J, Watson L, Moore M, Warner G, Fahey T, Williamson I. Information Leaflet and Antibiotic Prescribing Strategies for Acute Lower Respiratory Tract Infection: A Randomized Controlled Trial. JAMA 2005;293:3029-35.

36. Howie JG, Heaney DJ, Maxwell M, Walker JJ. A comparison of a Patient Enablement Instrument (PEI) against two established satisfaction scales as an outcome measure of primary care consultations. Fam Pract 1998;15:165-71.

37. Goossens MEJB, Molken MPMHR-v, Vlaeyen JWS, van der Linden SMJP. The cost diary: a method to measure direct and indirect costs in cost-effectiveness research. Journal of Clinical Epidemiology 2000;53:688-95.

38. Butler CC, Robling M, Prout H, Hood K, Kinnersley P. Management of suspected acute viral upper respiratory tract infection in children with intranasal sodium cromoglicate: a randomised controlled trial. The Lancet 2002;359:2153-8.

39. Barlow GD, Lamping DL, Davey PG, Nathwani D. Evaluation of outcomes in communityacquired pneumonia: a guide for patients, physicians, and policy-makers. The Lancet Infectious Diseases 2003;3:476-88.

40. Mason J, Freemantle N, Nazareth I, Eccles M, Haines A, Drummond M. When Is It Costeffective to Change the Behavior of Health Professionals? JAMA 2001;286:2988-92.

41. Campbell MJ. Extending CONSORT to include cluster trials. BMJ 2004;328:654-5. 
42. Montgomery A, Peters T, Little P. Design, analysis and presentation of factorial randomised controlled trials. BMC Medical Research Methodology 2003;3:26.

43. Yudkin PL, Moher M. Putting theory into practice: a cluster randomized trial with a small number of clusters. Statistics in Medicine 2001;20:341-9.

44. Campbell MK, Mollison J, Steen N, Grimshaw JM, Eccles M. Analysis of cluster randomized trials in primary care: a practical approach. Fam. Pract. 2000;17:192-6. 




\section{Abstract}

\section{Objective}

To determine if a communication skills training program for general practitioners involving contextrich learning experiences and 'peer review' of consultation transcripts results in communication skills acquisition and maintenance, while preserving time-efficiency in consultations.

\section{Methods}

A pre-test - post-test evaluation of training 20 General Practitioners (GPs) in enhanced communication skills. Audio taped consultations with simulated patients in routine practice conducted before, within two weeks and again six months after communication skills training were analysed and consultation length measured. Transcripts were scored for specific skills to determine differences in short and longer-term competence of GPs for the communication skills.

\section{Results}

There was good evidence that GPs acquired key communication skills after training and that these were maintained over six months. Consultations remained within normal consultation length in primary care.

\section{Conclusion}

Specific communication skills for acute bronchitis can be successfully acquired by GPs through context-rich communication training with peer review of transcripts with simulated patients, without making consultation length unfeasible.

\section{Practice Implications}

This approach to skill acquisition is useful for enhancing communication skills competence in general medical practice. 


\section{Introduction}

Unnecessary antibiotic prescribing in primary care remains an important public health threat in an era of increasing antimicrobial resistance. ${ }^{1}$ It is particularly common in lower respiratory tract infections (LRTI) where approximately $80 \%$ of patients receive a prescription for antibiotics despite evidence for little or no benefit. $^{2-5}$ LRTI is one of the most common reasons for people to consult general practitioners (GPs), and use of broad-spectrum antibiotics is increasing for this indication. ${ }^{6-8}$ General practitioners are aware that they over prescribe antibiotics for LRTI. ${ }^{3,4,9}$ Diagnostic uncertainty and non clinical factors, such as time-pressure, perceived patients' expectations and the desire to maintain good relationships play an important role in the decision to prescribe antibiotics. ${ }^{10-15}$ However, patient satisfaction is influenced more by the quality of information provision and physical examination than by whether or not an antibiotic is prescribed. ${ }^{9,15,16}$ Moreover, diagnostic uncertainty needs to be minimised through appropriate clinical assessment and additional testing to exclude pneumonia, rather than through prescribing antibiotics to cover the eventuality of a bacterial aetiology. ${ }^{11,17}$

The quality of communication between physicians and patients is a critical factor for optimal medical care generally. In acute bronchitis, GPs need sophisticated communication skills to manage non-medical influences within the consultation by efficiently identifying and responding to the patient's agenda, setting realistic expectations about the natural course, exploring the possible benefits and harms of antibiotic treatment, describing self management strategies and appropriate reconsultation. Communication skills training for GPs focussing on these issues may lead to higher quality consultations, where patients accept evidence based prescribing decisions and become more confident about self management, without feeling 'sent away' with unsatisfactory explanations.

Rollnick et al. developed an innovative communication skills training method which proved to be practical and acceptable to experienced clinicians. ${ }^{18,19} \mathrm{We}$ adapted the training method and communication skills content for training GPs in advanced communication skills for LRTI consultations. While GPs may show enhanced short-term competence directly after training, sustainable performance in daily general practice requires demonstrable longer-term competence. $^{20}$ This study aimed to determine if GPs trained in the enhanced communication skills could apply these skills in a routine practice setting, and whether GPs could maintain these acquired skills over the longer-term. 


\section{Method}

\section{Study design}

We used a pre-test-post-test design for the evaluation of training GPs in enhanced communication skills for managing acute bronchitis using a contextrich training approach that included peer review of transcripts with simulated patients.

\section{General practitioners}

Twenty GPs from ten general practices participated in this aspect of our research program. These GPs are part of the IMPAC ${ }^{3} T$ study (ISRCTN85154857), which is currently recruiting patients into a controlled trial of LRTI management. ${ }^{21}$ This RCT will be reported later, and will evaluate the effect of our training program on antibiotic prescribing rates. The aspect of our study in the current report focuses on practitioners skills acquisition. Participating practices were geographically spread throughout a region that comprises both urban and rural areas. All GPs provided written consent to participate in all aspects of the training program.

\section{Overview of training interventions}

\section{Phase 1}

Consultation 1 with simulated patient (SP) in GPs' own surgery during routine consultation session within the week before a training seminar, generating baseline measurement and transcript 1 (T1).

\section{Phase 2}

Training seminar; transcript discussion (T1) and introduction to enhanced communication skills for managing acute bronchitis based on health behaviour counselling.

\section{Phase 3}

SP contact 2, within two weeks after training, generating transcript 2 (T2).

\section{Phase 4}

Feedback ('peer review') from colleague on own transcript T2, and providing peer review on a colleague's transcript. 


\section{Phase 5}

SP contact 3, six months after training, generating transcript 3 (T3).

SPs 2 and 3 were an opportunity to practice skills but could used for evaluating skills acquisition.

\section{Simulated patients in clinical encounter}

Three SPs were trained as acute bronchitis patients. All had experience in playing SP roles for at least ten years. They received a comprehensive written account of the clinical scenario and a full briefing on their role. Thereafter, a training session with two of the researchers (JC and NS) clarified the purpose of the project and the simulated role. All three SPs were trained to play a patient with a similar clinical history and presentation. A practice consultation with a GP was videotaped for each SP and discussed with the researchers.

The GPs were informed that an SP would consult during a routine surgery, but they were unaware of the exact date and time. At the beginning of each simulated encounter, GPs were given written instructions asking them to conduct the consultation as if it were an authentic encounter. An audiorecording device was then placed on the desk. The simulated clinical scenario was of a patient presenting with a cough of two weeks duration and with moderate to severe impairment of daily activities. The scenario was held constant over the three SP visits, but the actor differed. If a GP indicated they wished to proceed to the physical examination, the patient handed over a standardised leaflet, summarizing the main findings: moderate degree of general illness, no fever, no abnormalities on cardiac and pulmonary examination except generalised rhonchi on both lungs.

\section{Transcripts}

Audio-recordings of the SP consultations were transcribed by two experienced medical typists who were not aware of the purpose of the study. The consultation time was recorded.

\section{Communication skills training seminar}

The communication skills training seminar was based on a patient-centred strategy to achieve shared decision about investigation and treatment of acute infections. $^{22}$ The content of training was built around the 'elicit-provide-elicit' framework for efficient information exchange. This was derived from behaviour change counselling based on motivational interviewing ${ }^{23}$ Its principles include enhancing intrinsic motivation by building on patients' own appraisals for change, and to focus information provision on patients information needs but 
with patients themselves taking responsibility for appraising the personal implications of the information.

All 20 GPs were asked to participate in a one, two-hour long seminar at a central location. Three separate seminars were held with the same format and agenda. Five to eight GPs participated in each seminar. An overview of the seminar's components and their timing is given in Table 5.1. A communication expert of the Department of Vocational Training in General Practice (HG) moderated the seminars. After a brief introduction, GPs were presented with transcripts of their first SP contact. This written version of their consultation was used as a basis to reflect upon the potential of enhanced communication skills to improve the quality of such clinical encounters. Noteworthy aspects and difficulties in acute bronchitis consultations were discussed. Then the elicitprovide-elicit framework was outlined in which the GP elicits what the patient knows about his condition and what the patient's main worries and expectations are. Crucially, the GP also actively asks how the patient feels about antibiotics. This serves two purposes; firstly, it elucidates the patient's knowledge and expectations, and secondly, it provides a platform for the GP to openly discuss the possible benefits and harms of antibiotic treatment. The GP then provides information relevant to the patients' individual understanding and interest and discusses implications for help seeking behaviour, including alarm symptoms for which the patient should reconsult. Then the GP elicits the patients' interpretation about what has been said and done.

In order to stress the importance of quality improvement of LRTI consultations, the facilitator provided a contrast between the evidence-base, including the existing international guidelines for $L R T I^{2-4}$, and daily practice. A video demonstration of the elicit-provide-elicit approach was presented and contrasted with a video example of a more 'common practice' consultation. Finally, GPs were asked to implement the specific steps of the communication training in their routine acute bronchitis consultation, supported by a desk reminder. The desk reminder contained a summary of the communication skills and information on the inclusion criteria of the planned LRTI randomised controlled trial. The GPs then had the opportunity to practice these skills with SPs in a scenario commonly encountered in general practice during routine surgeries. 
Table 5.1 Content and time planning of training seminar.

Introduction (5 minutes)

General round of introduction. Participants and trainers ( $\mathrm{HG}$ and $\mathrm{JC}$ ) agreed on the clinical area studied; antibiotic prescribing for lower respiratory tract infections, acute bronchitis in particular, and specific difficulties in LRTI consultations and opportunities to enhance communication skills.

Transcripts (20 minutes)

Transcripts of the consultation of the first standardised simulated patient in the previous week were distributed to all participants. They were asked to thoroughly read the document, write down noteworthy aspects and experienced difficulties within the consultation.

Discussion - evaluation of transcripts (20 minutes)

The trainer (HG) elicited their ideas and weaved in supporting evidence. How did this consultation evolve? Was this patient very ill? What aspects of the consultation were predominantly difficult? Did the patient expect antibiotic treatment?

Sharing evidence (15 minutes)

A short presentation of the latest insights and evidence on lower respiratory tract infections, including information on existing guidelines and evidence on non-medical factors influencing the LRTI consultation was given (JC). The aim was to position both the acute cough patient and GP in a good clinical practice setting with all the attached doubts and exceptions, relevant to a clinical presentation with a significant diagnostic uncertainty.

Discussion - sharing ideas on optimal consultation (10 minutes)

The trainer actively elicited the participants' ideas on strategies to optimise consultation for acute bronchitis. Suggestions of individuals were written down and gradually consensus was reached by the team of participants on specific items necessary in an optimal LRTI consultation.

The elicit-provide-elicit method for LRTI consultations (35 minutes)

A solid outline of the elicit-provide-elicit method, developed by Rollnick et al. (2002) was given and the trainer outlined the potential for acute bronchitis consultations. Key ingredients of evidence based LRTI consultations accompanied by general communication skills were discussed. GPs were asked to notice similarities with previously self-defined specific items. In all three sessions most items had been suggested by individual GPs in the previous part of the training.

Once all steps were clarified a video clip of a standard consultation was played followed by a video clip of the same GP using the elicit-provide-elicit method incorporating all defined LRTI communication items. GPs were asked to identify the different items in the video. After discussion of the differences between the two strategies the last video was replayed.

Discussion - acceptability and applicability in general practice (10 minutes)

The trainer initiated a short evaluation of the acceptability and applicability in daily practice. Lessons learned were discussed and GPs recognised possibilities and opportunities to enhance communication skills. GPs were asked to individually define two key messages of the seminar and reflect upon them.

Debriefing and practical arrangements (5 minutes)

Further study procedures including the visit of a second simulated patient were discussed. GPs were asked to directly endeavour to use the presented skills in daily practice. The process of peerreviewing transcript was elucidated. 


\section{Peer review of colleagues transcripts of consultation with simulated patient}

After the training seminar, the second SP visited the GPs during regular consultation hours in the following week. Anonymised transcripts of these visits were sent out to fellow GPs participating in the study. GPs were asked to comment on the transcript of one of their study colleagues guided by their knowledge of the enhanced communication method, making suggestions for improvement. Instructions for peer-reviewing were provided on a three-page form. First, GPs were asked to read the transcript and identify evidence of the use of specific communication items. These skills reflect the items contained in Table 5.2. The peer-reviewer was asked to write the number matching the skill next to the text that contained evidence of the use of that skill. Secondly, they were asked to decide if a specific item was satisfactorily present throughout the transcript by scoring the item as 'sufficient' or 'not sufficient'. Finally, peerreviewers were asked to identify a single skill requiring particular attention in the future consultations of their peer, and to justify why this skill was selected for special focus. This structured 'peer-reviewed' transcript was then returned to the research team who performed a completion check. The transcript was then sent to the GP who conducted the consultation. All GPs therefore acted as a 'peer reviewer' and received feedback form a colleague on their own transcript. Six months after the seminar the third SP visited the GPs for a similar clinical encounter. This visit was once again unannounced.

\section{Development of measuring scale}

We developed a scale to quantify evidence of the use of the skills we judged necessary to implement the enhanced communication approach. Eleven items were developed based on components we felt were key ingredients of our communication skills strategies and constituted good practice in the acute bronchitis consultations. The scale items included five general communication items and six specific LRTI communication items (Table 5.2). Each item was rated on a four point scale ranging from 0 to 3 , to reflect 'behaviour not observed at all'(score=0) to 'behaviour observed at a high standard' (score=3). A detailed manual for scoring each item was developed to ensure that the raters used the same criteria to score the specific communication skills.

Two raters (NS and JC) piloted the use of the scale on four randomly chosen transcript and compared their rating scores. Each scale item and its rating were discussed, which resulted in some scale items and the scoring manual being revised. Subsequently, four researchers who were not involved in the present study were asked to rate the items in a randomly chosen transcript. These ratings were discussed and final alterations made to the measuring scale and scoring manual. The two initial raters then independently rated the same four 
randomly chosen transcripts. A mean 93.2\% agreement on separate items and a Cohen's Kappa of 0.91 on the total score was found, which was regarded as adequate for commence rating all transcripts.

Table 5.2 Measuring scale listing individual communication items, based on the context-bound communication training. Inter-rater agreement (\%) and agreement adjusted by chance (K) for all 60 transcripts of two raters.

\begin{tabular}{|c|c|c|}
\hline General communication items & $\begin{array}{c}\% \\
\text { agreement }\end{array}$ & $\begin{array}{c}\text { Cohen's } \\
\text { Kappa (к) }\end{array}$ \\
\hline \multicolumn{3}{|l|}{ The general practitioner: } \\
\hline 1. elicits patient's concerns (worries) about the cough problem & 96.7 & 0.91 \\
\hline 2. elicits patient's expectations about management & 91.7 & 0.83 \\
\hline 3. summarizes the consultation & 98.3 & $N / A^{a}$ \\
\hline 4. checks patients understanding of the given information & 96.7 & 0.92 \\
\hline 5. reaches agreement with the patient on proposed treatment & 86.7 & 0.73 \\
\hline \multicolumn{3}{|l|}{ LRTI specific communication items } \\
\hline \multicolumn{3}{|l|}{ The general practitioner: } \\
\hline 6. actively asks for patient's opinion/view on antibiotics & 90.0 & 0.79 \\
\hline 7. mentions a likely duration of cough caused by LRTI & 95.0 & 0.89 \\
\hline 8. states that patient's own body will overcome the illness & 88.3 & 0.74 \\
\hline 9. mentions both pros and cons of antibiotic treatment to the patient & 95.0 & 0.90 \\
\hline 10. mentions self management strategies (e.g. limit activities) & 90.0 & 0.80 \\
\hline 11. mentions alarming symptoms, when to reconsult (e.g. high fever) & 93.3 & 0.85 \\
\hline \multicolumn{3}{|l|}{ Rating options } \\
\hline \multicolumn{3}{|l|}{$\begin{array}{l}0=\text { The behaviour is not observed }(0 \text { points }) \\
1=A \text { minimal attempt is made to exhibit the behaviour ( } 1 \text { point }) \\
2=\text { The behaviour is observed and an average skill level achieved ( } 2 \text { points) } \\
3=\text { The behaviour is exhibited to a good/high standard ( } 3 \text { points })\end{array}$} \\
\hline
\end{tabular}

\section{Rating of transcripts}

For final rating of transcripts, the two researchers rated all 60 transcripts in random order (T1, T2 or T3). The researchers were not only blinded to transcript order, but also to the transcript number and GP identity. Ratings of all transcripts were then compared. Where there was lack of congruence between scores given to individual scale items for each transcript, the two raters discussed their disagreement. If resolution through consensus was not rapidly achieved, a third blinded researcher (HG) was available for rating and decided the final score for the particular item. Final scores $(0,1,2$ or 3 points) per item were added to form a total score for the communication scale and the two subscales: general and LRTI specific communication items (Table 5.2). Interitem correlations for the added items were all positive or indistinguishable from zero. Transcripts preceding the seminar were regarded as the baseline 
measurement, and scores for this transcript (T1) were compared with scores shortly afterwards (T2) and with scores 6 months after the training seminar (T3), for evidence of short and longer-term competence for the implementation of the communication skills.

\section{Outcome measures}

The primary outcome measures were short and longer-term competence of GPs for evidence of the specific communication skills. Secondary outcome measures were short-term and longer-term competence for LRTI communication sub-items and general communication sub-items (Table 5.2). We also measured consultation time. All short and longer-term outcomes were compared to baseline measurements.

\section{Statistical analyses}

Inter-rater agreement was calculated by summing the proportions of equal interpretations (\%) and by Cohen's kappa statistic $(\kappa)$ to adjust for agreement by chance. For determining inter-rater agreement, the four point-scale was simplified to a measure for evidence of shown acquired skills, with score 0 and 1 representing no evidence and score 2 and 3 representing evidence of acquired skill.

The total scores for the whole communication scale and the two subscales at baseline, short-term follow-up and longer-term follow-up were compared using Wilcoxon matched pairs signed ranks tests. This test was also used to assess the impact of the communication training on the consultation time. Statistical analyses were performed with SPSS 13.0

\section{Results}

All 20 GPs were visited by three SPs, which generated 60 complete transcripts for analysis. Two GPs were visited by the same SP twice and the remaining 18 were consulted by three different SPs. The GPs average age was 46.0 years $(S D=7.3)$, they had an average total clinical experience of 19.7 years $(S D=6.9)$, and their average GP experience was 14.6 years $(S D=8.2)$. Nine were female.

Table 5.2 shows inter-rater agreement per item in percentages ranging from $86.7 \%$ to $98.3 \%$, and by agreement adjusted for chance, ranging from $\kappa=0.73$ to 0.92 . For item 3 (summary) $\kappa$ could not be calculated due to absence of evidence for this skill in all 60 transcripts.

Table 5.3 shows mean and median scores for the total scale and the two subscales at baseline (T1), short-term follow-up (T2) and longer-term follow-up 
(T3). Compared to baseline, GPs used significantly more communication skills in both the short-term (median score 22.00 vs. $7.50, P<0.001$ ), and the longerterm (median score 20.00 vs. 7.50, $P<0.001$ ). Competence slightly declined from the short to the longer-term (median score 22.00 vs. 20.00, $P=0.002$ ). Both the general communication and LRTI specific subscales showed an increase in competence at both short and longer-term. Changes in the median consultation time were not statistically significant, both at short and longer-term follow-up.

Table 5.4 lists the individual items for which competence changed significantly as a result of the intervention at both short and longer-term follow-up compared to baseline.

Table 5.3 Mean scores and consultation time and changes in median scores for total measuring scale (all communication items) and the two subscales (general communication items and LRTI specific communication items) and median consultation time at baseline (T1), short term follow-up (T2) and long term follow-up (T3) by Wilcoxon signed ranks test.

\begin{tabular}{|c|c|c|c|c|c|c|c|c|c|c|}
\hline & \multicolumn{2}{|c|}{ Mean \pm SD } & \multicolumn{2}{|c|}{ Median } & \multirow[t]{2}{*}{$P$-value } & \multicolumn{2}{|c|}{ Mean \pm SD } & \multicolumn{2}{|c|}{ Median } & \multirow[t]{2}{*}{$P$-value } \\
\hline & $\mathrm{T} 1$ & T2 & $\mathrm{T} 1$ & $\mathrm{~T} 2$ & & T1 & T3 & $\mathrm{T} 1$ & T3 & \\
\hline $\begin{array}{l}\text { All communication items } \\
\text { Maximum score } 33^{a}\end{array}$ & $6.90 \pm 4.34$ & $22.30 \pm 3.57$ & 7.50 & 22.00 & $<0.001$ & $6.90 \pm 4.34$ & $18.40 \pm 4.71$ & 7.50 & 20.00 & $<0.001$ \\
\hline $\begin{array}{l}\text { - General communication } \\
\text { items }\end{array}$ & $3.85 \pm 2.70$ & $8.45 \pm 2.91$ & 3.50 & 9.00 & $<0.001$ & $3.85 \pm 2.70$ & $7.00 \pm 3.11$ & 3.50 & 8.50 & 0.001 \\
\hline $\begin{array}{l}\text { - LRTI communication items } \\
\text { Maximum score } 18^{a}\end{array}$ & $3.00 \pm 2.10$ & $12.95 \pm 3.10$ & 3.00 & 13.00 & $<0.001$ & $3.00 \pm 2.10$ & $11.40 \pm 3.10$ & 3.00 & 11.50 & $<0.001$ \\
\hline $\begin{array}{l}\text { Consultation time } \\
\text { Seconds }\end{array}$ & $469 \pm 108$ & $517 \pm 98$ & 444 & 504 & 0.064 & $469 \pm 108$ & $506 \pm 111$ & 444 & 483 & 0.073 \\
\hline
\end{tabular}

a scores per item as described in table 5.2; minimum score $=0$, maximum score per item $=3$

Table 5.4 Changes in competence per communication item from baseline to short-term follow-up (T1:T2) and from baseline to longer-term follow-up (T1:T3) by Wilcoxon signed ranks test.

$\begin{array}{lcc}\text { Communication Items } & \text { T1:T2 } & \text { T1:T3 } \\ \text { General communication items } & +{ }^{a} & +{ }^{a} \\ \text { 1. Worries } & +{ }^{a} & \\ \text { 2. Expectations } & +{ }^{a} & \\ \text { 3. Summary consultation } & +{ }^{a} & \\ \text { 4. Understanding of given info } & & +{ }^{a} \\ \text { 5. Agreement on treatment } & +{ }^{a} & +{ }^{b} \\ \text { LRTI communication items } & +{ }^{b} & +{ }^{a} \\ \text { 6. Opinion on antibiotics } & +{ }^{a} & +{ }^{a} \\ \text { 7. Duration of cough } & +{ }^{b} & +{ }^{b} \\ \text { 8. Own body will overcome } & +{ }^{a} & +{ }^{a}\end{array}$

${ }^{\mathrm{a}} P<0.05,{ }^{\mathrm{b}} P<0.001$ 


\section{Discussion}

\section{Summary of main findings}

We have demonstrated that a significant increase in evidence of competence in selected, core communication skills for managing acute bronchitis in primary care can be achieved through our enhanced communication skills training, both over the short-term and longer-term. Key features of the program were the brevity of workshop based training, its context-rich nature and the innovative use of 'peer review' of colleagues transcripts with SPs. This increase was evident both for general communication items as well as LRTI specific communication items. Importantly, the length of consultations did not increase after training in the communication skills.

\section{Comparison with other studies}

Communication skills training has been shown to be effective in changing practitioners consulting behaviour in the short-term, although most of the supporting evidence is derived from studies among students and less experienced practitioners. ${ }^{24}$ Once physicians are well established in clinical practice, they rarely receive specific training to enhance their communication skills. $^{25}$ No previous study of GP communication skills training, to our knowledge, has demonstrated both short- and longer-term effects of this type of intervention. Remarkably, whilst summarizing is one of the basic communication skills learnt in medical school, we found no evidence that this skill was implemented by any of the GPs, either at baseline or at follow-up. A study investigating communication skills acquisition in postgraduate training showed a small increase of this skill during GP training, but these trainees did not demonstrate enhanced communication skills in general. ${ }^{26}$ Although taught in a clinically rich context, communication skills were in the foreground and presented in general terms. In our study, we attempted to develop a context-rich training for better managing the challenges of LRTI consultations in the foreground with communication skills in the background, but with the aim of enhancing both specific as well as general communication skills. This emphasis may be a reason for the successful demonstration of competence after our training program.

Some GPs regard antibiotic prescribing as a time-saving manoeuvre in timepressured surgeries. Antibiotic prescribing, however, is only associated with a marginally shorter visit duration for respiratory tract infections. ${ }^{27}$ Our intervention did not have a negative impact on consultation duration. Consultations at all three time points (T1-T3) remained within the bounds of usual primary care consultation length for European countries and the US. ${ }^{27,28}$ A decrease in consultation length might even be expected as clinicians become more 
proficient at using newly acquired skills. Moreover, enhanced communication may have longer-term benefits in reducing workload, as patients increasingly recognise that antibiotics are usually not indicated for acute bronchitis and grow in confidence about self-management.

Important criteria in selecting appropriate foci for communication skills training are the frequency of the encountered problem in daily practice and the physicians' sense of importance of improving skills for a clinical problem. ${ }^{29}$ While the former is obvious from continuous morbidity registration ${ }^{30}$, the latter has become more and more evident in recent years. ${ }^{9,31,32}$ Previous studies of interventions aimed at GPs have resulted in less antibiotic prescribing. ${ }^{33,34}$ In one study, patient-centred communication in general RTI did not reduce the rate of antibiotic prescriptions below an already unusual low level. ${ }^{35}$ Nonetheless, to our knowledge, the effect of specific, context-rich communication skills training in the management of LRTI has not been evaluated.

\section{Strengths and limitations}

An important part of our training, practising skills with SPs, took place in the GPs' own surgeries during regular consultation hours. As such, a major component of the training and assessment was performed in a clinically rich context. Whether this intervention should be called context-bound or not depends on its definition. Rollnick et al. suggested that the essential features of context-bound training are:

- Training taking place in places of usual clinical care

- Using SPs playing roles constructed by the learners themselves to meet their self identified learning needs

- Sharing transcribed encounters with SPs with close colleagues as a springboard for discussion about how best to solve the clinical challenge

- In the light of these discussions, the simulated consultation is adjusted by the learners according to their evolving learning needs, and repeated visits made with SPs. This cycle can be repeated in accordance with learning needs and resources.

- Crucially, everyday clinical challenges remains in the foreground with communication skills seen simply as a means of addressing these problems. $^{18}$

This context bound approach can be contrasted to say learning communication skills through role play, away from the usual place of clinical care, and using static scenarios developed exclusively by trainers without the input of the learners. In this sense, our training can be considered context-bound. However, our seminar was off site, and the scenario played by our SPs was not designed by the learners themselves and did not evolve in the light of their discussions. 
Some may therefore argue that our intervention was not entirely context bound. We therefore describe our intervention as 'context rich'.

The GPs received additional learning opportunities through reading and providing feedback on their colleagues' SP consultation transcripts and from receiving such feedback on their own peer-reviewed transcript. To our knowledge, this is the first time such 'peer review' of consultation transcripts has been evaluated as a component of skills acquisition training. We are not able to disentangle the effect of the different components of our intervention (communication items and evidence-based information on LRTI discussed during the training seminar, practising with SPs or peer-review of a colleague's transcript, and receiving peer feedback on ones own transcript). If this intervention proves effective in decreasing antibiotic prescribing rates, a qualitative evaluation of GPs' experiences with the different components of the intervention will be undertaken. Informal comments at different stages of the training have been positive, particularly about consulting with SPs and reflecting on the transcript, receiving feedback from a peer, and providing peer review of a colleagues transcript. As evidence-based information on LRTI was presented during the training, we are unable to disentangle the effect of the provision of guidelines from the effects of the communication skills training itself. The provision of the evidence about LRTI management may have influenced the use of LRTI specific communication skills. However, GPs also showed an increased use of general communication skills over time, supporting the view that the communication training did have an effect. When investigating the effect of this training on antibiotic prescribing in the associated trial, we will be able to analyse the added effect of communication skills training over guideline provision, since GPs in the control group received the same information on LRTI.

We combined general communication strategies with illness-specific items to form a communication skills training relevant to daily practice for GPs. For this reason, we chose to develop a measurement instrument to assess those skills considered key communication skills by trainers and GPs in a LRTI consultation. We did not use a previously published scale for measuring patientcentered communication, as we aimed to measure LRTI specific communication skills in addition to the use of certain general communication skills. Our main focus was not specifically on patient-centeredness, although we believe that the LTRTI specific skills are useful tools for achieving patient centeredness in these consultations. Although it has been suggested that an effective communication skills training program should have a minimum duration of one day ${ }^{24}$, we have provided evidence that our briefer program has been effective in enhancing competence. Most previously evaluated training interventions, however, were based entirely outside of clinicians' practices and were thus not context-rich. One may argue that GPs may be able to recall a certain number of items shortly 
after the seminar when prompted by a SP. Nevertheless, we still found evidence of competence in using the skills six months later. We considered using unannounced, concealed simulated patients ${ }^{36}$, but this proved impractical regarding standardisation and data collection (recording), as the first two encounters were used to practise skills as well as to evaluate skills acquisition.

By implementing an illness-specific communication training, sustainable effects may be achieved, since GPs will be reminded of the method when a patient with the particular illness consults. Although we were able to show an effect on competence over a period of six months, uncertainty remains about longer-term sustainability.

In this study, we demonstrated GPs competence, not performance, of implementing new communication skills in daily practice. Competency based assessments measure what doctors can do in controlled representations of professional practice; performance based assessments measure what doctors actually do in professional practice. ${ }^{20}$ Competence, therefore, is a prerequisite for performance. As the intervention mainly took place in the GPs' practices and as acute bronchitis is a frequently encountered problem in general practice, performance might closely approach competence in this study. Nevertheless, real life patients present in a wide range of ways. Sustainable implementation of the acquired skills in different scenarios in daily practice will be a challenge and needs further evaluation.

\section{Conclusion}

This study has shown that specific communication skills for acute bronchitis can successfully be learned by GPs through a largely practice-based and contextrich communication training, with opportunity to practice skills with SPs in routine surgeries, without adding to consultation length. A unique feature of the training was peer review of simulated patient consultation transcripts.

\section{Practice implications}

Given the number of patients with acute bronchitis that consult their GPs on a regular basis, our findings may have relevance for everyday clinical practice. Enhanced communication skills for acute bronchitis may not only facilitate shared decision-making, it could also lead to a decline in antibiotic prescribing, and may also increase patient's and GP's satisfaction. Patients may feel that expectations are better addressed and more involved in the decision on treatment after receiving evidence based information on natural course of the illness and the pros and cons of antibiotic treatment. The GPs may achieve greater professional satisfaction though implementing evidence based decisions 
on treatment without threatening physician-patient relationships. Moreover, if this can all be accomplished within consultation of routine length, time pressure may be substituted by time efficiency, which is essential for the acceptability and applicability of an intervention in primary care. The effect of this intervention on antibiotic prescribing rates for LRTI, patient satisfaction and enablement will be assessed in a cluster randomised controlled trial, which is currently recruiting patients. $^{21}$ This trial will enable us to compare the effect of training clinicians in enhanced communication skills on outcomes for more than 400 LRTI patients in everyday care.

Development of interventions targeted at GPs, who are the main antibiotic prescribers, merit further attention. ${ }^{37}$ This study has demonstrated efficacy of a training method that is feasible. If further developed and evaluated in a larger population of GPs, could similarly be used to enhance quality of consultations for other common infections in primary care, potentially leading to a more judicious approach to antimicrobial prescribing and superior outcomes for patient, doctor and society. 


\section{References}

1. Nordberg P, Monnet DL, Cars O. Antibacterial drug resistance: options for concerted action. World Health Organization Department of Medicines Policy and Standards. Geneva, 2005: $1-48$.

2. Smucny J, Fahey T, Becker L, Glazier R. Antibiotics for acute bronchitis. Cochrane Database Syst Rev 2004(4):CD000245.

3. Woodhead M, Blasi F, Ewig S, Huchon G, leven M, Ortqvist A, Schaberg T, Torres A, van der Heijden G, Verheij TJ; European Respiratory Society; European Society of Clinical Microbiology and Infectious Diseases. Guidelines for the management of adult lower respiratory tract infections. Eur Respir J 2005;26:1138-80.

4. Verheij TJM, Salomé PL, Bindels PJ, Chavannes AW, Ponsioen BP, Sachs APE, et al. NHGStandaard Acuut hoesten. Dutch College of General Practitioners Guidelines on Acute Cough. Huisarts Wet 2003;46:496-506.

5. Gonzales R, Barrett PH, Jr., Crane LA, Steiner JF. Factors associated with antibiotic use for acute bronchitis. J Gen Intern Med 1998;13:541-8.

6. Kuyvenhoven MM, Verheij TJ, de Melker RA, van der Velden J. Antimicrobial agents in lower respiratory tract infections in Dutch general practice. Br J Gen Pract 2000;50:133-4.

7. Steinman MA, Gonzales R, Linder JA, Landefeld CS. Changing Use of Antibiotics in Community-Based Outpatient Practice, 1991-1999. Ann Intern Med 2003;138:525-33.

8. Kuyvenhoven MM, Van Balen FA, Verheij TJ. Outpatient antibiotic prescriptions from 1992 to 2001 in The Netherlands. J Antimicrob Chemother 2003;52:675-8.

9. Butler CC, Rollnick S, Pill R, Maggs Rapport F, Stott N. Understanding the culture of prescribing: qualitative study of general practitioners' and patients' perceptions of antibiotics for sore throats. BMJ 1998;317:637-42.

10. Little P, Dorward M, Warner G, Stephens K, Senior J, Moore M. Importance of patient pressure and perceived pressure and perceived medical need for investigations, referral, and prescribing in primary care: nested observational study. BMJ 2004;328:444-

11. Butler CC, Rollnick S, Kinnersley P, Jones A, Stott N. Reducing antibiotics for respiratory tract symptoms in primary care: consolidating 'why' and considering 'how'. $\mathrm{Br} \mathrm{J}$ Gen Pract 1998;48:1865-70.

12. Coenen S, Michiels B, Renard D, Denekens J, Van Royen P. Antibiotic prescribing for acute cough: the effect of perceived patient demand. Br J Gen Pract 2006;56:183-90.

13. Cockburn J, Pit S. Prescribing behaviour in clinical practice: patients' expectations and doctors' perceptions of patients' expectations-a questionnaire study BMJ 1997;315:520-3.

14. Macfarlane J, Holmes W, Macfarlane R, Britten N. Influence of patients' expectations on antibiotic management of acute lower respiratory tract illness in general practice: questionnaire study. BMJ 1997;315:1211-4.

15. Welschen I, Kuyvenhoven M, Hoes A, Verheij $\mathrm{T}$. Antibiotics for acute respiratory tract symptoms: patients' expectations, GPs' management and patient satisfaction. Fam Pract 2004;21:234-7.

16. Hamm RM, Hicks RJ, Bemben DA. Antibiotics and respiratory infections: are patients more satisfied when expectations are met? J Fam Pract 1996;43:56-62.

17. Hopstaken RM, Coenen S, Butler CC. Treating patients not diagnoses: challenging assumptions underlying the investigation and management of LRTI in general practice. $\mathrm{J}$ Antimicrob Chemother 2005;56:941-3.

18. Rollnick S, Kinnersley P, Butler C. Context-bound communication skills training: development of a new method. Med Educ 2002;36:377-83.

19. Rollnick S, Seale C, Kinnersley P, Rees M, Butler C, Hood K. Developing a new line of patter: can doctors change their consultations for sore throat? Med Educ 2002;36:678-81.

20. Rethans JJ, Norcini JJ, Barón-Maldonado M, Blackmore D, Jolly BC, LaDuca T, Lew S, Page GG, Southgate LH. The relationship between competence and performance: implications for assessing practice performance. Medical education 2002;36:901-9. 
21. Cals JW, Hopstaken RM, Butler CC, Hood K, Severens JL, Dinant GJ. Improving management of patients with acute cough by C-reactive protein point of care testing and communication training (IMPAC3T): study protocol of a cluster randomised controlled trial. BMC Fam Pract 2007;8:15.

22. Butler CC, Kinnersley P, Prout H, Rollnick S, Edwards A, Elwyn G. Antibiotics and shared decision-making in primary care. J Antimicrob Chemother 2001;48:435-40.

23. Rollnick S, Mason P, Butler C. Health Behavior Change; a guide for practitioners: Churchill Livingston, 1999.

24. Aspegren K. BEME Guide No.2: Teaching and learning communication skills in medicine-a review with quality grading of articles. Medical Teacher 1999;21:563-70.

25. Levinson $W$, Roter $D$. The effects of two continuing medical education programs on communication skills of practicing primary care physicians. J Gen Intern Med 1993;8:318-24.

26. Kramer AW, Dusman H, Tan LH, Jansen JJ, Grol RP, van der Vleuten CP. Acquisition of communication skills in postgraduate training for general practice. Med Educ 2004;38:158-67.

27. Linder JA, Singer DE, Stafford RS. Association between antibiotic prescribing and visit duration in adults with upper respiratory tract infections. Clinical Therapeutics 2003;25: 2419-30.

28. Deveugele M, Derese A, van den Brink-Muinen A, Bensing J, De Maeseneer J. Consultation length in general practice: cross sectional study in six European countries. BMJ 2002;325:472.

29. Sanson Fisher R, Cockburn J. Effective teaching of communication skills for medical practice: selecting an appropriate clinical context. Medical education 1997;31:52-7.

30. Okkes IM, Oskam SK, Lamberts H. Van klacht naar diagnose: episodegegevens uit de huisartspraktijk. [From complaint to diagnosis: Disease episodes in general practice]. Bussum: Couthino, 1998.

31. Altiner A, Knauf A, Moebes J, Sielk M, Wilm S. Acute cough: a qualitative analysis of how GPs manage the consultation when patients explicitly or implicitly expect antibiotic prescriptions. Fam Pract 2004;21:500-6.

32. Coenen S, Michiels B, Van Royen P, Van der Auwera JC, Denekens J. Antibiotics for coughing in general practice: a questionnaire study to quantify and condense the reasons for prescribing. BMC Fam Pract 2002;3:16.

33. Welschen I, Kuyvenhoven MM, Hoes AW, Verheij TJM. Effectiveness of a multiple intervention to reduce antibiotic prescribing for respiratory tract symptoms in primary care: randomised controlled trial. BMJ 2004;329:431.

34. Coenen S, Van Royen P, Michiels B, Denekens J. Optimizing antibiotic prescribing for acute cough in general practice: a cluster-randomized controlled trial. J Antimicrob Chemother 2004;54:661-72.

35. Briel M, Langewitz W, Tschudi P, Young J, Hugenschmidt C, Bucher HC. Communication training and antibiotic use in acute respiratory tract infections. A cluster randomised controlled trial in general practice. Swiss Med Wkly 2006;136:241-7.

36. Maiburg BHJ, Rethans J-JE, van Erk IM, Mathus-Vliegen LMH, van Ree JW. Fielding incognito standardised patients as 'known' patients in a controlled trial in general practice. Medical Education 2004;38:1229-35.

37. Arnold SR, Straus SE. Interventions to improve antibiotic prescribing practices in ambulatory care. Cochrane Database Syst Rev 2005. 


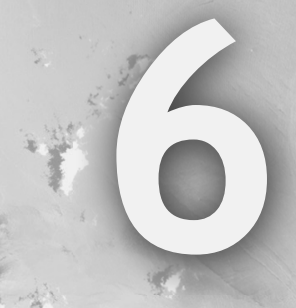

Effect of point of care testing for C-reactive protein and training in communication skills on antibiotic use in lower respiratory tract infections: cluster randomised trial

Jochen Cals, Christopher Butler, Rogier Hopstaken, Kerenza Hood, Geert-Jan Dinant

British Medical Journal 2009;338:b1374

Huisarts en Wetenschap 2009;52:576-83

Huisarts Nu 2009;38:297-305 


\section{Abstract}

\section{Objective}

To assess the effect of general practitioners testing for C-reactive protein (disease approach) and receiving training in enhanced communication skills (illness approach) on antibiotic prescribing for lower respiratory tract infection.

\section{Design}

Pragmatic, $2 \times 2$ factorial, cluster randomised controlled trial.

\section{Setting}

Twenty general practices in the Netherlands.

\section{Participants}

Fourty general practitioners from 20 practices recruited 431 patients with lower respiratory tract infection.

\section{Main outcome measures}

The primary outcome was antibiotic prescribing at the index consultation. Secondary outcomes were antibiotic prescribing during 28 days' follow-up, reconsultation, clinical recovery, and patients' satisfaction and enablement.

\section{Interventions}

General practitioners' use of C-reactive protein point of care testing and training in enhanced communication skills separately and combined, and usual care.

\section{Results}

General practitioners in the C-reactive protein test group prescribed antibiotics to $31 \%$ of patients compared with $53 \%$ in the no test group $(P=0.02)$. General practitioners trained in enhanced communication skills prescribed antibiotics to $27 \%$ of patients compared with $54 \%$ in the no training group $(P<0.01)$. Both interventions showed a statistically significant effect on antibiotic prescribing at any point during the 28 days' follow-up. Clinicians in the combined intervention group prescribed antibiotics to $23 \%$ of patients (interaction term was non-significant). Patients' recovery and satisfaction were similar in all study groups.

\section{Conclusion}

Both general practitioners' use of point of care testing for C-reactive and training in enhanced communication skills significantly reduced antibiotic prescribing for lower respiratory tract infection without compromising patients' recovery and satisfaction with care. A combination of the illness and disease focused approaches may be necessary to achieve the greatest reduction in antibiotic prescribing for this common condition in primary care. 


\section{Introduction}

Contrasting broad approaches to improved management in general medicine have been emphasised. ${ }^{1}$ A disease focused approach seeks to improve diagnosis, whereas the illness focused, patient centred approach emphasises understanding the whole patient and sharing decisions, which may be more contingent on clear information about prognosis rather than making an accurate diagnosis. ${ }^{2,3}$ A combination of these approaches, however, may be required to achieve the best outcome for patients. We evaluated the effect of two interventions on achieving evidence based management of lower respiratory tract infections in primary care.

Lower respiratory tract infection is one of the commonest acute reasons to consult, accounting for 17 million consultations in the European Union and 11 million in the United States each year. ${ }^{4-6}$ Acute bronchitis accounts for $80 \%$ of lower respiratory tract infections ${ }^{6,7}$ and despite evidence of little or no benefit from antibiotics, up to $80 \%$ of patients consulting for this condition are prescribed them. ${ }^{8-10}$ Moreover, lower respiratory tract infection is associated with increasing use of broad spectrum antibiotics. ${ }^{8,11}$ Everyday decisions about whether or what antibiotic to prescribe for lower respiratory tract infection therefore constitutes an important part of the burden of antibiotic use that drives antimicrobial resistance..$^{9,12,13}$

Diagnostic or disease focused solutions address the limited value of medical history and physical examination in differentiating between pneumonia and self limiting acute bronchitis. ${ }^{14-16}$ Diagnostic uncertainty increases the chances of inappropriate antibiotic prescribing, ${ }^{17}$ and general practitioners often prescribe to give patients "the benefit of the doubt" in the face of possible pneumonia and possible clinical benefit ${ }^{18}$ especially since routinely requesting chest radiography for all patients with lower respiratory tract infection is neither feasible nor appropriate in most primary care settings. C-reactive protein is a promising biomarker for improving the assessment of lower respiratory tract infection in primary care: it performs better in predicting the diagnosis of pneumonia than any individual or combination of clinical symptoms and signs in lower respiratory tract infection. Furthermore, it is feasible and robust as a point of care test, making it the best available biomarker to enhance the diagnosis of lower respiratory tract infection in primary care. ${ }^{15,16,19,20}$ However, there is no evidence from pragmatic trials that testing for $\mathrm{C}$-reactive protein safely reduces antibiotic prescribing for lower respiratory tract infection in primary care.

IIIness focused solutions, including enhanced clinician-patient communication, recognise the importance of non-medical influences on the decision to prescribe antibiotics for lower respiratory tract infection, and emphasise eliciting and responding to patients' feelings, ideas, fears, and expectations about their illness experience. ${ }^{3}$ General practitioners are often unable to satisfactorily deal 
with these influences to achieve evidence based prescribing decisions in time pressured consultations. ${ }^{21-25}$ The resulting inappropriate prescribing of antibiotics reinforces misconceptions that impact on future help seeking and expectations for antibiotics. ${ }^{26-28}$ Shared decision making, building on a patient centred approach to better understand patients' perspectives and achieve enhanced clinician-patient communication, may be useful in achieving evidence based decisions on prescribing, particularly in the face of diagnostic certainty. ${ }^{3}$ Exploring the illness experience and finding common ground are particular tasks of the patient centred consultation that may be relevant to illness focused solutions to over prescribing of antibiotics. ${ }^{29}$ Training clinicians to elicit patients concerns about their illness and asking their views on antibiotics increased patients' participation in consultations. ${ }^{30}$ However, no pragmatic clinical trial has evaluated this shared decision making approach for lower respiratory tract infections in primary care.

Interventions to enhance the quality of decisions on antibiotic prescribing for lower respiratory tract infection have generally focused on either reducing diagnostic uncertainty (disease perspective) ${ }^{31-33}$ or on educational, often multifaceted, interventions tackling non-medical influences (illness perspective). ${ }^{33-38}$

We evaluated the effect of general practitioners using a point of care test for C-reactive protein and being trained in enhanced communication skills, separately and combined, on antibiotic prescribing for lower respiratory tract infection and on patient recovery. We hypothesised that either intervention alone would be more effective than their controls and that the combined intervention would show a combined positive effect on reducing antibiotic prescribing for lower respiratory tract infection in primary care.

\section{Method}

This study was a pragmatic, cluster randomised, factorial, controlled trial. While recognising certain limitations, ${ }^{39}$ we chose a cluster randomisation design to optimise the pragmatic nature of the study and to minimise contamination: once general practitioners within a practice had been trained in new communication skills they could not switch at random between using these skills and usual consulting practice. A $2 \times 2$ factorial design was used to assess the effect of each intervention and to explore the effect of the interventions combined. ${ }^{40}$ Such trials require a prespecified factorial analysis plan with assessments for treatment interactions. We selected this design because we planned to test two treatment hypotheses. The four allocated groups were general practitioners' use of C-reactive protein testing (1), training in enhanced communication skills (2), the interventions combined (3), and usual care (4). The groups were combined 
for analysis as follows: factor A, C-reactive protein test (cells 1 and 3 ) compared with no test (2 and 4) (controlling for the effect of general practitioners' training in enhanced communication skills in the model); and factor B, training in enhanced communication skills ( 2 and 3 ) compared with no training ( 1 and 4 ) (controlling for the effects of $\mathrm{C}$-reactive protein testing in the model).

\section{Outcomes, sample size, and randomisation}

The primary outcome was antibiotic prescribing in the index consultation. Our study required 400 patients with lower respiratory tract infection to detect a reduction in antibiotic prescribing from $80 \%$ to $60 \%$ (power $80 \%$, a 0.05 , followup $90 \%$ ) when adjusted for clustering at practice level (intracluster coefficient 0.06). The sample size was for the main effects only and assumed no interaction between the two interventions. Secondary outcomes were antibiotic prescribing during 28 days' follow-up, reconsultation, clinical recovery, and patients' satisfaction and enablement. Cost effectiveness will be reported separately. We planned to recruit 20 general practices with two participating general practitioners per practice within a large suburban region of the Netherlands. All practices and general practitioners were recruited and provided written consent before randomisation.

Practices were randomised into two groups of ten practices per intervention, balanced for recruitment potential, resulting in four trial arms (Figure 6.1). The balancing factor used for randomisation was the amount of general practitioners' consultation time (expressed as full time equivalent) that the practice was contributing to the study, and this equated to between one and two full time equivalent for clinical contact time. The randomisation was balanced for those with 1.5 or less full time equivalent and those with more than 1.5 full time equivalent. The Dutch guideline for managing acute cough, including diagnostic and therapeutic advice for lower respiratory tract infection, is distributed to all general practitioners in the Netherlands and informs usual care. ${ }^{41}$ 


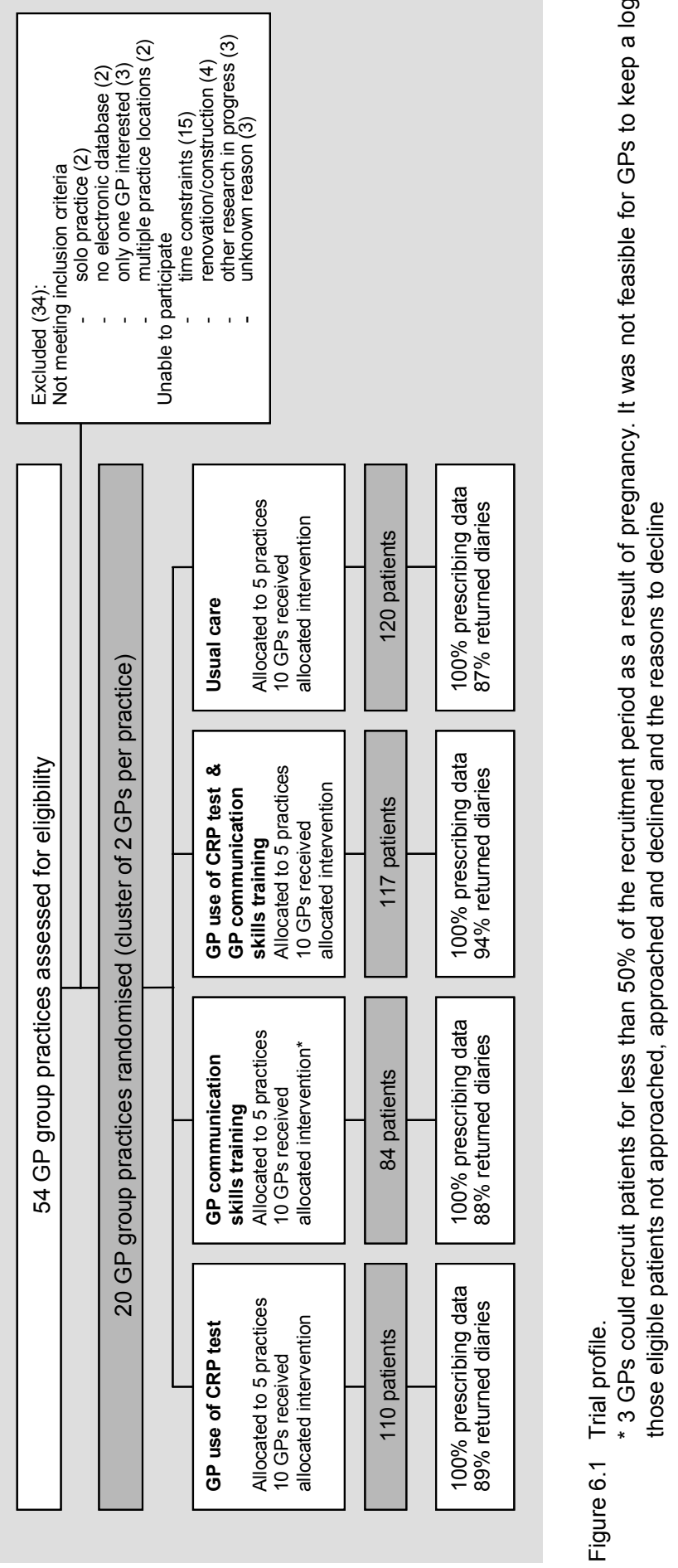




\section{Interventions}

The interventions and study methods are described in detail elsewhere. ${ }^{39}$ Both interventions were targeted at the level of the general practitioner. The clinicians were given devices to test for C-reactive protein (NycoCard II Reader; AxisShield, Norway), according to the manufacturer's instructions. A result can be available within three minutes, using a drop of blood obtained by finger prick. The validity and robustness of this test is established in primary care. ${ }^{20}$ General practitioners were given guidance on how to use the test results within the consultation during a 30 minute practice based training session delivered by the study team. The additional value of C-reactive protein in ruling out serious infection was emphasised. ${ }^{39}$ An eight week run-in period enabled familiarisation with the devices before patient recruitment to the trial began.

The communication skills intervention was built around 11 key tasks (for example, exploring patients' fears and expectations, asking patients' opinion on antibiotics, and outlining the natural duration of cough in lower respiratory tract infection), with information exchange throughout based on the elicit-provideelicit framework from counselling in behaviour change. ${ }^{42}$ Key features of the training programme were the brevity of workshop based training, its context rich nature, and the innovative use of peer reviewing colleagues' transcripts of the consultations with simulated patients. A full description of the components of the training and demonstration of general practitioners' sustained competence in implementing the acquired skills in daily practice after training has been reported. ${ }^{43}$

\section{Procedures}

General practitioners were asked to recruit sequential eligible adults within regular consultation hours during the winters of 2005-6 and 2006-7. Patients were eligible if they had a suspected lower respiratory tract infection with a cough lasting less than four weeks together with one focal and one systemic symptom. ${ }^{39}$ Patients provided written informed consent after the study had been explained by their general practitioner, and written information was provided. Apart from the point of care C-reactive protein tests the general practitioners decided on investigations and treatment according to their usual practice. Patients rated symptoms (cough, phlegm, shortness of breath, disturbance of daily activities, sleeping problems, and generally feeling unwell) on a 7 point scale in a daily diary for 28 days. This diary was validated for use in a randomised controlled trial on management of lower respiratory tract infection in primary care. ${ }^{44}$ The diary also included a Likert scale question on satisfaction, and the patient enablement index. ${ }^{45}$ On days 4,14 , and 28 the participants received a telephone or postcard reminder about diary completion. Patients who 
were still unwell after 28 days were followed-up, up to a maximum of ten weeks, until they reported recovery. Antibiotic prescribing and reconsultation data for the 28 days of follow-up were obtained from the participants' medical records. Data were double entered, with discrepancies resolved by checking the original data.

\section{Data analysis}

Discrete variables were expressed as percentages (counts) and continuous variables as means (standard deviations), unless stated otherwise. The primary analysis was intention to treat and assessed the predefined effects of the two interventions on antibiotic prescribing at the index consultation, incorporating an interaction effect, which we included to test and correct for a synergistic or antagonistic relation between the two interventions. Analysis was done using a three level logistic regression model to account and correct for variation at the level of the practice, general practitioner, and patient using a second order penalised quasi likelihood approach. To correct for the effects on secondary outcomes we used a three level model, linear or logistic where appropriate. To explore simplification of the model we carried out analyses to investigate if the general practitioner level could be left out of the multilevel approach. Exploratory analyses investigating the influence of patients' and practitioners' characteristics on the main effects were carried out as sensitivity analyses. Results are presented as rates with corresponding $P$-values (see web table for full logistic models).

Scores for each of the individual items on symptoms were added to create a total daily symptom score that ranged from $0 \%$ to $100 \%$. We plotted the median daily symptom scores for the treatment groups. The Cronbach $\alpha$ for the full scale was greater than 0.7. A four level autoregressive moving average $(1,1)$ model was fitted to the symptom scores (logged) to account for practice, general practitioner, patient, and repeated measurements over time using restrictive maximum likelihood. This modelled the correlation between repeated assessments within individual patients to allow for greater correlation between assessments that were closer in time. The effects of the interventions on recovery were studied by comparing the slopes of symptom scores over time in the groups. ${ }^{46}$ Analysis was done using SPSS 13.0, R, and Mlwin 2.0.

Our trial follows the consolidated standards of reporting trials guidelines, extended for cluster randomised controlled trials. ${ }^{47}$ Further details of the trial protocol, including descriptions of the C-reactive protein test and training in enhanced communication are described elsewhere. ${ }^{39,43}$ 


\section{Results}

All 30 general practitioners received the allocated intervention, and 10 general practitioners were assigned to the usual care arm (Figure 6.1). All the general practitioners recruited patients. Three general practitioners in the training group went on maternity leave half way through the study. The characteristics of the general practitioners were similar across the groups and comparable to Dutch general practitioners (Table 6.1). In total, 431 patients with lower respiratory tract infection were recruited (factor A, 227 to the C-reactive protein test group vs. 204 to the no test group, and factor B, 201 to the training in enhanced communication skills group vs. 230 to the no training group), and for all of these, data for the primary outcome measure were available. Diary data were available for $90 \%$ of participants (Figure 6.1). Table 6.2 shows patients' baseline characteristics.

Table 6.1 Characteristics of study general practitioners.

\begin{tabular}{|c|c|c|c|c|c|c|}
\hline & GP use of & GP & GP use of & Usual Care & Total & Netherlands* \\
\hline & \multicolumn{6}{|c|}{$\begin{array}{l}\text { CRP test only communication CRP test \& GP } \\
\text { skills training communication } \\
\text { only skills training }\end{array}$} \\
\hline & $n=10$ & $n=10$ & $n=10$ & $n=10$ & $n=40$ & $n=8495$ \\
\hline $\begin{array}{l}\% \text { of male general } \\
\text { practitioners }\end{array}$ & 60 & 50 & 60 & 70 & 60 & 66 \\
\hline Age & $42.4(7.0)$ & $46.5(9.4)$ & $45.7(4.9)$ & $47.0(9.9)$ & $45.4(8.0)$ & 47.4 \\
\hline Patient list size & $1770(260)$ & 1920 (690) & $1925(560)$ & $2050(570)$ & $1920(540)$ & $\begin{array}{c}1725 \\
\text { (for } 0.75 \mathrm{fte})\end{array}$ \\
\hline Full time equivalent & $0.71(0.13)$ & $0.78(0.18)$ & $0.74(0.21)$ & $0.77(0.18)$ & $0.75(0.17)$ & 0.75 \\
\hline $\begin{array}{l}\text { Years in general } \\
\text { practice }\end{array}$ & $12.9(8.5)$ & $12.9(9.7)$ & $16.2(6.4)$ & $17.9(10.5)$ & $15.0(8.9)$ & 10 \\
\hline
\end{tabular}

Data are means (SD) unless stated otherwise. * Numbers derived from Netherlands Institute for Health Services Research (NIVEL) 2006 (www.nivel.nl)

\section{Interventions}

C-reactive protein was measured in all 227 patients recruited by general practitioners allocated to point of care testing (range $<8-225 \mathrm{mg} / \mathrm{l}$ ). Overall, $69 \%$ of patients' had test results of $<20 \mathrm{mg} / \mathrm{l}, 24 \%$ of $20-99 \mathrm{mg} / \mathrm{l}$, and $7 \%$ of greater than $100 \mathrm{mg} / \mathrm{l}$. This distribution is similar to previous findings for lower respiratory tract infection in primary care. ${ }^{15}$ Standard laboratory testing for C-reactive protein was not ordered for any patient in the no test group. Overall, $66 \%$ of the patients recruited by general practitioners allocated to training in enhanced communication skills recalled their doctors using at least three of four specific communication skills (asking opinions on antibiotics, exploring worries, 
eliciting expectations, and providing information on the natural course and duration of lower respiratory tract infection) compared with $19 \%$ of patients in the no training group.

Table 6.2 Characteristics of patients managed by general practitioners in intervention and control arms.

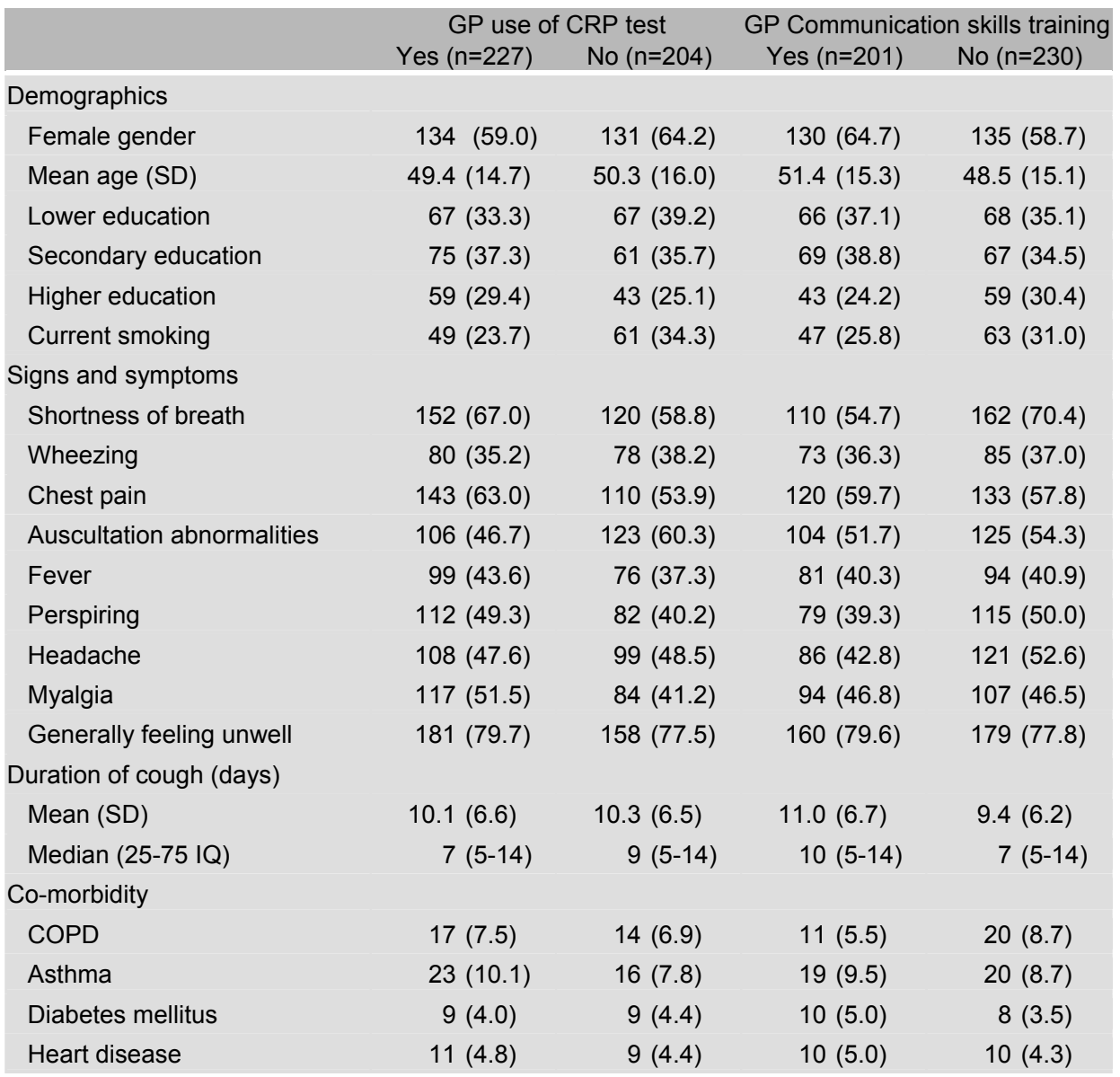

Data are numbers $(\%)$ unless otherwise stated

\section{Effects on antibiotic prescribing and reconsultation}

General practitioners in the C-reactive protein test group prescribed significantly fewer antibiotics than those in the no test group (31\% vs. $53 \%, P=0.02$; Table 6.3). Similarly, general practitioners in the communication skills training group prescribed significantly fewer antibiotics than those in the no training group $(27 \%$ vs. $54 \%, P<0.01)$. The two interventions showed no statistically significant interaction effect $(P=0.78)$, although there was a trend for a synergistic effect. 
Adjustment at the level of the general practitioner in a simplified two level model led to improvement of model fit, so analyses were done according to the predefined three level model strategy (see web table).

Table 6.3 Effects of interventions on antibiotic prescribing at index consultation and antibiotic prescribing and reconsultation during 28 days follow-up.

\begin{tabular}{|c|c|c|c|c|c|c|}
\hline & \multicolumn{4}{|c|}{ GP use of CRP } & \multirow[b]{2}{*}{$P$-value* } & \multirow[b]{2}{*}{ ICC } \\
\hline & Yes $(n=227)$ & Crude $95 \% \mathrm{Cl}^{\#}$ & No $(n=204)$ & Crude $95 \% \mathrm{Cl}^{\#}$ & & \\
\hline Antibiotics at index consultation & $\begin{array}{c}30.8 \% \\
(70 / 227)\end{array}$ & $21.8-39.8 \%$ & $\begin{array}{c}52.9 \% \\
(108 / 204)\end{array}$ & $43.0-62.8 \%$ & 0.02 & 0.12 \\
\hline Antibiotics day 1 to 28 & $\begin{array}{c}44.9 \% \\
(102 / 227)\end{array}$ & $35.2-54.6 \%$ & $\begin{array}{c}58.3 \% \\
(119 / 204)\end{array}$ & $48.5-68.1 \%$ & $<0.01$ & 0.12 \\
\hline \multirow[t]{3}{*}{ Reconsultation within 28 days } & $\begin{array}{c}34.8 \% \\
(79 / 227)\end{array}$ & $28.3-41.3 \%$ & $\begin{array}{c}30.4 \% \\
(62 / 204)\end{array}$ & $23.8-37.0 \%$ & 0.50 & 0.01 \\
\hline & \multicolumn{4}{|c|}{ GP communication skills training } & & \\
\hline & Yes $(n=201)$ & Crude $95 \% \mathrm{Cl}^{\#}$ & No $(n=230)$ & Crude $95 \% \mathrm{Cl}^{\#}$ & $P$-value* & ICC \\
\hline Antibiotics at index consultation & $\begin{array}{c}27.4 \% \\
(55 / 201)\end{array}$ & $25.6-36.6 \%$ & $\begin{array}{c}53.5 \% \\
(123 / 230)\end{array}$ & $43.8-63.2 \%$ & $<0.01$ & 0.12 \\
\hline Antibiotics day 1 to 28 & $\begin{array}{c}37.8 \% \\
(76 / 201)\end{array}$ & $28.1-47.5 \%$ & $\begin{array}{c}63.0 \% \\
(145 / 230)\end{array}$ & $53.6-72.4 \%$ & $<0.001$ & 0.12 \\
\hline Reconsultation within 28 days & $\begin{array}{c}27.9 \% \\
(56 / 201)\end{array}$ & $21.4-34.4 \%$ & $\begin{array}{c}37.0 \% \\
(85 / 230)\end{array}$ & $30.4-43.6 \%$ & 0.14 & 0.01 \\
\hline
\end{tabular}

Data are \% (number). ${ }^{\#}$ crude $95 \%$ confidence intervals were calculated and inflated for clustering by using the standard deviation inflated by the variance inflation factor. ${ }^{53}$

* $P$-values were calculated from a $2^{\text {nd }}$ order PQL multilevel logistic regression model adjusted for variance at GP and practice level (random intercept at practice and GP level). Models included both interventions and the interaction term of the interventions. See web table for corresponding $\beta$ coefficients.

The interventions showed no statistically significant difference in reconsultations. Prescribing during the 28 days after the index consultation was slightly lower for patients in the communication skills training group. After adjusting for clustering, however, this effect was not statistically significant.

Antibiotic prescribing at any point during the 28 days' follow-up (prescribing rates at the index consultation combined with prescribing rates at reconsultations) remained significantly lower in patients in the C-reactive protein test group compared with those in the no test group ( $45 \%$ vs. $58 \%, P<0.01)$ as well as for patients in the communication skills training group compared with patients in the no training group ( $38 \%$ vs. $63 \%, P<0.001$ ).

Systemic symptoms were not associated with antibiotic prescribing. Of the signs and symptoms recorded by the general practitioners only abnormal auscultation was associated with antibiotic prescribing when tested in a multiple regression analysis. No associations were found between systemic symptoms and reconsultation in similar analyses. This model was corrected for reconsultations at the general practitioners' request; $20.6 \%$ of reconsultations within 28 days of 
the index consultation were scheduled by the general practitioner, with the remaining $79.4 \%$ initiated by the patient. In total, 47 patients $(10.9 \%)$ reconsultated more than once within the 28 days. This reconsultation pattern was similar across the groups.

General practitioners prescribed a wide range of antibiotics during the study: doxycycline for $41 \%$ of patients, amoxicillin for $26 \%$, amoxicillin-clavulanate for $16 \%$, clarithromycin for $7 \%$, azithromycin for $4 \%$, and others for $6 \%$. Doxycycline and amoxicillin are first line antibiotics for lower respiratory tract infection according to the Dutch national guidelines for acute cough. ${ }^{41}$

\section{Sensitivity analyses}

Although the interaction term was not significant, as this test has low power, an exploratory analysis was carried out to study the magnitude of differences between the four individual trial groups. General practitioners using the C-reactive protein point of care test and who were also trained in communication skills prescribed antibiotics to $23 \%$ of participants compared with $67 \%$ in the usual care group (Table 6.4).

Table 6.4 Exploratory analysis of antibiotic prescribing at index consultation by GP intervention group.

\begin{tabular}{|c|c|c|c|c|}
\hline & \multicolumn{4}{|c|}{ GP Intervention } \\
\hline & $\begin{array}{l}\text { GP use of CRP } \\
\text { test only } \\
(n=110)\end{array}$ & $\begin{array}{l}\text { GP communication } \\
\text { skills training only } \\
(n=84)\end{array}$ & $\begin{array}{l}\text { GP use of CRP test \& } \\
\text { GP communication } \\
\text { skills training }(n=117)\end{array}$ & $\begin{array}{l}\text { GP usual care } \\
\qquad(n=120)\end{array}$ \\
\hline $\begin{array}{l}\text { Antibiotics at inc } \\
\text { consultation }\end{array}$ & & & & \\
\hline$\%$ of patients $(n)$ & $39.1 \%(43 / 110)$ & $33.3 \%(28 / 84)$ & $23.1 \%(27 / 117)$ & $66.7 \%(80 / 120)$ \\
\hline Crude $95 \% \mathrm{Cl}^{\#}$ & $25.6-52.6$ & $19.5-47.1$ & $11.6-34.6$ & $53.9-79.5$ \\
\hline
\end{tabular}

This is an exploratory analysis, therefore testing for significance was not performed as the trial was designed as a factorial trial. " crude $95 \%$ confidence intervals were calculated and inflated for clustering by using the standard deviation inflated by the variance inflation factor. ${ }^{53}$

Possible moderation of effect was explored in a sensitivity analysis of the primary end point by including personal factors, case-mix, and relevant comorbidities (Table 6.2) in a multilevel logistic model. This produced similar effects for the interventions as in the primary analysis, suggesting that the interventions were principally responsible for the reduction in antibiotic prescribing. The effect of the interventions was similar during both recruitment winters.

Possible recruitment bias after randomisation was investigated by considering rates for consultation and overall antibiotic prescribing (anatomical therapeutic chemical classification J001) for international classification primary care codes 
R78 (acute broch(iol)itis) and R81 (pneumonia) for the two recruitment winters in a subsample of 14 study general practitioners who contributed to a regional medical registration database. Antibiotic prescribing for study patients by this subset of general practitioners at index consultations was similar to all their 325 patients registered with lower respiratory tract infection on the international classification primary care database (Table 6.5). Patients recruited to the trial were slightly younger than the registered patients.

Table 6.5 Non-inclusion analysis. Antibiotic prescribing rates at index consultation and demographics for enrolled and non-enrolled LRTI patients seen by 14 trial General practitioners* during the two study winters.

\begin{tabular}{|c|c|c|c|c|}
\hline & \multicolumn{2}{|c|}{ GP Use of CRP (8 GPs) } & \multicolumn{2}{|c|}{ GP No use of CRP (6 GPs) } \\
\hline & $\begin{array}{c}\text { Enrolled } \\
\text { LRTI patients } \\
n=76\end{array}$ & $\begin{array}{c}\text { Non-enrolled } \\
\text { LRTI patients } \\
n=84\end{array}$ & $\begin{array}{c}\text { Enrolled } \\
\text { LRTI patients } \\
n=39\end{array}$ & $\begin{array}{c}\text { Non-enrolled } \\
\text { LRTI patients } \\
n=189\end{array}$ \\
\hline $\begin{array}{l}\text { Antibiotics prescribed at } \\
\text { index consultation }\end{array}$ & $36.8 \%(28 / 76)$ & $27.4 \%(23 / 84)$ & $43.6 \%(17 / 39)$ & $50.3 \%(95 / 189)$ \\
\hline Female gender & $63.2 \%(48 / 76)$ & $59.5 \%(50 / 84)$ & $69.2 \%(27 / 39)$ & $55.0 \%(104 / 189)$ \\
\hline \multirow[t]{3}{*}{ Mean age (SD) } & $50.2(14.6)$ & $61.7(19.9)$ & $51.3(16.2)$ & $61.3(18.9)$ \\
\hline & \multicolumn{2}{|c|}{$\begin{array}{l}\text { GP communication skills training } \\
\qquad(6 \mathrm{GPs})\end{array}$} & \multicolumn{2}{|c|}{$\begin{array}{l}\text { GP No communication skills } \\
\text { training (8 GPs) }\end{array}$} \\
\hline & $\begin{array}{c}\text { Enrolled } \\
\text { LRTI patients } \\
n=46\end{array}$ & $\begin{array}{c}\text { Non-enrolled } \\
\text { LRTI patients } \\
n=101\end{array}$ & $\begin{array}{c}\text { Enrolled } \\
\text { LRTI patients } \\
n=69\end{array}$ & $\begin{array}{l}\text { Non-enrolled } \\
\text { LRTI patients } \\
n=172\end{array}$ \\
\hline $\begin{array}{l}\text { Antibiotics prescribed at } \\
\text { index consultation }\end{array}$ & $30.4 \%(14 / 46)$ & $26.7 \%(27 / 101)$ & $44.9 \%(31 / 69)$ & $52.9 \%(91 / 172)$ \\
\hline Female gender & $80.4 \%(37 / 46)$ & $59.4 \%(60 / 101)$ & $55.1 \%(38 / 69)$ & $54.7 \%(94 / 172)$ \\
\hline Mean age (SD) & $53.0(16.1)$ & $61.3(18.9)$ & $48.9(14.3)$ & $55.6(20.7)$ \\
\hline
\end{tabular}

Data are \% (number) unless otherwise stated. * Data was derived from the central registration system of the foundation of primary health care centres Eindhoven (SGE). ICPC codes for acute bronchitis (R78) and pneumonia (R81) were used and antibiotic prescribing per consultation using ATC code J001 could be determined. 14 (of 40) GPs were connected to this system at the time of the trial.

\section{Clinical recovery}

The interventions had no discernible effect on recovery, resulting in comparable median daily symptom scores for all four groups of patients. Recovery slopes are presented as median symptom scores per day in Figure 6.2. Clinical recovery based on symptom scores and analysed by a multilevel autoregressive moving average model was similar for all study groups resulting in one recovery slope for all groups (effect of test on recovery $P=0.99$, effect of 
training on recovery $P=0.97$, see web figure). Baseline characteristics were similar between patients who completed the symptom scores $(90 \%)$ and those who did not. Median patient reported time to recovery was 22 days (interquartile range 14-28). Although this trial was not designed to assess safety of either intervention in lower respiratory tract infection, no serious adverse events (death or admission to hospital) occurred.



Figure 6.2 Median symptoms scores (\%) for treatment groups (see web figure for full four level corrected recovery slopes). Treatment groups had identical clinical recovery despite fewer antibiotics prescribed in intervention groups

\section{Patient satisfaction, enablement, and intention to reconsult}

Overall, satisfaction with the index consultation was high, with no statistically significant differences between treatment groups. Fewer patients in the communication skills training group indicated that they would consult with similar symptoms in the future, but differences in future consulting intentions were not statistically significant between groups. The score for the patient enablement index was similar for all groups (Table 6.6). 


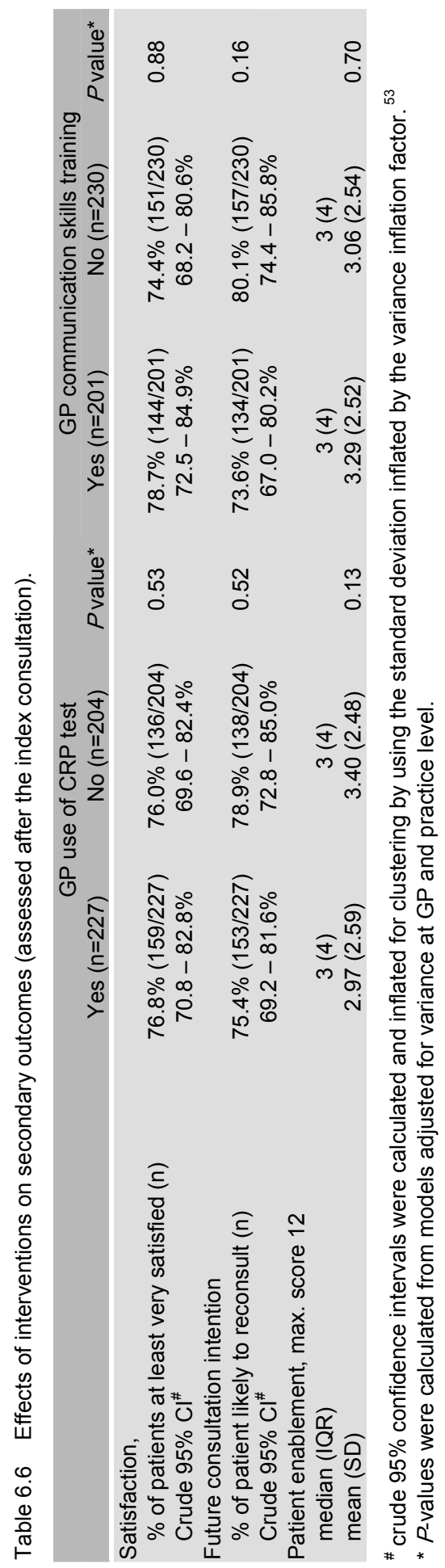




\section{Discussion}

Both general practitioners' use of point of care testing for C-reactive protein and training in enhanced communication skills had a clinically important effect on antibiotic prescribing at the index consultation for lower respiratory tract infection and antibiotic prescribing during the 28 days' follow-up period, without affecting clinical recovery or patients' satisfaction.

\section{Strengths and limitations of the study}

Factorial designs are efficient for assessing two interventions when they act independently of each other. ${ }^{40}$ Our results did not show interaction effects between the $\mathrm{C}$-reactive protein test and the enhanced communication skills strategy - that is, the combined effect of the test and training was neither synergistic nor antagonistic. We nevertheless included interaction coefficients in all models to correct for possible undetected interactions.

The sustainability of the acquired communication skills may be questioned. We previously reported sustained competence in implementing these skills. ${ }^{43} \mathrm{~A}$ sensitivity analysis of the results by winter period (2005-6 and 2006-7) showed that the observed effects on antibiotic prescribing were similar during both periods. Moreover, most patients seeing general practitioners who had been allocated to communication skills training recalled key topics being covered during the consultation. The enhanced communication skills may therefore have become embedded in the general practitioners' daily routine as the method does not increase mean consultation times, which is crucial in time pressured practice. ${ }^{43}$ However, general practitioners may need time to gain confidence and experience in interpreting the results of the C-reactive protein test in general, and in using the point of care result to guide treatment in particular. At the time of the study, point of care testing for C-reactive protein was nearly nonexistent in Dutch primary care. We did, however, observe similar effects on antibiotic prescribing across the winters, despite the short run-in and familiarisation period with the test of a maximum of eight weeks before the trial started. Our results contrast with recent findings from Scandinavia where overprescribing of antibiotics was associated with intermediate elevated test results. ${ }^{48}$ In addition, excessive C-reactive protein testing for self limiting respiratory tract infections such as the common cold is widespread in settings where C-reactive protein point of care testing is widely used in primary care. ${ }^{49}$ Hence a proper introduction to the test with recommendations on the interpretation of the additional diagnostic value for a specific respiratory tract infection as implemented in our trial seems crucial for optimal utilisation.

We recruited 431 patients, with $100 \%$ ascertainment of the primary outcome and $90 \%$ ascertainment of patient reported outcomes. This higher than 
expected follow-up rate increased the study power. The target number of patients in the training arm was not achieved because three general practitioners went on maternity leave. Nevertheless, with over 200 patients in both groups we were able to evaluate the effect of training in enhanced communication skills. Validity was increased by taking variation at both practice and doctor levels into account. ${ }^{50,51}$

A common potential weakness in randomised controlled trials using a cluster design is recruitment bias after randomisation, as differential numbers and types of patient may be enrolled after the intervention has been allocated. ${ }^{52-54}$ However, the baseline characteristics of the recruited patients were similar across the groups, and inclusion of known covariates (personal characteristics and case-mix) in our models did not affect the observed effects. Both suggest that differential recruitment was not an issue in this study. Nevertheless, unmeasured covariates may have influenced outcomes. Individual randomisation, which balances unknown variables, was not an option for our study design because our interventions were targeted at the level of general practitioner, and once trained in enhanced communication skills general practitioners could not be expected to revert to an untrained state at random.

The participation of the general practitioners would have been hampered if they could not have decided on patient recruitment. In studies of acute conditions in primary care it is seldom feasible for anyone other than the treating clinician to identify and recruit suitable patients. Non-inclusion analysis suggests that differential enrolment to our study groups did not occur.

Patients recruited into our trial groups were slightly younger than patients with lower respiratory tract infection in a large database of routine primary care clinical records. This may be explained by our inclusion criteria - for example, patients seen during home visits or in old people's care homes were ineligible. Strikingly, based on this trial and on the non-inclusion analysis, women were more likely to be enrolled by general practitioners allocated to the training in enhanced communication skills group, shedding interesting light on this sex issue, as most people consulting for lower respiratory tract infection in primary care are female.

\section{Comparison with other studies}

While some previous randomised studies failed to find an effect on antibiotic prescribing, ${ }^{32,34}$ those that did mostly involved multifaceted complex interventions. $^{35,36,38,55}$ The effect size of both our interventions was greater than in any previous study of which we are aware. Another partly illness focused approach, delayed prescribing, also yielded large effects on antibiotic prescribing. However, the applicability of the largest trial on delayed prescribing for lower respiratory tract infection was limited by its exclusion of patients with a 
history suggestive of pneumonia, since the difficulty in differentiating pneumonia from acute bronchitis is one of the biggest drivers of unnecessary prescribing in lower respiratory tract infection. ${ }^{37}$ Other useful biomarkers, such as procalcitonin, have been suggested to guide antibiotic treatment for lower respiratory tract infection. These tests are not yet available as point of care, however, thereby limiting their applicability to general practice. ${ }^{56,57}$

\section{Implications}

The broad approach exemplified by the interventions evaluated in this trial may enhance management of a wider range of patients than just those with lower respiratory tract infection. Both approaches (excluding serious infections by using a biomarker and eliciting patients' expectations, concerns, and opinion on antibiotics while providing evidence based information on treatment and clinical course by training doctors in communication skills) could be used for most common infections in primary care. Moreover, the combined effect of the interventions stresses the importance of a shared approach; serious infection needs to be ruled out, and patients' expectations and worries should be identified and responded to, all without unduly increasing consultation time. ${ }^{43}$ These interventions not only aim to reduce antibiotic prescribing. Crucially, combining the disease and illness approach implies that decisions on antibiotic prescribing should focus on targeting the drug to the patient while balancing benefits and possible harms of treatment to those with potential societal benefits from restrictive prescribing. ${ }^{58}$ C-reactive protein may contribute to safely withholding antibiotics from most people with low C-reactive protein values who most probably would not benefit from antibiotic treatment, while enhanced communication may increase patients' understanding of prescribing decisions without feeling dismissed with unsatisfactory explanations. This may lead to enhanced self care in the future.

We intended to study effectiveness and not efficacy (as in an explanatory trial). ${ }^{59}$ The pragmatic nature of our study enhances the generalisability of the results. Our study included the full range of patients with lower respiratory tract infection seen by general practitioners, with all the associated diagnostic uncertainty. If the interventions prove cost effective, implementation on a larger scale will be facilitated by the close to daily practice approach used in the trial. Our results may guide investment in primary care to either C-reactive protein test devices or training in communication skills, or a combination of both.

Although the Netherlands has one of the lowest overall prescribing rates for antibiotics worldwide, prescribing for lower respiratory tract infection remains high, with rates similar to other European countries and the United States. As most patients in our study did not undergo chest radiography we do not know the number who had community acquired pneumonia. The characteristics of the 
patients, however, seem comparable to previous studies on lower respiratory tract infection, in which about $11 \%$ of patients had community acquired pneumonia. ${ }^{15}$ Chest radiography before deciding to prescribe is carried out less often in Dutch primary care than in the United States, therefore requiring all patients to undergo chest radiography in this study would have limited generalisability. We acknowledge that the use of such ancillary tests varies between countries, ${ }^{60}$ but the method of recruitment, the use of standardised clinical criteria, and the finding of similar prescribing rates for antibiotics between the United States, the Netherlands, and other parts of Europe add weight to the wider applicability of our findings.

The antibiotic prescribing rate of $67 \%$ for our usual care group (see Table 6.4) is comparable to other studies in the Netherlands and elsewhere, including the United States and the United Kingdom. ${ }^{8-10}$ Given that 370.000 prescriptions for antibiotics are issued in 550.000 consultations for lower respiratory tract infection (based on 44 adults consulting for lower respiratory tract infection per 1000 adults per year ${ }^{4,61}$ ) in the Netherlands each year, up to 240.000 prescriptions may be avoided annually if our findings were to be replicated on a national scale. Reducing antibiotic prescribing in primary care may decrease levels of antibiotic resistance nationally and internationally, but it may also have substantial effects locally. General practices that reduced antibiotic prescribing the most over a seven year period in the United Kingdom showed the greatest reductions in antibiotic resistance locally. ${ }^{62}$ Implementing the approaches we evaluated for this common condition in primary care in other healthcare settings is feasible.

\section{Conclusions}

Both interventions were effective on their own. These effects could have major implications for the management of lower respiratory tract infection. Prescribing fewer antibiotics in the intervention groups did not result in poorer patient outcomes. Both interventions required training clinicians in new skills and have potential applicability in primary care beyond the condition we studied. For example, C-reactive protein may effectively guide treatment for other infections and inflammatory conditions. Shared decision making skills are applicable to most medical conditions. Clinical methods in primary care may be most successful in achieving evidence based management if disease focused and illness focused interventions are integrated. 
Web Table 1 Three-level logistic regression models for primary outcomes.

\begin{tabular}{|c|c|c|c|}
\hline & \multicolumn{3}{|c|}{ Antibiotic prescribing at index consultation } \\
\hline & $\beta$ coefficient & SE & $P$-value* \\
\hline \multirow{6}{*}{$\begin{array}{l}\text { Intercept } \\
\text { GP use of CRP } \\
\text { GP communication skills training } \\
\text { Interaction term } \\
\text { (GP use of CRP * GP communication skills training) }\end{array}$} & 1.241 & 0.496 & \\
\hline & -1.551 & 0.667 & 0.02 \\
\hline & -2.152 & 0.710 & $<0.01$ \\
\hline & 0.854 & 0.966 & 0.78 \\
\hline & \multicolumn{3}{|c|}{ Antibiotics day 1 to 28} \\
\hline & $\beta$ coefficient & SE & $P$-value* \\
\hline \multirow{6}{*}{$\begin{array}{l}\text { Intercept } \\
\text { GP use of CRP } \\
\text { GP communication skills training } \\
\text { Interaction term } \\
\text { (GP use of CRP * GP communication skills training) }\end{array}$} & 1.640 & 0.412 & \\
\hline & -1.382 & 0.536 & $<0.01$ \\
\hline & -2.287 & 0.573 & $<0.001$ \\
\hline & 1.355 & 0.751 & 0.07 \\
\hline & \multicolumn{3}{|c|}{ Reconsultation with GP within 28 days } \\
\hline & $\beta$ coefficient & SE & $P$-value* \\
\hline Intercept & 0.635 & 0.212 & \\
\hline GP use of CRP & -0.205 & 0.302 & 0.50 \\
\hline GP use of communication & 0.514 & 0.347 & 0.14 \\
\hline $\begin{array}{l}\text { Interaction term } \\
\text { (GP use of } C R P * G P \text { communication skills training) }\end{array}$ & -0.139 & 0.463 & 0.76 \\
\hline
\end{tabular}

* Models are $2^{\text {nd }}$ order PQL multilevel logistic regression model adjusted for variance at GP and practice level (random intercept at practice and GP level). Models included both interventions and the interaction term of the interventions.

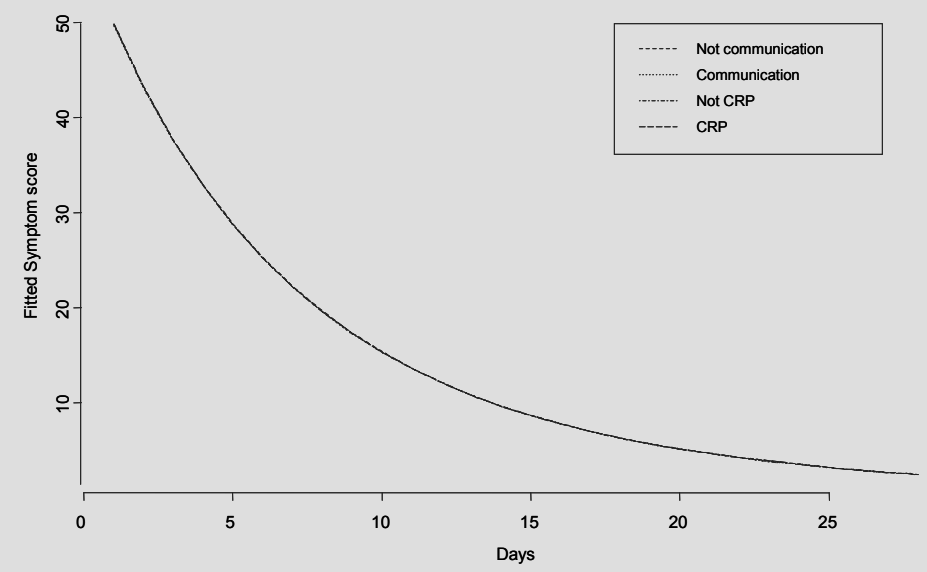

Web Figure 1 Clinical recovery.

Recovery slopes for the 4 factors overlap completely in this figure. Recovery slopes were obtained by exponentiating the summated parameter coefficients from the ARMA model for 380 patients with completed symptom scores. Neither of the interventions had any effect on clinical recovery: Coefficient GP use of CRP $0.000866, P=0.99$. Coefficient GP use of communication skills $-0.003875, P=0.97$. As a consequence recovery slopes are identical across all study groups. Interaction was non-significant $(P=0.60)$. Hence, all patient groups had identical clinical recovery despite less antibiotics with the intervention groups. 


\section{References}

1. McWhinney IR. A textbook of family medicine. 2nd edn. New York, Oxford: Oxford University Press, 1997.

2. Dinant GJ, Buntinx FF, Butler CC. The necessary shift from diagnostic to prognostic research. BMC Fam Pract 2007;8:53.

3. Butler CC, Kinnersley P, Prout H, Rollnick S, Edwards A, Elwyn G. Antibiotics and shared decision-making in primary care. J Antimicrob Chemother 2001;48:435-40.

4. Macfarlane J, Holmes W, Gard P, Macfarlane R, Rose D, Weston V, Leinonen M, Saikku P, Myint S. Prospective study of the incidence, aetiology and outcome of adult lower respiratory tract illness in the community. Thorax 2001;56:109-14.

5. Schappert SM, Burt CW. Ambulatory care visits to physician offices, hospital outpatient departments, and emergency departments: United States, 2001-02. Vital Health Stat 13 2006:1-66.

6. Woodhead M, Blasi F, Ewig S, Huchon G, leven M, Ortqvist A, Schaberg T, Torres A, van der Heijden G, Verheij TJ; European Respiratory Society; European Society of Clinical Microbiology and Infectious Diseases. Guidelines for the management of adult lower respiratory tract infections. Eur Respir J 2005;26:1138-80.

7. Smucny J, Fahey T, Becker L, Glazier R. Antibiotics for acute bronchitis. Cochrane Database Syst Rev 2004;(4):CD000245.

8. Gonzales R, Steiner JF, Sande MA. Antibiotic prescribing for adults with colds, upper respiratory tract infections, and bronchitis by ambulatory care physicians JAMA 1997;278: 901-4.

9. Kuyvenhoven MM, Verheij TJ, de Melker RA, van der Velden J. Antimicrobial agents in lower respiratory tract infections in Dutch general practice. Br J Gen Pract 2000;50:133-4.

10. Macfarlane J, Lewis SA, Macfarlane R, Holmes W. Contemporary use of antibiotics in 1089 adults presenting with acute lower respiratory tract illness in general practice in the U.K.: implications for developing management guidelines. Respir Med 1997;91:427-34.

11. Goossens H, Ferech M, Vander Stichele R, Elseviers M. Outpatient antibiotic use in Europe and association with resistance: a cross-national database study. Lancet 2005;365:579-87.

12. Bradley JS, Guidos R, Baragona S, Bartlett JG, Rubinstein E, Zhanel GG, Tino MD, Pompliano DL, Tally F, Tipirneni P, Tillotson GS, Powers JH, Tillotson GS. Anti-infective research and development-problems, challenges, and solutions. Lancet Infect Dis 2007;7: 68-78.

13. Nordberg P, Monnet DL, Cars O. Antibacterial drug resistance: options for concerted action. Geneva: Department of Medicines Policy and Standards, World Health Organization, 2005:1-48.

14. Fischer T, Fischer S, Kochen MM, Hummers Pradier E. Influence of patient symptoms and physical findings on general practitioners' treatment of respiratory tract infections: a direct observation study. BMC Fam Pract 2005;6:6.

15. Hopstaken RM, Muris JWM, Knottnerus JA, Kester ADM, Rinkens PELM, Dinant GJ. Contributions of symptoms, signs, erythrocyte sedimentation rate and C-reactive protein to a diagnosis of pneumonia in acute lower respiratory tract infection. Br J Gen Pract 2003;53: 358-64.

16. Melbye H, Straume B, Aasebo U, Brox J. The diagnosis of adult pneumonia in general practice. The diagnostic value of history, physical examination and some blood tests. Scand $\mathrm{J}$ Prim Health Care 1988;6:111-7.

17. Mclsaac WJ, Butler CC. Does clinical error contribute to unnecessary antibiotic use? Med Decis Making 2000;20:33-8.

18. Wood F, Simpson S, Butler CC. Socially responsible antibiotic choices in primary care: a qualitative study of GPs' decisions to prescribe broad-spectrum and fluroquinolone antibiotics. Fam Pract 2007;24:427-34.

19. Van der Meer V, Neven AK, Broek PJvd, Assendelft WJJ. Diagnostic value of $C$ reactive protein in infections of the lower respiratory tract: systematic review. BMJ 2005;331:26-9. 
20. Dahler Eriksen BS, Lassen JF, Petersen PH, Lund ED, Lauritzen T, Brandslund I. Evaluation of a near-patient test for C-reactive protein used in daily routine in primary healthcare by use of difference plots. Clin Chem 1997;43:2064-75.

21. Davey $P$, Pagliari $C$, Hayes $A$. The patient's role in the spread and control of bacterial resistance to antibiotics. Clin Microbiol Infect 2002;8(suppl 2):43-68.

22. Avorn J, Solomon DH. Cultural and economic factors that (mis)shape antibiotic use: the nonpharmacologic basis of therapeutics. Ann Intern Med 2000;133:128-35.

23. Altiner A, Knauf A, Moebes J, Sielk M, Wilm S. Acute cough: a qualitative analysis of how GPs manage the consultation when patients explicitly or implicitly expect antibiotic prescriptions. Fam Pract 2004;21:500-6.

24. Butler CC, Rollnick S, Pill R, Maggs Rapport F, Stott N. Understanding the culture of prescribing: qualitative study of general practitioners' and patients' perceptions of antibiotics for sore throats. BMJ 1998;317:637-42.

25. Coenen S, Michiels B, Renard D, Denekens J, Van Royen P. Antibiotic prescribing for acute cough: the effect of perceived patient demand. Br J Gen Pract 2006;56:183-90.

26. Little $\mathrm{P}$, Dorward M, Warner G, Stephens K, Senior J, Moore M. Importance of patient pressure and perceived pressure and perceived medical need for investigations, referral, and prescribing in primary care: nested observational study. BMJ 2004;328:444-6.

27. Little P, Gould C, Williamson I, Warner G, Gantley M, Kinmonth AL. Reattendance and complications in a randomised trial of prescribing strategies for sore throat: the medicalising effect of prescribing antibiotics. BMJ 1997;315:350-2.

28. Cals JWL, Boumans D, Lardinois RJM, Gonzales R, Hopstaken RM, Butler CC, Dinant GJ. Public beliefs on antibiotics and respiratory tract infections: an internet-based questionnaire study. Br J Gen Pract 2007;57:942-7.

29. Stewart M. Patient-centered medicine: transforming the clinical method. 2nd edn. Abingdon: Radcliffe Medical, 2003.

30. Rollnick S, Seale C, Rees M, Butler C, Kinnersley P, Anderson L. Inside the routine general practice consultation: an observational study of consultations for sore throats. Fam Pract 2001;18:506-10.

31. Christ-Crain M, Jaccard-Stolz D, Bingisser R, Gencay MM, Huber PR, Tamm M, Müller B. Effect of procalcitonin-guided treatment on antibiotic use and outcome in lower respiratory tract infections: cluster-randomised, single-blinded intervention trial. Lancet 2004;363:600-7.

32. Diederichsen HZ, Skamling M, Diederichsen A, Grinsted P, Antonsen S, Petersen PH, Munck AP, Kragstrup J. Randomised controlled trial of CRP rapid test as a guide to treatment of respiratory infections in general practice. Scand J Prim Health Care 2000;18:39-43.

33. Samore MH, Bateman K, Alder SC, Hannah E, Donnelly S, Stoddard GJ, Haddadin B, Rubin MA, Williamson J, Stults B, Rupper R, Stevenson K. Clinical decision support and appropriateness of antimicrobial prescribing: a randomized trial. JAMA 2005;294:2305-14.

34. Briel M, Langewitz W, Tschudi P, Young J, Hugenschmidt C, Bucher HC. Communication training and antibiotic use in acute respiratory tract infections. A cluster randomised controlled trial in general practice. Swiss Med Wkly 2006;136:241-7.

35. Altiner A, Brockmann S, Sielk M, Wilm S, Wegscheider K, Abholz HH. Reducing antibiotic prescriptions for acute cough by motivating GPs to change their attitudes to communication and empowering patients: a cluster-randomized intervention study. J Antimicrob Chemother 2007;60:638-44.

36. Coenen S, Van Royen P, Michiels B, Denekens J. Optimizing antibiotic prescribing for acute cough in general practice: a cluster-randomized controlled trial. J Antimicrob Chemother 2004;54(3):661-72.

37. Little P, Rumsby K, Kelly J, Watson L, Moore M, Warner G, Fahey T, Williamson I. Information leaflet and antibiotic prescribing strategies for acute lower respiratory tract infection: a randomized controlled trial. JAMA 2005;293:3029-35.

38. Welschen I, Kuyvenhoven MM, Hoes AW, Verheij TJM. Effectiveness of a multiple intervention to reduce antibiotic prescribing for respiratory tract symptoms in primary care: randomised controlled trial. BMJ 2004;329:431-3. 
39. Cals JW, Hopstaken RM, Butler CC, Hood K, Severens JL, Dinant GJ. Improving management of patients with acute cough by C-reactive protein point of care testing and communication training (IMPAC3T): study protocol of a cluster randomised controlled trial. BMC Fam Pract 2007;8:15.

40. Montgomery A, Peters T, Little P. Design, analysis and presentation of factorial randomised controlled trials. BMC Med Res Method 2003;3:26.

41. Verheij TJM, Salomé PL, Bindels PJ, Chavannes AW, Ponsioen BP, Sachs APE, et al. NHGStandaard Acuut hoesten. [Dutch College of General Practitioners Guidelines on Acute Cough]. Huisarts Wet 2003;46:496-506.

42. Rollnick S, Kinnersley P, Butler C. Context-bound communication skills training: development of a new method. Med Educ 2002;36:377-83.

43. Cals JW, Scheppers NA, Hopstaken RM, Hood K, Dinant GJ, Goettsch H, Butler CC. Evidence based management of acute bronchitis; sustained competence of enhanced communication skills acquisition in general practice. Patient Educ Couns 2007;68:270-8.

44. Watson L, Little P, Moore M, Warner G, Williamson I. Validation study of a diary for use in acute lower respiratory tract infection. Fam Pract 2001;18:553-4.

45. Howie JG, Heaney DJ, Maxwell M, Walker JJ. A comparison of a patient enablement instrument (PEI) against two established satisfaction scales as an outcome measure of primary care consultations. Fam Pract 1998;15:165-71.

46. Box GEP, Jenkins GM, Reinsel GC. Time series analysis: forecasting and control. 3rd ed. Englewood Cliffs, NJ: Prentice Hall, 1994.

47. Campbell MJ. Extending CONSORT to include cluster trials. BMJ 2004;328:654-5.

48. Andre M, Schwan A, Odenholt I. The use of CRP tests in patients with respiratory tract infections in primary care in Sweden can be questioned. Scand J Infect Dis 2004;36:192-7.

49. Engstrom S, Molstad S, Lindstrom K, Nilsson G, Borgquist L. Excessive use of rapid tests in respiratory tract infections in Swedish primary health care. Scand J Infect Dis 2004;36:213-8.

50. Mollison J, Simpson JA, Campbell MK, Grimshaw JM. Comparison of analytical methods for cluster randomised trials: an example from a primary care setting. J Epidemiol Biostat 2000;5:339-48.

51. Campbell MK, Fayers PM, Grimshaw JM. Determinants of the intracluster correlation coefficient in cluster randomized trials: the case of implementation research. Clin Trials 2005;2:99-107.

52. Puffer S, Torgerson D, Watson J. Evidence for risk of bias in cluster randomised trials: review of recent trials published in three general medical journals. BMJ 2003;327:785-9.

53. Donner A, Klar N. Design and analysis of cluster randomization trials in health research. London: Arnold, 2000.

54. Hahn S, Puffer S, Torgerson DJ, Watson J. Methodological bias in cluster randomised trials. BMC Med Res Methodol 2005;5:10.

55. Arnold SR, Straus SE. Interventions to improve antibiotic prescribing practices in ambulatory care. Cochrane Database Syst Rev 2005;(4):CD003539.

56. Christ-Crain M, Muller B. Biomarkers in respiratory tract infections: diagnostic guides to antibiotic prescription, prognostic markers and mediators. Eur Respir J 2007;30:556-73.

57. Holm A, Pedersen SS, Nexoe J, Obel N, Nielsen LP, Koldkjaer O, Pedersen C. Procalcitonin versus $\mathrm{C}$-reactive protein for predicting pneumonia in adults with lower respiratory tract infection in primary care. Br J Gen Pract 2007;57:555-60.

58. Cosby JL, Francis N, Butler CC. The role of evidence in the decline of antibiotic use for common respiratory infections in primary care. Lancet Infect Dis 2007;7:749-56.

59. Roland M, Torgerson DJ. Understanding controlled trials: what are pragmatic trials? BMJ 1998;316:285.

60. Cals J, Hopstaken R. Lower respiratory tract infections: treating patients or diagnoses? J Fam Pract 2006;55:545-6; author reply 546-7.

61. Hak E, Rovers MM, Kuyvenhoven MM, Schellevis FG, Verheij TJ. Incidence of GP-diagnosed respiratory tract infections according to age, gender and high-risk co-morbidity: the second dutch national survey of general practice. Fam Pract 2006;23:291-4. 
62. Butler CC, Dunstan F, Heginbothom M, Mason B, Roberts Z, Hillier S, Howe R, Palmer S, Howard A. Containing antibiotic resistance: decreased antibiotic-resistant coliform urinary tract infections with reduction in antibiotic prescribing by general practices. $\mathrm{Br} \mathrm{J}$ Gen Pract 2007;57:785-92. 


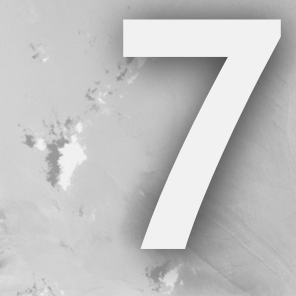

Cost-effectiveness of C-reactive protein point of care testing and physician communication skills training in reducing antibiotic prescribing for lower respiratory tract infections in general practice

Jochen Cals, Andre Ament, Kerenza Hood, Christopher Butler, Rogier Hopstaken, Geert Wassink, Geert-Jan Dinant

Submitted 


\section{Abstract}

\section{Objective}

An economic evaluation of general practitioner (GP) use of C-reactive protein (CRP) point of care test, GP communication skills training, and both GP use of CRP and communication skills training on antibiotic use for lower respiratory tract infections (LRTI) in general practice.

\section{Design}

Cost-effectiveness analysis with a time horizon of 28 days alongside a factorial, cluster randomised trial.

\section{Participants}

431 patients with lower respiratory tract infections recruited by 40 general practitioners.

\section{Interventions}

Usual care (control group), GP use of CRP point of care test, GP communication skills training, and both CRP use and communication skills training.

\section{Main outcome measure}

Health care costs. Cost-effectiveness, using the primary outcome measure antibiotic prescribing at index consultation, was assessed by incremental cost-effectiveness ratios. To adjust for skewed data and clustering, we used non-parametric bootstrapping re-sampling to derive percentile intervals for the mean difference in total costs and the mean difference in effectiveness between the groups. Various implementation scenarios according to GP preference were modelled with corresponding net monetary benefit (NMB) curves based on a given willingness-to-pay $(\lambda)$ for a $1 \%$ lower antibiotic prescribing rate.

\section{Results}

The total mean cost per patient in the usual care group was $€ 35.96$ with antibiotic prescribing of $68 \%, € 37.58$ per patient managed by GPs using CRP tests (antibiotic prescribing $39 \%$, ICER $€ 5.79$ ), $€ 25.61$ per patient managed by GPs trained in enhanced communication skills (antibiotic prescribing $33 \%$, dominant), and $€ 37.78$ per patient managed by GPs using both interventions (antibiotic prescribing 23\%, ICER €4.15). The interventions are cost-effective in any combination (yielding NMB at no willingness-to-pay), taking into account GPs' preferences where at least $15 \%$ of GPs choose to implement the communication skills training.

\section{Conclusion}

The two strategies, both singly and combined, are cost-effective interventions to reduce antibiotic prescribing for LRTI, at no, or low willingness-to-pay. Taking GP preferences into account will optimize investment in strategies to reduce antibiotic prescribing for LRTI. 


\section{Introduction}

Cough is the most common acute reason to consult in general practice. Lower respiratory tract infections (LRTIs) account for 28 million consultations each year in general practice in the US and the EU. ${ }^{1-3}$ Unnecessary antibiotic prescribing for LRTI remains common. Moreover, patients often reconsult for the same illness episode, increasing workload and costs in general practice. ${ }^{4,5}$ The origins and potential solutions to over prescribing in primary care can be seen from two contrasting viewpoints; the 'disease perspective' emphasises the lack of adequate diagnostic tools to differentiate serious from self-limiting infections, ${ }^{6}$ and the 'illness perspective' emphasises non-medical influences such as patients' expectations and time pressured consultations that lead to suboptimal clinician patient communication, reinforcing patients' misconceptions and inappropriate help seeking. ${ }^{7-10}$

While interventions have been targeted at these influences separately, no trial of LRTI management has evaluated the effect of an illness perspective based intervention combined with an intervention that has a disease focus, thus tackling diagnostic uncertainty and non-medical influences simultaneously. We assessed the effect of GP use of C-reactive protein point of care testing and enhanced communication skills training for GPs on antibiotic prescribing for LRT using a factorial design. ${ }^{11,12}$

There have been few studies of the cost -effectiveness of interventions aimed at improving antimicrobial stewardship. Such studies are urgently needed to guide investment in strategies to combat inappropriate antibiotic prescribing, given increasing antibiotic resistance and lack of development of new antimicrobials. ${ }^{13,14}$

We therefore performed a cost effectiveness analysis alongside our trial to determine the incremental cost-effectiveness of three strategies - GP use of CRP, GP communication skills training, and GP use of both CRP and communication training - compared to usual care from a health care perspective. We aimed to model different scenarios of the consequences of implementing the illness and disease focused strategies according to GP preference.

\section{Method}

\section{Study design}

The design of the cluster randomised factorial clinical trial which forms the basis of this cost-effectiveness study is described in detail elsewhere. ${ }^{11}$ In summary, we randomly allocated two interventions (CRP point of care testing and training 
in enhanced communication skills) to GP surgeries in a 2x2 factorial design. This resulted in groups of 10 GPs, allocated to one of four study conditions; GP use of CRP point of care testing (1), GP communication skills training (2), both GP use of CRP point of care testing and GP communication skill straining (3) or Usual Care (4).

\section{Patients}

Eligible patients were aged 18 years or older, consulting with their GP with a new episode of acute cough of up to 28 days and caused by an LRTI in the GPS view. $^{11}$

\section{Interventions}

The interventions have been described in detail elsewhere. ${ }^{11}$ In summary, GPs managed patients in the usual care group with the availability of the Dutch College of General Practitioners guidelines for acute cough. ${ }^{15}$ GPs in the CRP intervention groups received a 30-minute, practice-based introduction on the usefulness of CRP point of care testing in general practice. Practice nurses were given an introduction to technical and practical aspects. Devices were provided and installed by a commercial company.

The communication skills training intervention was largely practice-based and included peer review of transcripts of consultations with simulated patients. The communication skills themselves were developed based on a patient centred strategy for shared decision making about investigation and treatment of common infections. The elicit-provide-elicit framework for information sharing was a key component. ${ }^{16,17}$ Simulated patients visited each GP on two occasions (10 minute consultation) during regular consultation hours, prior to, and shortly after a face-to-face seminar. Two-hour seminars for groups of between five and eight GPs were held at a central location and moderated by a social scientist and a researcher $(\mathrm{JC}){ }^{17}$ The training program took four hours in total to complete.

\section{Clinical outcomes}

The primary outcome was antibiotic prescribing at the index consultation. Antibiotic prescribing at any time during the 28-day follow-up period, reconsultation, patient satisfaction, enablement and clinical recovery were also investigated, but are not included in this cost-effectiveness analysis. These outcomes can be found in the randomised clinical trial paper. ${ }^{12}$ 


\section{Costs}

Data were collected from a health care perspective. Differences among the groups in days off work and production loss were not expected in this acute common illness. However, we collected data on days off work to check this assumption. Use of health care facilities was prospectively recorded in a standardised way and included all reconsultations, out-of-hours consultations, (repeat) prescription of antibiotics and other cough related drugs (type, dosage, duration), and additional diagnostic tests, including bacteriological culture and X-ray. Days off work, actual medication use and other medical costs to the patient were assessed using data from the electronic patient record and a 28-day patient completed diary. ${ }^{18}$ Patient reported data on medication use and reconsultation were compared with prescription and reconsultation data obtained from the medical records. Data from medical records were used if there was inconsistency between medical record data and patient reported data. The costs of the index consultation with the GP were not considered as these applied to all patients.

Unit resource prices were based on the guideline prices of the Dutch Insurance Board to improve generalisability of results. ${ }^{19}$ The Dutch Insurance Board provides a comprehensive overview of standard prices for GP consultations, emergency department visits etc.

Costs of direct health care utilization were calculated by multiplying the number of GP visits with the prices presented in Table 7.1. The additional direct health care costs of prescribed medication were calculated by allocating costs per defined dose, based on data provided by the pharmacotherapeutic database of the Dutch Insurance Board. ${ }^{19}$ The same method was used to calculate the direct non-health care costs of over the counter medication. Average costs were taken when multiple costs for specific generic products were available from several manufacturers. All medication prices were calculated by multiplying the number of doses by their unit costs. The mean monthly costs were used for inhaled medication (e.g. salbutamol), as the number of inhalations could not be accurately identified using patient records and patient diaries. The cost analysis was extended beyond patient level data for the groups of GPs trained in enhanced communication skills and/or CRP testing. Training led to additional costs (organising and giving the training and GPs' time investment) which was included in the analysis. ${ }^{20}$ These overhead costs were one-off, and were therefore regarded as fixed costs measured at the level of the trained GPs and discounted against patients consulting during the study period. Based on epidemiological data (44 LRTI consultations per 1000 adult patients per year ${ }^{1,21}, 1850$ adult patients within an average GP practice with a mean work time equivalent per GP of 0.75 ), we estimated that 122 LRTI patients per GP could have consulted for such complaints during the study period. Possible long-term effects on antimicrobial resistance were regarded as intangible costs and 
therefore not included in the analysis. Neither cost nor effects were discounted, as the time horizon was only 28 days.

Table 7.1 Resource components and associated cost sources.

$\begin{array}{lcl}\text { Resource } & \text { Cost }(€) & \text { Source } \\ \begin{array}{l}\text { Direct health care cost per contact } \\ \text { Medication }\end{array} & * & \text { Dutch Insurance Board } \\ \text { - prescribed by GP } & * & \text { Dutch Insurance Board } \\ \text { - over the counter (OTC) } & 20.20 & \text { Dutch Insurance Board } \\ \text { General Practitioner } & 63.30 & \text { GP out of hours Eindhoven } \\ \text { GP out of hours department } & 56.00 & \text { Dutch Insurance Board } \\ \text { Internal medicine physician } & 56.00 & \text { Dutch Insurance Board } \\ \text { Pulmonologist } & 139.00 & \text { Dutch Insurance Board } \\ \text { Emergency department } & & \\ \text { Additional diagnostic testing } & 58.50 & \text { Dutch Insurance Board } \\ \text { Spirometry } & 47.30 & \text { Dutch Insurance Board } \\ \text { Chest X-ray } & \# & \text { Dutch Insurance Board } \\ \text { Blood } & 47.05 & \text { Dutch Insurance Board } \\ \text { Sputum culture } & & \end{array}$

* Depending on medication; ${ }^{\#}$ Depending on requested tests

\section{Statistical analysis}

We performed a cost effectiveness, intention to treat analysis from a health care perspective that included costs of over the counter (OTC) medication with a time horizon of 28 days. An exploratory analysis of differences in production costs was planned to determine whether the cost-effectiveness analysis could be presented from the health care rather than the societal perspective. Because cost data are typically highly skewed and to adjust for clustering, we used nonparametric bootstrapping re-sampling with a Microsoft Excel macro to derive percentile intervals for the mean difference in total costs and the mean difference in effectiveness between the groups. ${ }^{22-24}$ The intervention groups (having received one or both interventions) were compared to the usual care group, leading to incremental cost-effectiveness ratios (ICER). Resulting estimates of net monetary benefit (NMB) values took into account the statistical uncertainty regarding the cost-effectiveness of the different strategies. Incremental Net Benefits (INB) curves were calculated and plotted based on the bootstrap replications for a range of plausible willingness-to-pay values $(\lambda)$. Definitions of the cost-effectiveness terms are given in Appendix 1.

\section{Sensitivity analysis and scenarios of implementation}

If ever implemented on a larger scale, one might assume that staff costs associated with delivering the interventions (simulated patients, teachers giving the seminars, providing instruction on use of CRP etc.) will be higher than in the 
this study, where academics performed these functions. We therefore performed a sensitivity analysis with labour costs related to the interventions at a double rate and calculated corresponding new ICERs.

Our base case analysis achieved $100 \%$ uptake of the intervention by the GPs as they were willing volunteers for the study. However, GPs in routine care will have preferences regarding adopting the disease and illness focused approaches. Reimbursement of one of the interventions, for example, may increase uptake over an intervention that was not reimbursed. If we were to choose one intervention for implementation by all GPs, and if only half of all trained GPs might actually deliver the intervention, the other $50 \%$ would then manage their patients according to usual care, leading to suboptimal implementation. In the sensitivity analyses, we modelled various scenarios according to GP preference and constructed corresponding INB curves based on different values within of $\lambda$ within a plausible range.

\section{Results}

\section{Patients}

All GPs received the allocated training. 431 Patients were recruited during two winters. Three GPs allocated to the group trained in communication skills were unable to complete recruitment due to maternity leave. This resulted in 84 patients recruited by this group rather than the planned 100. Demographic characteristics, co-morbidity and case mix were comparable across the intervention groups (Table 7.2). As expected, we did not find any notable or statistically significant difference in days off work due to the index illness across the groups. We therefore decided not omit costs related to production loss from our cost-effectiveness analysis. 
Table 7.2 Characteristics and outcomes of patients recruited and managed by GPs in intervention groups.

\begin{tabular}{|c|c|c|c|c|}
\hline & GP use of CRP & $\begin{array}{c}\text { GP } \\
\text { communication } \\
\text { skills training } \\
n=84\end{array}$ & $\begin{array}{c}\text { GP use of CRP } \\
\& \text { GP } \\
\text { communication } \\
\text { skills training } \\
n=117\end{array}$ & Usual Care \\
\hline \multicolumn{5}{|l|}{ Demographics } \\
\hline Female gender & $63(57.3)$ & $59(70.2)$ & $71(60.7)$ & $72(60.0)$ \\
\hline Mean age (SD) & $48.3(14.4)$ & $52.8(15.8)$ & $50.5(15.0)$ & $48.6(15.9)$ \\
\hline \multicolumn{5}{|l|}{ Duration of cough (days) } \\
\hline Mean (SD) & $9.1(6.2)$ & $11.1(6.8)$ & $11.0(6.9)$ & $9.7(6.2)$ \\
\hline Median (25-75 IQ) & $7(5-14)$ & $10(5-14)$ & $10(5-14)$ & $7(4-14)$ \\
\hline \multicolumn{5}{|l|}{ Co-morbidity } \\
\hline COPD & $9(8.2)$ & $3(3.6)$ & $8(6.8)$ & $11(9.2)$ \\
\hline Asthma & $13(11.8)$ & $9(10.7)$ & $10(8.5)$ & $7(5.8)$ \\
\hline Diabetes mellitus & $3(2.7)$ & $4(4.8)$ & $6(5.1)$ & $5(4.2)$ \\
\hline Effect data available & $110(100)$ & $84(100)$ & $117(100)$ & $120(100)$ \\
\hline Cost diary data available & $98(89.1)$ & $74(88.1)$ & $110(94.0)$ & $104(86.7)$ \\
\hline Antibiotics at index consultation & $43(39.1)$ & $28(33.3)$ & $27(23.1)$ & $80(66.7)$ \\
\hline Days off work (SD) & $3.35(4.54)$ & $3.37(4.02)$ & $3.39(4.08)$ & $3.37(3.77)$ \\
\hline
\end{tabular}

Data are numbers (\%) unless otherwise stated

\section{Cost data from patient diaries}

Complete cost data were available for $386(90 \%)$ patients. Most cost related data, including reconsultation, hospital visits, prescribed medication were confirmed as accurate through checking with data from GP medical records. These records were available for all patients. Costs of OTC drugs were not available for $45(10 \%)$ patients. As OTC drugs formed only a small part of the total costs, and as the low number of missing diaries was comparable across the groups, we chose not to impute these missing data and set these OTC costs to zero. Effects and costs of all patients were therefore included in the cost-effectiveness analysis.

\section{Clinical outcomes}

Antibiotics were prescribed at the index consultation for $67 \%$ of patients seen by GPs in the usual care group, for $39 \%$ seen by GPs using CRP tests $(\Delta \mathrm{E}=28 \%)$, for $33 \%$ seen by GPs trained in enhanced communication skills $(\Delta \mathrm{E}=33 \%)$, and for $23 \%$ by GPs using CRP who were also trained in the enhanced communication skills $(\Delta \mathrm{E}=44 \%)$. Symptom scores and patient reported time to recovery were similar for all groups, despite lower prescribing rates in the intervention groups.12 


\section{Costs}

Direct health care utilisation volumes are shown in Table 7.3, and derived mean direct health care costs summarised in Table 7.4. Intervention costs for the CRP $(€ 4.72)$ and communication skills training intervention $(€ 5.34)$ were assigned by patient. Table 7.4 shows a break-down of the costs of the components of the interventions.

Total mean costs per patient were $€ 35.96$ (SD58.12) in the usual care group, $€ 37.58$ (SD 45.24, $\Delta C$ 1.62) in the GP use of CRP group, $€ 25.61$ (SD44.49, $\triangle \mathrm{C}-10.61$ ) in the GP communication skills training group and $€ 37.78$ (SD 42.08, $\Delta C$ 1.82) in the combined GP use of CRP and communication skills training group (Table 7.4).

Table 7.3 Average resource use per intervention group.

\begin{tabular}{|c|c|c|c|c|}
\hline & GP use of CRP & $\begin{array}{l}\text { GP communication } \\
\text { skills training }\end{array}$ & $\begin{array}{c}\text { GP use of CRP \& } \\
\text { GP } \\
\text { communication } \\
\text { skills training }\end{array}$ & Usual Care \\
\hline & $n=110$ & $n=84$ & $n=117$ & $n=120$ \\
\hline \multicolumn{5}{|l|}{ Physician visits } \\
\hline GP (reconsultation) & 0.40 & 0.18 & 0.27 & 0.37 \\
\hline GP out of hours office & 0.01 & 0.05 & 0.02 & 0.08 \\
\hline $\begin{array}{l}\text { Hospital (outpatient or } \\
\text { emergency department) }\end{array}$ & 0.02 & 0.00 & 0.02 & 0.00 \\
\hline \multicolumn{5}{|l|}{ Diagnostic testing } \\
\hline Chest X-ray & 0.05 & 0.05 & 0.09 & 0.07 \\
\hline Blood & 0.01 & 0.01 & 0.05 & 0.00 \\
\hline Other (spirometry, sputum) & 0.02 & 0.00 & 0.02 & 0.02 \\
\hline
\end{tabular}

\section{Cost-effectiveness analysis}

Total costs were used for further cost-effectiveness analysis. All three interventions yielded effects, some at higher costs, some with cost savings (Table 7.5). The incremental cost-effectiveness ratio (ICER) of GP use of CRP versus usual care was $€ 5.79$ and for GP use of both CRP and communication versus usual care $€ 4$.15. This implies that an additional investment of $€ 5.79$ or $€ 4.15$ is needed for every additional unit of outcome (1\% reduction in antibiotic prescribing) in the intervention group compared with the usual care group. Communication was superior to usual care (Table 7.5). 


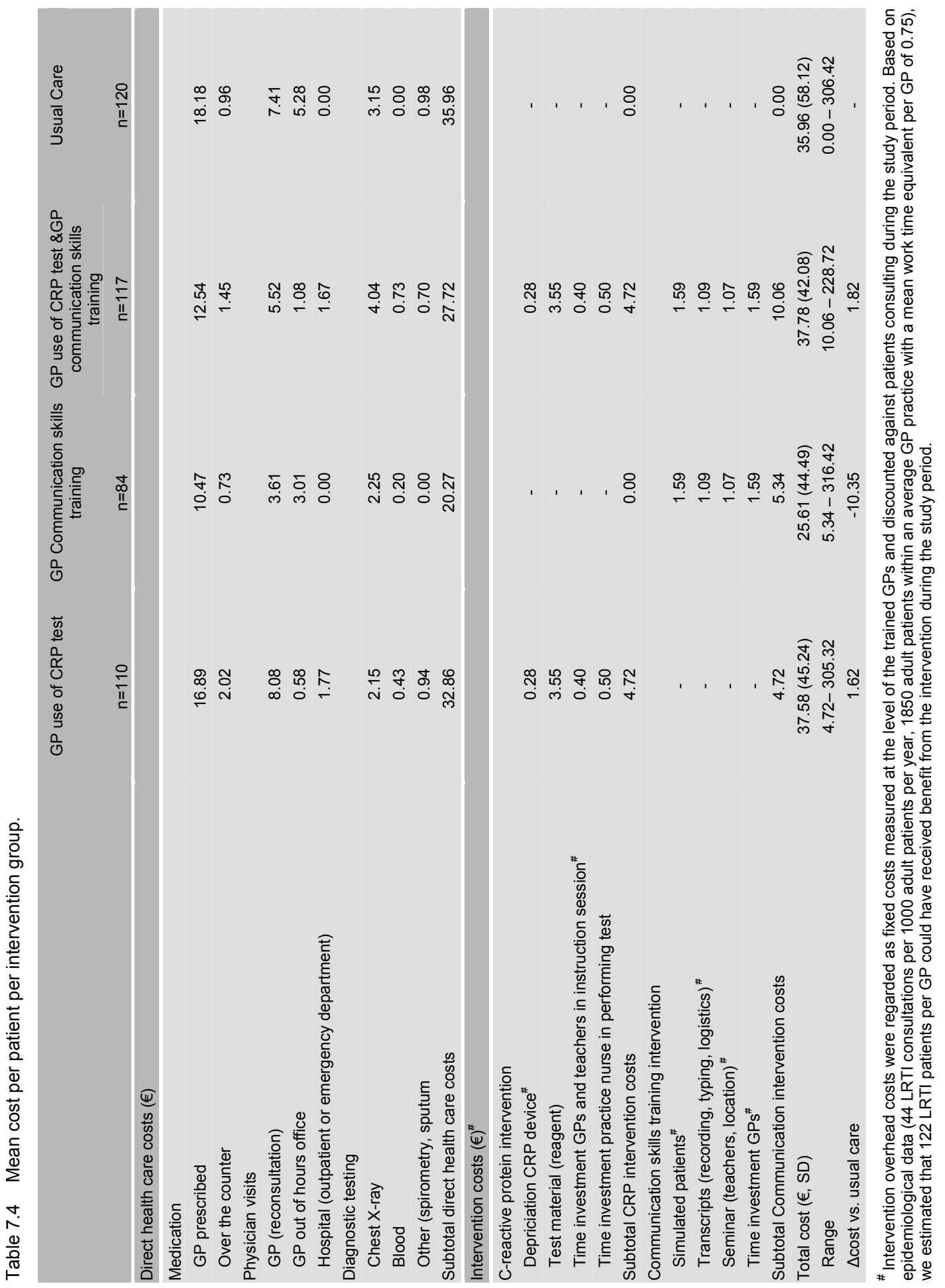




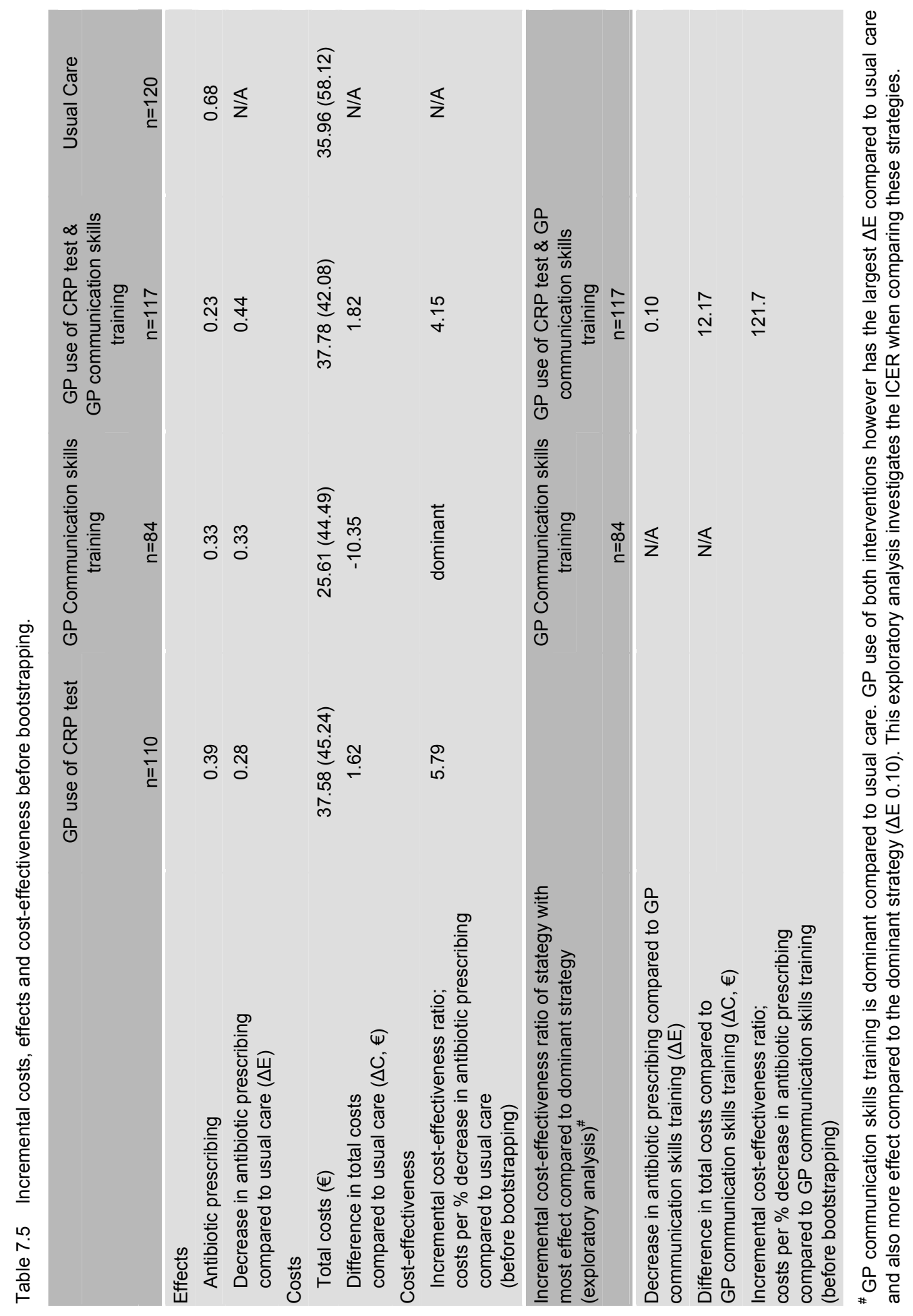


As a single intervention, the communication intervention was dominant compared to usual care, and also clearly better than CRP because of dominance. The next question was whether adding CRP to communication proved to be cost-effective. The answer depends on the value of the effect parameter (1\% reduction in antibiotic prescribing). The specific ICER (see Table $7.5)$ is $€ 121.7$, which means that if society were willing to pay more than $€ 121.7$ for a $1 \%$ reduction in antibiotic prescribing, adding CRP to communication would be cost-effective.

The cost-effectiveness plane after 1000 bootstrap replications of the three groups versus usual care are shown in Figure 7.1. All cost-effect pairs for antibiotic prescriptions prevented are located in the north east or south east quadrant of the cost-effectiveness plane, suggesting that all three strategies are more effective, some at higher costs and some at lower costs. For GP use of CRP, $62 \%$ of all pairs were located north-eastern, while $38 \%$ were in the south eastern (dominant) quadrant. For GP communication skills training this is $8 \%$ and $93 \%$ respectively, and for GP use of CRP and communication skills training $62 \%$ and $38 \%$. Resulting cost-effectiveness acceptability curves are shown in Figure 7.2.

Incremental net benefits for the three intervention groups at different values of $\lambda$ are plotted in Figure 7.3.

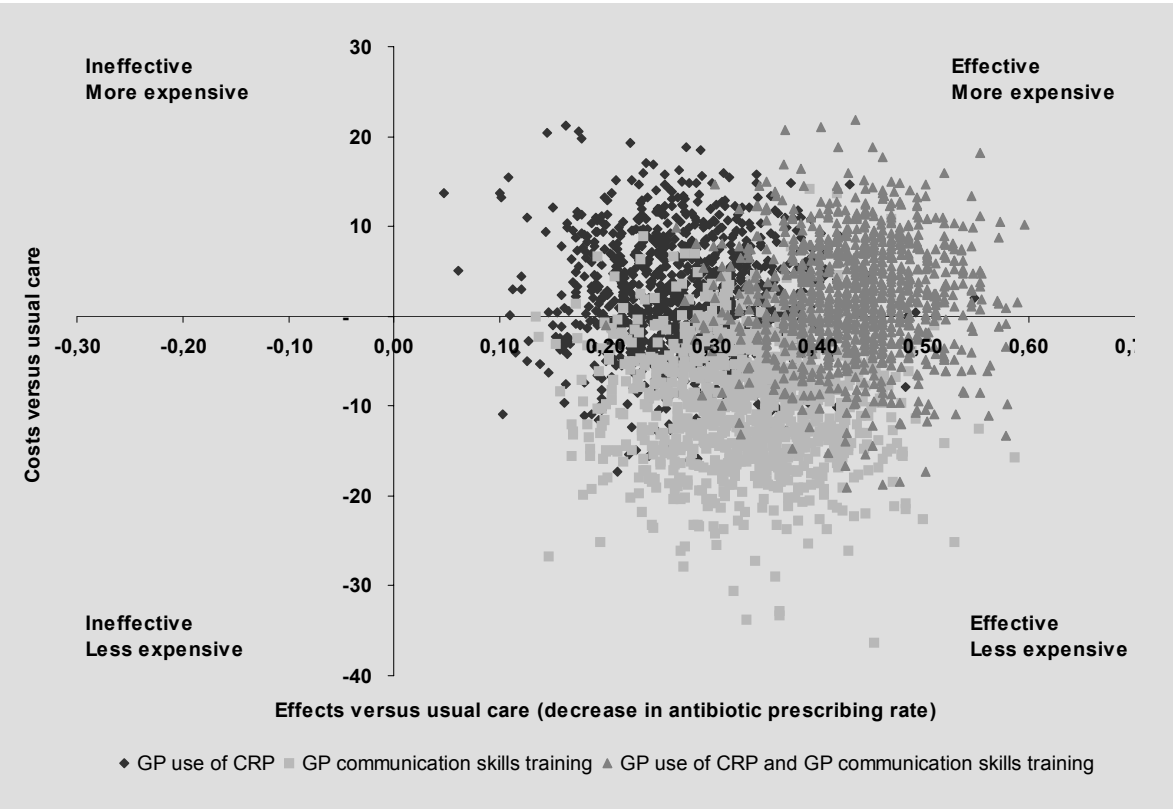

Figure 7.1 Cost-effectiveness plane. 

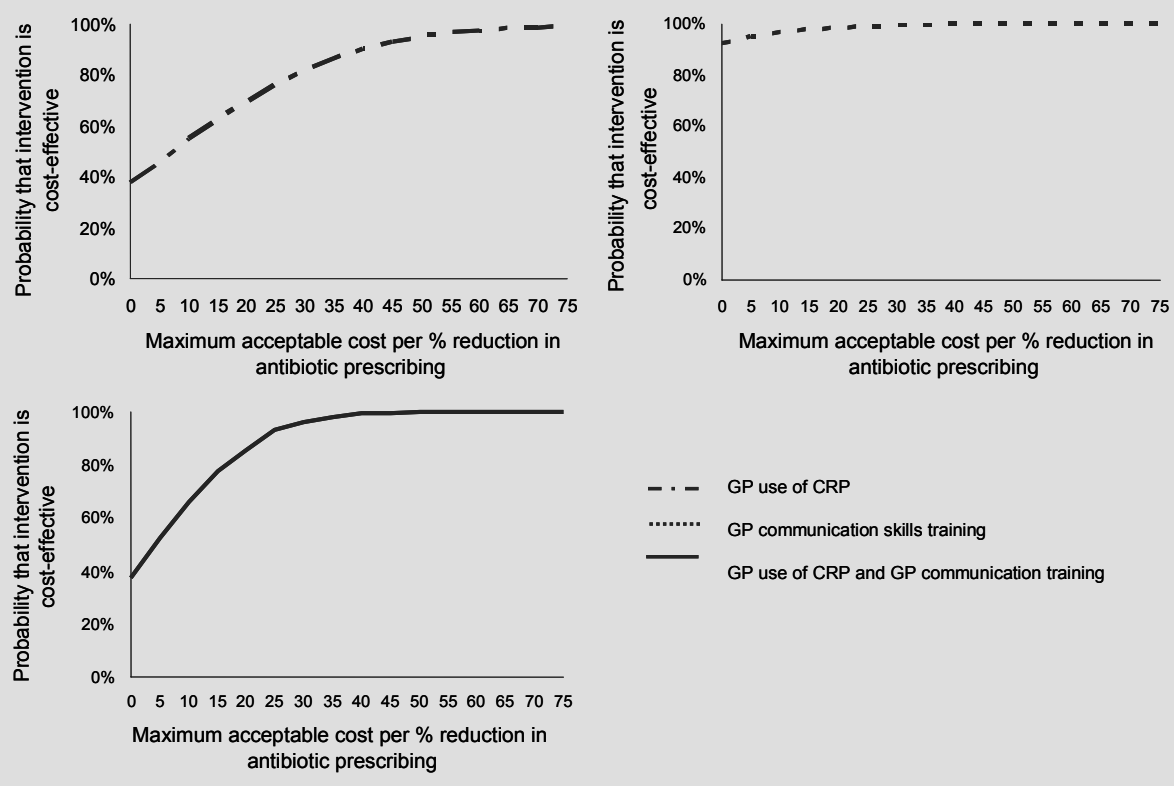

Figure 7.2 Cost-effectiveness acceptability curves for interventions versus usual care.

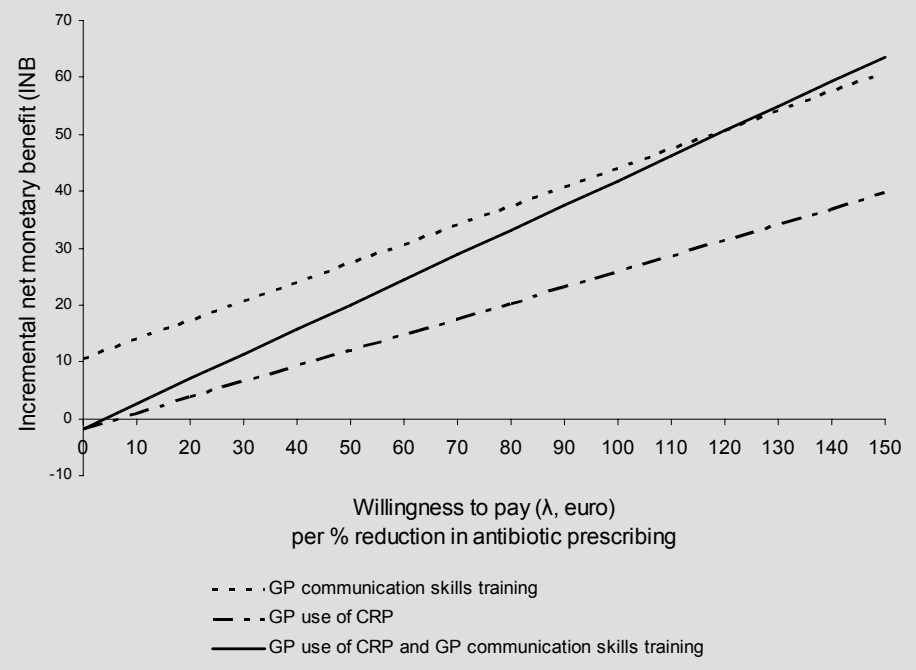

Figure 7.3 Incremental Net Monetary Benefit curves for interventions compared to usual care. 


\section{Sensitivity analyses}

We doubled the staff costs associated with intervention development and delivery in a first sensitivity analysis to a more commercial rate, which would be used when the interventions were to be more widely implemented. Costs related to the CRP intervention rose from $€ 4.72$ to $€ 5.12$ per patient and costs of the communication skills training increased from $€ 5.34$ to $€ 8.74$ per patient. Resulting new ICERs compared to usual care are provided in Table 7.6. GP communication skills training remained dominant. GP use of CRP had an ICER of $€ 7.21$ and GP use of both interventions $€ 12.19$.

Table 7.6 Sensitivity analyis showing incremental costs, effects and cost-effectiveness with double staff costs for the intervention.

\begin{tabular}{|c|c|c|c|c|}
\hline & $\begin{array}{l}\text { GP use of } \\
\text { CRP test }\end{array}$ & $\begin{array}{l}\text { GP } \\
\text { communication } \\
\text { skills training }\end{array}$ & $\begin{array}{l}\text { GP use of CRP } \\
\text { test \& GP } \\
\text { communication } \\
\text { skills training }\end{array}$ & Usual Care \\
\hline & $n=110$ & $n=84$ & $n=117$ & $n=120$ \\
\hline \multicolumn{5}{|l|}{ Effects } \\
\hline Antibiotic prescribing & 0.39 & 0.33 & 0.23 & 0.68 \\
\hline $\begin{array}{l}\text { Decrease in antibiotic } \\
\text { prescribing compared to } \\
\text { usual care }(\Delta E)\end{array}$ & 0.28 & 0.33 & 0.44 & $\mathrm{~N} / \mathrm{A}$ \\
\hline \multicolumn{5}{|l|}{ Costs } \\
\hline Total costs $(€)$ & $37.98(44.88)$ & $28.75(45.02)$ & $41.32(42.68)$ & $\begin{array}{l}35.96 \\
(58.12)\end{array}$ \\
\hline $\begin{array}{l}\text { Difference in total costs } \\
\text { compared to usual care }(\Delta C, €)\end{array}$ & 2.02 & -7.21 & 5.36 & $\mathrm{~N} / \mathrm{A}$ \\
\hline \multicolumn{5}{|l|}{ Cost-effectiveness } \\
\hline $\begin{array}{l}\text { Incremental cost-effectiveness } \\
\text { ratio; costs per \% decrease in } \\
\text { antibiotic prescribing compared to } \\
\text { usual care (before bootstrapping) }\end{array}$ & 7.21 & dominant & 12.19 & $\mathrm{~N} / \mathrm{A}$ \\
\hline
\end{tabular}

In a second sensitivity analysis the consequences of implementation strategies were further analysed. The base case analysis shows the costs and effects of the strategies in our trial (Table 7.5). Figure 7.4 shows four implementation scenarios:

- In scenario 1, all investment is directed towards communication skills training, yet only $50 \%$ of GPs trained in communication skills use the intervention (and the other $50 \%$ perform as usual care) Therefore, the NMB at a given $\lambda$ is lower than in Figure 7.3.

- Scenario 2 has the same assumption but for GP use of CRP. 
- Scenario 3 shows the INB curve for an implementation model where GPs are free to choose the intervention that is most appealing to them. In this scenario, we assume that $50 \%$ of GPs choose the illness-focused approach (communication skills training) and the remaining 50\% choose the diseasefocused approach (CRP testing). This scenario produces higher INB than scenario 1 from a willingness to pay of $€ 7$ or more.

In the final scenario, we modelled similar choices as scenario 3 but with a more conservative $80 \%$ implementation rate of the chosen interventions, so $20 \%$ of targeted GP receive the intervention of choice, but perform at level of usual care.

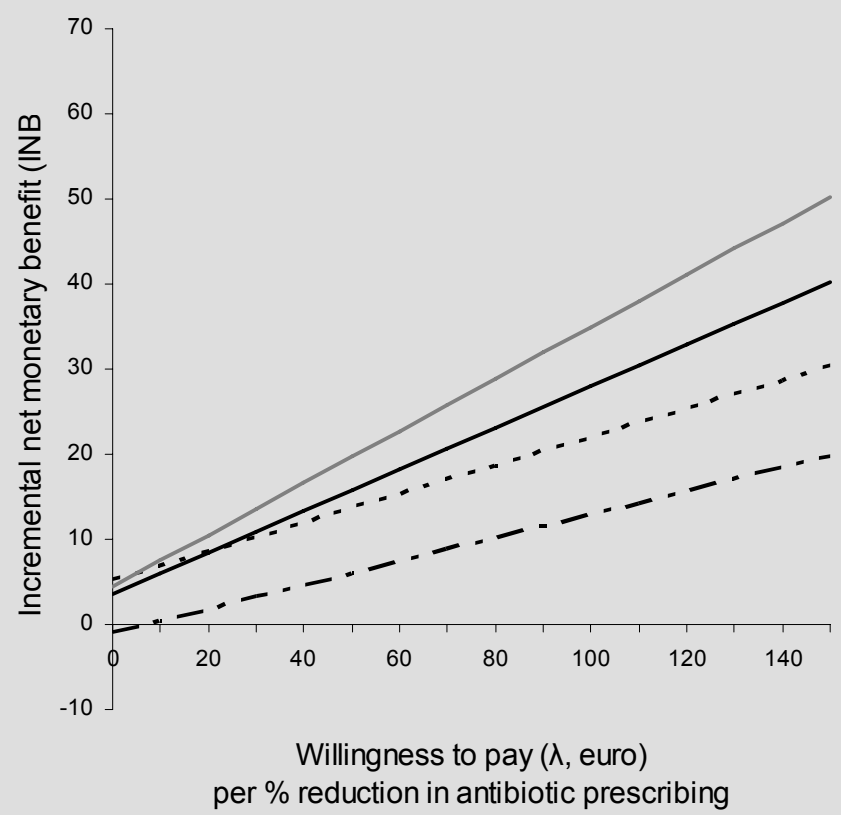

- - . Scenario 1: GP communication skills training if implementation is $50 \%$ succesful and other $50 \%$ of GPs perform as usual care

- - . Scenario 2: GP use of CRP if implementation is $50 \%$ succesful and other $50 \%$ of GPs perform as usual care

Scenario 3: If GPs are allowed to choose prefered intervention (50\% GPs implement Communication, $50 \%$ GPs implement CRP)

Scenario 4: same as scenario 3, total succesful implementation $80 \%$, so $20 \%$ of GPs perform as usual care

Figure 7.4 Sensitivity analysis: Incremental Net Monetary Benefit curves for implementation scenarios. 


\section{Discussion}

\section{Summary of main findings}

This study shows that communication skills training and clinician use of CRP point of care testing, as well as the combination of both interventions, are costeffective strategies to reduce antibiotic prescribing for LRTI in primary care. GP communication skills training only was superior to usual care, while the other two strategies are cost-effective at a very low willingness-to-pay.

\section{Methodological considerations, strengths and limitations}

Economic analysis of pragmatic trials is complex and challenging. We tried to overcome the difficulties of non-parametric distribution of cost data by using appropriate bootstrap techniques. ${ }^{22-24}$ We aimed to present an overview of the cost-effectiveness of three strategies compared to usual care. As it was a factorial design, we analysed and presented the clinical data in terms of the factorial (marginal) groups. ${ }^{12}$ However, the interpretation of this analysis with respect to the economic evaluation is complicated. We have therefore presented an analysis of the individual intervention groups results in this economic evaluation, in order to facilitate interpretation. We specifically chose not to use Quality Adjusted Life Years (QALY) and not to do a cost-utility analysis, as it is unreasonable to expect any difference in QALY for this typically short illness. Furthermore, the interventions aimed at avoiding unnecessary antibiotic prescriptions, which, if succeeded, would by definition not often lead to gain in individual health.

We were able to calculate incremental net monetary benefit (INB) curves, weighting effects (reduction in antibiotic prescribing) by defining net monetary benefits (NMB) using the maximum willingness to pay $(\lambda)$ for an effect, and subtracting the cost difference. Interpretation for the NMB is unambiguous, unlike the negative ICER. ${ }^{25}$ The NMB can easily be extended to more than two treatments. When comparing several treatments, the NMB is properly ordered. That is, a treatment with the largest NMB is considered the most cost effective. This unique approach also allowed us to model scenarios of implementation to inform policy makers and physicians on cost-effectiveness of interventions with GP preference as a variable.

We present findings from a health care perspective. Patients in all groups were off work for a similar mean duration. We have no indication that our intervention effected production loss or clinical recovery. ${ }^{12}$ Therefore, we chose to exclude these costs from the analysis instead of presenting them from the societal perspective. Another justification for this decision is the magnitude of these production loss costs compared to the small total mean management cost per patient in this trial, which was approximately $€ 30-40$. These costs of a cough 
related illness episode are similar to findings from a British acute cough study. ${ }^{26}$ Hence, the costs we included in our final analysis are from a health care perspective and included direct non-health care costs such as OTC medicines. We included OTC medication costs as these may be influenced by levels of antibiotic prescribing.

\section{Clinical implications and comparison with other literature}

The effects we found of the interventions on antibiotic prescribing in this trial are unprecedented, and could have profound consequences for containing antimicrobial resistance if replicated on an (inter)national scale. Crucially, patient outcomes were not affected by low antibiotic prescribing rates in the intervention groups. $^{12}$

There were favourable effects in all three intervention groups on antibiotic prescribing compared to usual care. The communication skills training intervention was the most cost effective of the three. Cost savings for this strategy arose mainly from fewer reconsultations and reductions in prescribed antibiotic and non-antibiotic medication. These findings are congruent with an intervention that sought to promote clinicians' understanding of the patients illness experience and to achieve shared decisions on treatment, while providing information on natural course and appropriate help seeking. ${ }^{17}$ Improved communication skills for managing LRTI may be beneficial in managing other conditions.

We assumed sustainability of the intervention effects over two years. Effects were similar when investigated separately by recruitment winter. Both interventions are likely to have a longer lasting effect on antibiotic prescribing, so our estimates are conservative. As we have no data on effects outside the trial period, we can only draw conclusions on cost-effectiveness for two years. Training may need to be repeated to ensure ongoing (cost)-effectiveness.

\section{Scenarios of implementation}

GPs may prefer one or other of the intervention styles, which may affect uptake. Different stakeholders in health care use different approaches to changing clinical practice; most of these approaches are insufficiently supported by rigorous evidence. Our communication skills training focused on the importance of change and on skills to implement this change in a practical, feasible way. Implementation of physician behaviour change strategies must consider barriers and enabling factors and GP preference to optimise outcome and net health benefits. $^{27,28}$ Uptake of CRP testing is influenced by system, patient and personal factors. ${ }^{29}$ An example of system factors is the time needed to perform a test within a consultation. Concerning the communication skills training intervention, several characteristics that facilitate or impede communication 
guideline uptake have been formulated and evidence suggests that implementation partly depends on preferred learning style..$^{30,31}$ The costs associated with the communication skills training were relatively low in this study. Should implementation on a larger scale be initiated, one needs to consider that labour costs and overhead costs for logistics in the training process may be higher than the costs per patient in this study. In our sensitivity analysis with double labour costs, communication skills training was still superior to usual care.

Combining CRP with the communication intervention is only acceptable from an economic point of view, if society is willing to pay more than $€ 121,70$ for a $1 \%$ reduction in antibiotic prescribing. The above expression is the same as willing to pay more than $€ 1217$ for a $10 \%$ reduction, or a willing to pay of more than $€ 3651$ for a $30 \%$ reduction for that matter, a level that is reached in this study. Although we did not further investigate societal willingness to pay, we doubt that this is a reasonable level, in which case the 'illness focused' communication skills training is the most cost-effective strategy. If society is willing to invest in the 'disease focused approach', CRP testing ${ }^{32}$, a $30 \%$ reduction in antibiotic prescribing would require an investment of $€ 173,40$. And although CRP is less cost effective than communication skills training, further analyses revealed that CRP could play an important role under various implementation scenarios.

We therefore modelled several scenarios of possible intervention uptake by GPs. For clarity purposes we chose not to display percentile lines in the INB curves in Figure 7.2 and 7.3. Although one may conclude from Figure 7.2 that communication skills training should be offered to all GPs to achieve maximum NMB (even at $\lambda=0$ ), scenario 3 and 4 (Figure 7.3) show us that if GPs preferences guide optimal uptake, greater NMB will be achieved compared to a suboptimal uptake when GPs preferences and characteristics are not taken into account. However, even when GPs may choose interventions, implementation is unlikely to be complete. We therefore constructed scenario 4 with characteristics similar to scenario 3 , but with an $80 \%$ successful implementation rate, the remaining $20 \%$ of trained GPs performing as usual care. Bottom line of the scenarios is that the studied interventions are cost-effective (yielding NMB at no willingness-to-pay) if we take into account GPs preferences and at least $15 \%$ of GPs choose to follow the communication skills training.

Between 150000 to 240000 antibiotic prescriptions could be avoided annually in the Netherlands if either of the study strategies were implemented nationally, depending on scenario and level of implementation. This potential gain in antibiotic prescription reduction is particularly significant, given its context; the Netherlands is one of the lowest antibiotic prescribing countries worldwide. ${ }^{33}$ Different scenarios can be constructed; the scenarios we presented represent examples. We are unaware of the preferences of GPs regarding implementation of these illness- and disease-focused interventions. Models, like the ones we 
present in Figure 7.3, can be drafted according to actual preference. Essentially, we think it is crucial to combine evidence-based medicine with evidence-based implementation. ${ }^{28,34}$ The presented approach contributes to this process.

\section{Implications for clinical practice and research}

These results indicate that communication skills training and CRP point of care testing are cost-effective. Qualitative research indicates that diagnostic uncertainty and difficulties in efficiently managing patient ideas, concerns and expectations are drivers of inappropriate prescribing among general practitioners. ${ }^{35}$ Studies of implementation and uptake are therefore now needed. ${ }^{10}$ We regarded costs associated with increasing antimicrobial resistance as intangible, so consequences of excessive prescribing including costs are difficult to predict and model. Yet, even without taking these costs into account we demonstrated that positive NMB could be achieved at no willingness to pay. Antibiotic prescribing in primary care is a driver of antibiotic resistance. ${ }^{36}$ Moreover, the use of broad-spectrum antibiotics is increasing, which compounds the problem. ${ }^{37,38}$ The costs associated with bacterial resistant bacteria are considerable. For example, restrictive and preventive measures for Meticillin Resistant Staphylococcus Aureus in one average Dutch hospital costs approximately $€ 280000$ per year. ${ }^{39}$

Given that there is a limited pipeline of new antibiotics, cost effectiveness data on effective interventions aimed at containing antibiotic resistance through improved prescribing are particularly important. ${ }^{14,40,41}$ We have presented two feasible, acceptable and applicable strategies to target inappropriate antibiotic prescribing for LRTI. From the health care perspective (including OTC costs), the two interventions, singly or combined, are cost-effective at a low willingness to pay. If GP preferences are taken into account when implementing these interventions, investment can be optimised and a higher net monetary benefit can be expected. 


\section{Appendix 1: Definitions of Economic Terms}

\section{Net Benefit (NB)}

NB is an alternative method (alternative to the ICER) to present the results of an economic evaluation. In essence it is the absolute difference between benefits and cost (benefits minus costs) and therefore can only be calculated if benefits are expressed in the same unit as costs. Theoretically costs could be expressed in equivalent units of health gain or loss, which is than called Net Health Benefit, but in general benefits are expressed in monetary terms, often referred to as Net Monetary Benefit.

\section{Net Monetary Benefit (NMB)}

When outcomes are expressed in money terms and costs are subtracted this would result in a NMB, in formula:

$\mathrm{NMB}=\mathrm{H}^{*} \mathrm{~V}-\mathrm{C}$

Where:

$\mathrm{H}$ : Units of health outcomes

$\mathrm{V}$ : Price (value) of one unit of outcome

C: Costs

\section{Incremental Net Benefit (INB)}

The difference between the NB of two alternative programs.

\section{Incremental cost-effectiveness ratio (ICER)}

If there are two alternative programs the difference in cost (incremental cost) is divided by the difference in outcome (incremental effect). This ratio can be interpreted as the amount of money that is needed to produce one extra unit of outcome and is therefore an efficiency parameter.

\section{Dominance}

An intervention dominates another intervention if such an intervention is both more effective and less costly than the other intervention. If there are multiple possible interventions to choose from, a dominated (inferior) intervention can be neglected. 


\section{Willingness to pay (WTP)}

If a good or service has no price, for instance in health care, using WTP is a way to measure preferences. When this preference is expressed in monetary terms, it can be considered as the value or price of such a good and can be used to determine the NMB of this good. 


\section{References}

1. Macfarlane J, Holmes W, Gard P, Macfarlane R, Rose D, Weston V, Leinonen M, Saikku P, Myint S. Prospective study of the incidence, aetiology and outcome of adult lower respiratory tract illness in the community. Thorax 2001;56:109-14.

2. Schappert SM, Burt CW. Ambulatory care visits to physician offices, hospital outpatient departments, and emergency departments: United States, 2001-02. Vital Health Stat 13 2006: $1-66$.

3. Woodhead M, Blasi F, Ewig S, Huchon G, leven M, Ortqvist A, Schaberg T, Torres A, van der Heijden G, Verheij TJ; European Respiratory Society; European Society of Clinical Microbiology and Infectious Diseases. Guidelines for the management of adult lower respiratory tract infections. Eur Respir J 2005;26:1138-80.

4. Avorn J, Solomon DH. Cultural and Economic Factors That (Mis)Shape Antibiotic Use: The Nonpharmacologic Basis of Therapeutics. Ann Intern Med 2000;133:128-35.

5. Fleming DM, Smith GE, Charlton JR, Charlton J, Nicoll A. Impact of infections on primary care--greater than expected. Commun Dis Public Health 2002;5:7-12.

6. Hopstaken RM, Muris JWM, Knottnerus JA, Kester ADM, Rinkens PELM, Dinant GJ. Contributions of symptoms, signs, erythrocyte sedimentation rate and C-reactive protein to a diagnosis of pneumonia in acute lower respiratory tract infection. Br J Gen Pract 2003;53: 358-64.

7. Butler CC, Rollnick S, Kinnersley P, Jones A, Stott N. Reducing antibiotics for respiratory tract symptoms in primary care: consolidating 'why' and considering 'how'. $\mathrm{Br} \mathrm{J}$ Gen Pract 1998;48:1865-70.

8. Little P, Gould C, Williamson I, Warner G, Gantley M, Kinmonth AL. Reattendance and complications in a randomised trial of prescribing strategies for sore throat: the medicalising effect of prescribing antibiotics. BMJ 1997;315:350-2.

9. Cals JWL, Boumans D, Lardinois RJM, Gonzales R, Hopstaken RM, Butler CC, Dinant GJ. Public beliefs on antibiotics and respiratory tract infections: an internet-based questionnaire study. Br J Gen Pract 2007;57:942-7.

10. Cosby JL, Francis N, Butler CC. The role of evidence in the decline of antibiotic use for common respiratory infections in primary care. Lancet Infect Dis 2007;7:749-56.

11. Cals JW, Hopstaken RM, Butler CC, Hood K, Severens JL, Dinant GJ. Improving management of patients with acute cough by C-reactive protein point of care testing and communication training (IMPAC3T): study protocol of a cluster randomised controlled trial. BMC Fam Pract 2007;8:15.

12. Cals JWL, Butler CC, Hopstaken RM, Hood K, Dinant GJ. Effect of C-reactive protein point of care testing and clinician communication skills training on antibiotic use and patient recovery in lower respiratory tract infections: a cluster randomised trial. BMJ 2009;in press.

13. Finch R, Hunter PA. Antibiotic resistance--action to promote new technologies: report of an EU Intergovernmental Conference held in Birmingham, UK, 12-13 December 2005 J. Antimicrob. Chemother. 2006;58(S1):i3-22.

14. Metlay JP, Powers JH, Dudley MN, Christiansen K, Finch RG. Antimicrobial drug resistance, regulation, and research. Emerg Infect Dis 2006;12:183-90.

15. Verheij TJM, Salomé PL, Bindels PJ, Chavannes AW, Ponsioen BP, Sachs APE, et al. NHGStandaard Acuut hoesten. [Dutch College of General Practitioners Guidelines on Acute Cough]. Huisarts Wet 2003;46:496-506.

16. Rollnick S, Kinnersley $\mathrm{P}$, Butler $\mathrm{C}$. Context-bound communication skills training: development of a new method. Med Educ 2002;36:377-83.

17. Cals JW, Scheppers NA, Hopstaken RM, Hood K, Dinant GJ, Goettsch H, Butler CC. Evidence based management of acute bronchitis; sustained competence of enhanced communication skills acquisition in general practice. Patient Educ Couns 2007;68:270-8.

18. Goossens MEJB, Molken MPMHR-v, Vlaeyen JWS, van der Linden SMJP. The cost diary: a method to measure direct and indirect costs in cost-effectiveness research. Journal of Clinical Epidemiology 2000;53:688-95. 
19. Oostenbrink JB, Bouwmans CAM, Koopmanschap MA, Rutten FFH. Handleiding kostenonderzoek. Amstelveen: College voor zorgverzekeringen, 2004.

20. Barlow GD, Lamping DL, Davey PG, Nathwani D. Evaluation of outcomes in communityacquired pneumonia: a guide for patients, physicians, and policy-makers. The Lancet Infectious Diseases 2003;3:476-88.

21. Hak E, Rovers MM, Kuyvenhoven MM, Schellevis FG, Verheij TJ. Incidence of GP-diagnosed respiratory tract infections according to age, gender and high-risk co-morbidity: the Second Dutch National Survey of General Practice. Fam Pract 2006;23:291-4.

22. Thompson SG, Barber JA. How should cost data in pragmatic randomised trials be analysed? Bmj 2000;320:1197-200.

23. Briggs $\mathrm{AH}$, Wonderling $\mathrm{DE}$, Mooney $\mathrm{CZ}$. Pulling cost-effectiveness analysis up by its bootstraps: a non-parametric approach to confidence interval estimation. Health Econ 1997;6:327-40.

24. Campbell MK, Torgerson DJ. Bootstrapping: estimating confidence intervals for costeffectiveness ratios. Qjm 1999;92:177-82.

25. Dinh $\mathrm{P}$, Zhou $\mathrm{XH}$. Nonparametric statistical methods for cost-effectiveness analyses. Biometrics 2006;62:576-88.

26. Hollinghurst $S$, Gorst C, Fahey T, Hay AD. Measuring the financial burden of acute cough in pre-school children: a cost of illness study. BMC Fam Pract 2008;9:10.

27. Grol R. Personal paper. Beliefs and evidence in changing clinical practice. BMJ 1997;315:41821.

28. Grol R, Grimshaw J. From best evidence to best practice: effective implementation of change in patients' care. Lancet 2003;362:1225-30.

29. Butler CC, Simpson S, Wood F. General practitioners' perceptions of introducing near-patient testing for common infections into routine primary care: a qualitative study. Scand J Prim Health Care 2008;26:17-21.

30. Veldhuijzen W, Ram PM, van der Weijden T, Niemantsverdriet S, van der Vleuten CP. Characteristics of communication guidelines that facilitate or impede guideline use: a focus group study. BMC Fam Pract 2007;8:31.

31. Goossens A, Bossuyt PM, de Haan RJ. Physicians and nurses focus on different aspects of guidelines when deciding whether to adopt them: an application of conjoint analysis. Med Decis Making 2008;28:138-45.

32. Nordberg P, Monnet DL, Cars O. Antibacterial drug resistance: options for concerted action. World Health Organization Department of Medicines Policy and Standards. Geneva, 2005:148.

33. Goossens H, Ferech M, Coenen S, Stephens P. Comparison of outpatient systemic antibacterial use in 2004 in the United States and 27 European countries. Clin Infect Dis 2007;44:1091-5.

34. Knottnerus JA, Dinant GJ. Medicine based evidence, a prerequisite for evidence based medicine. BMJ 1997;315:1109-10.

35. Wood F, Simpson S, Butler CC. Socially responsible antibiotic choices in primary care: a qualitative study of GPs' decisions to prescribe broad-spectrum and fluroquinolone antibiotics. Fam Pract 2007;24:427-34.

36. Goossens H, Ferech M, Vander Stichele R, Elseviers M. Outpatient antibiotic use in Europe and association with resistance: a cross-national database study. Lancet 2005;365:579-87.

37. Kuyvenhoven MM, Van Balen FA, Verheij TJ. Outpatient antibiotic prescriptions from 1992 to 2001 in The Netherlands. J Antimicrob Chemother 2003;52:675-8.

38. Steinman MA, Gonzales R, Linder JA, Landefeld CS. Changing Use of Antibiotics in Community-Based Outpatient Practice, 1991-1999. Ann Intern Med 2003;138:525-33.

39. MRSA policy in the Netherlands, Health Council of the Netherlands, publication no. 2006/17. In: Netherlands HCot, editor, 2006:publication no. 2006/17.

40. Wenzel RP. The antibiotic pipeline--challenges, costs, and values. N Engl J Med 2004;351:523-6.

41. Wise R. Antimicrobial resistance: paradox, actions and economics. J. Antimicrob. Chemother. 2006;57:1024-5. 



\section{Predictors of patient-initiated reconsultation for lower respiratory tract infections in general practice}

Jochen Cals, Kerenza Hood, Nienke Aaftink, Rogier Hopstaken, Nick Francis, Geert-Jan Dinant, Christopher Butler British Journal of General Practice 2009;59:761-4 


\section{Abstract}

Reconsultation for lower respiratory tract infection (LRTI) is common in general practice, but those who reconsult rarely have more significant illness warranting antibiotics. Knowledge of factors that predict patient-initiated reconsultation may allow clinicians to address specific issues during the initial consultation that could reduce reconsultations. $33 \%$ of a cohort of $431 \mathrm{LRTI}$ patients in a RCT reconsulted. Excluding 35 with GP-requested reconsultation left $28 \%(112 / 396)$ with a patientinitiated reconsultation during 28-day follow up. Patient-reported dyspnoea and concerns that persisted after the initial consultation independently predicted patient-initiated reconsultation.

\section{How this fits in?}

Lower respiratory tract infection (LRTI) accounts for considerable workload in general practice. Reconsultation is common, and may often be unnecessary in that no further treatment is indicated apart from reassurance. Understanding the predictors of reconsultation may help clinicians appropriately modify help-seeking behaviour and could potentially reduce workload through promotion of appropriate self-care. Patient-reported dyspnoea and concerns persisting beyond the initial consultation independently predicted patient-initiated reconsultation. Patients with intermediately elevated levels of C-reactive protein were also more likely to reconsult. 


\section{Introduction}

Reconsulting for lower respiratory tract infections (LRTI) is common in general practice, and may often be unnecessary. ${ }^{1-3}$ This increases workload and puts patients at risk for unnecessary antibiotic prescribing. Reconsultation can either be requested by the physician - for a check-up after the initial consultation - or initiated by the patient. Knowledge of factors that predict patient-initiated reconsultation may allow clinicians to address specific issues during the initial consultation that could make reconsultations unnecessary.

\section{Method}

We conducted a secondary analysis of data from 431 patients enrolled into a pragmatic cluster-randomised factorial trial investigating the effect of general practitioner (GP) use of C-reactive protein (CRP) point of care testing and GP training in enhanced communication skills on antibiotic prescribing for LRTI in general practice. ${ }^{4,5}$

GPs made their own decisions about diagnostic procedures and treatment, including whether to prescribe antibiotics or to request a follow up consultation. GPs were informed that CRP was an additional diagnostic tool to complement findings from medical history taking and physical examination. Extensive information on the training in the use of point of care CRP testing and enhanced communication training can be found elsewhere. ${ }^{4,5}$ Reconsultation data for the 28-day follow-up was obtained from patients' medical records and were crosschecked with patient diary data. Patient-initiated reconsultation was defined as any LRTI related reconsultation within 28 days after the first consultation not specifically requested by the managing GP.

Demographical, clinical and psychosocial variables possibly associated with patient-initiated reconsultation were predefined by the study team and are shown in Table 8.1. Post-consultation worries were assessed by a Likert type scale diary question. The association of these variables with patient initiated reconsultation was assessed with chi-square tests in univariate analysis. Variables with $p$-values $\leq 0.20$ were selected for multilevel logistic regression analysis and odds ratios $(\mathrm{OR})$ with $95 \%$ confidence intervals $(\mathrm{Cl})$ are presented. Analyses were by a three level model to account and correct for variation at the level of the practice, GP and patient. ${ }^{4}$ In a second model, CRP categories with measured values at baseline were added to the multiple regression model (available for 227 patients). All models were corrected for the intervention effects, including the interaction term as in the primary analysis. ${ }^{4}$ Data were analysed using SPSS 13.0 and Mlwin 2.0. 


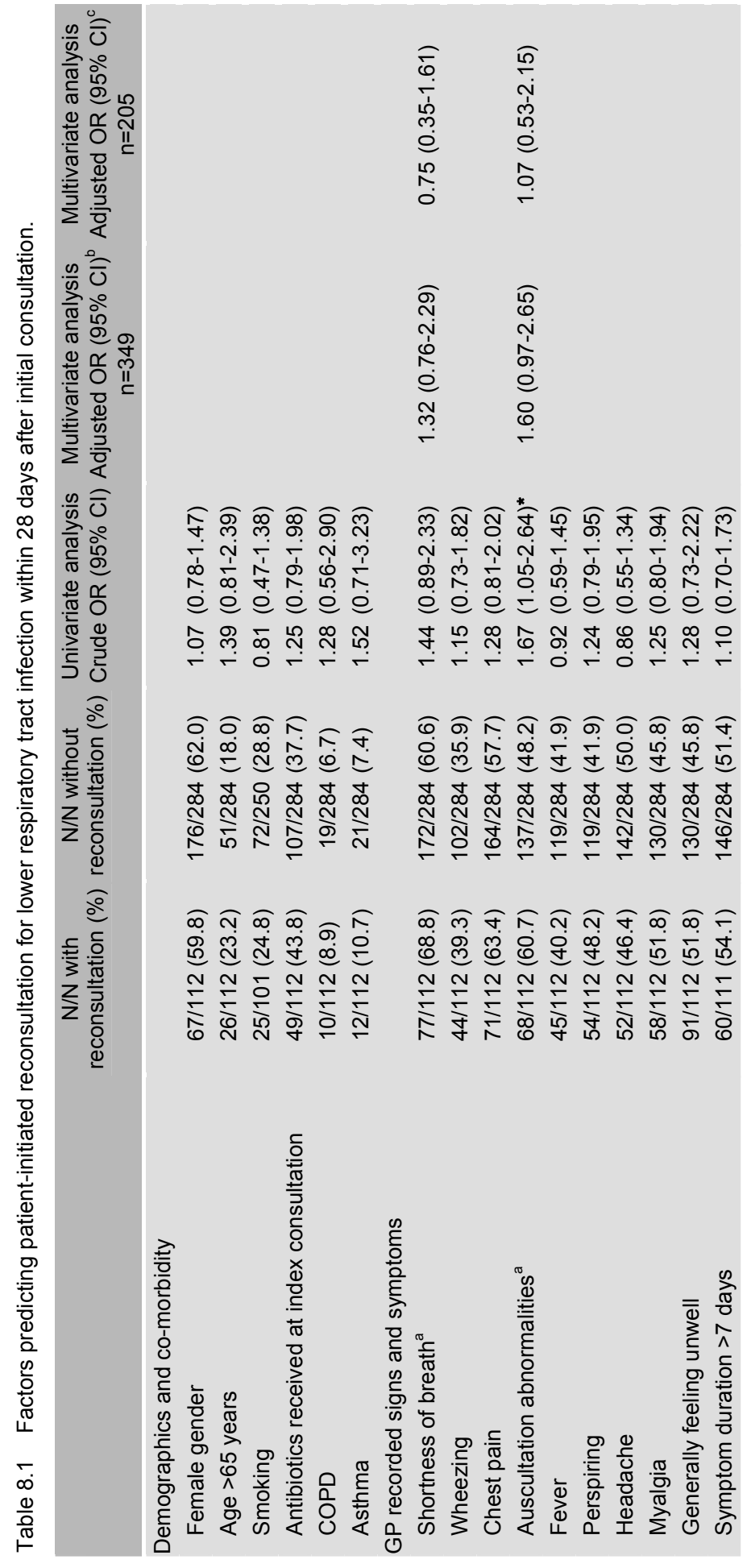




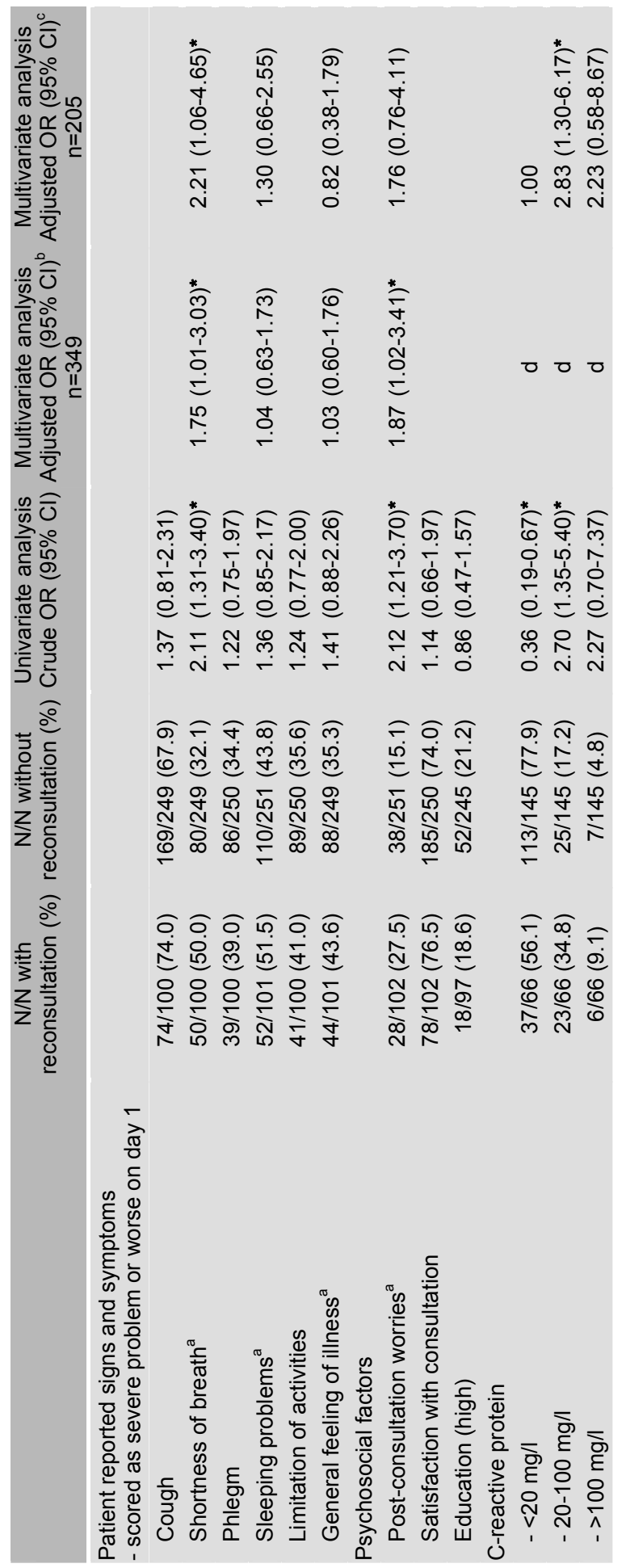

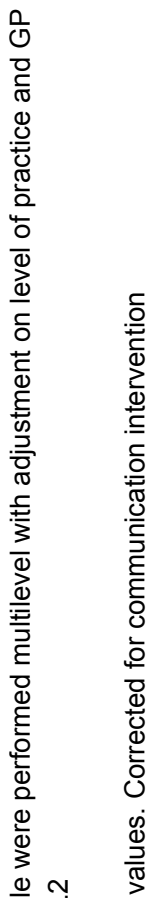

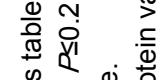
兵

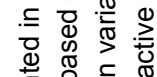

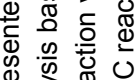

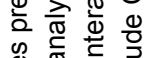

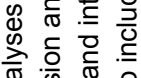
ते $\frac{0}{\mathrm{~N}}$ ㄷำ ते

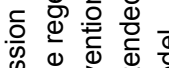

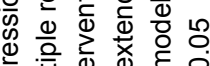
क्षे

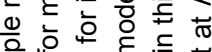

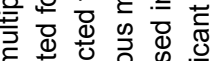

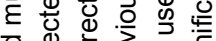
๙

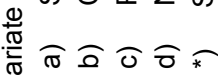
초 


\section{Results}

The reconsultation rate in the total study population was $32.7 \%$. After exclusion of patients with GP-initated reconsultations $(n=35)$, data of 396 patients were available, of which $112(28.2 \%)$ reconsulted during the 28-day follow-up period. Of these 112 patients, 48 (43\%) were prescribed antibiotics on reconsultation (of which 12 received a second course of antibiotics). Hence, a total of 85 of $112(76 \%)$ reconsulting patients received antibiotics throughout their LRTI episode. Table 8.1 shows the associations of the predefined variables with patient-initiated reconsultation. Reconsultation was univariately associated with auscultation abnormalities and shortness of breath as recorded by the GP, and three patient rated symptoms on day 1. Ongoing concerns after the initial consultation was most strongly associated with patient initiated reconsultation (OR $2.12,95 \% \mathrm{Cl} 1.21-3.70)$. Subsequent multiple regression analysis showed that patients who reported severe dyspnoea on day 1 (OR $1.75,95 \% \mathrm{Cl} 1.03-$ 3.03 ) and those with ongoing post-consultation concerns (OR $1.87,95 \% \mathrm{Cl}$ 1.03-3.41) were more likely to revisit their GP during the 28 days following their first consultation for their LRTI. In the subset of patients for whom CRP was measured, CRP values greater than $20 \mathrm{mg} / \mathrm{l}$ in general, and intermediately elevated results $(21-100 \mathrm{mg} / \mathrm{l}$, OR $2.83,95 \% \mathrm{Cl} 1.30-6.17)$ in particular were additional independent predictors of reconsultation. Ongoing concerns after the initial consultations were not significant in the model. However, this was due to the widening confidence interval associated with the smaller sample size and the point estimate of the odds ratio remained nearly unchanged.

\section{Discussion}

Identifying one or more of the factors predictive of patient initiated reconsultation during an initial consultation for acute cough may prompt GPs to provide more information to the patient and further discuss symptoms and the usual clinical course of the condition. In our study, patient reported dyspnoea strongly predicted patient initiated reconsultation, confirming the findings of Holmes and colleagues. ${ }^{1}$ We know from findings in chronic pulmonary disease patients that dyspnoea contributes to discomfort and anxiety. ${ }^{6}$ Interestingly, and in line with previous findings, no antibiotics received at index consultation was not associated with patient initiated reconsultation, suggesting that patients may mainly be seeking symptom relief or reassurance when reconsulting. ${ }^{1,7,8}$

Addressing both unnecessary reconsultation and antibiotic prescribing is required to optimise management of respiratory tract infections in general practice ${ }^{9}$, and the two issues are closely interrelated. Fewer reconsultations for LRTI decreases workload and will decrease antibiotic prescribing for patients 
who are at particular risk of unnecessary antibiotic prescribing during reconsultations. Nearly half of all patients were prescribed antibiotics during patient initiated reconsultations, despite evidence suggesting that they are unlikely to benefit at the point of reconsultation, except for a minority of patients with evident deteriorating illness. ${ }^{3}$ Antibiotic prescribing during reconsultations - as well as at the index consultation - encourages patients to assume recovery is caused by the antibiotics which encourages future consultations.

Reconsultation behaviour may be culturally determined and may differ between countries. Yet our findings and overall reconsultation rate from the Dutch context are in line with the limited available evidence in this field. ${ }^{1,2}$ Because of our broad inclusion criteria, a wide range of LRTI patients from general practice were included in this study. The patient-reported variables that were included in our models may shed light on non-medical influences affecting help seeking behaviour in LRTI. The chance of attrition bias in our study was minimal as we had a follow-up rate of $90 \%$ on patient-reported outcomes. ${ }^{4}$ This study was powered for group comparisions in the trial rather than for this analysis, however the sample size achieved gives adequate power $(80 \%)$ to detect an OR of 2 at a $5 \%$ significance level. ${ }^{10}$ When the analysis of the subset of patient with CRP values was analysed, similar point estimates were obtained for the other factors in the model, but they were no longer significant.

Concerns regarding the potential medicalising effect of point of care testing have been expressed. ${ }^{11,12}$ Our primary analysis showed no association between CRP testing and reconsultation, and no association with future intention to reconsult for similar symptoms. ${ }^{4}$ Patients with a low CRP value are probably reassured about their illness. Patients with high CRP values $(>100 \mathrm{mg} / \mathrm{l})$ are likely to receive an antibiotic, and may most likely benefit from antibiotic treatment. Yet, patients with intermediately elevated CRP values $(24 \%$ of patients with measured CRP in the study) may not be reassured by this result. Indeed, an intermediate CRP test result may increase anxiety, resulting in requests for re-assessment. But elevated CRP could also be an indicator of intermediate illness, as some patients with elevated CRP values may deteriorate and therefore reconsult. Yet, we did not find an influence of CRP level on recovery, with a median patient reported time to full recovery of 22 days for the full group. In cases with elevated CRP, a follow-up CRP test result may guide both the GP as well as the patient towards further management: antibiotics or even referral in cases of severe deterioration and increased CRP levels or reassurance in cases of clinical improvement and reduced CRP levels. The delayed prescription strategy, commonly used in the UK but not in the Netherlands, might be particularly suited to preventing these reconsultations without unnecessarily increasing antibiotic prescribing in this group of patients with intermediately elevated CRP values. All together, this stresses the 
importance of explanation provided to the patient on the implications of CRP values.

Communication remains a cornerstone of quality management of LRTI and this includes communication about point of care tests. Eliciting concerns and expectations is associated with less medication prescribing, both in general and in antibiotic prescribing decisions in particular. ${ }^{4,13}$ Moreover, describing the often longer than realised natural course of LRTI and addressing ongoing patient concerns may lead to fewer reconsultations. Finally, it may also be enlightening to realise that not prescribing antibiotics at index consultation does not mean that patients are more likely to reconsult. 


\section{References}

1. Holmes WF, Macfarlane JT, Macfarlane RM, Lewis S. The influence of antibiotics and other factors on reconsultation for acute lower respiratory tract illness in primary care. $\mathrm{Br} \mathrm{J}$ Gen Pract 1997;47:815-8.

2. Macfarlane J, Holmes W, Gard P, Macfarlane R, Rose D, Weston V, Leinonen M, Saikku P, Myint S. Prospective study of the incidence, aetiology and outcome of adult lower respiratory tract illness in the community. Thorax 2001;56:109-14.

3. Macfarlane J, Prewett J, Rose D, Gard P, Cunningham R, Saikku P, Euden S, Myint S. Prospective case-control study of role of infection in patients who reconsult after initial antibiotic treatment for lower respiratory tract infection in primary care. BMJ 1997;315: 1206-10.

4. Cals JW, Butler CC, Hopstaken RM, Hood K, Dinant GJ. Effect of point of care testing for C reactive protein and training in communication skills on antibiotic use in lower respiratory tract infections: cluster randomised trial. BMJ 2009;338:b1374.

5. Cals JW, Hopstaken RM, Butler CC, Hood K, Severens JL, Dinant GJ. Improving management of patients with acute cough by C-reactive protein point of care testing and communication training (IMPAC3T): study protocol of a cluster randomised controlled trial. BMC Fam Pract 2007;8:15.

6. Bailey PH. The dyspnea-anxiety-dyspnea cycle--COPD patients' stories of breathlessness: "It's scary /when you can't breathe". Qual Health Res 2004;14:760-78.

7. van Driel ML, De Sutter A, Deveugele M, Peersman W, Butler CC, De Meyere M, De Maeseneer J, Christiaens T. Are sore throat patients who hope for antibiotics actually asking for pain relief? Ann Fam Med 2006;4:494-9.

8. Welschen I, Kuyvenhoven M, Hoes A, Verheij T. Antibiotics for acute respiratory tract symptoms: patients' expectations, GPs' management and patient satisfaction. Fam Pract 2004;21:234-7.

9. Francis N, Butler C, Hood K, Simpson S, Wood F, Nuttall J. Use of an interactive booklet on childhood respiratory tract infections in primary care consultations: a cluster randomised controlled trial. BMJ 2009;in press.

10. Demidenko E. Sample size determination for logistic regression revisited. Stat Med 2007;26:3385-97.

11. Hay AD, Juttner KV. Antibiotics for acute cough in primary care. BMJ 2009;338:b834.

12. Hobbs FD, Kenkre JE, Carter YH, Thorpe GH, Holder RL. Reliability and feasibility of a near patient test for C-reactive protein in primary care. BMJ 1996;46:395-400.

13. Matthys J, Elwyn G, Van Nuland M, Van Maele G, De Sutter A, De Meyere M, Deveugele M. Patients' ideas, concerns, and expectations (ICE) in general practice: impact on prescribing. Br J Gen Pract 2009;59:29-36. 




\section{Abstract}

\section{Objectives}

To explore general practitioners' (GP) attitudes to and experiences of introducing C-reactive protein (CRP) point of care testing (POCT) for lower respiratory tract infections (LRTI) in primary care.

\section{Methods}

Semi-structured interview study with $20 \mathrm{GPs}$ who participated in the IMPAC ${ }^{3} \mathrm{~T}$ randomised trial evaluating the effect of GP use of CRP POCT on management of LRTI. Main outcomes were GPs' experiences and views about CRP POCT in general practice, including its role in guiding antibiotic prescribing decisions, and applicability and implementation in daily practice.

\section{Results}

GPs expressed mainly positive attitudes. Test results were rapidly available to support diagnostic and therapeutic processes for LRTI and other common infections, enhancing patient and GP confidence in prescribing decisions and empowering GPs to prescribe antibiotics less often. GPs were concerned about responding to ambiguous test results. They regarded financial reimbursement for using the test as essential for successful uptake, and requested that treatment guidelines be updated to include use of the test.

\section{Conclusion}

GPs were generally positive about CRP POCT, and they felt it empowered them to safely prescribe fewer antibiotics for LRTI without alienating their patients. Successful wider implementation should address reimbursement and updating management guidelines to include the place of CRP POCT. 


\section{Introduction}

Quantitative as well as qualitative studies have identified factors that may contribute to inappropriate antibiotic prescribing by general practitioners (GPs). ${ }^{1-6}$ The often-difficult diagnostic and prescribing decisions in LRTI in general practice call for new approaches to reduce antibiotic use without compromising patient safety.

C-reactive protein is a well-known diagnostic marker that helps differentiate serious infections like pneumonia, sepsis and acute appendicitis from selflimiting illnesses. There is evidence to support its use in primary care, especially for lower respiratory tract infection (LRTI). ${ }^{7-10}$ Improved diagnosis and associated prescribing decisions have far-reaching consequences, as at least $80 \%$ of patients presenting with LRTI have acute bronchitis which is not helped by antibiotic treatment. ${ }^{11}$ CRP test results can only influence initial antibiotic prescribing decisions if they are available at the point of the prescribing decision within the consultation. CRP point of care (POCT) measurements are valid and robust in general practice. ${ }^{12,13}$

The effectiveness of CRP POCT in reducing antibiotic prescribing for LRTI has recently been demonstrated in a randomised trial. ${ }^{14}$ However, to accomplish sustained evidence-based use of the test and uptake by practising clinicians, we need more insight on the actual experiences of GPs who introduced POCT CRP testing into their practice.

We therefore aimed to use the opportunity of the randomised controlled trial of the introduction of CRP POCT use in general practice to gain insight into GPs' attitudes to and experiences of using the test for LRTI and other common infections in general practice. We hoped that identifying the perceptions of barriers and opportunities to uptake among those who had recently started using the test would help develop plans for successful wider implementation into routine clinical care for the benefit of patients.

\section{Subjects and methods}

\section{Subjects}

Twenty GPs from ten general practices in Southeast Netherlands participated in individual, face-to-face interviews. These GPs took part in the IMPAC ${ }^{3} T$ study (ISRCTN85154857), a factorial, cluster randomised controlled trial assessing the effect of CRP point of care testing and enhanced physician communication skills training, separately or combined, on antibiotic prescribing for LRTI. In this trial, 20 GPs received a CRP test device, practice nurses were trained in its use and GPs were given guidance on the interpretation of results. ${ }^{15}$ Full clinical 
outcomes have been reported. ${ }^{14}$ The participating GPs had no prior experience with the CRP POCT prior to the trial, but had been using the test for nearly three years by the time we conducted the present qualitative evaluation. CRP tests were provided free of charge to participating GPs during, but not after, patient recruitment for the trial. At the time of the interview, GPs were unaware of the trial results. All GPs provided written consent to participate in this study. Ethical approval for the trial was obtained from the Ethics Committee of Catharina Hospital in Eindhoven, The Netherlands. The committee did not consider that separate ethical approval was required for this interview study.

\section{Study design}

We chose a qualitative study design, as our goal was to explore respondent's beliefs and understanding of the experiences and opinions of the GPs. ${ }^{16}$ GPs were aware that the purpose of the interview was to explore attitudes and experiences and not to audit practice.

Two trained interviewers (FC and $\mathrm{ML}$ ) conducted the semi-structured interviews using an interview guide. The interview guide was pilot-tested in a video taped interview with a GP from our research group. All questions were open. The topic guide underwent iterative revisions as the interview process progressed and new insights emerged. The interviews took place in the GPs' surgeries during the first winter after patient recruitment (2008), and each typically lasted about 30 minutes.

Questions covered three themes; general experience with the test, influence of the use of CRP testing on antibiotic prescribing for LRTI and influence of the use of CRP testing on everyday consultations for other illnesses. We aimed to interview all predefined 20 GPs regardless of the timing of the point where no new items within themes would emerge.

\section{Analysis}

An experienced typist transcribed the audio taped interviews verbatim according to a protocol. The anonymised transcripts were used as a basis for analysis and were read in detail by $\mathrm{FC}, \mathrm{ML}$ and $\mathrm{JC}$. Analysis and data collection were conducted in parallel, assisted by the software package Nvivo. Coding schedules were agreed and piloted. Reliability was assured by coding $70 \%$ of the data by more than one researcher. Disagreements between coders were resolved by discussion. In case of persisting disagreement, a third decisive coder (JC) was consulted who made the final decision. A thematic content analysis was conducted. This method of analysis is essentially a process of summarization, categorization, and counting frequency of responses. ${ }^{17}$ 


\section{Results}

\section{General practitioners}

All 20 GPs agreed to participate. GPs' characteristics were similar and comparable to average Dutch GPs. ${ }^{14}$ By the 12 th interview no new items within themes were emerging.

\section{General experiences with the test}

All GPs said that the CRP POCT was a useful, and much needed, additional diagnostic tool, especially when they were uncertain whether or not a patient had a serious infection. A typical comment included: "Before this test, I didn't really have that much to go on, helped only a bit by temperature, a bit by the patient's illness history, the severity of the illness. It was mostly guesswork really... I think this CRP does improve my clinical pattern recognition. You immediately get feedback as to whether your impression agrees with the objective measure.(GP9)"

Nearly all also acknowledged that they used the CRP POCT mainly to exclude pneumonia, while nine GPs also used it to confirm their own diagnoses. Although they felt that the CRP POCT was a very useful tool in LRTI consultations, most mentioned that clinical findings remained central to deciding about antibiotic treatment.

Half of the clinicians said that the use of CRP POCT had very little influence on their workload. They felt it did not influence their consultation time, whereas 8 others stated that it might slightly increase consultation time. When talking about general experience with the test within their practice, the vast majority agreed that it was a user-friendly test, and practice nurses had a positive experience in performing the test. One clinician stated, "The fact that it's immediately available means you get fewer short term repeat consultations or phone calls. So in that sense, it just makes things that bit quicker.(GP19)"Five others, however, had some concerns on organisational issues, such as interference with practice nurses' activities including answering phone calls. Apart from one GP mentioning the finger prick itself was unpleasant for patients, no other negative effects for patients were raised: "I think since it's not a very invasive test, not a great burden to the patient, and easy to use for the practice nurses. All of this means that it is an added value for general practice, in a wide variety of situations (GP1)."'

Although some GPs did not describe disadvantages of the test in general, others considered that potentially, the test could be relied on too much, detracting from the value of clinical diagnostic skills. Two typical clinicians' opinions were: "What you mustn't do is hide behind it. It could cause you to do even less physical examination, to stop paying attention to that (GP1)." and 
"There's a risk that you let the test determine your management. In the end, what matters is the person who's sitting there and what you hear and what you find on physical examination (GP8). "'”

Although 12 clinicians said that the costs of the CRP POCT did not have any meaningful influence on the use of the test in their everyday practice, all 20 agreed that there should be a financial compensation of the incurrent costs. Three clinicians stated that absence of reimbursement currently prevented them from using the test. Some practitioners mentioned that experience in using the CRP test is crucial to gain full benefit. Thirteen GPs acknowledged that they would miss the test if removed from their practice and would welcome updated national LRTI guidelines that considered the place of CRP.

\section{Influence of the test on antibiotic prescribing and consulting for LRTI}

Sixteen GPs reposted that low CRP results helped avoid antibiotic treatment. Almost every practitioner felt that the test generally confirmed their clinical findings and management and decreased their diagnostic uncertainty. A normal CRP test result was reassuring and convinced both the GP and the patient that further diagnostic testing and antibiotic treatment was unnecessary. Although two GPs said that they had always been conservative antibiotic prescribers for LRTI, 16 reported that their antibiotic prescribing had decreased since using the CRP POCT. "It also helps you to be a bit more careful in prescribing antibiotics, that's true. It makes you more aware that you may be using them too often (GP19)." GPs mentioned that the test increased their motivation to use antibiotics more cautiously. "We need a bit more awareness of the problem of antibiotics, and the CRP test may show that it's not so bad, that there are fewer pneumonia cases than you might think at first (GP5)."

When test results were in conflict with clinical findi'hgs, most GPs relied on clinical findings when deciding on treatment. They based their management on the combination of clinical factors such as physical examination findings, duration of illness, medical history, medication, patients' expectations, and the CRP test result. One practitioner acknowledged that, at first, patients' previous experiences with antibiotic treatment were an obstacle "If a GP they consulted previously for the same complaint gave them an antibiotic, that makes it harder to say. "Well you don't really need it (GP19)."

Twelve GPs said that elevated CRP (mostly referred to as CRP>20 mg/l) mostly confirmed their judgment of illness severity. Highly elevated CRP test results (>100 mg/l) supported decisions to prescribe antibiotics. In fact, both low $(<20 \mathrm{mg} / \mathrm{l})$ and high test results (>100 mg/l) supported the GPs' initial judgment and helped reduce residual uncertainty. One practitioner said: "You use it so 
you know whether it's serious or not. Very high or very low values offer clear clues (GP11)."'

Intermediately elevated results were considered a limitation of the test by half of the GPs. Their main concern was explaining intermediate test results to patients, as this could create uncertainty in patients' minds: "If the CRP is at an intermediate level, the patient may think that their blood was not entirely OK, so that may make them insecure and worried (GP18). "Although 11 GPs said they routinely advise their patients when to reconsult in the event of persisting symptoms, seven said that an elevated CRP test result reinforced this 'safety netting'. However, generally GPs did not feel that these patients would actually reconsult more often: "I don't think patients are more likely to return if the test shows an intermediate level. I think it's because if patients have relatively high intermediate levels, and corresponding clinical features, I would treat them anyway. Whereas people in the lower part of the intermediate values, with mild symptoms, they will soon get better without treatment (GP14). "Seven GPs said they often had used the test in follow-up consultations, while two only considered doing this, depending on the severity of the patient's symptoms.

More than 15 GPs mentioned the tests useful role in convincing patients about management decisions, and the advantage of a rapidly available test result. GPs believed that a major advantage of using the CRP test was that patients felt that their complaints were being taken seriously and they were more reassured. They felt that patients' satisfaction increased by using the CRP test. One doctor elaborated, "You first evaluate the patient's story, you examine them and you then also offer them a test. I think that means patients feel they're being taken very seriously, and that reassures them a lot (GP14)." And "If a patient clearly expects to get an antibiotic, it can support you in your explanation. And patients understand that. You explain to them that the test doesn't indicate anything serious - the CRP is normal - and then it's easier to get patients to accept a wait-and-see policy (GP20)." Even in situations were GPs were certain about the self-limiting nature of symptoms, the test would further empower GPs to safely avoid prescribing antibiotics without alienating patients.

In general, GPs were unconcerned by the possible medicalising effect of the test with associated reconsultations and increasing workload. In fact, three GPs stressed the potential educational effect of natural recovery without antibiotic treatment: "If you don't treat a patient with antibiotics [after CRP testing] and the complaints resolve spontaneously, I think that patients will tend to wait and see and not consult the doctor again for the next similar illness episode. So what we hope is that this management including CRP will lead to fewer consultations or repeat consultations for new infections (GP17)."

After patient recruitment for the trial, clinicians generally used the test to help reduce diagnostic and prognostic uncertainty. The majority of GPs said they 
continued to use the test and half of all GPs mainly use it to rule out serious disease. A typical clinician's opinion was; "There's a group of patients where I think no, this is just a mild respiratory tract infection, and I won't use it then. And there's also a group where I think, well, these people are so ill, they have so many signs and symptoms, or have had complaints for so long, and then I won't use it either. It's the group in between, where I'm thinking whether it might be pneumonia, and whether / should advise them to take an antibiotic, that's where I still use it. When I'm not very sure myself (GP5). "While most commented on selective use for the subset of patients, one GP expressed concerns regarding over-testing: "Perhaps it's being used a bit too often. I think you need to be careful about that. It's so easy, since it's available in your own office, but I think you need to be critical and consider whether you really need a CRP test for your further management or not (GP1)."

\section{Influence of using the CRP test on everyday consultations for other illnesses}

All but one mentioned using CRP POCT for helping to diagnose abdominal complaints, including appendicitis, diverticulitis or vague abdominal complaints and saw the test as a useful aid for ruling out serious acute pathology and to guide hospital referral decisions. Other possible uses, but less frequently mentioned, were for tonsillitis, rhinosinusitis, joint pain and children with fever. Eight GPs mentioned that colleagues working in the same general practice had also started using the CRP POCT, but they used it less often than the clinicians initially trained to use the test. Three clinicians believed that a reason for this was that these colleagues were not trained in how to use the test, had less experience with the test, and sometimes did not even know about it.

\section{Discussion}

\section{Main findings}

This is the first in depth study exploring GPs attitudes towards and experiences of CRP point of care testing after they had recently started using the test. We identified mostly positive attitudes towards the use of CRP POCT in general and its role in LRTI in particular. Commonly mentioned positive themes included its supportive role in the diagnostic and therapeutic process, its role in empowering GPs to safely reduce antibiotic prescribing without alienating their patients, and the rapidly available test results. Concerns included handling intermediate elevated test results. GPs reported that the test had helped them prescribe 
fewer antibiotics for LRTI through reducing diagnostic and prognostic uncertainty, and in achieving patient's reassurance and agreement.

\section{Strengths and limitations}

Qualitative research is best suited for obtaining a better understanding of experiences and attitudes. We successfully interviewed all twenty general practitioners who had recently starting using the CRP POCT. Since we continued interviews once no new items within themes were emerging, we are confident we did not miss important views. Participating GPs were not aware of the trial results on the effectiveness of the CRP POCT in reducing antibiotic prescribing at the time of interview, so results could not have influenced responses. Double coding of the majority of transcripts ensured reliability. Recall bias may have been an issue as the interviews took place in the winter period after the end of patient recruitment for the trial. But seeing that most GPs continued to use the test after the trial, this bias will be small.

At the time of the study, CRP POCT was virtually never used in Dutch primary care. All participating GPs had no prior experience with the test. Despite this, GPs reported the test empowered them to prescribe antibiotics less often. In general, GPs may need time to gain experience in interpreting and responding to the results of a new test. We did not interview patients managed with the aid of CRP testing. GPs views on patient related factors such as satisfaction are therefore based on GPs perceptions alone. Half of the GPs we interviewed were also trained in additional communication skills for managing LRTI. ${ }^{18} \mathrm{We}$ did not observe difference in accounts from GPs trained and not trained in communication skills. The views of the Dutch GPs who participated in this study do not necessarily represent attitudes across Europe or beyond, as each country specific health system and cultural factors may influences attitudes to implementation and uptake of such tests.

\section{Comparison with other studies}

GPs indicated that the CRP POCT empowered them to safely prescribe antibiotics less often for LRTI. This is supported by quantitative data form the trial in which these GPs participated. ${ }^{14}$

Some GPs in our study expressed concerns about relying too much on the test result, which could undermine confidence and skill in clinical examination, potentially leading to test over-use. Excessive CRP testing for self-limiting respiratory tract infections such as the common cold has occurred in settings where CRP is widely used in primary care. ${ }^{19}$ Moreover, a potential drawback of the CRP test is uncertainty on how to respond to intermediately elevated results. A Swedish group suggested that moderately elevated CRP values in patients with LRTI might lead to prescriptions of antibiotics that would have 
been avoided if the test had not been carried out. ${ }^{20} \mathrm{GPs}$ in our study reported that, even though a moderately elevated test result did not take away diagnostic uncertainty, it did not encourage them to prescribe more antibiotics. One explanation could be that the CRP test assisted GPs in their decision-making, while previously they mostly prescribed antibiotics in the face of doubt. Delayed prescribing is not widely used in The Netherlands. Yet, this strategy could possibly provide an acceptable alternative for both patient and GP in some cases of intermediately elevated results.

In their recent systematic review of CRP and community-acquired pneumonia (CAP) in ambulatory care Falk et al. concluded that CRP may be of value in ruling out the diagnosis of CAP in situation where the probability is higher than $10 \%$. ${ }^{10}$ There is usually a lower probability in primary care. Nonetheless, GPs in our study confirmed that they continued to use the test well after the trial had ended in that subgroup of patients where they were uncertain about whether or not to prescribe antibiotics. Consequently, this subgroup of patients will have a higher probability of CAP than all patients consulting with LRTI. Moreover, our trial results indicated an extensive decrease in antibiotic prescribing. This effect may relate to the diagnostic value of the test but also to its role in empowering GPs not to prescribe antibiotics and in gaining patient acceptance of these decisions. This latter aspect of the test may be of greatest value in the large subgroup of patients with self-limiting acute bronchitis who hope for and expect antibiotic treatment.

In a recent qualitative study on UK GPs' perceptions of introducing near-patient testing for common infections into routine primary care, it was shown that many physicians emphasised that near patient tests would be particularly valuable in 'selling' decisions to patients. ${ }^{21}$ GPs involved in that study stressed that, before considering uptake of a near patient test, they would have to be convinced by research evidence supporting the use of these tests. Moreover, they would have to be cheap, easy to use and acceptable to patients. Our data provide confirmatory evidence.

Studies have suggested benefit for CRP POCT additional to clinical and laboratory data in diagnosing acute appendicitis. Some GPs in our study commented that they had found the test useful in this situation. CRP performs well in diagnosing appendicitis. While an elevated CRP value cannot effectively establish the diagnosis of acute appendicitis, low values exclude it and may help avoid unnecessary hospital referral. ${ }^{22,23}$

\section{Practice implications}

Evidence from both our trial of the effect of CRP POCT on antibiotic prescribing, as well as the views expressed in this qualitative study, support a cautious introduction of the CRP POCT in general practice in the Netherlands. GP 
respondents specifically recognised and stressed the supportive role of the test as an additional tool to empower them to reduce diagnostic and prognostic uncertainty and safely prescribe fewer antibiotics without alienating their patients. GPs in this study felt that the place of the test should be outlined in updated management guidelines. Introducing the test in routine care will be most successful therefore is accompanied with recommendations on when to use and how to interpret the test results, and additional information about the diagnostic value for LRTI. Most GPs continued to use the tests after the trial and plan to continue doing so. However, reimbursement for using the test was considered essentially for them to continue using the test in daily practice.

\section{Conclusion}

These accounts of GPs who started using CRP POCT for LRTI indicate a generally positive experience and sustained changes in practice that has led to reduced antibiotic prescribing. Both the positive experiences and concerns expressed by the GP participants in this study should inform further implementation research and roll out of CRP POCT into routine primary care. 


\section{References}

1. Butler CC, Rollnick S, Pill R, Maggs Rapport F, Stott N. Understanding the culture of prescribing: qualitative study of general practitioners' and patients' perceptions of antibiotics for sore throats. BMJ 1998;317:637-42.

2. Welschen I, Kuyvenhoven M, Hoes A, Verheij T. Antibiotics for acute respiratory tract symptoms: patients' expectations, GPs' management and patient satisfaction. Fam Pract 2004;21:234-7.

3. Hopstaken RM, Butler CC, Muris JW, Knottnerus JA, Kester AD, Rinkens PE, Dinant GJ. Do clinical findings in lower respiratory tract infection help general practitioners prescribe antibiotics appropriately? An observational cohort study in general practice. Fam Pract. 2006; 23:180-7.

4. Akkerman AE, Kuyvenhoven MM, van der Wouden JC, Verheij TJ. Prescribing antibiotics for respiratory tract infections by GPs: management and prescriber characteristics. $\mathrm{Br} \mathrm{J}$ Gen Pract 2005;55:114-8.

5. Simpson SA, Wood F, Butler CC. General practitioners' perceptions of antimicrobial resistance: a qualitative study. J Antimicrob Chemother 2007;59:292-6.

6. Wood F, Simpson S, Butler CC. Socially responsible antibiotic choices in primary care: a qualitative study of GPs' decisions to prescribe broad-spectrum and fluroquinolone antibiotics. Fam Pract 2007;24:427-34.

7. Hopstaken RM, Muris JWM, Knottnerus JA, Kester ADM, Rinkens PELM, Dinant GJ. Contributions of symptoms, signs, erythrocyte sedimentation rate and C-reactive protein to a diagnosis of pneumonia in acute lower respiratory tract infection. $\mathrm{Br} J$ Gen Pract 2003;53: 358-64.

8. Melbye H, Straume B, Aasebo U, Brox J. The diagnosis of adult pneumonia in general practice. The diagnostic value of history, physical examination and some blood tests. Scand $\mathrm{J}$ Prim Health Care 1988;6:111-7.

9. van der Meer V, Neven AK, Broek PJvd, Assendelft WJJ. Diagnostic value of $C$ reactive protein in infections of the lower respiratory tract: systematic review. BMJ 2005;331:26-9.

10. Falk G, Fahey T. C-reactive protein and community-acquired pneumonia in ambulatory care: systematic review of diagnostic accuracy studies. Fam Pract 2009;26:10-21.

11. Smucny J, Fahey T, Becker L, Glazier R. Antibiotics for acute bronchitis. Cochrane Database Syst Rev 2004(4): CD000245..

12. Seamark DA, Backhouse SN, Powell R. Field-testing and validation in a primary care setting of a point-of-care test for C-reactive protein. Ann Clin Biochem 2003;40(Pt 2):178-80.

13. Dahler Eriksen BS, Lauritzen T, Lassen JF, Lund ED, Brandslund I. Near-patient test for Creactive protein in general practice: assessment of clinical, organizational, and economic outcomes. Clin Chem 1999;45:478-85.

14. Cals JWL, Butler CC, Hopstaken RM, Hood K, Dinant GJ. Effect of C-reactive protein point of care testing and clinician communication skills training on antibiotic use and patient recovery in lower respiratory tract infections: a cluster randomised trial. BMJ 2009;338:b1374.

15. Cals JW, Hopstaken RM, Butler CC, Hood K, Severens JL, Dinant GJ. Improving management of patients with acute cough by C-reactive protein point of care testing and communication training (IMPAC3T): study protocol of a cluster randomised controlled trial. BMC Fam Pract 2007;8:15.

16. Britten N. Qualitative interviews in medical research. BMJ 1995;311:251-3.

17. Green J, Thorogood N. Qualitative methods for health research. London: Sage Publications, 2004.

18. Cals JW, Scheppers NA, Hopstaken RM, Hood K, Dinant GJ, Goettsch H, Butler CC. Evidence based management of acute bronchitis; sustained competence of enhanced communication skills acquisition in general practice. Patient Educ Couns 2007;68:270-8.

19. Engstrom S, Molstad S, Lindstrom K, Nilsson G, Borgquist L. Excessive use of rapid tests in respiratory tract infections in Swedish primary health care. Scand J Infect Dis 2004;36:213-8. 
20. Andre M, Schwan A, Odenholt I. The use of CRP tests in patients with respiratory tract infections in primary care in Sweden can be questioned. Scand J Infect Dis 2004;36:192-7.

21. Butler CC, Simpson S, Wood F. General practitioners' perceptions of introducing near-patient testing for common infections into routine primary care: a qualitative study. Scand J Prim Health Care 2008;26:17-21.

22. Sengupta A, Bax G, Paterson-Brown S. White cell count and C-reactive protein measurement in patients with possible appendicitis. Ann R Coll Surg Engl 2008.

23. Andersson RE. Meta-analysis of the clinical and laboratory diagnosis of appendicitis. $\mathrm{Br} \mathrm{J}$ Surg 2004;91:28-37. 

Testing C-reactive protein at the point of care to assist antibiotic prescribing for respiratory tract infections: a randomized controlled trial in family practice

Jochen Cals, Marjolein Schot, Sanne de Jong, Geert-Jan Dinant, Rogier Hopstaken 


\section{Abstract}

\section{Purpose}

Antibiotics are only beneficial for subgroups of patients with acute lower respiratory tract infections (LRTI) and rhinosinusitis in family practice, yet overprescribing for these conditions is common. C-reactive protein (CRP) point of care testing and delayed prescribing are useful strategies to reduce antibiotic prescribing, but both have limitations. We evaluated the effect of CRP assistance in antibiotic prescribing strategies - including delayed prescribing - in LRTI and rhinosinusitis consultations to stimulate antimicrobial stewardship in family practice.

\section{Methods}

We conducted a randomised controlled trial, in which 258 patients were enrolled (107 LRTI and 151 rhinosinusitis) by 32 family physicians. Patients were individually randomised to CRP assistance or control (routine care). Primary outcome was antibiotic use following index consultation. Secondary outcomes included antibiotic use during 28-day follow-up, patient satisfaction and clinical recovery.

\section{Results}

Patients in the CRP assisted group used less antibiotics (43.4\%) than control patients $(56.6 \%)$ following index consultation ( $R R \quad 0.77,95 \% \mathrm{Cl} 0.56-0.98, P=0.03$ ). This difference remained significant during follow-up $(52.7 \%$ vs. $65.1 \%$, RR $0.81,95 \% \mathrm{Cl} 0.62-0.99, P=0.04)$. Delayed prescriptions in the CRP assisted group were only filled in minority of cases $(23 \%$ vs. $72 \%$ in control group, $P<0.001)$. Recovery was similar across groups. Satisfaction with care was higher in patients managed with CRP assistance $(P=0.03)$.

\section{Conclusions}

CRP point of care testing to assist prescribing decisions - including delayed prescribing - for LRTI and rhinosinusitis may be a useful strategy to target the right prescription at the right patient, with favorable outcomes on antibiotic use, patient satisfaction and no detrimental effects on recovery. 


\section{Introduction}

Respiratory tract infections are among the most common reasons to consult in family practice. Although antibiotic treatment is only considered necessary for community acquired pneumonia and for small subgroups of the other lower and upper respiratory tract infections ${ }^{1-5}$, antibiotics are prescribed to roughly 80 percent of patients consulting for lower respiratory tract infection (LRTI) or acute rhinosinusitis. ${ }^{6,7}$ Signs and symptoms are of limited value in identifying those patients in need of antibiotic treatment for these conditions. ${ }^{2,8-10}$ Diagnostic uncertainty and patient related factors, such as patient expectations and pressure, often lead to unjustified antibiotic prescribing by family physicians (FPs). ${ }^{11,12}$

C-reactive protein (CRP) is an acute phase protein with levels quickly rising during inflammatory processes. Currently, CRP can be measured by using a point of care test which has been proven both accurate and robust in a family practice setting. ${ }^{13}$ A CRP value, combined with clinical parameters, increases diagnostic certainty ${ }^{14-16}$ and may thereby help to identify those patients that will benefit from antibiotic treatment. Latest randomised evidence has shown that antibiotic prescribing rates fall significantly when using CRP assistance within LRTI consultations without compromising clinical outcomes. ${ }^{17}$ Similar effects are suggested for rhinosinusitis. ${ }^{18}$

Delayed prescriptions are prescriptions written under the condition that they are not used immediately but only if symptoms persist. ${ }^{19}$ Several studies in the United Kingdom found lower antibiotic use when introducing delayed prescribing. ${ }^{20-22}$

Both CRP testing and delayed prescribing are valuable strategies in lowering antibiotic use, but there are limitations. Most studies investigating delayed prescribing involved uncomplicated RTI solely, thereby limiting generalization of the study results to the full range of LRTI patients, including cases of pneumonia. The strategy does not help FPs to estimate illness severity and identify patients with a possible need for immediate antibiotic treatment. CRP assistance and guidance may be of great use in this regard, since it helps to identify both low and high risk patients, with the emphasis on ruling out RTIs with a potential complicated course. Nonetheless, FPs experience difficulties in interpreting and communicating intermediate, elevated test results to patients. ${ }^{23}$ In these patients with intermediate elevated CRP results, delayed prescribing may provide an appropriate safety net for both patients and FPs.

We hypothesised that FP use of CRP assistance within the consultation would result in a rationalization of antibiotic use without compromising patient outcomes. We therefore conducted a randomised trial of CRP assisted prescribing strategies in LRTI and rhinosinusitis. 


\section{Method}

\section{Design}

The study was an open, individually randomised controlled trial, evaluating the effect of CRP assistance on the management of LRTI and rhinosinusitis.

\section{Patients and setting}

A total of $33 \mathrm{FPs}$ working in 11 family practice centres in the South-eastern part of the Netherlands participated in the study. FPs recruited patients with LRTI or rhinosinusitis from November 2007 until April 2008. All patients of 18 years and older who consulted for the first time for a current episode of LRTI or rhinosinusitis and met the defined inclusion criteria were eligible for the trial. Inclusion criteria for LRTI: First consultation for current episode of acute cough (duration $<4$ weeks) regarded by the FP to be caused by an acute lower respiratory tract infection with at least one out of following four focal signs and symptoms: 1 . shortness of breath 2 . wheezing 3 . chest pain 4 . auscultation abnormalities AND at least one of the following systemic signs and symptoms: 1. fever 2. perspiring 3. headache 4 . myalgia 5 . feeling generally unwell.

For rhinosinusitis: First consultation for current episode of rhinosinusitis (duration <4 weeks) with at least one of the following symptoms: 1. history of rhinorroea 2. blocked nose AND one of the following symptoms/signs: 1. purulent rhinorroea 2. unilateral facial pain 3 . headache 4 . teeth pain 5 . pain when chewing 6. maxillary/frontal pain when bending over 7 . worsening of symptoms after initial improvement.

Exclusion criteria included immediate requirement of admission to hospital, no understanding of Dutch language, previous participation in the study, antibiotic use or hospitalisation in the past two weeks and immuno-compromised patients. All patients gave written informed consent before inclusion.

\section{Clinical evaluation at baseline and randomization}

The FPs performed a routine consultation, including medical history and physical examination at their own discretion. The FPs recorded inclusion criteria, signs and symptoms and rated illness severity on a visual analogue scale (VAS). Once these criteria were recorded, randomization took place.

Each FP was provided with one pile of sequentially numbered opaque sealed envelopes (SNOSE). ${ }^{24}$ The use of this method prevents researchers, FPs and patients from predicting and thus influencing which patient will be allocated to which intervention. The SNOSE pile per FP was prepared by a remote independent research team, using permuted block randomisation to ensure similar enrolment in both groups. Different block sizes were chosen to prevent 
the allocation sequence from being anticipated. Patients were randomised into one of two groups:

- Intervention (CRP assistance): CRP was measured by the practice nurse within the consultation and patients returned to the FP with the test result. The FP could use the CRP test result on top of clinical assessment to decide on management (immediate, delayed or no antibiotics).

- Control (no CRP assistance): the FP had to decide on management (immediate, delayed or no antibiotics) based on clinical assessment and finished the consultation (usual care). CRP was measured and recorded by the practice nurse after the consultation. Practice nurses were instructed not to communicate the test result to either FP or patient until after the study.

\section{C-reactive protein point of care testing}

The CRP analysis was carried out using QuikRead CRP analysers, product of Orion Diagnostica. A CRP test result is available within three minutes after obtaining a drop of blood by finger prick. Validity and robustness is established for primary care. ${ }^{13}$ Prior to the start of the study, the practice nurses received a demonstration of the device by a product specialist of Orion Diagnostica. FPs were informed on the trial procedure and on the evidence-based use of CRP in a 30-minute practice based seminar given by the study team (JC or RH). In this seminar we stressed the additional value of CRP in ruling out serious infection and emphasised that the test should always be used combined with clinical findings. We advised not to prescribe antibiotics when CRP $<20 \mathrm{mg} / \mathrm{l}$, to give immediate antibiotics when CRP $>100 \mathrm{mg} / \mathrm{l}$ and to consider a delayed prescription when CRP was between 20 and $99 \mathrm{mg} / \mathrm{l}$. FPs were allowed to deviate from the proposed prescribing strategies at any time. The cut-offs above were not presented as strict rules but solely as a recommendation, to be taken into account in combination with the clinical findings from medical history and physical examination when deciding on management. Cut-offs are based on previous diagnostic research and available evidence on CRP for RTI. ${ }^{15,16,18,25}$ FPs in the Netherlands are not familiar with CRP point of care testing, so a 4-week run-in period enabled familiarization with the devices and interpretation of CRP test results before patient recruitment started.

If the FP decided to hand out a delayed prescription (to either a CRP or control patient), the patient was informed about this strategy by the FP and by an information sheet. The sheet did not indicate specific information on alarm symptoms and time to wait-and-see. These advices were left at the discretion of the FP. If required, the patient could collect the prescription at the practice front desk. 


\section{Follow-up}

Patients filled out a self-complete diary including questions regarding reasons for consultation and symptoms during seven days. Patients rated symptoms cough, phlegm, shortness of breath and sleeping problems (for LRTI), rhinorroea, blocked nose, dental pain, headache, pain at bending over (for rhinosinusitis) and disturbance of daily activities and general well-being (for both conditions) on a 7-point scale each day. The diary also included a Likert scale question on satisfaction and the Patient Enablement Index. ${ }^{26}$ The LRTI part of the diary was previously used in a randomised controlled trial of LRTI management in family practice. ${ }^{17}$ Patients handed in the diaries after one week. Patients who indicated not to be recovered from their illness on day 7 were contacted by the research team to check and record recovery on day 14 and 28 by telephone. After day 28 the electronic medical records were accessed from the FP databases to retrieve relevant information on antibiotic prescriptions, reconsultations, relevant co-morbidity and complications.

\section{Endpoints}

The primary outcome was antibiotic use following index consultation (defined as those patients using immediate antibiotics and those filling a delayed prescription). Secondary outcomes were antibiotic use within 28 day follow-up (defined as any antibiotic use for the current respiratory tract infection within 28 days after index consultation); reconsultation; patient satisfaction, enablement and clinical recovery.

\section{Sample size calculation}

To calculate the sample size we assumed that $40 \%$ of eligible patients would have LRTI and $60 \%$ would have rhinosinusitis. As reported prescribing rates for both conditions vary greatly (range $30-80 \%$ ) in large GP database studies from the Netherlands ${ }^{27-29}$, we decided to take a conservative approach by expecting $50 \%$ prescribing in the control group. To detect a significant difference in antibiotic prescriptions of $20 \%$ (30\% in the intervention group vs. $50 \%$ in the control group) for both clinical entities combined with $80 \%$ power at a $5 \%$ significance level and with the patient as unit of analysis, at least 188 patients (94 per group) would be required. Based on incidence figures from Dutch general practice and an estimated $5 \%$ loss to follow-up, we aimed to recruit at least 200 patients within one winter period, with an estimated 80 LRTI patients and 120 rhinosinusitis patients. 


\section{Statistical analysis}

Discrete variables were expressed as percentages (counts) and continuous variables as mean (standard deviation, SD), unless otherwise stated. The primary analysis was intention to treat and assessed the effects of the intervention (CRP assistance) on antibiotic use following the index consultation compared to usual care (control group). Scores for each of the individual symptom items were added to create a total daily symptom score that ranged from $0 \%$ to $100 \%$, for LRTI patients and rhinosinusitis patients separately. Median daily symptom scores were plotted for the treatment groups, and compared per day and over the full period. Differences were assessed using Chi-Square, Mann-Whitney $U$ or Wilcoxon, where applicable. Exploratory analyses investigating the influence of patient and physician characteristics on the main effects were performed as sensitivity analyses. All analyses were performed by a multi-level approach using a two level logistic regression model to account and correct for variation at the level of FP using a $2^{\text {nd }}$ order penalised quasi likelihood (PQL) approach. Results are presented as rates with corresponding $p$-values. Odds ratio obtained from the models were recalculated to relative risks. ${ }^{30}$ Analysis was performed using SPSS 15.0 and Mlwin 2.0.

\section{Ethical approval and trial registration}

The Ethics Committee of Catharina Hospital in Eindhoven, The Netherlands, approved this study. The CAPRESA trial was registered at The Netherlands National Trial Register, trial identifier TC1112, and is reported following CONSORT guidelines for randomised controlled trials. ${ }^{31}$

\section{Results}

\section{Patient enrolment and characteristics}

Thirty-two FPs recruited patients for the trial. A total of 258 patients were enrolled, of whom 107 patients had acute LRTI and 151 patients acute rhinosinusitis. 129 patients were randomised into the CRP assisted group (56 LRTI and 73 rhinosinusitis) and 129 patients (51 LRTI and 78 rhinosinusitis) into the control group. Data for the primary outcome were available for all of these patients (Figure 10.1). Patient-reported outcomes were available for $94 \%$ (243/258) of all recruited patients.

The two groups were similar in terms of sex, age, educational level, comorbidity and smoking history (Table 10.1). Patients had a mean age of 44 , with nearly $70 \%$ of participants being female. The median number of days with symptoms before consulting the FP was 7 for the whole study population. Mean 
illness severity as judged by the FP on a $100 \mathrm{~mm}$ Visual Analogue Scale was $46 \mathrm{~mm}$ (SD 22.9) in the LRTI-CRP group and 42 (SD 23.1) in the LRTI-control group. For rhinosinusitis this was $41 \mathrm{~mm}$ (SD 22.0) in both groups.

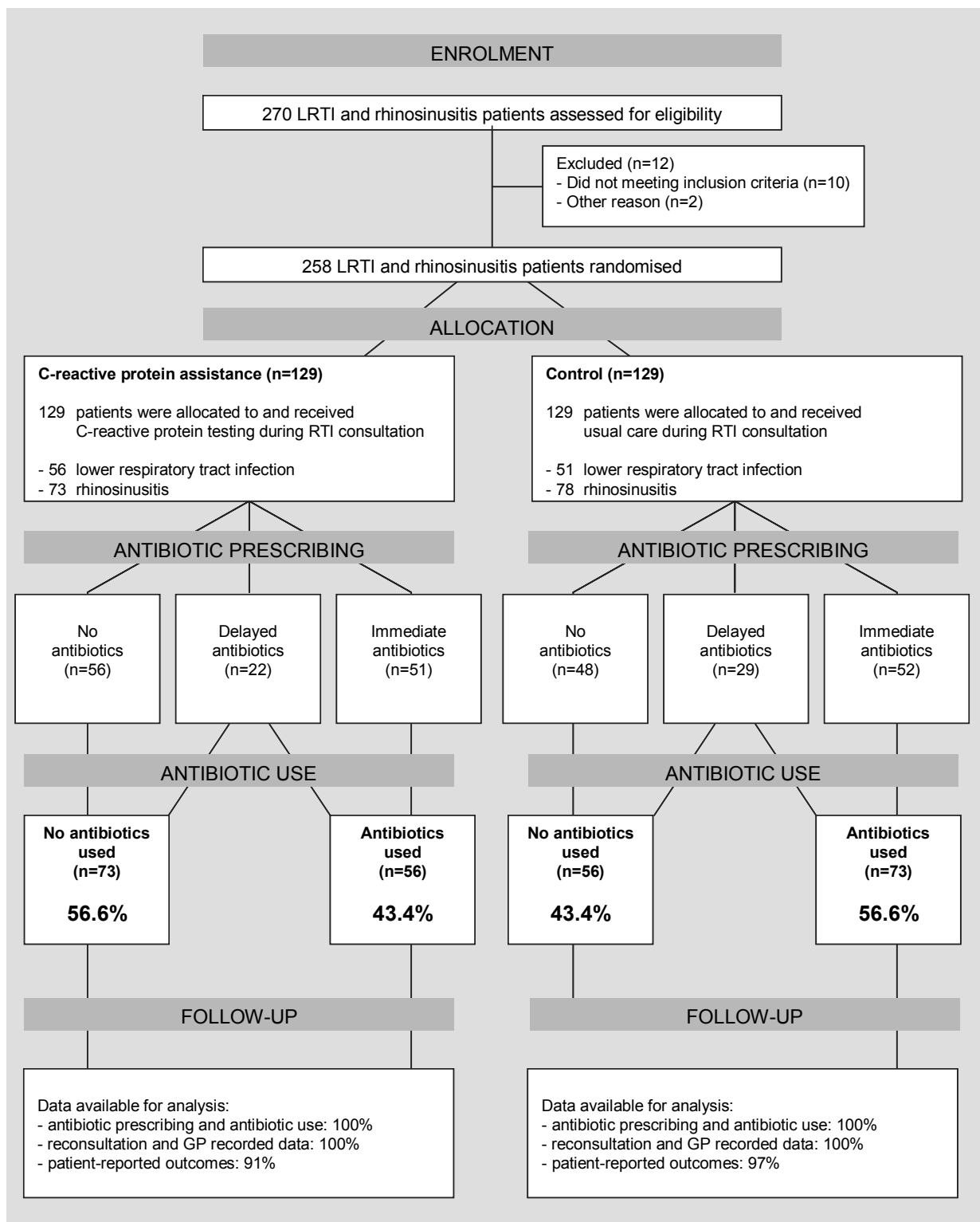

Figure 10.1 Trial profile. 
Table 10.1 Characteristics of randomised patients.

\begin{tabular}{|c|c|c|}
\hline & $\begin{array}{c}\text { CRP assistance } \\
n=129\end{array}$ & $\begin{array}{l}\text { Control } \\
n=129\end{array}$ \\
\hline \multicolumn{3}{|l|}{ Demographics } \\
\hline Female gender & $68.2(88 / 129)$ & $70.5(91 / 129)$ \\
\hline Mean age (SD) & $43.0(13.4)$ & $45.5(14.0)$ \\
\hline Lower education & $29.2(31 / 106)$ & $19.8(21 / 106)$ \\
\hline Secondary education & $43.4(46 / 106)$ & $42.5(45 / 106)$ \\
\hline Higher education & $27.4(29 / 106)$ & $37.7(40 / 106)$ \\
\hline Current smoking & $30.8(33 / 129)$ & $25.5(27 / 129)$ \\
\hline \multicolumn{3}{|l|}{ Co-morbidity } \\
\hline COPD & $3.9(5 / 129)$ & $2.3(3 / 129)$ \\
\hline Asthma & $7.8(10 / 129)$ & $7.0(9 / 129)$ \\
\hline Allergic rhinitis & $10.1(13 / 129)$ & $9.3(12 / 129)$ \\
\hline Diabetes mellitus & $7.0(9 / 129)$ & $3.1(4 / 129)$ \\
\hline Heart disease & $4.7(6 / 129)$ & $6.2(8 / 129)$ \\
\hline \multicolumn{3}{|l|}{ Signs and symptoms } \\
\hline Lower respiratory tract infection & $\mathrm{n}=56$ & $\mathrm{n}=51$ \\
\hline Shortness of breath & $66.1(37 / 56)$ & $58.8(30 / 51)$ \\
\hline Wheezing & $39.3(22 / 56)$ & $29.4(15 / 51)$ \\
\hline Chest pain & $51.8(29 / 56)$ & $56.9(29 / 51)$ \\
\hline Auscultation abnormalities & $44.6(25 / 56)$ & $41.2(21 / 51)$ \\
\hline Fever & $48.2(27 / 56)$ & $49.0(25 / 51)$ \\
\hline Perspiring & $51.8(29 / 56)$ & $41.2(21 / 51)$ \\
\hline Headache & $32.1(18 / 56)$ & $43.1(22 / 51)$ \\
\hline Myalgia & $46.4(26 / 56)$ & $49.0(25 / 51)$ \\
\hline Generally feeling unwell & $75.0(42 / 56)$ & $78.4(40 / 51)$ \\
\hline \multicolumn{3}{|l|}{ Duration of symptoms (days) } \\
\hline Mean (SD) & $8.07(5.12)$ & $8.82(6.16)$ \\
\hline Median (25-75 IQ) & $7(5-14)$ & $7(4-14)$ \\
\hline VAS Ilness severity scored by FP(SD) & $46.16(22.92)$ & $42.07(23.07)$ \\
\hline Rhinosinusitis & $n=73$ & $n=78$ \\
\hline History of rhinorroea & $71.2(52 / 73)$ & $76.9(60 / 78)$ \\
\hline Purulent rhinorroea & $52.1(38 / 73)$ & $56.4(44 / 78)$ \\
\hline Blocked nose & $78.1(57 / 73)$ & $75.6(59 / 78)$ \\
\hline Unilateral facial pain & $53.4(39 / 73)$ & $56.4(44 / 78)$ \\
\hline Headache & $69.9(51 / 73)$ & $76.9(60 / 78)$ \\
\hline Dental pain & $34.2(25 / 73)$ & $28.2(22 / 78)$ \\
\hline Pain at chewing & $19.2(14 / 73)$ & $10.3(8 / 78)$ \\
\hline Pain at bending over & $60.3(44 / 73)$ & $66.7(52 / 78)$ \\
\hline Worsening symtoms after initial improvement & $19.2(14 / 73)$ & $25.6(20 / 78)$ \\
\hline \multicolumn{3}{|l|}{ Duration of symptoms (days) } \\
\hline Mean (SD) & $9.28(6.70)$ & $10.04(6.85)$ \\
\hline Median (25-75 IQ) & $7(4-14)$ & $8(5-14)$ \\
\hline VAS Ilness severity scored by FP (mm, SD) & $40.61(22.28)$ & $40.51(21.05)$ \\
\hline
\end{tabular}

Data are $\%(n / n)$ unless otherwise stated. 


\section{C-reactive protein point of care testing}

CRP test results at the index consultation were available for all patients. Median CRP was $17 \mathrm{mg} / \mathrm{l}$ in the CRP assisted group and $19 \mathrm{mg} / \mathrm{l}$ in the control group $(P=0.88)$. Table 10.2 displays the number of patients per CRP category with $54.3 \%$ of patients having a CRP level $<20 \mathrm{mg} / \mathrm{l}$. In the CRP assisted group, the CRP value was revealed to both patient and FP within the consultation in all 129 cases. In the control group CRP testing was set up to be blinded to both FP and patient. As a result of logistical issues (eg. patient still present in nurse's room when CRP device displayed test result) the CRP value was revealed to 13 patients in the control group, according to patient's self-reported diary data. Nonetheless, CRP testing in the control group was performed after the consultation with the FP and this did not influence the FPs' prescribing decision. In one case a control patient CRP result was revealed to the FP, with no implications for this patient's management.

Table 10.2 Mean and median C-reactive protein values at index consultation and number of patients within CRP categories.

$\begin{array}{lcccc} & \begin{array}{c}\text { All patients } \\ \mathrm{n}=258\end{array} & \begin{array}{c}\text { CRP assistance } \\ \mathrm{n}=129\end{array} & \begin{array}{c}\text { Control } \\ \mathrm{n}=129\end{array} & P \text {-value* } \\ \text { Mean (SD) } & 34.17(37.33) & 34.89(38.41) & 33.46(36.36) & \\ \text { Median }(25-75 \mathrm{IQ}) & 18(<8-46) & 17(<8-52) & 19(<8-42) & 0.88 \\ \text { Min -max } & <8->160 & <8->160 & <8->160 & \\ 0-20 \mathrm{mg} / \mathrm{l} & 54.3 \%(140 / 258) & 56.6 \%(73 / 129) & 51.9 \%(67 / 129) & \\ 21-50 \mathrm{mg} / \mathrm{l} & 24.0 \%(62 / 258) & 17.8 \%(23 / 129) & 30.2 \%(39 / 129) & \\ 51-100 \mathrm{mg} / \mathrm{l} & 14.3 \%(37 / 258) & 17.1 \%(22 / 129) & 11.6 \%(15 / 129) & \\ >100 \mathrm{mg} / \mathrm{l} & 7.4 \%(19 / 258) & 8.5 \%(11 / 129) & 6.2 \%(8 / 129) & \end{array}$

* difference between CRP vs. control calculated using Mann-Whitney U for non-parametric testing

\section{Effect on antibiotic prescribing}

Antibiotic use following the index consultation was recorded for $43.4 \%(56 / 129)$ of patients managed with CRP versus $56.6 \%(73 / 129)$ of patients in the control group (RR 0.77, 95\% Cl 0.56-0.98, $P=0.03$ ) (Table 10.3 and Figure 10.1). This difference in antibiotic use remained significant for the 28-day follow-up period, $52.7 \%$ vs. $65.1 \%$ (RR $0.81,95 \% \mathrm{Cl} 0.62-0.99, \mathrm{p}=0.04$ ). At index consultation, $39.5 \%$ of patients in the CRP assisted group received immediate antibiotics, while $43.4 \%$ received no antibiotics and $17.1 \%(22 / 129)$ received a delayed prescription from their FP. In the control group these rates were $40.3 \%$ (immediate antibiotics), 37.2\% (no antibiotics) and 22.5\% (29/129, delayed antibiotics), respectively (Figure 10.1). Of those patients having received a delayed prescription in the control group $72.4 \%(21 / 29)$ filled their delayed 
prescription in the following days versus only $22.7 \%(5 / 22)$ in the CRP assisted group $(P<0.001)$.

Table 10.3 Effects of intervention on antibiotic use following the index consultation (by CRP category) and within 28 day follow-up. Exploratory data on antibiotic use per respiratory tract infection.

\begin{tabular}{lllllc} 
Antibiotic use & CRP assistance Control & RR & $95 \% \mathrm{Cl}$ & $P$-value \\
\hline Following index consultation & $43.4 \%(56 / 129)$ & $56.6 \%(73 / 129)$ & 0.77 & $0.56-0.98$ & 0.03 \\
Rhinosinusitis & $45.2 \%(33 / 73)$ & $60.3 \%(47 / 78)$ & & & \\
LRTI & $41.1 \%(23 / 56)$ & $51.0 \%(26 / 51)$ & & & \\
Within 28-day follow-up & $52.7 \%(68 / 129)$ & $65.1 \%(84 / 129)$ & 0.81 & $0.62-0.99$ & 0.04 \\
Rhinosinusitis & $57.5 \%(42 / 73)$ & $69.2 \%(54 / 78)$ & & & \\
LRTI & $46.4 \%(26 / 56)$ & $58.8 \%(30 / 51)$ & & & \\
Antibiotic use by CRP category & CRP assistance Control & & \\
$0-20 \mathrm{mg} / \mathrm{l}(\mathrm{n}=140)$ & $26.0 \%(19 / 73)$ & $49.3 \%(33 / 67)$ & & \\
$21-50 \mathrm{mg} / \mathrm{l}(\mathrm{n}=62)$ & $56.5 \%(13 / 23)$ & $59.0 \%(23 / 39)$ & & \\
$51-100 \mathrm{mg} / \mathrm{l}(\mathrm{n}=37)$ & $68.2 \%(15 / 22)$ & $66.7 \%(10 / 15)$ & & & \\
$>100 \mathrm{mg} / \mathrm{l}(\mathrm{n}=19)$ & $81.8 \%(9 / 11)$ & $87.5 \%(7 / 8)$ & &
\end{tabular}

Data are \% (number). Relative risks are corrected for clustering.

No statistical testing was performed on the exploratory data on antibiotic use per respiratory tract infections as this trial was designed to detect differences between the total group of patients per group.

Table 10.3 also shows antibiotic use per CRP category for the two groups. The effect of use of CRP to guide antibiotic prescribing is most evident in the category of CRP values below $20 \mathrm{mg} / \mathrm{l}$, which comprises $54.9 \%$ of all patients in this trial. In this large subgroup only $26 \%$ of patients used antibiotics in the CRP assisted group vs $49.3 \%$ in the control group (RR 0.53, 95\% Cl 0.30-0.85, $P=0.04$ ).

Those patients actually using antibiotics following the index consultation in the CRP assisted group had significantly higher median CRP values $(34 \mathrm{mg} / \mathrm{l}, 25-$ $75 \mathrm{IQ} 17-70)$ than those patients using antibiotics in the control group (22 $\mathrm{mg} / \mathrm{l}$, $25-75 I Q<8-48, P=0.04)$.

\section{Sensitivity analyses}

In a pre-specified exploratory analysis we investigated if demographic factors, case-mix and relevant co-morbidities affected the shown effect of CRP assistance on antibiotic prescribing. Inclusion of these variables in a logistic model as a sensitivity analysis of the primary endpoint did not alter the shown effect of CRP within LRTI and rhinosinusitis consultations. Moreover, to account and correct for variation at the level of the FP, we performed an additional multilevel analysis of the primary comparison. The effect of the intervention on 
antibiotic use following the index consultation (RR $0.75,95 \% \mathrm{Cl} 0.54-0.97$ ) and within the follow-up period ( $\mathrm{RR} 0.79,95 \% \mathrm{Cl} 0.60-0.99$ ) remained significant.

\section{Clinical recovery}

The interventions had no discernable effect on recovery, resulting in comparable median daily symptom scores for intervention and control group for LRTI and rhinosinusitis. Recovery slopes are presented as median symptom scores per day in Figure 10.2. Of all patients $22.9 \%$ felt fully recovered on day 7 in the CRP assisted group vs. $24.8 \%$ in the control group ( $P=0.73$ ). Median patient reported time to full recovery (self-assessment) was comparable across the groups for both conditions (Table 10.4). Although this trial was not designed to assess safety, there were no serious adverse events (death or hospitalisation).

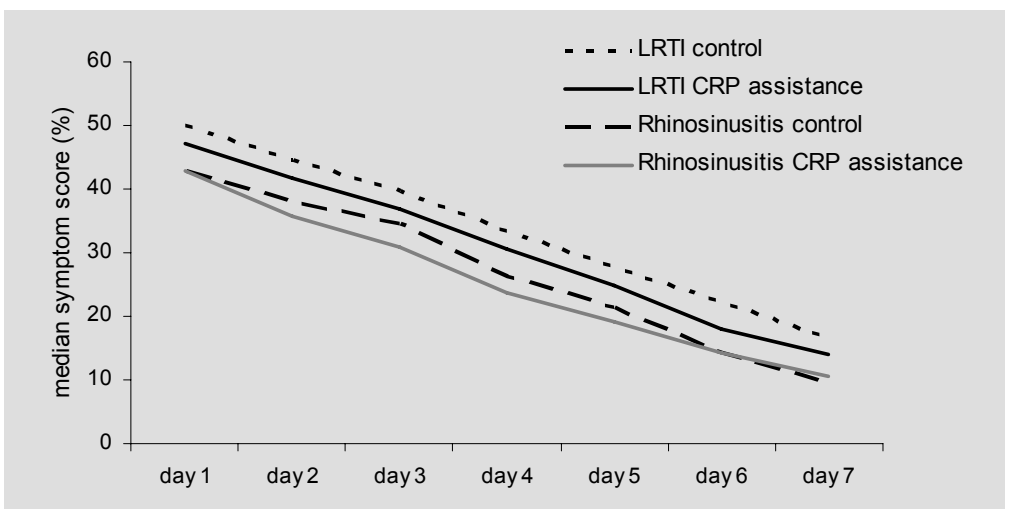

Figure 10.2 Median symptom scores per group during first week after index consultation.

Symptom scores for LRTI were calculated by summing and deriving percentual total scores for 6 symptoms: cough, phlegm, sleeping problems, dyspnoe, degree of illness and limiations in daily activities. Symptom scores for rhinosinusitis were calculated by summing and deriving percentual total scores for 7 symptoms: rhinorroe, blocked nose, dental pain, headache, pain at bending over, degree of illness and limitions in daily activities. Median symptom scores of intervention and control groups were not significantly different at any day in week 1 .

\section{Reconsultation, satisfaction and enablement}

Reconsultation, either initiated by the patient or the FP, occurred in about one out of four patients in the CRP assisted group, with slightly lower reconsultation rates for the control group, yet non-significant (Table 10.4). Patients' intention to reconsult with future similar symptoms was higher in the group using CRP assistance, with $75 \%$ of patients indicating that they would return to their FP 
with similar symptoms versus $61 \%$ in the control group ( $P=0.02$, Table 10.4). Overall, satisfaction with the index consultation was high. However, satisfaction scores were higher for patients in the CRP assisted group within the consultation. In the intervention group, $76 \%$ of patients were at least very satisfied with the consultation compared to $63 \%$ of patients in the control group $(P=0.03)$. In an exploratory analysis we found that a comparison of Likert scores for this question on satisfaction yielded a similar outcome. The Patient Enablement Index was similar for all groups (Table 10.4).

Table 10.4 Effects of interventions on patient-reported recovery and secondary outcomes (assessed after the index consultation).

\begin{tabular}{|c|c|c|c|}
\hline & CRP assistance & Control & $P$ value* \\
\hline \multicolumn{4}{|l|}{ Lower respiratory tract infection } \\
\hline$\%$ of patients feeling recovered on day 7 & $23.5(12 / 51)$ & $18.4(9 / 49)$ & 0.53 \\
\hline $\begin{array}{l}\text { Patient reported time to full recovery } \\
\text { median }(25-75 \mathrm{IQ}) \\
\text { mean (SD) }\end{array}$ & $\begin{array}{l}15.5(9.5-28) \\
17.5(9.2)\end{array}$ & $\begin{array}{c}20(13.3->28) \\
19.8(9.5)\end{array}$ & 0.21 \\
\hline \multicolumn{4}{|l|}{ Rhinosinusitis } \\
\hline$\%$ of patients feeling recovered on day 7 & $22.4(15 / 67)$ & $28.9(22 / 76)$ & 0.37 \\
\hline $\begin{array}{l}\text { Patient reported time to full recovery } \\
\text { median }(25-75 \mathrm{IQ}) \\
\text { mean (SD) }\end{array}$ & $\begin{array}{c}14(10-28) \\
17.3(9.3)\end{array}$ & $\begin{array}{c}14(7->28) \\
16.6(9.9)\end{array}$ & 0.77 \\
\hline All patients $(n=258)$ & CRP assistance & Control & $P$ value* \\
\hline Reconsultation & $25.6 \%(33 / 129)$ & $17.8 \%(23 / 129)$ & 0.13 \\
\hline $\begin{array}{l}\text { Satisfaction, } \\
\% \text { of patients at least very satisfied }\end{array}$ & $76.3(90 / 118)$ & $63.2(79 / 125)$ & 0.03 \\
\hline $\begin{array}{l}\text { Future consultation intention } \\
\% \text { of patient likely to reconsult }\end{array}$ & $74.8(86 / 115)$ & $61.0(75 / 123)$ & 0.02 \\
\hline $\begin{array}{l}\text { Patient enablement, max. score } 12 \\
\text { median (IQR) } \\
\text { mean (SD) }\end{array}$ & $\begin{array}{c}2(4) \\
2.5(2.6)\end{array}$ & $\begin{array}{c}2(4) \\
2.3(2.4)\end{array}$ & 0.58 \\
\hline
\end{tabular}

* Calculated using Chi-square and Mann-Whitney U where applicable

\section{Discussion}

\section{Main findings}

The introduction of CRP testing to assist antibiotic prescribing decisions in LRTI and rhinosinusitis consultations resulted in a reduction of antibiotic use directly following index consultation and during 28-day follow-up. Those patients receiving a CRP assisted delayed prescription only filled the prescription in the 
minority of cases, whereas the majority of patients in the control group filled these prescriptions. Patient satisfaction with care was higher when CRP was used during the consultation and those patients managed with CRP assistance indicated more often that they would reconsult with similar symptoms in the future. Although antibiotic use went down in the CRP assistance group, clinical recovery was not affected.

\section{Strengths and limitations}

The number of patients assessed for eligibility but not recruited may have been higher than actually recorded by the FPs, which is commonly seen in practicebased primary care studies. Yet, we are confident that this did not influence the results and generalizability of our findings. Unlike the previous CRP cluster randomised trial we performed ${ }^{17}$, risk of recruitment bias is lower in this trial, because patients were individually randomised with balanced baseline characteristics. Also, if we compare baseline CRP values and signs and symptoms we see comparable rates to those recorded in previous LRTI and rhinosinusitis studies in family practice. ${ }^{17,18}$ These findings indicate that we have recruited patients who are representative for those consulting in family practice for these conditions.

Our broad inclusion criteria allowed recruitment of the full range of adult patients seen in family practice with acute LRTI or rhinosinusitis, further enhancing the generalizability of our findings for family practice. Inclusion criteria for LRTI have been previously used ${ }^{15,32}$, but those for rhinosinusitis are ambiguous and inconsistently used throughout studies and guidelines. To the best of our knowledge, we based our rhinosinusitis criteria on those studies performed in family practice settings. ${ }^{2334}$ We combined these two respiratory tract infections in this trial, because these conditions show the highest antibiotic prescribing figures, despite evidence of hardly any benefit for patients. Additionally, it helped to increase the likelihood of including the required number of participants. As a result however, our trial was not powered to detect differences in subgroups of the two separate conditions. Larger trials assessing the chosen approach may be warranted, also to provide more insight in the group using delayed prescriptions. This group of patients was relatively small in the present study.

Blinding was not an issue in this study, as knowledge of the intervention was crucial for the FPs to decide on management within the consultation. In contrast, allocation concealment was crucial in this trial. We chose to use the SNOSE (Sequentially Numbered Opaque Sealed Envelopes) method with each pile per practice prepared using permuted block randomisation to ensure similar enrolment in both groups. ${ }^{24}$ As the primary purpose of randomizing patients into treatment arms is to prevent clinicians and patients from predicting, and thus 
influencing, which patients will receive which intervention, we eliminated this potential bias by concealing the upcoming allocation sequence in a practical and effective way. Importantly, this method did not require any additional actions by the FP, such as dialling to a randomization centre, further minimizing workload for the FP and resembling daily practice consultations.

We aimed to recruit at least 200 patients during the pre-defined recruitment period from November 2007 until April 2008. By the end of recruitment we had 258 patients with no loss to follow-up for the primary outcome and a higher than expected response rate on patient reported outcomes of $94 \%$. Hence, attrition bias will be minimal and this can be regarded as a strength of our study. It is increasingly recognised that clustering should be taken into account in individual RCTs. ${ }^{35}$ We performed a multilevel analysis as a sensitivity analysis, which accounted for variation on the level of FP. The effect size remained significant, further strengthening the reliability of the shown effect on antibiotic use.

\section{Comparison with other studies - delayed prescribing}

Although our intervention was primarily aimed at clinicians in assisting them in antibiotic prescribing, the role of the patient in the outcome is crucial. Only a minority of patients in the CRP assisted group actually used their delayed prescription (23\%), while in the control group $73 \%$ of those receiving a delayed prescription returned to fill it. In the end, this led to significantly less antibiotic use in the CRP assisted group, both following index consultation as well as during 28-day follow-up. A systematic review of five controlled trials investigating delayed prescribing for various RTIs showed a consistent reduction in antibiotic usage, with filling rates of delayed prescription of 24 to $65 \%$. Ancillary analysis of our data revealed that control patients who got a delayed prescription had a lower median CRP $(16 \mathrm{mg} / \mathrm{l})$ in a wider range $(>150$ $\mathrm{mg} / \mathrm{l})$ compared to the patients receiving a delayed prescription in the CRP assisted group $(29 \mathrm{mg} / \mathrm{l}$, range $70 \mathrm{mg} / \mathrm{l})$. Hence, in the intervention group, delayed prescriptions were better focused on patients with intermediately elevated CRP levels.

We have incomplete data on the stated reasons of all patients filling delayed prescriptions, but of those patients with data, none indicated that their illness had deteriorated. This finding gives rise to the assumption that non-medical reasons may be the driving force behind filling delayed prescriptions. Earlier research indicates that most patients are confident in making the decision about whether or not to take their antibiotics when receiving a delayed prescription for URTIs and $92.5 \%$ would choose to receive a delayed prescription again. ${ }^{36} \mathrm{We}$ also know that patients may pressure their FPs for unnecessary antibiotics either by directly asking or indirectly by the way they present their complaint. ${ }^{12,37}$ 
A qualitative study on delayed prescribing showed that physicians are likely to use delayed prescription as a technique to decrease antibiotic use in patients they perceive as wanting antibiotics regardless of the medications' appropriateness. ${ }^{38}$ In our study, CRP testing and communicating the test results and its implications with the patient may have addressed patients' issues and may have provided reassurance to a certain extent, resulting in fewer filled delayed prescriptions.

\section{Comparison with other studies - C-reactive protein point of care testing}

While the FP's agenda may be adequately addressed by CRP testing (differentiating serious from self-limiting disease) and delayed prescribing (safety-netting), the full patient's agenda must not be forgotten. We recently showed that a context-rich communication skills training method for FPs significantly reduced antibiotic prescribing for LRTI without compromising clinical outcomes or patient satisfaction. In that same cluster randomised trial we showed the positive effect of CRP point of care testing on reducing antibiotic use for LRTI. Both interventions combined - CRP addressing the FPs' agenda (disease perspective) and communication principally addressing the patients' agenda (illness perspective) - did have the largest effect on antibiotic prescribing, although the trial was not designed to study this effect. ${ }^{17}$ Although patients in the current trial did not reconsult more often when manage by CRP, they did more frequently indicate that they would reconsult with similar future symptoms, highlighting a possible medicalising effect of a diagnostic test.

A recent study comparing CRP with a clinical algorithm in the emergency room setting did not find an effect on antibiotic use for acute cough illness. ${ }^{39}$ However, this study was not performed in family practice. The authors suspect a Hawthorne effect of physicians changing prescribing behavior during trial monitoring, as the prescribing rate in control group was significantly lower than rates in periods before the trial. Also, chest X-rays were ordered in half of the patients, while in Dutch family practice these radiographs are hardly used prior to prescribing decision.

Other biomarkers, such as procalcitonin, have been suggested. Despite unmistakable effect on antibiotic use in a recent efficacy trial $^{40}$, the future potential of procalcitonin as a pragmatic intervention in family practice may be limited for two reasons as acknowledged by the authors. First of all, procalcitonin is not available as a point of care test. And secondly, costs are considerable, which is not desirable for high incidence common infections in family practice with low costs per illness episode. CRP by contrast, is an officebased test with acceptable accuracy and cost (approximately \$3-5 per point of 
care test), that is available to be integrated into the ambulatory management of respiratory infections.

\section{Practice implications and future research}

Many patients with non-severe acute LRTI or rhinosinusitis could ideally be assessed and managed based on clinical findings in ambulatory care. Yet, when in doubt of diagnosis and illness severity, or when confronting serious patient demands regarding antibiotics, CRP point of care testing is a helpful, additional tool. It can decrease diagnostic uncertainty, guide treatment and may possibly make a non-antibiotic management more acceptable to the patient. The test result adds incremental information to the FPs' obtained information from medical history and physical examination. The relation of CRP with an infiltrate on chest radiography as a reference standard showed an area under the Receiver Operating Curve (ROC) of 0.80 , and even 0.85 for high quality diagnostic studies. ${ }^{16}$ In a diagnostic study involving 243 LRTI patients recruited in family practice, the addition of CRP to a model based on signs and symptoms increased the area under the curve from 0.70 to $0.90 .^{15}$

In particular, a low CRP test result $(<20 \mathrm{mg} / \mathrm{l})$, which was the case in more than $50 \%$ of the patients in our study, as well as in our previous study ${ }^{17}$, is helpful in excluding serious illness and leads to a strong reduction of antibiotic use without compromising outcome. Crucially, all RTI consultations, with or without CRP testing or delayed prescribing, should be accompanied by an evidencebased clear explanation about natural course and alarm symptoms and should ideally address the patient's illness experience including worries and expectations. The interventions studied in this trial are additional tools to facilitate and support the RTI consultation.

Similar to FPs in the US, the participating FPs did not have any experience with CRP point of care testing before the start of the study, apart from the four week run-in period. Confidence in CRP testing, in particular not prescribing antibiotics in case of low test results, takes time and may not have reached its full potential during the 6 months study period, so reduction in antibiotic prescribing rates could have been larger with a longer study period.

A delayed prescription with explanation on natural course and indications when to use the antibiotic may be a valuable tool for both FP and patient in patients with intermediate CRP levels and associated clinical features. We have limited information on patients' views on delayed prescribing in our country, although in a nationwide public survey, we found that $40 \%$ of people would find it an acceptable strategy. ${ }^{41}$ Two commonly mentioned disadvantages of delayed prescribing are firstly the possibility of giving mixed messages about the purpose and benefits of antibiotics, and secondly considerable inconsistency and contradictory practices regarding its use. The former could be restricted by 
giving clear information on when to use it and when to reconsult. In this trial delayed prescriptions were handed out together with a short information sheet. Concerning the latter, CRP assistance may guide prescribing by identifying those patients who will probably get better without treatment, but may need a safety net for the next few days in case a increasing illness severity.

As the vast majority of antibiotics are prescribed in family practice, introduction of CRP assisted prescribing in routine family practice can improve antimicrobial stewardship with a sharp decrease in actual numbers of antibiotic prescriptions per year. The effect size may even be higher in the US, as a higher outpatient antibiotic expenditure is observed when compared to the Netherlands, which has the lowest outpatient antibiotic use in Europe. ${ }^{42}$

\section{Conclusion}

CRP point of care testing to assist antibiotic prescribing decisions for LRTI and rhinosinusitis - including delayed prescribing - is a useful strategy to target the right prescription at the right patient, with favourable outcomes on antibiotic use, patient satisfaction and no detrimental effects on clinical recovery, hence supporting antimicrobial stewardship. 


\section{References}

1. Hirschmann JV. Antibiotics for Common Respiratory Tract Infections in Adults. Arch Intern Med 2002;162:256-64.

2. De Sutter A, Lemiengre M, Van Maele G, van Driel M, De Meyere M, Christiaens $T$, De Maeseneer J. Predicting Prognosis and Effect of Antibiotic Treatment in Rhinosinusitis. Ann Fam Med 2006;4:486-93.

3. Smucny J, Fahey T, Becker L, Glazier R. Antibiotics for acute bronchitis. Cochrane Database Syst Rev 2004(4).

4. Arroll B, Kenealy $\mathrm{T}$, Kerse N. Do delayed prescriptions reduce antibiotic use in respiratory tract infections? A systematic review. Br J Gen Pract 2003;53:871-7.

5. Young J, De Sutter A, Merenstein D, van Essen GA, Kaiser L, Varonen H, Williamson I, Bucher HC. Antibiotics for adults with clinically diagnosed acute rhinosinusitis: a meta-analysis of individual patient data. Lancet 2008;371:908-14.

6. Holmes WF, Macfarlane JT, Macfarlane RM, Hubbard R. Symptoms, signs, and prescribing for acute lower respiratory tract illness. Br J Gen Pract 2001;51:177-81.

7. Akkerman AE, Kuyvenhoven MM, van der Wouden JC, Verheij TJ. Prescribing antibiotics for respiratory tract infections by GPs: management and prescriber characteristics. $\mathrm{Br} \mathrm{J}$ Gen Pract 2005;55:114-8.

8. Hopstaken RM, Stobberingh EE, Knottnerus JA, Muris JWM, Nelemans P, Rinkens PELM, Dinant GJ. Clinical items not helpful in differentiating viral from bacterial lower respiratory tract infections in general practice. Journal of Clinical Epidemiology 2005;58:175-83.

9. Macfarlane J, Holmes W, Gard P, Macfarlane R, Rose D, Weston V, Leinonen M, Saikku P, Myint S. Prospective study of the incidence, aetiology and outcome of adult lower respiratory tract illness in the community. Thorax 2001;56:109-14.

10. Lindbaek M, Hjortdahl P, Johnsen UL. Randomised, double blind, placebo controlled trial of penicillin $\mathrm{V}$ and amoxycillin in treatment of acute sinus infections in adults. BMJ 1996;313:325-9.

11. Coenen S, Michiels B, Renard D, Denekens J, Van Royen P. Antibiotic prescribing for acute cough: the effect of perceived patient demand. Br J Gen Pract 2006;56:183-90.

12. Little P, Dorward M, Warner G, Stephens K, Senior J, Moore M. Importance of patient pressure and perceived pressure and perceived medical need for investigations, referral, and prescribing in primary care: nested observational study. BMJ 2004;328:444.

13. Seamark DA, Backhouse SN, Powell R. Field-testing and validation in a primary care setting of a point-of-care test for C-reactive protein. Ann Clin Biochem 2003;40(Pt 2):178-80.

14. Flanders SA, Stein J, Shochat G, Sellers K, Holland M, Maselli J, Drew WL, Reingold AL, Gonzales R. Performance of a bedside C-reactive protein test in the diagnosis of communityacquired pneumonia in adults with acute cough. Am J Med 2004;116:529-35.

15. Hopstaken RM, Muris JWM, Knottnerus JA, Kester ADM, Rinkens PELM, Dinant GJ. Contributions of symptoms, signs, erythrocyte sedimentation rate and C-reactive protein to a diagnosis of pneumonia in acute lower respiratory tract infection. $\mathrm{Br} J$ Gen Pract 2003;53: 358-64.

16. van der Meer V, Neven AK, Broek PJvd, Assendelft WJJ. Diagnostic value of C reactive protein in infections of the lower respiratory tract: systematic review. BMJ 2005;331:26-9.

17. Cals JWL, Butler CC, Hopstaken RM, Hood K, Dinant GJ. Effect of C-reactive protein point of care testing and clinician communication skills training on antibiotic use and patient recovery in lower respiratory tract infections: a cluster randomised trial. BMJ 2009;338:b1374.

18. Bjerrum L, Gahrn Hansen B, Munck AP. C-reactive protein measurement in general practice may lead to lower antibiotic prescribing for sinusitis. Br J Gen Pract 2004;54(506):659-62.

19. Arroll B, Kenealy T, Goodyear-Smith F, Kerse N. Delayed prescriptions. BMJ 2003;327: 1361-1362.

20. Spurling GK, Del Mar CB, Dooley L, Foxlee R. Delayed antibiotics for symptoms and complications of respiratory infections. Cochrane Database Syst Rev 2004(4):CD004417. 
21. Little P, Rumsby K, Kelly J, Watson L, Moore M, Warner G, Fahey T, Williamson I. Information Leaflet and Antibiotic Prescribing Strategies for Acute Lower Respiratory Tract Infection: A Randomized Controlled Trial. JAMA 2005;293:3029-35.

22. Dowell J, Pitkethly M, Bain J, Martin S. A randomised controlled trial of delayed antibiotic prescribing as a strategy for managing uncomplicated respiratory tract infection in primary care. Br J Gen Pract 2001;51:200-5.

23. Cals JWL, Chappin FHF, Hopstaken RM, van Leeuwen ME, Hood K, Butler CC, Dinant GJ. Creactive protein point of care testing for lower respiratory tract infections; a qualitative evaluation of experiences in general practice. submitted 2009.

24. Doig GS, Simpson F. Randomization and allocation concealment: a practical guide for researchers. J Crit Care 2005;20:187-91; discussion 191-3.

25. Cals JW, Hopstaken RM, Butler CC, Hood K, Severens JL, Dinant GJ. Improving management of patients with acute cough by C-reactive protein point of care testing and communication training (IMPAC3T): study protocol of a cluster randomised controlled trial. BMC Fam Pract 2007;8:15.

26. Howie JG, Heaney DJ, Maxwell M, Walker JJ. A comparison of a Patient Enablement Instrument (PEI) against two established satisfaction scales as an outcome measure of primary care consultations. Fam Pract 1998;15:165-71.

27. Kuyvenhoven M, van Essen G, Schellevis F, Verheij T. Management of upper respiratory tract infections in Dutch general practice; antibiotic prescribing rates and incidences in 1987 and 2001. Fam Pract 2006;23:175-9.

28. Kuyvenhoven MM, Van Balen FA, Verheij TJ. Outpatient antibiotic prescriptions from 1992 to 2001 in The Netherlands. J Antimicrob Chemother 2003;52:675-8.

29. van Duijn HJ, Kuyvenhoven MM, Tiebosch HM, Schellevis FG, Verheij TJ. Diagnostic labelling as determinant of antibiotic prescribing for acute respiratory tract episodes in general practice. BMC Fam Pract 2007;8:55.

30. Zhang J, Yu KF. What's the relative risk? A method of correcting the odds ratio in cohort studies of common outcomes. Jama 1998;280:1690-1.

31. Altman DG, Schulz KF, Moher D, Egger M, Davidoff F, Elbourne D, Gøtzsche PC, Lang T; CONSORT GROUP (Consolidated Standards of Reporting Trials). The revised CONSORT statement for reporting randomized trials: explanation and elaboration. Ann Intern Med 2001;134:663-94.

32. Cals JW, Butler CC, Hopstaken RM, Hood K, Dinant GJ. Effect of point of care testing for C reactive protein and training in communication skills on antibiotic use in lower respiratory tract infections: cluster randomised trial. BMJ 2009;338:b1374.

33. Lindbaek M, Hjortdahl $\mathrm{P}$. The clinical diagnosis of acute purulent sinusitis in general practice-a review. Br J Gen Pract 2002;52:491-5.

34. Young J, Bucher $\mathrm{H}$, Tschudi $\mathrm{P}$, Periat $\mathrm{P}$, Hugenschmidt $\mathrm{C}$, Welge Lussen A. The clinical diagnosis of acute bacterial rhinosinusitis in general practice and its therapeutic consequences. J Clin Epidemiol 2003;56:377-84.

35. Lee KJ, Thompson SG. Clustering by health professional in individually randomised trials. BMJ 2005;330:142-4.

36. Edwards M, Dennison J, Sedgwick P. Patients' responses to delayed antibiotic prescription for acute upper respiratory tract infections. Br J Gen Pract 2003;53:845-50.

37. Scott JG, Cohen D, DiCicco Bloom B, Orzano AJ, Jaen CR, Crabtree BF. Antibiotic use in acute respiratory infections and the ways patients pressure physicians for a prescription. $J$ Fam Pract 2001;50:853-8.

38. Arroll B, Goodyear-Smith F, Thomas DR, Kerse N. Delayed antibiotic prescriptions: what are the experiences and attitudes of physicians and patients? J Fam Pract 2002;51:954-9.

39. Gonzales R, Aagaard EM, Camargo CA Jr, Ma OJ, Plautz M, Maselli JH, McCulloch CE, Levin SK, Metlay JP. C-Reactive protein testing does not decrease antibiotic use for acute cough illness when compared to a clinical algorithm. J Emerg Med 2008.

40. Briel M, Schuetz P, Mueller B, Young J, Schild U, Nusbaumer C, Périat P, Bucher HC, ChristCrain M. Procalcitonin-guided antibiotic use vs a standard approach for acute respiratory tract infections in primary care. Arch Intern Med 2008;168:2000-7. 
41. Cals JWL, Boumans D, Lardinois RJM, Gonzales R, Hopstaken RM, Butler CC, Dinant GJ. Public beliefs on antibiotics and respiratory tract infections: an internet-based questionnaire study. Br J Gen Pract 2007;57:942-7.

42. Goossens H, Ferech M, Coenen S, Stephens P. Comparison of outpatient systemic antibacterial use in 2004 in the United States and 27 European countries. Clin Infect Dis 2007;44:1091-5. 




\section{Abstract}

\section{Background}

Uptake of interventions to improve quality of care by clinicians is variable and is influenced by clinicians' attitudes. The influence of clinicians' experience with an intervention on their preference for adopting interventions is largely unknown.

\section{Methods}

Thematic analysis of semi-structured interviews exploring views and attitudes towards an illnessfocused intervention (specific communication skills training) and a disease-focused intervention (CRP point of care testing) to optimize management of lower respiratory tract infections (LRTI) among general practitioners (GPs) who had used both interventions for two years in a randomised trial (exposed GPs), and GPs without experience of either intervention (non-exposed GPs).

\section{Results}

All but two of the ten non-exposed GPs indicated that they would prioritise implementation of the disease-focused intervention of CRP testing over communication skills training, while all but one GP in the exposed group said that they would prioritise the illness focused approach of communication skills training as it was more widely applicable, whereas CRP testing was confirmatory and useful in a subgroups of patients.

\section{Conclusions}

There are differences in attitudes to prioritising contrasting interventions for optimising LRTI management among GPs with and without experience of using the interventions, although GPs in both groups recognised the importance of both approaches to optimise management of acute cough. GPs' experiences with and attitudes towards interventions need to be taken into account when planning rollout of interventions aimed at changing clinical practice. 


\section{Introduction}

Achieving effective uptake of new evidence into routine clinical care is challenging. Several barriers and enablers to evidence uptake have been identified. These range from practice environment and organisational factors to professional knowledge and attitudes. ${ }^{1}$

Continuing professional development is concerned with the acquisition, enhancement and maintenance of knowledge, skills and attitudes. Learning and improving practice, including uptake of new interventions, is mainly governed by individual clinicians' motivation and perceived needs. ${ }^{2}$ However, clinicians may not choose to adopt the most effective or important interventions and indentifying factors influencing health professionals' behaviours is challenging. ${ }^{3}$ For example, contrasting approaches have been suggested for enhancing physician antibiotic prescribing. ${ }^{4} \mathrm{~A}$ disease-focused perspective promotes interventions to decrease diagnostic uncertainty such as diagnostic tests. An illness-focused perspective promotes interventions aimed at addressing the patients' agenda such as physician communication skills training. However, it is not known how experience with one or other of these broad approaches influences GPs perceptions about which intervention type they would prioritise for adoption into their own practice.

We therefore studied the role of experience with interventions in influencing clinician prioritising of intervention uptake. We focused on two contrasting interventions for improved management of the exemplar condition of lower respiratory tract infections (LRTI) in general practice. ${ }^{5}$ We describe the attitude of physicians with experiences of implementing both approaches and the attitude of physicians who have no practical experience of either intervention. Our goal was to highlight the influence of physician exposure to contrasting approaches when considering prioritising interventions for adoption into their clinical practice.

\section{Method}

\section{IMPAC ${ }^{3} \top$ trial}

We analysed qualitative interview data obtained from general practitioners (GP) who participated in the IMPAC ${ }^{3} \mathrm{~T}$ trial (ISRCTN85154857). ${ }^{5}$ This study was a factorial, cluster randomised clinical trial assessing the effect of two contrasting interventions, singly and combined, on antibiotic prescribing for LRTI. These interventions were:

- Disease-focused: C-reactive protein (CRP) point of care testing, assisting GPs to differentiate serious from self-limiting LRTI. 
- Illness-focused: Clinician communication skills training, assisting GPs to provide evidence-based information on the natural course of LRTI and setting realistic expectations on the role of antibiotics for LRTI.

The trial protocol ${ }^{5}$ and description of the clinician communication skills training ${ }^{6}$ as well as the effectiveness ${ }^{7}$ and cost-effectiveness ${ }^{8}$ of the two interventions have been described elsewhere. In brief, both interventions were effective at reducing antibiotic prescribing for $\mathrm{LRTI}$, without compromising clinical outcome or patient satisfaction. Both interventions were cost-effective from the health care perspective. As part of the process evaluation, we interviewed all participating GPs after trial completions to explore their experiences with and attitudes towards the interventions.

As GP practices were randomised in the trial, we had the unique opportunity to explore views and attitudes towards these contrasting interventions of two distinct groups of GPs:

- GPs exposed to both interventions: 10 GPs had used both interventions (CRP and communication skills) for at least two years (exposed GPs)

- GPs not exposed to either intervention: $10 \mathrm{GPs}$ practicing as usual without either of the two interventions during these two years (non-exposed GPs).

\section{Interview procedure}

We used qualitative research methods as these are best suited to achieving a deep understanding of experiences and views from the perspective of the physicians (rather than quantifying the pre-conceived notions of researchers). ${ }^{9}$ We conducted individual, semi-structured interviews in GP surgeries. The average length was 30 minutes. Interviews were audio taped and took place in the first winter after the end of the trial. The GPs were told that our purpose was not to audit or pass judgement on practice but to understand their experiences and views. At the time of the interview, GPs were unaware of the trial results. Two trained interviewers conducted semi-structured interviews. For unexposed GPs, we extensively described the interventions and asked them about the possible impact on their own practice and about their preferences for prioritising the interventions. The interview guide was piloted in one videotaped interview. All questions were open, followed by predetermined prompts when there was no response to the initial question. We aimed to interview all 20 study GPs. The main question in the interview schedule that generated data for the present analysis was: Which intervention would help you most improving your management of LRTI and why?

\section{Data analysis}

The audio taped interviews were transcribed by an experienced medical typist. Three researchers then read the transcripts. Analysis and data collection were 
conducted in parallel. Coding schedules were agreed and piloted. $70 \%$ of the interviews were double coded, with the remaining transcripts coded by only one researcher. Discrepancies were resolved by discussion whenever possible. Where disagreement remained, a third researcher (JC) was consulted who made the final decision. We sought to identify commonly expressed themes as well as unusual cases using thematic content analysis. This method of analysis is essentially a process of summarization, categorization and counting frequency of responses. ${ }^{10}$ Data analysis and reporting was assisted by NVivo software.

\section{Results}

\section{Prioritising the illness or disease-focused intervention}

All $20 \mathrm{GPs}$ in the relevant randomisation groups in the cluster randomised controlled trial agreed to be interviewed. GPs' characteristics in each group were similar and comparable to average Dutch GPs. ${ }^{7}$ The quotations in Text box 1 illustrate that GPs in the two groups expressed contrasting initial reactions in answer to the key question (Which intervention would help you most improving your management of LRTI and why?)

All but two of non-exposed GPs indicated they would prefer to adopt the disease-focused intervention of CRP testing to optimise management of LRTI in their practice. This contrasted with the exposed GPs, where all but one indicated they favoured the illness-focused approach of enhanced communication skills training for LRTI management. The one exception in this group declined to make a choice, as he felt both approaches should always be integrated.

\section{Non-exposed GPs choosing the disease-focused intervention}

Non-exposed GPs expressed favourable attitudes to CRP point of care testing relating to the professional context of their working environment. "I'm convinced that it will enhance diagnostic certainty (GP5, non-exposed)" and "I'm sure that half of all prescriptions are not necessary and CRP is useful for confirming this assumption before actually making the decision about prescribing (GP19, nonexposed)" These attitudes arise from a disease-focused concern to rule out serious disease. Yet, achieving shared decisions with patients not to prescribe antibiotics was also frequently mentioned by nearly all non-exposed GPs. "CRP would be useful in my practice and because I feel I can get patients on my side with it. I think that the magic of the machine is more powerful than the magic of my words. (GP5, non-exposed)" 
This last quote is typical of non-exposed GPs who attached greater value to CRP testing compared to enhanced communication skills training. A typical quote from a non-exposed GP addressed barriers: "I don't think that this is where my weakness is." (GP3, non-exposed) And "It [communication skills training] is never real life, training only tells you how you could or may do it. (GP16, non-exposed))" Four non-exposed GPs stated that communication skills training was not a priority for them, and four others said they already deployed excellent communication skills. Non-exposed GPs were sceptical of the value of the time investment required for enhanced communication skills training. They were also concerned by the potential negative impact on consultation length of focusing on communication about antibiotics with their patients. So many nonexposed GPs did not feel any compulsion to act in this regard. "What we want as GPs must fit in 10-minute consultations. So as long as we aim to do these things (communication skills) within the time restriction of 10 minutes, implementing communication skills will not be feasible" (GP5, non-exposed)"

Despite the overwhelming preference for CRP testing as their priority intervention, all but one of the non-exposed GPs also expressed positive attitudes towards illness-focused communication in LRTI. Typical comments were: "In the end it [good communication] will lead, so we hope, to a satisfied patient, a satisfied GP and less antibiotic use (GP12, non-exposed)" and "I always do it, I find it the most important part of my professional practice. (GP15, non-exposed)"

\section{Exposed GPs choosing the illness-focused intervention}

All but one of the GPs exposed to both interventions indicated that if they had to choose, they would select the illness-focused intervention over the diseasefocused intervention. The remaining GP preferred not to make a choice as he felt both approaches should always be integrated. However, all exposed GPs also saw a place for CRP testing as for some, but not all, patients with LRTI. Typical quotes are: "I think these communication skills are more essential, with CRP giving additional guidance (GP10, exposed)" and "Communication is of utmost importance in general practice. More important even than drugs, so I find this communication skill training crucial and CRP is a useful addition. (GP18, exposed)" Eight GPs indicated that they used their enhanced communication skills with all patients and used CRP only when faced with particular problems: "It depends on the patient. For some patients, [CRP] could be of additional value, but some I think will do fine without the test and the communication bit is more than adequate, while some patients want more objective measures [like CRP]. It certainly depends on the patient which strategy / choose (GP13, exposed)" 


\section{The best of both worlds?}

Despite differences in prioritising the interventions, both groups acknowledged a central role for both approaches to optimise management of acute cough, albeit from different perspectives.

In general, exposed GPs stressed the value of having both approaches. Half suggested the interventions would be synergistic and all agreed that having the combination available would be ideal. "I think you can combine both quite nicely, it is additive, like a said before. It is a very natural combination, very complete indeed (GP7, exposed)", "Management decisions are more robust if you combine them (GP9, exposed)" and "CRP is a confirmation of your account of things. If they [patients] hear that their blood test was also normal, your explanation becomes even more credible to patients (GP2, exposed)". Although the dominant view was that good communication skills would be adequate for optimal handling of most consultations, the GP's own agenda - including dealing with diagnostic uncertainty - was not forgotten and here CRP testing had a role "You can use it when patients are in doubt [not convinced], but certainly also when you yourself are uncertain (GP17, exposed)" Time constraints was the only commonly mentioned disadvantage of utilising both approaches within LRTI consultations. However, GPs in this group did not see this as a barrier to implementing the approaches. "It takes a bit more time, but I do think that we then confirm the decisions from two angles, which provides more satisfaction and reassurance. (GP2, exposed)"

Non-exposed GPs recognised the value of both approaches but were nevertheless inclined to express a preference for the one approach (CRP) over the other. On the one hand to decrease diagnostic uncertainty, but also to convince patients: "CRP would be useful in my practice and because I feel I can get patients on my side with it. I think that the magic of the machine is more powerful than the magic of my words. (GP5, non-exposed). "However, they saw good communication skills as a key competence for daily practice anyway, for example: "I have been GP for a long time and this is something I have always been mindful of, structured and focused communication. That's always something I strive for, time and time again, and I'll keep doing it until you get sick of it. (GP15, non-exposed)"'”

\section{Discussion}

This study found differences in GPs' expressed preferences for prioritising contrasting interventions to optimise LRTI management. Those GPs who had experience of both an illness-focused intervention (communication skills training) and a disease-focused intervention (CRP point of care test) indicated 
that they would chose to prioritise enhanced communication skills. Conversely, GPs without access to CRP point of care testing and enhanced communication skills training indicated they would prefer to have access to the disease-focused intervention (CRP).

The views and attitudes expressed in this study must be considered in the light of the quantitative findings from the randomised factorial trial. ${ }^{7}$ Here our primary analysis considered an issue of discrete choice about which intervention they would prioritise. Apart from the striking differences between the exposed and non-exposed clinicians in relation to the study question, many similarities between the two groups were identified. Both recognised a place for both approaches in the management of acute cough.

These findings may be helpful when considering barriers to, and incentives for achieving evidence-based practice and implementation, a process which is receiving greater research and policy attention. ${ }^{11}$ Although non-exposed GPs saw skilful communication as a core competency for daily practice, our data did not indicate a hunger for improving specific communication skills to better manage LRTI. Such professional barriers will determine whether or not an intervention is successfully adopted into routine care. On the other hand, GPs who had been exposed to the interventions saw a role for enhanced communication skills in all LRTI consultations. They stated that the diseasefocused intervention (CRP) could be useful in managing a subgroup of patients. This study included selected GPs: those that had recently participated in a RCT. Their views may no be typical of GPs' views on prescribing decisions and antimicrobial resistance. ${ }^{12-16}$ GPs' accounts of their experiences of CRP point of care testing for LRTI in this trial have been reported elsewhere. ${ }^{17}$ While nonexposed GPs did not have access to the interventions, they had been recruiting LRTI patients to the trial over two winters, and some contamination may have occurred. We did not explore patients' views in this research. However, we do know from the trial data that participating patients were highly satisfied with their consultations, irrespective of the intervention their managing clinician was exposed to. ${ }^{7}$

Effective communication is the foundation of good medical practice, which exposed GPs recognised. They also recognised the importance of the enhanced communication skills intervention for optimising the management of a specific condition, LRTI. Nevertheless, they did indicate that differentiating serious from self-limiting disease is a crucial component of their professional role. They found CRP testing valuable in a specific subgroup of patients, namely those who were not convinced of management decisions based on history and physical examination alone. It would be erroneous to conclude that exposed GPs would only want to use their communication skills and never use CRP point of care testing. All exposed GPs indicated that CRP testing had a useful role in LRTI management. Similarly, non-exposed GPs recognised the 
value of communication skills training in general, although they considered that they would find CRP point of care testing more useful. This may also be explained by how enhanced communication skills and a diagnostic test were conceptualised by this non-exposed group. Since communication is seen as already essential to good medical care, an intervention to further expand these skills may be seen as less important than a new diagnostic test, which adds to the physician's agenda of increasing diagnostic certainty. Similarly, a test result can also be seen as an aid to persuade patients to accept certain management decisions, exemplified by a striking quote by non-exposed GP5 (Table 11.1). Both interventions can affect the communication dynamics within a consultation and despite the fact that a diagnostic test is a disease-focused intervention, it may affect the illness experience of the patient as well.

As with previous research, GPs in this study were concerned about the impact of using enhanced communication skills and shared decision making on consultation length ${ }^{18,19}$. Implementing communication skills did not increase consultation time beyond feasible limits during competence assessment. ${ }^{6}$ Nonetheless, exposed GPs recognised that extra time invested in combining both approaches would be synergistic, providing enhanced reassurance from two directions.

Setting priorities for uptake of contrasting interventions may differ substantially between GPs with and without previous exposure to the interventions. GPs' level of experience with and attitudes towards interventions to improve clinical practice need to be taken into account when planning widespread dissemination. 
Table 11.1 Preferences of exposed and non-exposed GPs towards illness or disease-focused interventions to improve LRTI management.

\begin{tabular}{|c|c|}
\hline Exposed GPs & Preference \\
\hline "You can't take them apart, I want them both (GP1)" & Undecided \\
\hline "I found CRP less useful than communication skills training (GP2)" & CST \\
\hline $\begin{array}{l}\text { "Communication is the key component of our profession. If not doing it } \\
\text { [communication skills as thaught in the training] yet, one should immediately } \\
\text { consider it. The other thing [CRP] is an addition, but a very useful one in my } \\
\text { opinion (GP7)" }\end{array}$ & CST \\
\hline "Communication, as I think this is the most important in consultations, either in & \\
\hline $\begin{array}{l}\text { LRTI or another condition... CRP as a value is wonderful, but it doesn't tell you } \\
\text { everything (GP8)" }\end{array}$ & CST \\
\hline "Communication skills training (GP9)" & CST \\
\hline $\begin{array}{l}\text { "If I really need to choose I need to say communication skills training.... That was } \\
\text { great fun to do, to systematically use it, it works (GP10)" }\end{array}$ & CST \\
\hline $\begin{array}{l}\text { "The communicative bit has my preference yes. I always try to do without the test, } \\
\text { but well, if I don't succeed I pull out CRP to convince patients (GP13)" }\end{array}$ & CST \\
\hline $\begin{array}{l}\text { "Communication. I try to structure my consultation to give attention to all aspects, } \\
\text { and CRP can be one of them (GP14)" }\end{array}$ & CST \\
\hline $\begin{array}{l}\text { "Communication training... in the majority of patients you do well with these skills, } \\
\text { and when in doubt with CRP (GP17)" }\end{array}$ & CST \\
\hline "You'll achieve most by doing communication skills training (GP18)" & CST \\
\hline Non-exposed GPs & Preference \\
\hline $\begin{array}{l}\text { "I'd choose CRP. Two reason: I'm a games person, so I love such a test very } \\
\text { much... and because I feel that communication skills training thing, well..I don't } \\
\text { think I need to improve that much in that field... I don't feel communication is the } \\
\text { problem in antibiotic prescribing (GP3)" }\end{array}$ & CRP \\
\hline "Yes, CRP (GP4)"' & CRP \\
\hline $\begin{array}{l}\text { "CRP, as it is useful in my practice and because I feel I can get patients on my side } \\
\text { with it. I think that the magic of the machine is more than the magic of my words. } \\
\text { (GP5)" }\end{array}$ & CRP \\
\hline "Most obvious would be CRP, easier and less time consuming (GP6)" & CRP \\
\hline "CRP, as I think that I will not improve that much when knowing how to give & \\
\hline $\begin{array}{l}\text { information back to the patient, but I would find it useful to have such a test in my } \\
\text { practice (GP11)" }\end{array}$ & CRP \\
\hline "I think communication training, as I can buy CRP myself. (GP12)" & CST \\
\hline "CRP, it is useful to know that it is there to be used (GP15)" & CRP \\
\hline $\begin{array}{l}\text { "CRP could help me in case of doubt, I don't see how communication would help } \\
\text { me in that regard (GP16)" }\end{array}$ & CRP \\
\hline $\begin{array}{l}\text { "In the end communication skills training will benefit the most. It is, in any form, } \\
\text { always an eye-opener and even if only small bits are remembered, it is nice. } \\
\text { (GP19)" }\end{array}$ & CST \\
\hline $\begin{array}{l}\text { "CRP for sure. Much easier, much faster. I expect more of it than of } \\
\text { communication skills training. Such a training will offer some extra, but not much. } \\
\text { (GP20)" }\end{array}$ & CRP \\
\hline
\end{tabular}

CST = Communication skills training (Illness focused approach); CRP = C-reactive protein point of care testing (Disease focused approach) 


\section{References}

1. Grol R, Grimshaw J. From best evidence to best practice: effective implementation of change in patients' care. Lancet 2003;362:1225-30.

2. Grol R, Wensing M. What drives change? Barriers to and incentives for achieving evidencebased practice. Med J Aust 2004;180:57-60.

3. Godin G, Belanger-Gravel A, Eccles M, Grimshaw J. Healthcare professionals' intentions and behaviours: A systematic review of studies based on social cognitive theories. Implement Sci 2008;3:36.

4. Arnold SR, Straus SE. Interventions to improve antibiotic prescribing practices in ambulatory care. Cochrane Database Syst Rev 2005.

5. Cals JW, Hopstaken RM, Butler CC, Hood K, Severens JL, Dinant GJ. Improving management of patients with acute cough by $\mathrm{C}$-reactive protein point of care testing and communication training (IMPAC3T): study protocol of a cluster randomised controlled trial. BMC Fam Pract 2007;8:15.

6. Cals JW, Scheppers NA, Hopstaken RM, Hood K, Dinant GJ, Goettsch H, Butler CC. Evidence based management of acute bronchitis; sustained competence of enhanced communication skills acquisition in general practice. Patient Educ Couns 2007;68:270-8.

7. Cals JW, Butler CC, Hopstaken RM, Hood K, Dinant GJ. Effect of point of care testing for C reactive protein and training in communication skills on antibiotic use in lower respiratory tract infections: cluster randomised trial. BMJ 2009;338:b1374.

8. Cals JWL, Ament AA, Hood K, Butler CC, Hopstaken RM, Wassink GF, Dinant G. Costeffectiveness of C-reactive protein point of care testing and physician communication skills training in reducing antibiotic prescribing for lower respiratory tract infections in general practice. submitted 2009.

9. Britten N. Qualitative interviews in medical research. BMJ 1995;311:251-3.

10. Green J, Thorogood N. Qualitative methods for health research. London: Sage Publications; 2004.

11. Eccles MP, Armstrong D, Baker R, Cleary K, Davies H, Davies S, Glasziou P, Ilott I, Kinmonth AL, Leng G, Logan S, Marteau T, Michie S, Rogers H, Rycroft-Malone J, Sibbald B. An implementation research agenda. Implement Sci 2009;4:18.

12. Butler CC, Rollnick S, Pill R, Maggs Rapport F, Stott N. Understanding the culture of prescribing: qualitative study of general practitioners' and patients' perceptions of antibiotics for sore throats. BMJ 1998;317:637-42.

13. Britten N, Stevenson FA, Barry CA, Barber N, Bradley CP. Misunderstandings in prescribing decisions in general practice: qualitative study. BMJ 2000;320:484-8.

14. Petursson P. GPs' reasons for "non-pharmacological" prescribing of antibiotics. A phenomenological study. Scand J Prim Health Care 2005;23:120-5.

15. Wood F, Simpson S, Butler CC. Socially responsible antibiotic choices in primary care: a qualitative study of GPs' decisions to prescribe broad-spectrum and fluroquinolone antibiotics. Fam Pract 2007;24:427-34.

16. Simpson SA, Wood F, Butler CC. General practitioners' perceptions of antimicrobial resistance: a qualitative study. J Antimicrob Chemother 2007;59:292-6.

17. Cals JWL, Chappin FHF, Hopstaken RM, van Leeuwen ME, Hood K, Butler CC, Dinant GJ. Creactive protein point of care testing for lower respiratory tract infections; a qualitative evaluation of experiences in general practice. submitted 2009.

18. Gravel K, Legare F, Graham ID. Barriers and facilitators to implementing shared decisionmaking in clinical practice: a systematic review of health professionals' perceptions. Implement Sci 2006;1:16.

19. Legare F, Ratte S, Gravel K, Graham ID. Barriers and facilitators to implementing shared decision-making in clinical practice: update of a systematic review of health professionals' perceptions. Patient Educ Couns 2008;73:526-35. 



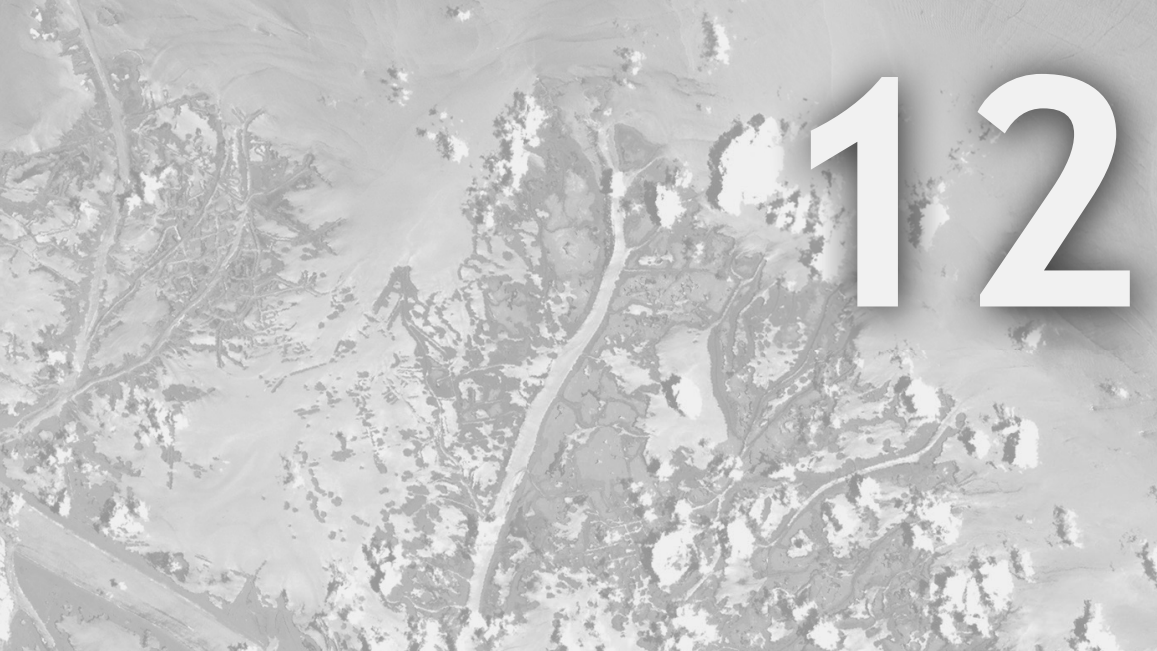

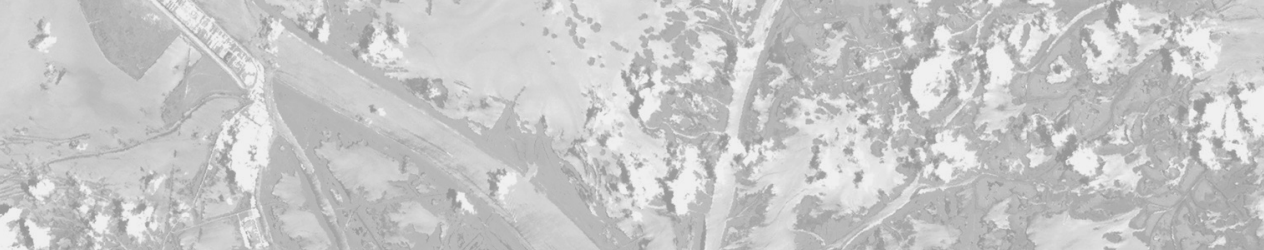
4

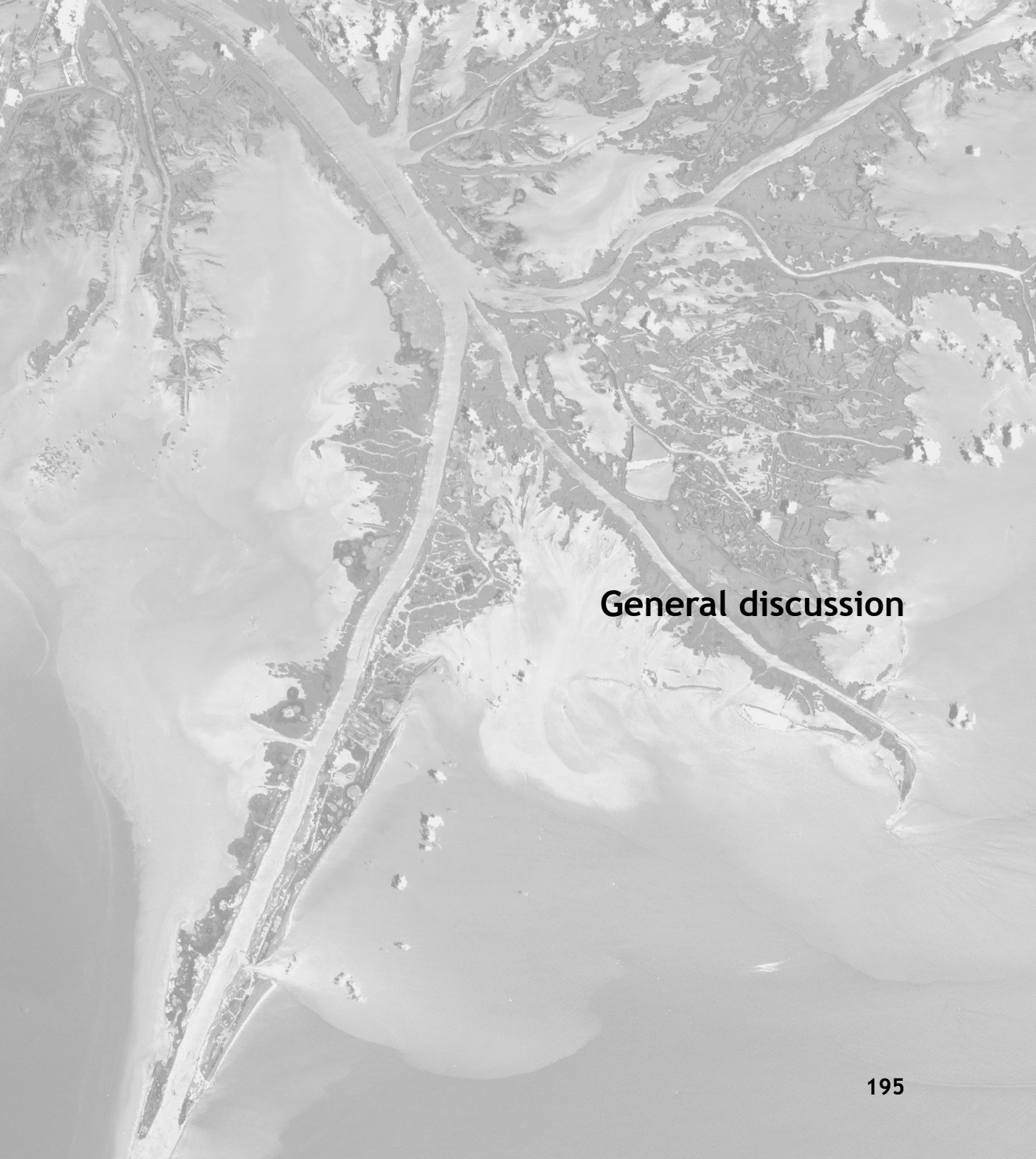


196 Chapter 12 


\section{General discussion}

The studies presented in this thesis were performed to address current gaps in the evidence base supporting the management of RTI, with the emphasis on LRTI, in general medical practice. The primary results of the studies are presented in the summary of this thesis. Specific strengths and limitations of the individual studies are addressed in chapters 2-11. In this general discussion the overall methodological considerations of our studies will be discussed and we will consider why the effects occurred and how our interventions could further be improved for successful wider implementation into routine clinical care, as well as future research opportunities in the light of this work.

\section{Methodological considerations}

This thesis comprises research findings obtained from 689 RTI patients enrolled in two randomised trials by 71 GPs from 31 primary care centres. Furthermore, public beliefs on antibiotics and RTI were studied in a cross-sectional questionnaire study in 935 Dutch citizens and compliance measures of 155 LRTI patients were assessed. Additionally, the experience with and attitudes towards the two contrasting interventions to optimise management of RTI in general practice were recorded in semi-structured interviews with 40 participating GPs.

We chose to use a combination of quantitative and qualitative research methods to thoroughly evaluate the interventions and subsequently achieve the best understanding of the effects and to consider further steps for improvement and implementation, which will be discussed in more detail later on in this chapter.

\section{Innovative methods}

At several occasions throughout this research project we were in the opportunity to adopt innovative research methods albeit with its associated pearls and pitfalls. First of all, to record public views and attitudes towards antibiotics and RTI we used an internet-based questionnaire. The internet is increasingly used as a platform for undertaking research into health and health care. Through this method and a meticulously developed questionnaire, we succeeded in achieving a high response rate $(75 \%)$ with full data on all of these respondents by efficiently routing respondents through our survey. Once commenced, data collection was fast and efficiently completed within two weeks. It is suggested that respondents from internet research may not be demographically representative for the average population, yet we aimed to 
achieve this by obtaining a stratified sample from a nationwide internet panel. And with the increasing availability of this medium and the increasing difficulty in contacting people otherwise, we can be sure that this form of research is here to stay, both as a source of health information and as a research medium, as is stated in a accompanying editorial with our paper. ${ }^{1}$

Secondly, compliance measurements have received a fair amount of attention for chronic conditions. ${ }^{2}$ Yet, at the time of this study we had hardly any reliable information on compliance with antibiotics for acute RTI using gold-standard measurement for compiling drug dosing histories in ambulatory patients, which is electronic monitoring. ${ }^{3}$ One small study using this method had been performed at that point ${ }^{4}$, and with the contribution of our recent analysis, we currently have four studies describing compliance in short term antibiotics for acute RTI. $^{4-7}$ The varying use of compliance outcomes is striking, limiting comparability across studies. This is why I called for uniform compliance measures in the field of short term antibiotics in a recent commentary. ${ }^{8}$ Within the domain of short-term antibiotic compliance for acute RTI, we now have the opportunity to provide standardisation in reporting with the steadily increasing evidence. The universal use of taking compliance, dosing compliance, timing compliance and mean interdose intervals should lead to uniformity in reporting on compliance with antibiotics for acute RTI and to increased transparency and improved comparability. Yet, within this specific field, and for future studies measuring compliance, the key question remains how much compliance is enough in specific dosing regimens of antibiotics when considering pharmacokinetic properties of the drugs. ${ }^{9,10}$

Thirdly, in our economic analysis and modelling we considered costs associated with antimicrobial resistance as intangible costs. For this reason economic analysis of interventions and its interpretation in RTI is complex, as antimicrobial resistance is hard, if not impossible, to measure and relate to costs. Cost-effectiveness analysis is mainly performed in situations where a decision-maker, given a set budget, is considering a range of options within a given field. As we have showed in chapter 11, GPs in routine care may have distinct preferences regarding adopting the disease and illness focused approaches. In our health economics evaluation, we modelled different scenarios of the consequences of implementing the illness and disease focused strategies according to GP preference. Although one could call this a sensitivity analysis, it is not a process with adjustment of assumptions on the level of costs, but more a translation of research findings to possible scenarios of implementation. This approach taken in our economic evaluation was an innovative step in economic analysis aiming to facilitate insight in the economic consequences of implementation of evidence-based research findings while taking possible existing GP factors - the ultimate users of the interventions into account. ${ }^{11,12}$ 


\section{Pragmatic versus explanatory trials}

Randomised trials are traditionally categorised as pragmatic or explanatory trials. While explanatory trials generally evaluate efficacy, pragmatic trials evaluate effectiveness. The two terms refer to the purpose of the trial, so one needs to take the nature of the trial into consideration when designing and conducting it, but also when interpreting its results. ${ }^{13}$ The two trials presented in this thesis may both be considered pragmatic. We designed both the IMPAC ${ }^{3} T$ (chapter 6) and the CAPRESA trial (chapter 10) to inform choices between treatments, while allowing variations between patients and between GPs that occur in real life practice. So our results aimed to answer the question: "Do these interventions work under usual conditions?" This is essential, because how useful a trial is depends not only on the design, but also on the similarity of the trial and the user's context. In our trials, this context is the GP's setting. We specifically aimed to be able to generalise our findings to everyday general practice ${ }^{14}$, although small parts, such as collecting patient data through diaries is not part of usual practice, but were needed to be able to make solid research conclusions.

As outlined in the introduction and throughout the chapters, there is considerable evidence on the reasons for antibiotic over prescribing and we know that the number of prescriptions could be restricted when drafting an explanatory trial, conducted under ideal conditions, with a homogenous group of patients and with close monitoring of a prescribing protocol and check-up visits for patients. Yet, this would not generate useful data to inform decisions on useful strategies to assist GPs in safely decreasing antibiotic prescribing.

When we analyse our trials with the recently developed PRECIS tool (pragmatic-explanatory continuum indicator summary) ${ }^{15}$ both IMPAC $^{3} \mathrm{~T}$ and CAPRESA are situated towards the pragmatic end of the continuum in all ten defined domains. Some of the items emphasising the pragmatic nature of our trial are: broad inclusion criteria and very limited exclusion criteria for LRTI and rhinosinusitis, considerable leeway for GPs in how to exactly merge the interventions into their daily consultations, usual practice as the comparison treatment and no formal follow-up visits for the patients, as this would affect GPs' behaviour and possible the outcomes. Moreover, our analyses were all intention to treat, attempting to show the effects of the intervention under normal conditions, with all the noise inherent. In general medicine, and primary care in particular, with busy consultation hours and a broad range of conditions to cover, we need more pragmatic evidence. Although published shortly after submission of our trials, we reported our studies as recommended in the CONSORT extension for pragmatic trials. ${ }^{16}$ 


\section{Individual and cluster randomisation and tailored analysis}

Another CONSORT extension we used in the IMPAC ${ }^{3} T$ trial was the one for cluster randomised trials. ${ }^{17}$ Sometimes, individual randomisation to find evidence for effectiveness - as promoted by Archie Cochrane while based in Cardiff $^{18}$ - is not possible and groups are randomised by cluster. The communication skills training in our trial was an obvious reason to choose cluster randomisation, mainly to avoid contamination. So why not individually randomise CRP then? The primary reason is that it would damage the pragmatic nature of our trial. Potential biases in cluster trials, which are not to be expected in individually randomised studies, can occur on two levels. Firstly, randomisation at the cluster level needs to be carefully undertaken to prevent biased allocation. Secondly, post-randomisation recruitment bias, another form of selection bias, may occur on the level of the patient and is often mentioned as the primary threat of bias in cluster RCTs. ${ }^{19,20}$ Nevertheless, with secured cluster allocation, no cluster attrition, no cluster imbalance and a thorough noninclusion analysis not indicating presence of post-randomisation recruitment bias, as rightfully commented in the editorial with our trial ${ }^{21}$, the findings of the IMPAC ${ }^{3} \mathrm{~T}$ trial are valid and not influenced by the biases commonly present when using cluster randomisation.

In contrast, in the CAPRESA trial we did use individual randomisation to test the effect of CRP guidance in antibiotic prescribing. The used SNOSE (sequentially numbered opaque sealed envelopes) method $^{22}$ to allocate patients to be managed with or without CRP is an innovative, yet simple office-based method of randomisation without needing to call into remote randomisation centres, particularly useful when randomisation takes places at more than one location, as is often the case in general practice trials.

The analyses of our trial data were all performed multi-level. As much as this is required in cluster RCTs, even when there is little apparent heterogeneity across recruiting practices or physicians, it can still have a large impact on the estimation and interpretation of the treatment effect, so multilevel analysis should also be performed in individual RCTs. ${ }^{23-26}$

The items discussed in this section are essential in achieving an appropriate reflection of trial results. Inappropriate analysis can give misleading precision (e.g. smaller confidence interval and lower $p$ values), yet it will rarely change the point estimate of the effect. Bias however, can give a misleading point estimate. We undertook all possible adjustments and presented sensitivity analyses to prevent either of this from happening in the IMPAC ${ }^{3} \mathrm{~T}$ and CAPRESA trials. 


\section{Improved management of RTI by point of care testing for C-reactive protein - Why?}

\section{Decreasing clinical uncertainty and differentiating serious from self-limiting disease}

The major contribution of CRP point of care testing seems to be in decreasing uncertainty. In particular, a CRP test result adds useful information that helps to identifying those patients not at risk for a complicated illness course. We observed the greatest antibiotic reduction in patients with CRP under $20 \mathrm{mg} / \mathrm{l}$. This is clinically relevant, as most patients consulting in general practice will have CRP values less than $20 \mathrm{mg} / \mathrm{l}$. Therefore, most can be gained in this specific group, when withholding antibiotic treatment in those patients with CRP under $20 \mathrm{mg} / \mathrm{l}$, albeit while considering the full clinical presentation and illness duration. Two previous studies, one in LRTI and one in rhinosinusitis, found similar opportunities for restrictive prescribing in this group with low CRP values. ${ }^{27,28}$ Hence, the greatest value of CRP point of care testing lies in ruling out serious disease, which is a key task of GPs on a daily basis. GPs involved in the IMPAC ${ }^{3} T$ study acknowledged this role of the test in their LRTI consultations (chapter 9 )

This brings us to a crucial role of CRP testing in general practice; the test needs to differentiate serious from self-limiting illness. The results from our studies indicate that this is how GPs succeeded in decreasing antibiotic prescribing. We know that the test can not differentiate bacterial from viral infections ${ }^{29-31}$, mainly because identifying causative organisms of RTIs is challenging. ${ }^{29,32-36}$ Also, a systematic review concluded that the test can not differentiate pneumonia from acute bronchitis. ${ }^{31}$ This conclusion is not valid. The analysis of CRP as a standalone diagnostic test for pneumonia is misguided. We know that individual signs and symptoms have poor operating characteristics as diagnostic tests, but in combination they are much more useful. ${ }^{37}$ Body temperature for instance, has poor operating characteristics as a stand-alone diagnostic test for pneumonia, but clinicians always include a consideration of temperature in the overall assessment of LRTI patients as it provides incremental information.

In conclusion, the more useful question is whether any new test provides incremental diagnostic information. Nonetheless, as stated in the introduction chapter, the ultimate aim of CRP testing would be to identify patients with antibiotic responsive serious illness and subsequently to withhold antibiotics in the large remaining group of patients with self-limiting illness. So in a way, CRP in RTI is as much a prognostic marker, as it is a diagnostic marker. ${ }^{38}$ 


\section{Decreasing patient uncertainty and providing reassurance}

Additionally, CRP point of care testing had a role in convincing patients to accept a non-antibiotic management strategy. This was an often-mentioned advantage of CRP by GPs with experience of using the test, thereby also impacting the illness perspective of the patient. Just as much as patient satisfaction with care is linked to physical examination ${ }^{39,40}$, the same may apply for CRP in relation to reassurance. When investigating CRP as an incremental test on top of routine consultations in the CAPRESA trial, those patients managed with CRP were more satisfied with the consultation compared to those managed without the test, albeit all patients showing relatively high overall satisfaction with care.

\section{Medicalisation}

The possible medicalising effect of biomedical testing for RTI has created debate among primary care researchers and clinicians, mainly in the UK. ${ }^{21,41,42}$ We did not observe any medicalisation in the current illness episode, reflected by an increase in reconsultations. However, future intention to reconsult was higher for those managed by CRP in the CAPRESA trial, suggesting a possible medicalisation effect of the test, although we did not observe this in the IMPAC ${ }^{3} T$ study. It remains to be seen if this is undesirable, especially knowing that over $80 \%$ of patients report intending to go back to their GP with similar future symptoms anyway. Respiratory tract symptoms constitute a great burden of illness and people do seek medical attention for it, mostly seeking symptom relief and reassurance. ${ }^{43-46}$ Different individuals have different thresholds for seeking help and this is an under researched area.

\section{Ambiguous test results}

Intermediately elevated test results proved difficult for GPs and its occurrence was independently associated with patient-initiated reconsultation in IMPAC ${ }^{3} \mathrm{~T}$. This association was not found in CAPRESA, where those test results were recommended to be followed by a delayed prescription. Strikingly, only the minority of patients managed with CRP filled their delayed prescription, versus the majority in the control group. Besides the fact that the delayed prescriptions in the CRP group were better targeted at intermediately elevated results, this interesting difference can also be explained by the reassuring role of CRP and the explanation of the GP why a delayed prescription is handed out for that specific clinical presentation with associated CRP level. 


\section{Improved management of RTI by physician communication skills training - Why?}

\section{Eliciting physician perceived patient expectations and addressing patient related factors}

GPs using the communication skills method showed competence in implementing the acquired communication skills (see chapter 5). Competence is a prerequisite of performance ${ }^{47}$, and the participating GPs also showed performance by restricting antibiotic prescriptions in their patients. Although the exact implementation of the communication items is difficult to record, we did contact patients shortly after the index consultation and asked questions about the doctor-patient interaction, while stressing that this was not done to audit practice of their treating GP. The majority of patients managed by a GP who had undergone the communication skills training recalled specific items, including the natural course of cough, and whether the question had been asked "What is your opinion on antibiotics?". This question was an eye-opener to many GPs as it served as a tool to open up the consultation and to elicit expectations and worries (unpublished qualitative data). Possibly, this question is a next step to improved concordance ${ }^{48,49}$ - an agreed plan on the use of medication between patient and physician - in antibiotic use with potential applications for other classes of drugs. With many communication skills training methods failing to reach a change in communication skills one may wonder why the effects shown in this thesis occurred. ${ }^{50,51}$ We are confident that in the light of current over prescribing due to perceived patient factors, eliciting the patient's agenda is a crucial component of our method. It results in physician awareness that fewer patients than expected actually want antibiotics, leading to a smaller chance of misunderstanding and conflict. ${ }^{39,52-54}$ Moreover, the context-rich method we used, including simulated patients, the interactive workshop-based training and the opportunity to provide peer-review on a colleague's transcript were all means to stimulate the use of the skills in daily practice.

\section{Decreasing patient uncertainty and providing reassurance}

Decreasing patients' uncertainty and worries has a central role in the communication skills method. Although not statistically significant we observed a trend for lower reconsultation rates in those patients managed by a GP using the communication skills. So presumably, some patients may have felt more empowered to manage their illness on their own. Interventions to enhance patient empowerment have been shown to reduce antibiotic prescribing. ${ }^{55}$ Furthermore, addressing patients' visit-specific expectations appears to affect patient satisfaction to a modest degree.$^{56,57}$ In our study, with all patients being 
highly satisfied with care regardless of the methods employed by their GP, we could not find any difference in satisfaction or patient enablement. Our finding of similar satisfaction rates despite less antibiotics prescribing are in line with previous findings of a trial which successfully reduced antibiotic use in acute bronchitis. $^{58}$ and further add to the evidence that antibiotic prescribing is not exclusively related to patient satisfaction. ${ }^{40,59}$ While satisfaction typically measures the extent to which expectations relating to the process of delivery of care have been met, enablement tries to measure a concept complementary to satisfaction, namely the perceived ability to manage the illness oneself. ${ }^{60}$ Both measures were reported very high by the majority of patients in our study, giving rise to the assumption that our studies lacked power to detect any differences in these measures. A limitation of our evaluation of the communication skills method at the level of the patient is that we did not measure patient involvement in the consultation. Incorporating any scales measuring this dimension, or recording all patient encounters, however may have hampered the nature of our data collection. What's more, patient involvement is very hard to record. ${ }^{61}$

\section{Impact on consultation length}

All the methods presented in this thesis require a considerable effort by GPs and often, particularly when it comes to changing communication skills and applying shared decision making methods, concerns are stressed about the potential negative effect on consultation duration. ${ }^{21,62}$ With the average GP session only lasting five to ten minutes ${ }^{63}$, eliciting expectations, exchanging information and eliciting if all what has been said throughout the encounter has been understood, is very challenging in time-pressured consultations. Still, immediately prescribing antibiotics is only marginally associated with shorter consultation length and the long-term effects on reattendance for similar illness will be adding to the workload. ${ }^{64,65}$ There are two findings in this thesis which show promise in this regard. First of all, in our competence assessment we did not find an increase in consultation duration (chapter 5). And secondly, although GPs expressed concerns regarding the extra time spent with LRTI patients using the new method, they emphasised that it may pay off both directly, by better patient reassurance and satisfaction, and possibly later on as well, by increased patient education and knowledge on appropriate antibiotic use for RTI, leading to fewer consultations in the future. Qualitative research reveals that GPs report that immediate antibiotic prescribing creates short term gains in terms of prescribing to shorten consultations, but also results in longer term problems as it encourages more consulting in the future. ${ }^{43}$ 


\section{Decreasing antibiotic prescribing for RTI}

\section{How low should we go and what do we also need to know?}

The interventions studied in this thesis, to the best of our knowledge, safely decreased antibiotic prescribing and overall antibiotic use in LRTI and rhinosinusitis. Serious adverse events did not occur. We used inclusion criteria based on symptoms to enrol patients with these RTI diagnoses. As important as using diagnostic labels in RTI may be to study the links between treatment and outcomes, as useless may they prove to be in daily practice. Their use by clinicians shows great inter-practitioner variation and is associated with prescribing. Also, people expect antibiotics more often when referring to disease labels than when referring to core symptoms usually associated with that diagnosis. ${ }^{66-70}$ It may therefore be advisable to refer to symptoms instead of diagnosis when communicating with patients, as this also better fits into the illness experience of the patient.

Serious adverse events in otherwise healthy ambulatory patients with a RTI episode do only occur rarely. However, our trials were not powered to study these adverse outcomes. Studies investigating antibiotic prescribing and serious complications in general practice present conflicting results. On the worrying side of things, two studies present an association of the general decrease in antibiotic prescribing for LRTI with an increase in possible hospital admission and pneumonia mortality. ${ }^{71,72} \mathrm{~A}$ similar trend has been observed in the Netherlands, yet the authors fail to underpin the exact cause of this association. ${ }^{73}$ Without neglecting safety issues concerning antibiotic prescribing for LRTI, these findings must be interpreted with caution, as they rely on crosssectional, retrospective data sets. Hence, more solid research evidence is needed linking (non) antibiotic prescribing with possible complications and outcomes in infections in primary care. For sore throat such an initiative is underway $^{21}$, yet LRTI with risk of complications and even death should deserve the full focus in this endeavour.

The elderly for that matter are a particular vulnerable population. They not only have a higher risk of developing RTIs ${ }^{74,75}$, cardiopulmonary co-morbidity and diabetes are more common and this puts them at an additional risk of complicated outcome ${ }^{76-78}$ This is why many GPs prescribe antibiotics to most of the elderly with LRTI. ${ }^{79}$ Only $17 \%$ of the 537 LRTI patients enrolled into one of our two trials was older than 65 years. Patients seen in nursing homes or during home visits could not be recruited, mainly since CRP measurements were typically done in the GP surgery. Therefore, our research findings may not be applicable to the frail elderly consulting with LRTI.

Clinical prediction rules to determine high and low risk elderly patients show promise in assisting GPs to decide what patients may be followed-up in the 
home situation or who needs closer monitoring in the home care or hospital setting. ${ }^{80,81}$ The CRB-65 rule to assess pneumonia severity includes age $>65$ years, the presence of new onset pneumonia associated mental confusion, hypotension and a respiratory rate $>30 /$ min and performs well in predicting 30 day mortality in elderly with LRTI in primary care ${ }^{80}$ Recently it was discovered that adding CRP levels to pneumonia severity scales, including the CRB-65 scale, improved the 30-days mortality prediction in elderly with LRTI. ${ }^{82}$ Other biomarkers, such as procalcitonin, did not independently contribute to prediction. Variables required for assessment with CRB-65 are all easily obtained in primary care consultations, and a point of care test result may further improve prediction, yet more research and validation is needed in this field.

And although it is widely assumed that the elderly may benefit from antibiotic treatment in acute bronchitis, large trials underpinning this assumption are still lacking. ${ }^{83}$ The ongoing GRACE study investigating aetiology, diagnosis, treatment and prognosis of LRTI in 14 European countries will hopefully identify clear subgroups of patients who may benefit from antimicrobial treatment. ${ }^{84}$

\section{Further improvement of management of RTI by talking and testing - How?}

Our results on the effectiveness of the interventions, and GPs' reflections on the actual use of them in daily practice, support our hypothesis that both interventions offered them feasible ways to change antibiotic prescribing. As explained in the introduction chapter of this thesis, the importance of change (the 'why' of change) was already recognised by GPs, and our interventions provided confidence to change (the 'how' of change), thereby facilitating readiness to change. Are disease and illness focused methods two separate worlds? In my opinion, they are complementary and sometimes even synergetic. The dynamic interplay between GP and patient in an LRTI consultation results in a weaving back and forth between the disease perspective of the GP and illness experience of the patient, so both entities are by definition non-exclusive. Ideally, GPs need to attend to both perspectives in order to achieve optimal management. In IMPAC ${ }^{3} \mathrm{~T}$, those GPs applying both the disease and the illness-focused approach were most successful in optimising antibiotic management of their patients without compromising patient outcome and satisfaction.

Figure 12.1 shows a scenario of how both approaches in the full range of LRTI patients consulting in general practice should be used in my opinion. Communication skills should be applied in all patients, while adding CRP testing in cases with diagnostic and prognostic uncertainty and possibly when wanting 
to further reassure patients. The size of the CRP rectangle and triangle may vary depending on degree of patient pressure and varying degree of general health in specific local populations.

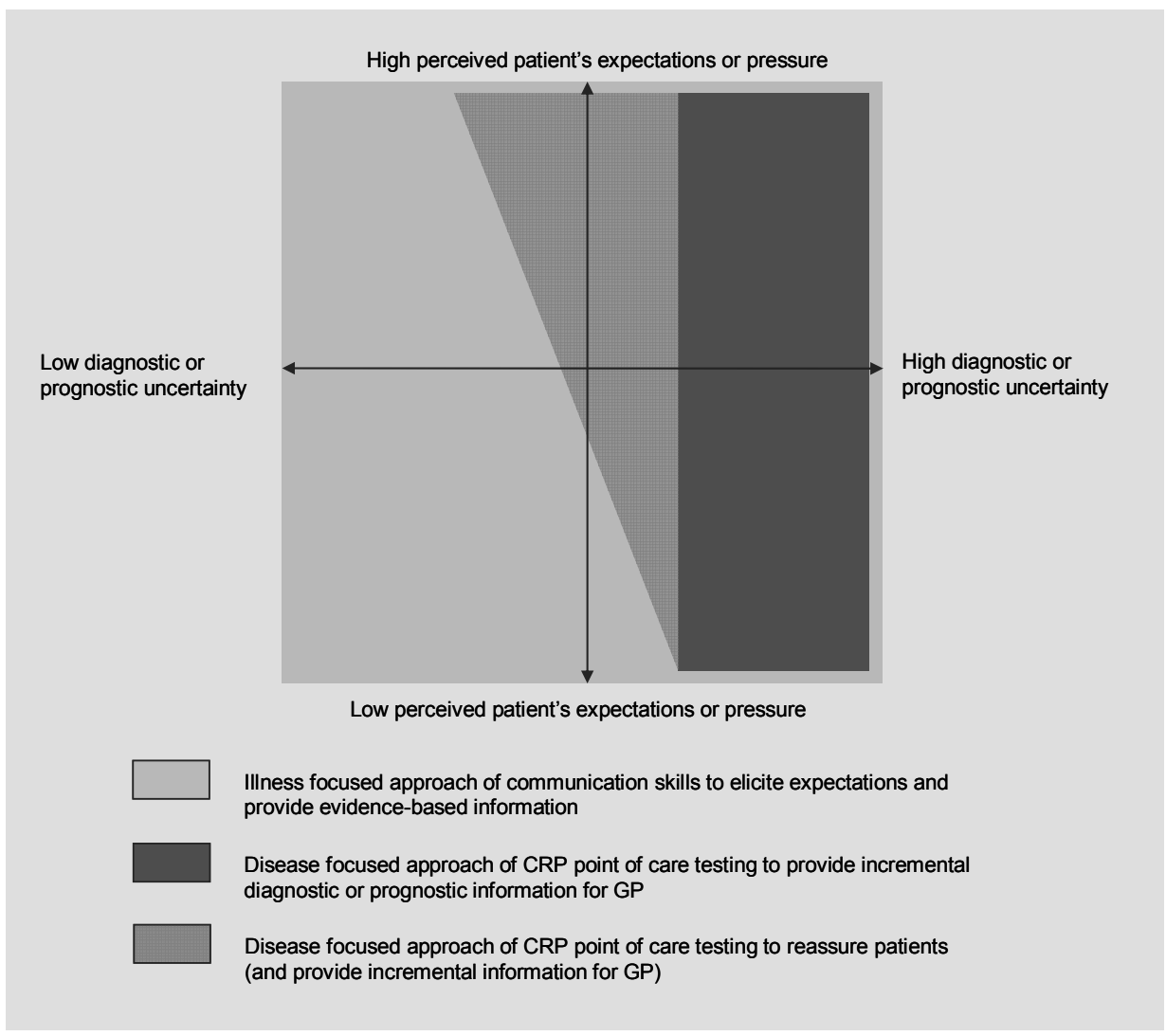

Figure 12.1 Use of contrasting approaches to improve LRTI management in the full range of LRTI patients.

The defined criteria for a successful point of care test in general practice as outlined in the introduction are all fulfilled with the evidence presented in this thesis. Other potential biomarkers to differentiate serious from self-limiting infection, such as procalcitonin and lipopolysaccharide-binding protein (LBP) have comparable diagnostic accuracies in LRTI in general practice. ${ }^{85,86}$ For the former there is also explanatory evidence that it can reduce antibiotic prescribing $^{87}$, yet it will not be available as a point of care test for RTI, and costs are considerable. These constitute two essential barriers for cost-effective use of this biomarker in common infections in general practice. So at present, CRP is the most promising biomarker to make a difference in primary care RTIs. 
Reimbursement of the test is essential for successful uptake in routine practice, also according to the GPs who worked with the test (chapter 9). Our costeffectiveness data are convincing to persuade health insurance companies to embark upon reimbursement. Furthermore, possible implementation of the results in the guideline on acute cough of the Dutch College of General Practitioners, which is currently in revision, will facilitate this process and may guide more GPs to consider using the test to optimise their management of LRTI and rhinosinusitis.

This last remark is important. We have only presented evidence on the role of CRP in decreasing antibiotic use for LRTI and rhinosinusitis. Examples in other countries have shown the over use of CRP point of care testing for other RTIs including many upper RTIs and common colds. ${ }^{88,89}$ Hence, based on our findings the use of CRP point of care testing for RTI in the Netherlands should only be advocated in LRTI and rhinosinusitis, and only when seeking incremental diagnostic or prognostic information or to ensure further patient reassurance.

Although we specifically developed our communication skills method to be applied in LRTI, the use of the items to elicit expectations and provide information on natural course and the risks and benefits of antibiotics, could be applied in a wider range of common infections in general practice. Reflections of GPs on the method suggest that, besides using it routinely in LRTI consultations, the acquired consultation style proved beneficial for other consultations as well. This further emphasises the potential of patient centred clinical methods in medicine. ${ }^{90}$ Implementation of the method on a larger scale remains the ultimate challenge. The method is labour intensive with a role for simulated patients and typists transcribing the audio-taped consultations, as well as the overall coordination and planning of simulated patient contacts and workshop-based seminars. A central role of communication in the previously mentioned guideline on acute cough will create awareness of the importance of communication skills in RTI consultations, yet undergoing the full method is what proved to be effective in this study.

Our analysis of exposed versus non-exposed GPs (chapter 11) indicated that routine GPs may not show a tremendous compulsion to act in choosing to follow communication skills training. This is something to keep in mind when planning widespread dissemination of the method. Strikingly and quite in contrast, those who had been using the method besides the availability of CRP testing prioritised the communication skills training when being asked to choose the intervention that would improve their LRTI management most. With all seven criteria for a useful communication training program (as outlined in the introduction) fulfilled based on the evidence in this thesis, there seems an obvious role for this training method in continuing medical education programs and vocational training in general practice. 
With a recently acquired grant we will aim to make further progress in disseminating our study results and the development of strategies to implement the methods in daily general practice. When these interventions find their way into daily practice in the Netherlands, long term effects of the use of these methods on general consultation frequency for RTI, public and patient beliefs on antibiotic use for RTI and overall antibiotic prescribing need to be determined.

\section{The answers to the research questions - in conclusion}

Talking and testing as applied in our trials contribute to (cost) effective management of LRTI. The methods are acceptable and applicable in general practice and may be adaptable to other conditions beyond LRTI. As a general recommendation, communication skills should be used in all patients consulting with LRTI. When faced with diagnostic and prognostic uncertainty, a point of care test for CRP will add incremental diagnostic and prognostic information (see also Figure 12.1). When still faced with insufficient certainty or unsatisfactory patient reassurance thereafter, a delayed prescription may offer an appropriate safety net. Targeting the right prescribing strategy at the right patient by the careful use of these methods will improve antimicrobial stewardship for RTI, while improving public and patient knowledge on the appropriate use of these valuable drugs. This will benefit the patient, the GP, the community and society for times to come.

"Change. In medicine, just as in anything else people do, individuals respond to new ideas in one of three different ways. A few become early adopters, as business usually calls them. Most become late adopters. And some remain persistent sceptics who never stop resisting. A doctor may have good reasons to take any of these stances. ...... Nonetheless, make yourself an early adopter. Look for the opportunity to change. I am not saying you should embrace every new trend that comes along. But be willing to recognise the inadequacies in what you do and to seek out solutions. As successful as medicine is, it remains replete with uncertainties and failure. This is what makes it human, at times painful, and also so worthwhile." Atul Gawanda in "Better" 


\section{References}

1. Murray E. Using the internet for research: results at a keystroke. $\mathrm{Br} J$ Gen Pract $2007 ; 57$ : 939-40.

2. Claxton AJ, Cramer J, Pierce C. A systematic review of the associations between dose regimens and medication compliance. Clin Ther 2001;23:1296-310.

3. Cramer JA. Microelectronic systems for monitoring and enhancing patient compliance with medication regimens. Drugs 1995;49:321-7.

4. Favre O, Delacretaz E, Badan M, Glauser M, Waeber B. Relationship between the prescriber's instructions and compliance with antibiotherapy in outpatients treated for an acute infectious disease. J Clin Pharmacol 1997;37:175-8.

5. Cals JW, Hopstaken RM, Le Doux PH, Driessen GA, Nelemans PJ, Dinant GJ. Dose timing and patient compliance with two antibiotic treatment regimens for lower respiratory tract infections in primary care. Int J Antimicrob Agents 2008;31:531-6.

6. Kardas P. Comparison of patient compliance with once-daily and twice-daily antibiotic regimens in respiratory tract infections: results of a randomized trial. J Antimicrob Chemother 2007;59:531-6.

7. Llor C, Sierra N, Hernández S, Moragas A, Hernández M, Bayona C, Miravitlles M. The higher the number of daily doses of antibiotic treatment in lower respiratory tract infection the worse the compliance. J Antimicrob Chemother 2009;63:396-9.

8. Cals JW. Comment on: The higher the number of daily doses of antibiotic treatment in lower respiratory tract infection the worse the compliance. J Antimicrob Chemother. 2009;63:1083-4

9. Urquhart J. Ascertaining how much compliance is enough with outpatient antibiotic regimens. Postgrad Med J 1992;68(S3):S49-58.

10. Vrijens B, Urquhart J. Patient adherence to prescribed antimicrobial drug dosing regimens. J Antimicrob Chemother 2005;55:616-27.

11. Grol R. Personal paper. Beliefs and evidence in changing clinical practice. BMJ 1997;315: 418-21.

12. Knottnerus JA, Dinant GJ. Medicine based evidence, a prerequisite for evidence based medicine. BMJ 1997;315:1109-10.

13. Roland M, Torgerson DJ. Understanding controlled trials: What are pragmatic trials? BMJ 1998;316:285.

14. Rothwell PM. External validity of randomised controlled trials: "to whom do the results of this trial apply?" Lancet 2005;365:82-93.

15. Thorpe KE, Zwarenstein M, Oxman AD, Treweek S, Furberg CD, Altman DG, Tunis S, Bergel E, Harvey I, Magid DJ, Chalkidou K. A pragmatic-explanatory continuum indicator summary (PRECIS): a tool to help trial designers. J Clin Epidemiol 2009;62:464-75.

16. Zwarenstein M, Treweek S, Gagnier JJ, Altman DG, Tunis S, Haynes B, Oxman AD, Moher D; CONSORT group; Pragmatic Trials in Healthcare (Practihc) group. Improving the reporting of pragmatic trials: an extension of the CONSORT statement. BMJ 2008;337:a2390.

17. Campbell MJ. Extending CONSORT to include cluster trials. BMJ 2004;328:654-5.

18. Cochrane AL. Archie Cochrane in his own words. Selections arranged from his 1972 introduction to "Effectiveness and Efficiency: Random Reflections on the Health Services" 1972. Control Clin Trials 1989;10:428-33.

19. Hahn S, Puffer S, Torgerson DJ, Watson J. Methodological bias in cluster randomised trials. BMC Med Res Methodol 2005;5:10.

20. Puffer S, Torgerson D, Watson J. Evidence for risk of bias in cluster randomised trials: review of recent trials published in three general medical journals. BMJ 2003;327:785-9.

21. Hay AD, Juttner KV. Antibiotics for acute cough in primary care. Bmj 2009;338:b834.

22. Doig GS, Simpson F. Randomization and allocation concealment: a practical guide for researchers. J Crit Care 2005;20:187-91.

23. Lee KJ, Thompson SG. The use of random effects models to allow for clustering in individually randomized trials. Clin Trials 2005;2:163-73. 
24. Lee KJ, Thompson SG. Clustering by health professional in individually randomised trials. Bmj 2005;330:142-4.

25. Localio AR, Berlin JA, Ten Have TR, Kimmel SE. Adjustments for center in multicenter studies: an overview. Ann Intern Med 2001;135:112-23.

26. Biau DJ, Porcher R, Boutron I. The account for provider and center effects in multicenter interventional and surgical randomized controlled trials is in need of improvement: a review. $\mathrm{J}$ Clin Epidemiol 2008;61:435-9.

27. Bjerrum L, Gahrn Hansen B, Munck AP. C-reactive protein measurement in general practice may lead to lower antibiotic prescribing for sinusitis. Br J Gen Pract 2004;54:659-62.

28. Takemura $\mathrm{Y}$, Ebisawa $\mathrm{K}$, Kakoi $\mathrm{H}$, Saitoh $\mathrm{H}$, Kure $\mathrm{H}$, Ishida $\mathrm{H}$, Kure M. Antibiotic selection patterns in acutely febrile new outpatients with or without immediate testing for $\mathrm{C}$ reactive protein and leucocyte count. J Clin Pathol 2005;58:729-33.

29. Graffelman AW, Knuistingh Neven A, le Cessie S, Kroes ACM, Springer MP, van den Broek PJ. Pathogens involved in lower respiratory tract infections in general practice. Br J Gen Pract 2004;54:15-9.

30. Hopstaken RM, Stobberingh EE, Knottnerus JA, Muris JWM, Nelemans P, Rinkens PELM, Dinant GJ. Clinical items not helpful in differentiating viral from bacterial lower respiratory tract infections in general practice. Journal of Clinical Epidemiology 2005;58:175-83.

31. van der Meer V, Neven AK, Broek PJvd, Assendelft WJJ. Diagnostic value of C reactive protein in infections of the lower respiratory tract: systematic review. BMJ 2005;331:26-9.

32. Creer DD, Dilworth JP, Gillespie SH, Johnston AR, Johnston SL, Ling C, Patel S, Sanderson G, Wallace PG, McHugh TD. Aetiological role of viral and bacterial infections in acute adult lower respiratory tract infection (LRTI) in primary care. Thorax 2006;61:75-9.

33. Holm A, Nexoe J, Bistrup LA, Pedersen SS, Obel N, Nielsen LP, Pedersen C. Aetiology and prediction of pneumonia in lower respiratory tract infection in primary care. $\mathrm{Br} \mathrm{J}$ Gen Pract 2007; 57: 547-54.

34. Hopstaken RM, Muris JWM, Knottnerus JA, Kester ADM, Rinkens PELM, Dinant GJ. Contributions of symptoms, signs, erythrocyte sedimentation rate and C-reactive protein to a diagnosis of pneumonia in acute lower respiratory tract infection. $\mathrm{Br} \mathrm{J}$ Gen Pract 2003;53: 358-64.

35. Macfarlane J, Holmes W, Gard P, Macfarlane R, Rose D, Weston V, Leinonen M, Saikku P, Myint S. Prospective study of the incidence, aetiology and outcome of adult lower respiratory tract illness in the community. Thorax 2001;56:109-14.

36. Melbye H, Straume B, Aasebo U, Dale K. Diagnosis of pneumonia in adults in general practice. Relative importance of typical symptoms and abnormal chest signs evaluated against a radiographic reference standard. Scand J Prim Health Care 1992;10:226-33.

37. Metlay JP, Fine MJ. Testing strategies in the initial management of patients with communityacquired pneumonia. Ann Intern Med 2003;138:109-18.

38. Dinant GJ, Buntinx FF, Butler CC. The necessary shift from diagnostic to prognostic research. BMC Fam Pract 2007;8:53.

39. Hamm RM, Hicks RJ, Bemben DA. Antibiotics and respiratory infections: are patients more satisfied when expectations are met? J Fam Pract 1996;43:56-62.

40. Lundkvist J, Akerlind I, Borgquist L, Molstad S. The more time spent on listening, the less time spent on prescribing antibiotics in general practice. Fam Pract 2002;19:638-40.

41. Hobbs FD, Kenkre JE, Carter YH, Thorpe GH, Holder RL. Reliability and feasibility of a near patient test for C-reactive protein in primary care. BMJ 1996;46:395-400.

42. Kolmos HJ, Little P. Controversies in management: should general practitioners perform diagnostic tests on patients before prescribing antibiotics? BMJ 1999;318:799-802.

43. Butler CC, Rollnick S, Pill R, Maggs Rapport F, Stott N. Understanding the culture of prescribing: qualitative study of general practitioners' and patients' perceptions of antibiotics for sore throats. BMJ 1998;317:637-42.

44. van Driel ML, De Sutter A, Deveugele M, Peersman W, Butler CC, De Meyere M, De Maeseneer J, Christiaens T. Are sore throat patients who hope for antibiotics actually asking for pain relief? Ann Fam Med 2006;4:494-9. 
45. Welschen I, Kuyvenhoven M, Hoes A, Verheij $\mathrm{T}$. Antibiotics for acute respiratory tract symptoms: patients' expectations, GPs' management and patient satisfaction. Fam Pract 2004;21:234-7.

46. Hickner JM, Bartlett JG, Besser RE, Gonzales R, Hoffman JR, Sande MA. Principles of appropriate antibiotic use for acute rhinosinusitis in adults: background. Ann Intern Med 2001;134:498-505.

47. Rethans JJ, Norcini JJ, Barón-Maldonado M, Blackmore D, Jolly BC, LaDuca T, Lew S, Page GG, Southgate LH. The relationship between competence and performance: implications for assessing practice performance. Medical education 2002;36:901-9.

48. Britten N, Jenkins L, Barber N, Bradley C, Stevenson F. Developing a measure for the appropriateness of prescribing in general practice. Qual Saf Health Care 2003;12:246-50.

49. Elwyn G, Edwards A, Britten N. "Doing prescribing": how might clinicians work differently for better, safer care. Qual Saf Health Care 2003;12(S1):i33-6.

50. Aspegren K. BEME Guide No.2: Teaching and learning communication skills in medicine-a review with quality grading of articles. Medical Teacher 1999;21:563-70.

51. Kramer AW, Dusman H, Tan LH, Jansen JJ, Grol RP, van der Vleuten CP. Acquisition of communication skills in postgraduate training for general practice. Med Educ 2004;38:158-67.

52. Britten N, Stevenson FA, Barry CA, Barber N, Bradley CP. Misunderstandings in prescribing decisions in general practice: qualitative study. BMJ 2000;320:484-8.

53. Cockburn J, Pit S. Prescribing behaviour in clinical practice: patients' expectations and doctors' perceptions of patients' expectations-a questionnaire study BMJ 1997;315:520-3.

54. Rollnick S, Seale C, Rees M, Butler C, Kinnersley P, Anderson L. Inside the routine general practice consultation: an observational study of consultations for sore throats. Fam Pract 2001;18:506-10.

55. Altiner A, Brockmann S, Sielk M, Wilm S, Wegscheider K, Abholz HH. Reducing antibiotic prescriptions for acute cough by motivating GPs to change their attitudes to communication and empowering patients: a cluster-randomized intervention study. J Antimicrob Chemother 2007;60:638-44.

56. Kinnersley $\mathrm{P}$, Stott N, Peters TJ, Harvey I. The patient-centredness of consultations and outcome in primary care. $\mathrm{Br} \mathrm{J}$ Gen Pract 1999;49:711-6.

57. Rao JK, Weinberger M, Kroenke K. Visit-specific expectations and patient-centered outcomes: a literature review. Arch Fam Med 2000;9:1148-55.

58. Gonzales R, Steiner JF, Maselli J, Lum A, Barrett PH, Jr. Impact of reducing antibiotic prescribing for acute bronchitis on patient satisfaction. Eff Clin Pract 2001;4:105-11.

59. Shapiro E. Injudicious antibiotic use: an unforeseen consequence of the emphasis on patient satisfaction? Clin Ther 2002;24:197-204.

60. Howie JG, Heaney DJ, Maxwell M, Walker JJ. A comparison of a Patient Enablement Instrument $(\mathrm{PEI})$ against two established satisfaction scales as an outcome measure of primary care consultations. Fam Pract 1998;15:165-71.

61. Elwyn G, Edwards A, Mowle S, Wensing M, Wilkinson C, Kinnersley P, Grol R. Measuring the involvement of patients in shared decision-making: a systematic review of instruments. Patient Educ Couns 2001;43:5-22.

62. Legare F, Ratte S, Gravel K, Graham ID. Barriers and facilitators to implementing shared decision-making in clinical practice: update of a systematic review of health professionals' perceptions. Patient Educ Couns 2008;73:526-35.

63. Deveugele M, Derese A, van den Brink-Muinen A, Bensing J, De Maeseneer J. Consultation length in general practice: cross sectional study in six European countries. BMJ 2002;325:472.

64. Linder JA, Singer DE, Stafford RS. Association between antibiotic prescribing and visit duration in adults with upper respiratory tract infections. Clinical Therapeutics 2003;25: 2419-30.

65. Little P, Gould C, Williamson I, Warner G, Gantley M, Kinmonth AL. Reattendance and complications in a randomised trial of prescribing strategies for sore throat: the medicalising effect of prescribing antibiotics. BMJ 1997;315:350-2.

66. Howie JG. Further observations on diagnosis and management of general practice respiratory illness using simulated patient consultations. BMJ 1974;2:540-3. 
67. Stocks N, Fahey T. Labelling of acute respiratory illness: evidence of between-practitioner variation in the UK. Fam Pract 2002;19:375-7.

68. Deschepper R, Vander Stichele RH, Haaijer-Ruskamp FM. Cross-cultural differences in lay attitudes and utilisation of antibiotics in a Belgian and a Dutch city. Patient Educ Couns 2002;48:161-9.

69. Gonzales R, Barrett PH, Jr., Crane LA, Steiner JF. Factors associated with antibiotic use for acute bronchitis. J Gen Intern Med 1998;13:541-8.

70. Cals JWL, Boumans D, Lardinois RJM, Gonzales R, Hopstaken RM, Butler CC, Dinant GJ. Public beliefs on antibiotics and respiratory tract infections: an internet-based questionnaire study. Br J Gen Pract 2007;57:942-7.

71. Price DB, Honeybourne D, Little P, Mayon-White RT, Read RC, Thomas M, Wale MC, FitzGerald P, Weston AR, Winchester CC. Community-acquired pneumonia mortality: a potential link to antibiotic prescribing trends in general practice. Respir Med 2004;98:17-24.

72. Winchester CC, Macfarlane TV, Thomas M, Price D. Antibiotic prescribing and outcomes of lower respiratory tract infection in UK primary care. Chest 2009;135:1163-72.

73. Oosterheert JJ, Bonten MJ, Hak E, Lammers JW, Schneider MM, Hoepelman IM. Toename van pneumoniegerelateerde ziekte en sterfte onder volwassenen in Nederland en mogelijke verklaringen daarvoor. Ned Tijdschr Geneeskd 2004;148:1765-9.

74. Hak E, Rovers MM, Kuyvenhoven MM, Schellevis FG, Verheij TJ. Incidence of GP-diagnosed respiratory tract infections according to age, gender and high-risk co-morbidity: the Second Dutch National Survey of General Practice. Fam Pract 2006;23:291-4.

75. Hak E, Bont J, Hoes AW, Verheij TJ. Prognostic factors for serious morbidity and mortality from community-acquired lower respiratory tract infections among the elderly in primary care. Fam Pract 2005;22:375-80.

76. File TM. The epidemiology of respiratory tract infections. Semin Respir Infect 2000;15:184-94.

77. Venmans LM, Bont J, Gorter KJ, Verheij TJ, Rutten GE, Hak E. Prediction of complicated lower respiratory tract infections in older patients with diabetes. Br J Gen Pract 2008;58:564-8.

78. van de Nadort C, Smeets HM, Bont J, Zuithoff NP, Hak E, Verheij TJ. Prognosis of primary care patients aged 80 years and older with lower respiratory tract infection. Br J Gen Pract 2009;59:e110-5.

79. Bont J, Hak E, Birkhoff CE, Hoes AW, Verheij TJ. Is co-morbidity taken into account in the antibiotic management of elderly patients with acute bronchitis and COPD exacerbations? Fam Pract 2007;24:317-22.

80. Bont J, Hak E, Hoes AW, Macfarlane JT, Verheij TJ. Predicting death in elderly patients with community-acquired pneumonia: a prospective validation study reevaluating the CRB-65 severity assessment tool. Arch Intern Med 2008;168:1465-8.

81. Bont J, Hak E, Hoes AW, Schipper M, Schellevis FG, Verheij TJ. A prediction rule for elderly primary-care patients with lower respiratory tract infections. Eur Respir J 2007;29:969-75.

82. Menéndez R, Martinez R, Reyes S, Mensa J, Filella X, Marcos MA, Martinez A, Esquinas C, Ramirez P, Torres A. Biomarkers improve mortality prediction by prognostic scales in community-acquired pneumonia. Thorax 2009.

83. Woodhead M, Blasi F, Ewig S, Huchon G, leven M, Ortqvist A, Schaberg T, Torres A, van der Heijden G, Verheij TJ; European Respiratory Society; European Society of Clinical Microbiology and Infectious Diseases. Guidelines for the management of adult lower respiratory tract infections. Eur Respir J 2005;26:1138-1180.

84. Goossens H, Little P. Community acquired pneumonia in primary care. BMJ 2006;332:1045-6.

85. Hopstaken RM, Cals JW, Dinant GJ. Accuracy of lipopolysaccharide-binding protein (LBP) and fibrinogen compared to C-reactive protein (CRP) in differentiating pneumonia from acute bronchitis in primary care. Prim Care Respir J 2009;18:227-30.

86. Holm A, Pedersen SS, Nexoe J, Obel N, Nielsen LP, Koldkjaer O, Pedersen C. Procalcitonin versus $\mathrm{C}$-reactive protein for predicting pneumonia in adults with lower respiratory tract infection in primary care. Br J Gen Pract 2007;57:555-60.

87. Briel M, Schuetz P, Mueller B, Young J, Schild U, Nusbaumer C, Périat P, Bucher HC, ChristCrain M. Procalcitonin-guided antibiotic use vs a standard approach for acute respiratory tract infections in primary care. Arch Intern Med 2008;168:2000-7. 
88. Engstrom S, Molstad S, Lindstrom K, Nilsson G, Borgquist L. Excessive use of rapid tests in respiratory tract infections in Swedish primary health care. Scand J Infect Dis 2004;36:213-8.

89. Briel M, Young J, Tschudi P, Hersberger KE, Hugenschmidt C, Langewitz W, Bucher HC. Prevalence and influence of diagnostic tests for acute respiratory tract infections in primary care. Swiss Med Wkly 2006;136:248-53.

90. Stewart M. Patient-centered medicine : transforming the clinical method. 2nd ed. Abingdon: Radcliffe Medical, 2003. 


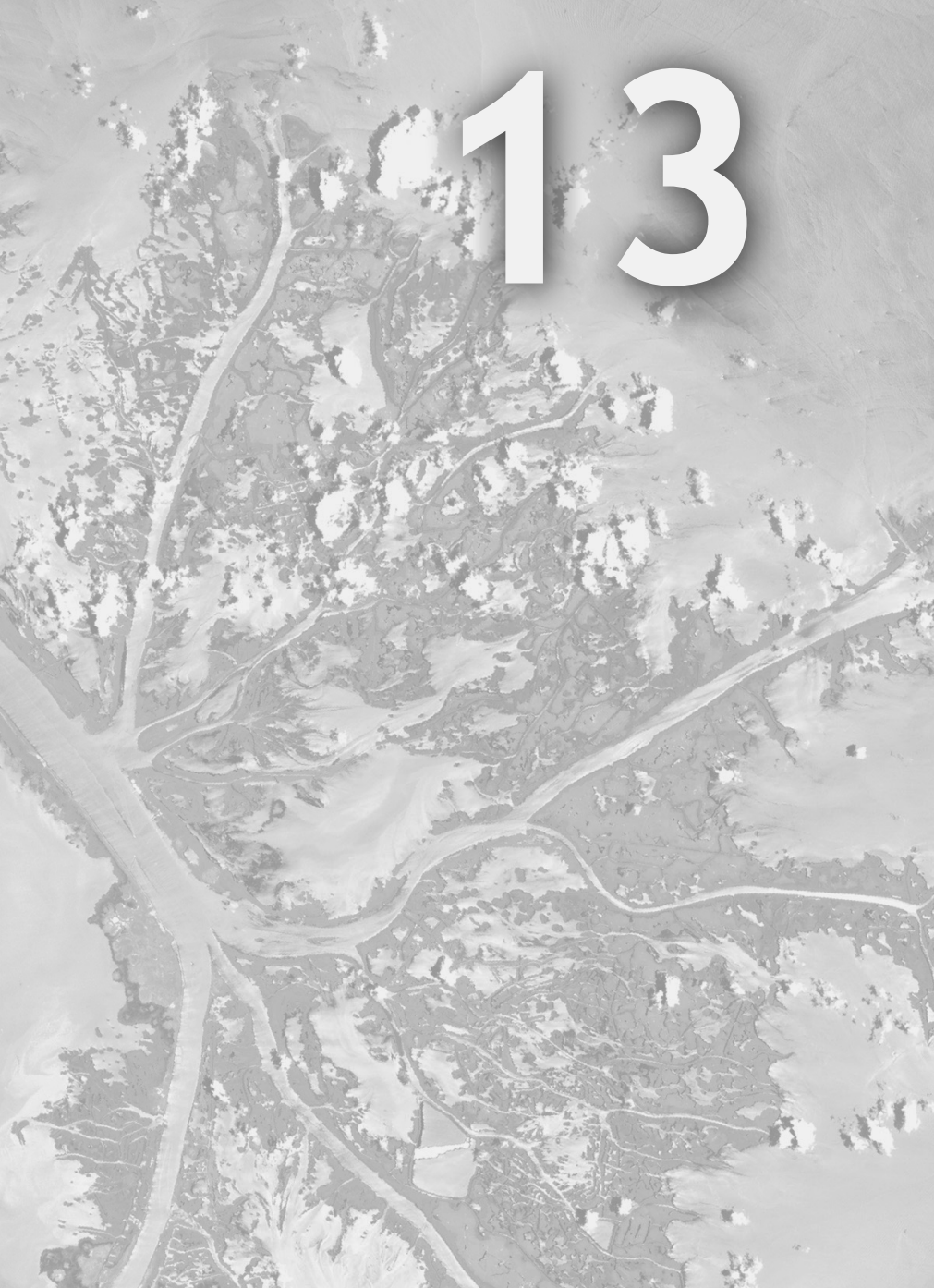

Wrapping it up and bringing these findings back to practice: a 10-minute consultation for acute cough

Jochen Cals, Nick Francis

Submitted 
216 Chapter 13 
It is another Monday morning in the life of GP Janssen. Cold and rainy weather outside, the waiting room jam-packed, and Mrs. Bosch consults with a severe acute cough. It started two weeks ago and it is restricting her activities during the day and keeping her awake at night. Mrs. Bosch is an otherwise healthy 54year old. "This is really bothering me doctor, I want to get rid of this cough sooner rather than later."

What can GP Janssen do? What needs to be covered and what needs to be said? Most clinicians know what they should do but don't always do it, largely because of diagnostic or prognostic uncertainty and wanting to maintain good relationships in time pressured consultations. So what can be said and done in a 10-minute consultation for acute cough in adults? The following outline suggests an approach to a first consultation for acute cough, in a primary care setting.

\section{What issues should be covered?}

\section{Medical history:}

- Patients consulting for acute cough ( $<3$ weeks) are often concerned about their cough and regularly expect antibiotics, therefore it is important to elicit their worries and what they expect from the consultation. Cough is mostly caused by infections of the respiratory tract or by local irritation of the airways ((passive) smoking, post nasal drip). Try to locate the part of the respiratory tract that is most affected (i.e. upper or lower respiratory tract).

- Ask about the duration and nature of cough, dyspnoea, wheezing, thoracic pain, smoking, and use of home medication. Explore restrictions in daily activities due to the cough.

- Is it something else? The differential diagnosis includes asthma, chronic obstructive pulmonary disease (COPD), whooping cough, gastro-oesophagal reflux disease (GORD), bronchial hyperreactivity, pulmonary embolism, heart failure, use of ACE inhibitors, and malignancy. Less common causes may also need to be considered, especially where additional risk factors exist.

- Consider risk-elevating factors including present use of oral glucocorticosteroids, co-morbities such as heart failure, COPD, insulindependent diabetes mellitus, serious neurological disorder, and older age (patients $>80$ years are particularly vulnerable). 


\section{What should be said and done?}

Physical examination and additional diagnostic testing:

- Assess the degree of illness by assessing fever, tachypnea, tachycardia, and level of consciousness. Examine the pharynx for signs of URTI, perform lung auscultation.

- Microbiological examinations are not routinely recommended in primary care. In cases of suspected LRTI and if still uncertain about illness severity after medical history and physical examination, a point of care test for C-reactive protein (CRP) can add incremental diagnostic and prognostic information (serious versus self-limiting LRTI). Always combine a CRP test result with clinical findings, duration of symptoms, and characteristics of the patient. In general, antibiotics can be withheld in all patients with CRP $<20 \mathrm{mg} / \mathrm{l}$ and in the majority of cases with $<50 \mathrm{mg} / \mathrm{l}$, and are advocated with CRP $>100 \mathrm{mg} / \mathrm{l}$. Intermediate values (21-99 $\mathrm{mg} / \mathrm{l})$ will usually recover at the same rate with or without antibiotics. If major clinical uncertainty persists after CRP measurement consider using a delayed prescribing approach (including an explanation on when to fill the prescription). Chest X-rays may be used to detect pneumonia or rule out malignancy, yet this test has a very limited role in acute cough on logistic and economic grounds.

- If whooping cough is suspected and the patient has a newborn or pregnant woman in close living proximity, a nasopharyngeal swab or polymerase chain reaction (PCR) test for diagnosis is indicated.

\section{Advice and treatment:}

- All patients should be provided with advice about managing symptoms and expected duration of illness. Clinicians tend to underestimate the duration of acute cough, which often lasts three to over four weeks in LRTI.

- The value of antitussives, expectorants, mucolytics, antihistamines, and inhaled bronchodilators is questionable. Encourage self-management strategies, including rest, analgesics and/or antipyretics, and regular fluids.

- Refer to a symptomatic and prognostic diagnosis rather than an aetiological or anatomical diagnosis. Aetiology in acute cough is often not known, and making the distinction between bacterial and viral infections can lead to confusion and generate assumptions about antibiotic treatment.

- URTIs causing acute cough and uncomplicated acute bronchitis do not need specific treatment. Explain self-limiting nature of symptoms and body's capability to overcome these symptoms without specific treatment.

- Always seek the patient's views on antibiotics. Often they will surprise clinicians and say they would prefer not to take them unless they are absolutely necessary. Discuss the balance between limited benefit and potential side effects from antibiotic treatment (diarrhoea, vomiting, rash), in 
relation to that individual patient. Patients generally don't want to take a drug when they recognise there is a slim chance of benefit and that it may cause harm.

- For community acquired pneumonia or LRTI with a potential complicated course (e.g. in elderly patients with fever, or patients with risk-elevating factors (see above)) antibiotic treatment is indicated. Follow the local guidelines on first-choice antimicrobial agent. The Dutch guideline recommends doxycyclin $100 \mathrm{mg}$ once-daily during one week with a first-day dose of $200 \mathrm{mg}$, or amoxicillin $3 \mathrm{dd} 500 \mathrm{mg}$ for seven days in pregnant or lactating women. Encourage dose intakes at regular intervals, particularly if prescribing a more than once-daily regimen.

- Referral to hospital is rarely needed, but may be indicated in severe cases, in those with high age or comorbidity in whom a complicated course is more likely, or when suspecting pulmonary embolism or malignancy. CRB-65 scoring can be used to help determine the most appropriate setting for treatment.

- Smoking may prolong symptoms. If applicable, encourage smoking cessation.

- Create a safety net by discussing factors that should prompt reconsultation or emergency assessment (e.g. fever lasting $>4$ days, increasing dyspnoea and fast breathing, decreasing consciousness and confusion).

- Check patient's understanding of what has been said and done and elicit any remaining worries. Provide an information leaflet to back up your advice. 


\section{Useful reading}

1. Verheij TJM, Salomé PL, Bindels PJ, Chavannes AW, Ponsioen BP, Sachs APE, et al. NHGStandaard Acuut hoesten. [Dutch College of General Practitioners Guidelines on Acute Cough]. Huisarts Wet 2003;46:496-506.

2. Tan $\mathrm{T}$, Little $\mathrm{P}$, Stokes $\mathrm{T}$. Antibiotic prescribing for self limiting respiratory tract infections in primary care: summary of NICE guidance. BMJ 2008;337:a437.

3. Butler CC, Francis N. Commentary: Controversies in NICE guidance on antibiotic prescribing for self limiting respiratory tract infections in primary care. BMJ 2008;337:a656.

4. Schroeder K, Fahey T. Systematic review of randomised controlled trials of over the counter cough medicines for acute cough in adults. BMJ 2002;324:329-31.

5. Woodhead M, Blasi F, Ewig S, Huchon G, leven M, Ortqvist A, Schaberg T, Torres A, van der Heijden G, Verheij TJ; European Respiratory Society; European Society of Clinical Microbiology and Infectious Diseases. Guidelines for the management of adult lower respiratory tract infections. Eur Respir J 2005;26:1138-80.

6. Cals JW, Butler CC, Hopstaken RM, Hood K, Dinant GJ. Effect of point of care testing for C reactive protein and training in communication skills on antibiotic use in lower respiratory tract infections: cluster randomised trial. BMJ 2009;338:b1374.

7. Davey $\mathrm{P}$, Pagliari $\mathrm{C}$, Hayes $\mathrm{A}$. The patient's role in the spread and control of bacterial resistance to antibiotics. Clin Microbiol Infect 2002;8(S2):43-68. 


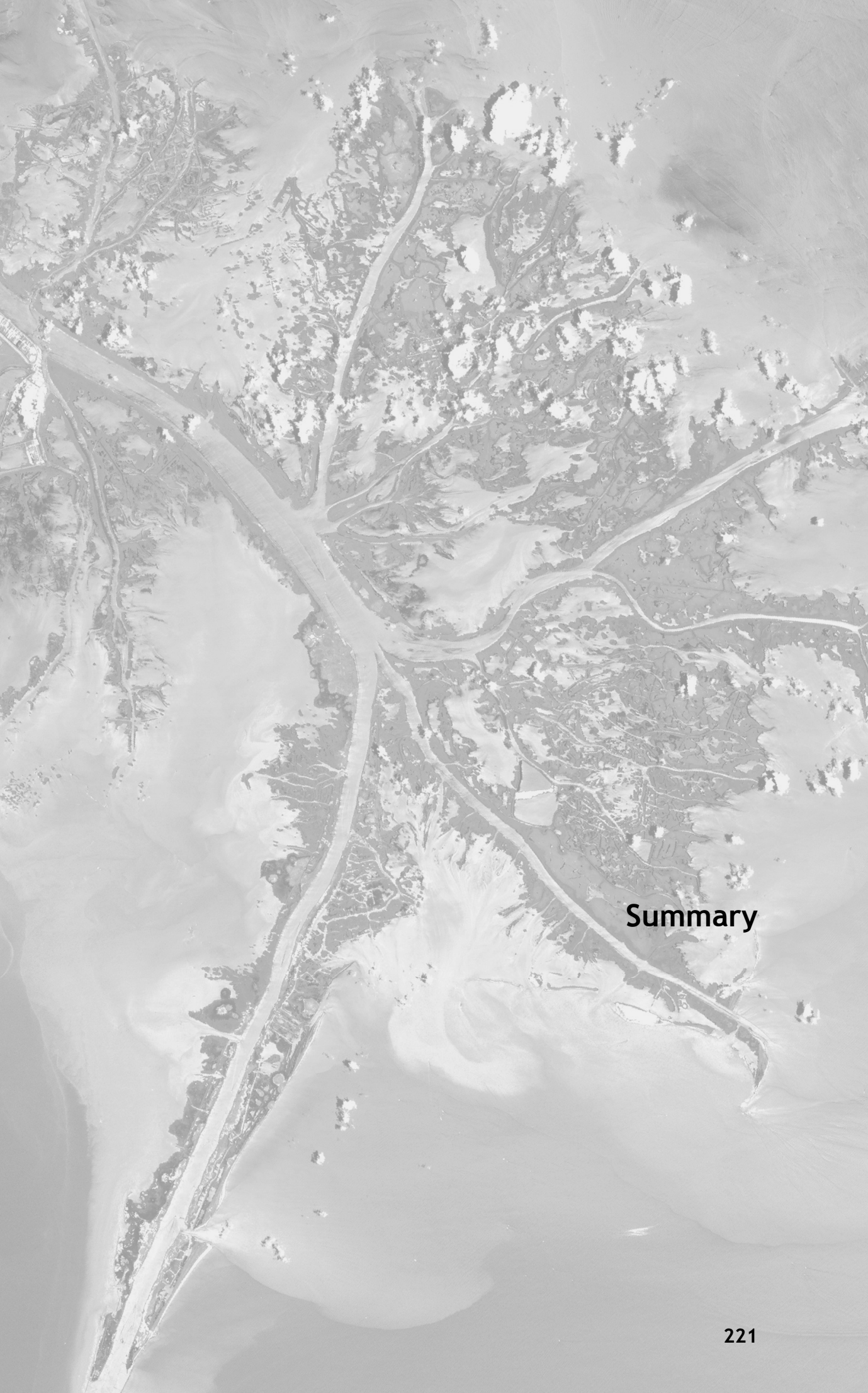




\section{Summary}

Lower respiratory tract infection (LRTI) is one of the commonest reasons for consulting in general practice. In most cases, antibiotic treatment is not warranted, but still the majority of patients receive a prescription for antibiotics. In general, antibiotic over prescribing for LRTI in general practice can broadly be related to two distinct factors within the consultation, as explained in chapter 1; clinicians' diagnostic uncertainty in differentiating serious from self-limiting disease and patient related factors during the time-pressured consultation.

These factors contributing to over prescribing can be seen from the disease perspective (diagnostic uncertainty) and the illness perspective (patient related factors, including (perceived) patients' expectations, validating concerns, understanding how the illness is impacting on the patients life, information exchange and conveying an accurate idea of prognosis by setting realistic expectations) and the possible solution may lie in targeting these factors based on a framework addressing both the general practitioners' (GP) and patients' agenda. Assuming that readiness to change antibiotic prescribing behaviour is driven by the 'importance of change' (the "why" of changing) and 'confidence in changing' (the "how" of changing), we need adequate tools to facilitate confidence in change, as the importance of change is recognised by GPs. Yet, they often prescribe during LRTI consultations nagged by prognostic uncertainty and aiming to maintain good relationships with patients in time-pressured consultations.

In this thesis we study two distinct interventions to improve management of LRTI; point of care testing for C-reactive protein (CRP) as a disease focused approach and enhanced communication skills training as an illness focused approach in LRTI consultations. CRP point of care testing can be seen from the disease perspective, aiding in making the right diagnosis and prognosis, while physician communication skills training may impact the illness experience of the patient when the GP elicits expectations and provides evidence-based information on natural course and the balances of pros and cons of antibiotic treatment.

Hence, the aim of this thesis was to study the effectiveness and costeffectiveness of CRP point of care testing and physician communication skills training on antibiotic use and clinical recovery in LRTI in general practice. Furthermore, we wanted to achieve a deeper understanding of the acceptability, applicability and adaptability of CRP point of care testing and physician communication skills training in the management of respiratory tract infections (RTI) in general practice. 
Patient expectations are among the strongest predictors of clinicians' antibiotic prescribing decisions. Although public knowledge, beliefs, and experiences of antibiotics contribute to these expectations, little is known about these public views. In chapter 2 we present an internet-based questionnaire study studying public beliefs on antibiotic use for RTI which reveals that nearly half of all 935 responders $(47.8 \%)$ to this survey incorrectly identified antibiotics as being effective in treating viral infections. This further stresses that doctors should be aware that unnecessary prescribing could facilitate misconceptions regarding antibiotics and RTI.

With little evidence available on patient compliance with short-term antibiotic use for LRTI, we assessed and compared taking compliance, timing compliance, correct dosing compliance and mean interdose intervals by using data from 155 LRTI patients who took medication (antibiotic or placebo) in a once-daily and three-times-daily regimen in chapter 3 . While overall taking compliance was good in both regimens, timing compliance was particularly poor in the three-times-daily regimen, additionally showing a considerable prolonged mean interdose interval of average 13 hours between the third daily dose and the first one on the following day.

In chapter 4 , the study protocol of the IMPAC ${ }^{3} \mathrm{~T}$ trial is described. This is a pragmatic factorial, cluster randomised trial investigating the effect of CRP point of care testing and enhanced physician communication skills training on antibiotic use for LRTI. In this trial $10 \mathrm{GPs}$ were randomised to using CRP point of care testing, $10 \mathrm{GP}$ were allocated to receive communication skills training, 10 GPs received both interventions and the remaining 10 provided care as usual. Methodological considerations focusing on cluster randomisation, factorial designs and associated analysis considerations are discussed in this chapter.

In chapter 5, we set out to determine if the developed communication skills training program for GPs involving context-rich learning experiences and 'peer review' of consultation transcripts resulted in communication skills acquisition and maintenance, while preserving time-efficiency in consultations. The evaluation of training $20 \mathrm{GPs}$-randomised to receive the illness focused intervention in the IMPAC ${ }^{3} \mathrm{~T}$ trial - in enhanced communication skills, revealed that there was good evidence that GPs acquired key communication skills after training and that these were maintained over 6 months. Moreover, consultations remained within normal consultation length in primary care. 
Chapter 6 describes the primary results of the IMPAC ${ }^{3} T$ trial. During two winter periods, $40 \mathrm{GPs}$ enrolled $431 \mathrm{LRTI}$ patients in this trial. GPs in the CRP point of care test group prescribed significantly fewer antibiotics than those in the no test group ( $31 \% \vee 53 \%, \mathrm{P}=0.02)$. Similarly, GPs in the communication skills training group prescribed significantly fewer antibiotics than those in the no training group $(27 \% \vee 54 \%, \mathrm{P}<0.01)$. Both interventions showed a statistically significant effect on antibiotic prescribing at any point during the 28 days' followup. Clinicians in the combined intervention group prescribed antibiotics to only $23 \%$ of patients, while the usual care GPs did so in $68 \%$. Crucially, patients' recovery, satisfaction with care and enablement were similar in all study groups. So both the disease focused and illness focused intervention were highly successful in safely reducing antibiotic prescribing for LRTI without compromising patients' recovery and satisfaction with care. We conclude that a combination of the illness and disease focused approaches may be necessary to achieve the greatest reduction in antibiotic prescribing.

In chapter 7, we present the results of the economic analysis performed alongside the IMPAC ${ }^{3} T$ clinical trial. We performed a cost-effectiveness analysis with a time horizon of 28 days studying the cost-effectiveness of the three strategies (CRP, communication skills or both) from the health care prespective, compared to usual care, using the primary outcome antibiotic prescribing at index consultation. The two strategies, both singly and combined, were costeffective interventions to reduce antibiotic prescribing for LRTI, at no, or low willingness-to-pay. Our implementation scenarios showed that taking GP preferences into account will optimise investment in these strategies to reduce antibiotic prescribing for LRTI.

Chapter 8 presents our findings on the predictors of patient-initiated reconsultation for LRTI in patients from the IMPAC ${ }^{3} T$ trial. Reconsultation for LRTI is common, and may often be unnecessary in that no further treatment is indicated apart from reassurance. Knowledge of factors that predict patientinitiated reconsultation may allow clinicians to address specific issues during the initial consultation that could reduce reconsultations. 33\% of the cohort of 431 LRTI patients reconsulted. Excluding 35 with GP-requested reconsultation left $28 \%(112 / 396)$ with a patient-initiated reconsultation during 28-day follow up. Patient-reported dyspnoea and concerns persisting beyond the initial consultation independently predicted patient-initiated reconsultation. Patients with intermediately elevated levels of CRP were also more likely to reconsult.

Chapter 9 describes the attitudes towards and experiences with CRP point of care testing of $20 \mathrm{GPs}$ involved in the IMPAC ${ }^{3} \mathrm{~T}$ trial. In a thematic content analysis of semi-structured interviews, we found that GPs expressed mainly 
positive attitudes. Test results were rapidly available to support diagnostic and therapeutic processes for LRTI and other common infections, enhancing patient and GP confidence in prescribing decisions and empowering GPs to prescribe antibiotics less often. GPs were concerned about responding to ambiguous test results, in particular intermediately elevated CRP results. They regarded financial reimbursement for using the test as essential for successful uptake, and requested that treatment guidelines be updated to include use of the test.

Inspired by findings in chapter 8 and 9 , and supported by the results of the IMPAC ${ }^{3} T$ trial, we designed a new randomised trial. GPs expressed difficulties in dealing with intermediately elevated test results and explaining these to their patients and intermediately elevated CRP results were independantly associated with reconsultation. Therefore, we set out to investigate if delayed prescriptions could be a suitable prescribing strategy for these patients. Furthermore, we decided to extend our inclusion criteria to rhinosinusitis patients.

Chapter 10 presents findings from the CAPRESA trial, involving 31 GPs who enrolled 258 patients with LRTI or rhinosinusitis and studied the effect of CRP assistance in antibiotic prescribing strategies - including delayed prescribing in LRTI and rhinosinusitis consultations in general practice. Patients in the CRP assisted group used less antibiotics $(43.4 \%)$ than control patients $(56.6 \%)$ following index consultation $(P=0.03)$. This difference remained significant during follow-up $(52.7 \%$ vs. $65.1 \%, P=0.04)$. Delayed prescriptions in the CRP assisted group were only filled in minority of cases $(23 \%$ vs. $72 \%$ in control group, $P<0.001)$. Recovery was similar across groups. Satisfaction with care was higher in patients managed with CRP assistance $(P<0.05)$. Hence, we conclude that CRP point of care testing to assist prescribing decisions including delayed prescribing - for LRTI and rhinosinusitis is a useful strategy to target the right prescription at the right patient, with favourable outcomes on antibiotic use, patient satisfaction and no detrimental effects on recovery.

Chapter 11 shows a thematic analysis of semi-structured interviews exploring views and attitudes towards the illness-focused intervention (specific communication skills training) and the disease-focused intervention (CRP point of care testing) to optimise management of LRTI among GPs who had used both interventions for two years in the IMPAC ${ }^{3} T$ trial (exposed GPs), and GPs without experience of either intervention (non-exposed GPs). All but two of the ten non-exposed GPs indicated that they would prioritise implementation of the disease-focused intervention of CRP testing over communication skills training, while all but one GP in the exposed group said that they would prioritise the illness focused approach of communication skills training as it was more widely applicable, whereas CRP testing was confirmatory and useful in a subgroups of 
patients. So, GPs' experiences with and attitudes towards interventions need to be taken into account when planning rollout of interventions aimed at changing clinical practice.

Chapter 12 discusses the overall methodological considerations of our studies (chapters 2-11) and considers why the effects occurred and how our interventions could further be improved for successful wider implementation into routine clinical care. It presents pearls and pitfalls of both the illness and disease focused interventions. Furthermore, clinical implications and threats of reducing antibiotic prescribing for RTI are presented, while providing recommendations for future research in this field. Finally, implementation and use of the interventions in routine general practice are discussed. This is accompanied by a personal view on when and how to use the specific interventions in routine general practice.

In conclusion, 'talking and testing' as applied in our trials contribute to (cost) effective management of LRTI. The methods are acceptable and applicable in general practice and may be adaptable to other conditions beyond LRTI.

Chapter 13 brings findings derived from the research projects in this thesis back to practice. It gives an outline of what can be said and done by GPs in a 10minute consultation for acute cough. It suggests an approach to a first consultation, with focus on both differentiating serious from self-limiting acute cough and physician-patient information exchange throughout the consultation for this common condition in a time-pressured primary care setting. 


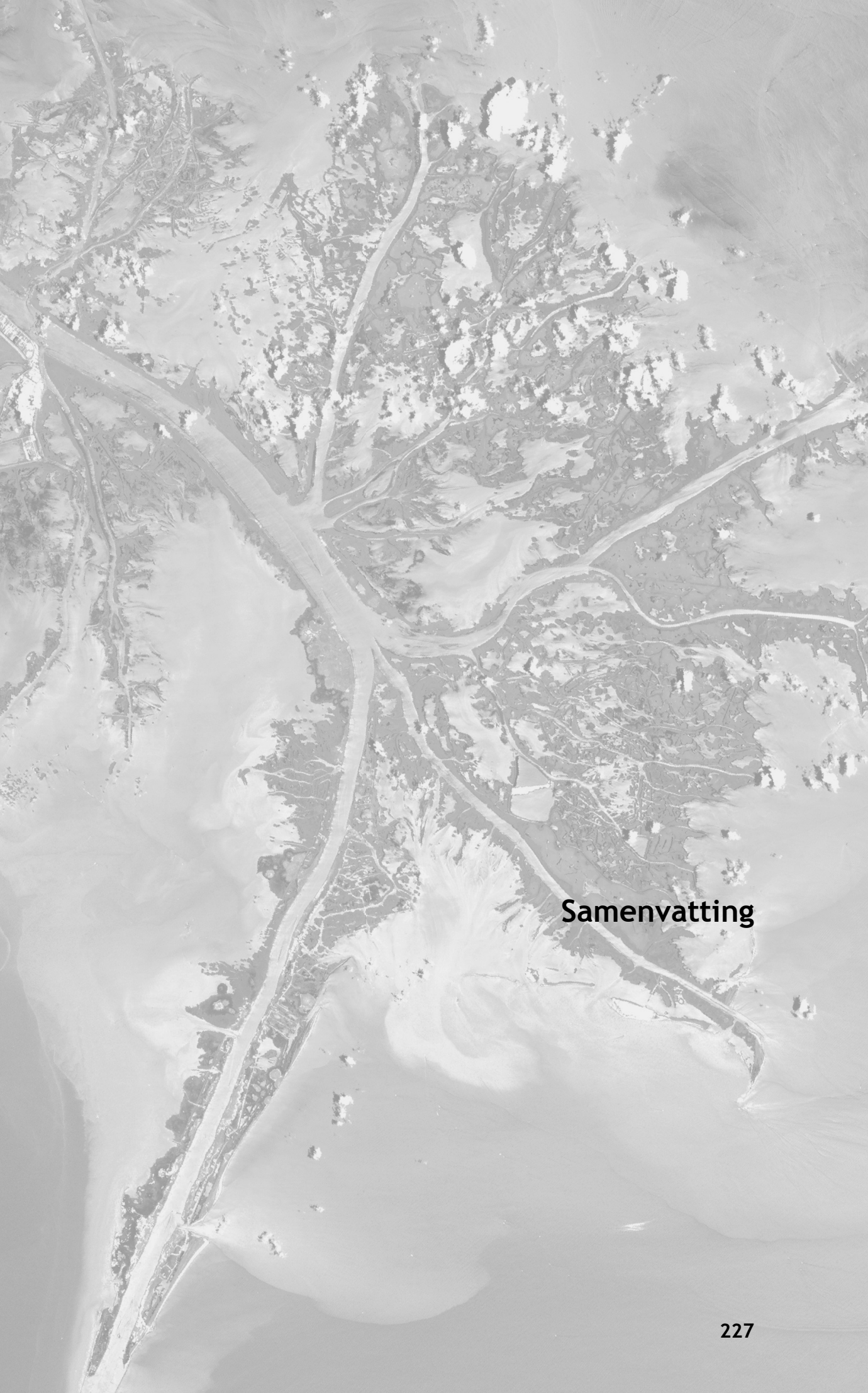




\section{Samenvatting}

Acute hoest door een lageluchtweginfectie is een van de meest voorkomende redenen om de huisarts te bezoeken. Ofschoon antibiotica bij de meerderheid van de patiënten met een lageluchtweginfectie niet zullen leiden tot een spoediger herstel, krijgt het merendeel toch een recept voor antibiotica bij een huisartsbezoek voor deze klachten. Het overmatig voorschrijven van antibiotica voor lageluchtweginfecties in de huisartsgeneeskunde kan grofweg worden toegedicht aan twee factoren die binnen een consult voor lageluchtweginfecties een rol spelen. Ten eerste de diagnostische onzekerheid van de huisarts om ernstige van onschuldige lageluchtweginfecties te onderscheiden. En ten tweede patiënt gerelateerde factoren tijdens het consult gedurende het spreekuur. In hoofdstuk 1 worden deze factoren die bijdragen aan overmatig antibioticavoorschrijfgedrag bekeken en beschreven vanuit het disease perspectief (diagnostische onzekerheid) en het illness perspectief (patiënt gerelateerde factoren, waaronder de verwachtingen en bezorgdheid van de patiënt, de weerslag van de klachten op het leven van de patiënt en de onzekerheid wat betreft de prognose van de klachten). Oplossingen om overmatig voorschrijven van antibiotica te beperken liggen derhalve in het aanpakken van beide factoren, waarbij zowel de agenda van de patiënt als de agenda van de dokter aan bod komen.

Verandering in antibiotica voorschrijfgedrag wordt gefaciliteerd door het "waarom" en het "hoe" van die verandering. Met andere woorden; vinden huisartsen een verandering in voorschrijfgedrag belangrijk ("waarom?") en hebben ze er vertrouwen in dat ze kunnen veranderen ("hoe?"). Uit voorgaand onderzoek weten we dat huisartsen verandering belangrijk vinden. Toch worden vaak antibiotica voorgeschreven tijdens lageluchtweginfectieconsulten, mede door prognostische onzekerheid en doordat men een goede relatie wil behouden met eisende patiënten tijdens drukke spreekuren. Derhalve zijn er interventies nodig waardoor huisartsen weten hoe ze kunnen veranderen.

In dit onderzoek bestudeerden we twee verschillende interventies om het beleid bij lageluchtweginfecties te verbeteren; de C-reactief proteïne (CRP) sneltest (disease perspectief) en een training in communicatieve vaardigheden voor huisartsen (illness perspectief). De CRP sneltest helpt de huisarts om een juiste diagnose en prognose te stellen, terwijl de communicatieve vaardigheden de huisarts helpen om de bezorgdheid en verwachtingen van de patiënt boven tafel te krijgen, om de patiënt gedegen informatie te verschaffen over het natuurlijk beloop van de klachten en om de voor- en nadelen van behandeling met antibiotica uit te leggen.

Het doel van het onderzoek in dit proefschrift was om de klinische effectiviteit en de kosten-effectiviteit van de CRP sneltest en de training in communicatieve vaardigheden op antibioticagebruik en klinisch herstel te bepalen bij patiënten 
met een lageluchtweginfectie in de huisartspraktijk. Verder hebben we getracht om inzicht te krijgen in de meningen over en ervaring met beide interventies bij luchtweginfecties in de huisartsenpraktijk.

De verwachtingen van patiënten zijn zeer sterke voorspellers van antibiotica voorschrijfgedrag van artsen. Publieke kennis en attitudes over antibiotica zullen bijdragen aan deze verwachtingen, maar we weten slechts weinig over de inzichten van de bevolking in antibiotica en luchtweginfecties. In hoofdstuk 2 presenteren we de bevindingen van een internet enquête onder 935 Nederlanders, waarbij $47,8 \%$ van de mensen onterecht aangaf dat antibiotica ook effectief zijn tegen virale infecties. De bevindingen van deze studie onderstrepen dat onterechte antibioticavoorschriften misconcepties over de werkzaamheid van deze middelen bij luchtweginfecties in stand kunnen houden. Willen we het antibioticagebruik voor luchtweginfecties in Nederland (nog) adequater maken, dan is het essentieel dat we rekening houden met de opvattingen van de algemene bevolking.

Als patiënten antibiotica krijgen, dan is slechts weinig bekend over de therapietrouw. Daarom bestudeerden we in hoofdstuk 3 middels electronische metingen de therapietrouw van patiënten die éénmaal of driemaal daags medicatie namen. We keken naar de algemene therapietrouw, per innamedag en weekdag, en we berekenden de intervallen tussen de ingenomen doses. De algemene therapietrouw was goed voor beide innameschema's. Het driemaal daagse schema liet echter een duidelijk slechtere timing zien met een afwijkend gemiddeld interval van 13 in plaats van 8 uur tussen de derde dagelijkse dosis en de eerste dosis van de volgende dag.

In hoofdstuk 4 wordt het studieprotocol van de IMPAC ${ }^{3} \mathrm{~T}$ trial beschreven. Dit is een factoriële, cluster gerandomiseerde interventiestudie naar het effect van de CRP sneltest en een training in communicatieve vaardigheden op antibioticagebruik voor lageluchtweginfecties. Aan deze studie deden 40 huisartsen mee, die gerandomiseerd werden over vier groepen: 10 huisartsen werden toegewezen aan de groep die de CRP sneltest mocht gebruiken, 10 huisartsen kreeg de training in communicatieve vaardigheden, 10 huisartsen mochten gebruik maken van beide interventies, en de resterende 10 huisartsen leverden gebruikelijke zorg. In dit hoofdstuk beschrijven we de methodologische overwegingen gerelateerd aan cluster randomisatie, de factoriële onderzoeksopzet en de daarbij behorende analysetechnieken.

De training in communicatieve vaardigheden evalueren we in hoofdstuk 5 . Belangrijke aspecten van het trainingsprogramma waren de beknoptheid van de workshop, het contextrijke karakter (veelal plaatsvindend in de eigen praktijk) 
en het vernieuwend gebruik van peer-review van transcripten van consulten door (collega)huisartsen. In deze studie toonden we aan dat huisartsen hun communicatieve vaardigheden met betrekking tot lageluchtweginfecties op de korte en de lange termijn (na 6 maanden) verbeteren en ook kunnen vasthouden door een ziektespecifieke communicatietraining te volgen. Onze interventie had geen negatief effect op de consultduur.

In hoofdstuk 6 presenteren we de belangrijkste resultaten van de IMPAC ${ }^{3} \mathrm{~T}$ trial. Veertig huisartsen includeerden 431 patiënten met een lageluchtweginfectie gedurende twee winterperiodes. Huisartsen die gebruik maakten van de CRP sneltest schreven significant minder antibiotica voor dan huisartsen die geen gebruik maakten van de test $(31 \%$ versus $53 \%, p=0.02)$. Huisartsen die de training in communicatieve vaardigheden volgden schreven minder antibiotica voor dan de artsen die deze training niet volgden $(27 \%$ versus $54 \%, p<0.01)$. Voor beide interventies bleef het antibioticagebruik tijdens de vervolgmaand significant lager dan de controlegroepen (CRP 45\% versus 58\%, $p<0.01$ en communicatietraining $38 \%$ versus $63 \%, p<0.001)$. Huisartsen in de groep met beide interventies schreven het minst vaak antibiotica voor $(23 \%)$, terwijl de huisartsen in de gebruikelijke zorggroep antibiotica voorschreven aan $68 \%$ van de patiënten. De verlaging van antibioticagebruik had geen negatief effect op het klinisch herstel van de patiënt of de tevredenheid met de geboden zorg. Gebruik van beide interventies (zowel de CRP sneltest vanuit het disease perspectief alsook de communicatietraining vanuit het illness perspectief) leidde tot een forse afname van het aantal antibioticumvoorschriften tijdens het eerste consult en gedurende 28 dagen follow-up. De combinatie van beide interventies, praten én prikken dus, zorgt voor een optimaal beleid bij lageluchtweginfecties.

In het kader van de IMPAC ${ }^{3} \mathrm{~T}$ studie verrichtten we tevens een economische analyse, die in hoofdstuk 7 wordt beschreven. We voerden een kosteneffectiviteitsanalyse uit vanuit het perspectief van de gezondheidszorg over een vervolgperiode van 28 dagen. We vergeleken de drie interventiearmen van de studie (CRP sneltest, communicatietraining en CRP sneltest + communicatietraining) met de gebruikelijke zorg groep en gebruikten het aantal antibioticavoorschriften als primaire uitkomstmaat. Beide interventies, zowel afzonderlijk als gecombineerd, waren kosteneffectief bij geen of een zeer lage willingness to pay per procent afname in antibioticavoorschriften. We presenteren tevens enkele implementatiescenario's die laten zien dat mogelijke voorkeuren van huisartsen voor een van beide interventies in een model kunnen worden meegenomen om eventuele investeringen te optimaliseren. 
In de IMPAC ${ }^{3} \mathrm{~T}$ studie keken we ook naar herhaalbezoeken van de patiënten in de eerste maand nadat ze bij de huisarts kwamen voor de luchtwegklachten (hoofdstuk 8). Herhaalbezoeken komen regelmatig voor bij lageluchtweginfecties, maar zijn vaak onnodig, aangezien het (medicamenteuze) beleid meestal niet hoeft te veranderen. In deze studie keken we naar patiënt geïnitieerde herhaalbezoeken. Kennis van factoren die deze herhaalbezoeken voorspellen stellen huisartsen in staat om deze factoren tijdens het eerste consult te bespreken, waardoor herhaalbezoeken kunnen afnemen. Van de 431 patiënten kwam 33\% terug op het spreekuur gedurende de maand follow-up. Nadat we 35 patiënten uitsloten die op expliciet verzoek van de huisarts terugkwamen, bleven er 112 patiënten over met een patiënt geïnitieerd herhaalbezoek (28\%). Kortademigheid gerapporteerd door de patiënt en persisterende ongerustheid na het eerste consult waren onafhankelijke voorspellers van patiënt geïnitieerde herhaalbezoeken. Patiënten die een matig verhoogde CRP waarde hadden kwamen ook vaker terug op het spreekuur.

In hoofdstuk 9 beschrijven we de ervaringen en meningen van de 20 huisartsen die in de IMPAC ${ }^{3} T$ studie de CRP sneltest gebruikten. In een thematische analyse van semi-gestructureerde interviews vonden we dat huisartsen hoofdzakelijk positieve attitudes hadden ten opzichte van de test. Testresultaten waren snel beschikbaar en ondersteunden het diagnostisch en therapeutisch proces bij lageluchtweginfecties en andere infecties. Verder droeg de test bij aan een verhoogd vertrouwen van huisarts en patiënt in de voorschrifbeslissing en zorgde de test ervoor dat huisartsen minder vaak antibiotica voorschreven. Huisartsen gaven wel aan bezorgd te zijn over het omgaan met matig verhoogde CRP waarden. Ze vonden dat een financiële vergoeding voor de test essentieel is voor een succesvolle opname in de dagelijkse praktijk en gaven aan dat de test een plaats dient te krijgen in richtlijnen.

Huisartsen gaven dus aan moeite te hebben om beleid te bepalen en patiënten voor te lichten bij matig verhoogde CRP waarden en we observeerden dat deze matig verhoogde CRP waarden een onafhankelijke associatie vertoonden met patiënt geïnitieerde herhaalbezoeken. Geïnspireerd door deze bevindingen uit hoofdstuk 8 en 9 en ondersteund door de resultaten van de IMPAC ${ }^{3} T$ studie (hoofdstuk 6) zetten we een nieuwe gerandomiseerde interventiestudie op, het CAPRESA onderzoek. Hierin wilden we onderzoeken of het uitgestelde antibioticarecept een goede voorschrijfstrategie is bij deze groep patiënten met een matig verhoogde CRP waarde. Verder besloten we om ook patiënten met rhinosinusitis in te sluiten in dit onderzoek. 
In hoofdstuk 10 presenteren we de bevindingen van de individueel gerandomiseerde interventiestudie CAPRESA. In deze studie includeerden 31 huisartsen 258 patiënten met een rhinosinusitis of lageluchtweginfectie en we bestudeerden het effect van CRP gestuurde voorschrijfstrategieën - inclusief het uitgestelde recept - in deze luchtweginfectieconsulten in de huisartspraktijk. Patiënten in de CRP groep gebruikten significant minder antibiotica (43.4\%) dan patiënten uit de controle groep (56.6\%) waar geen CRP waarde werd gebruikt tijdens het consult $(p=0.03)$. Dit verschil bleef bestaan tijdens de 28 dagen follow-up $(52,7 \%$ versus $65,1 \%, p=0.04)$. De uitgestelde recepten in de CRP groep werden slechts in de minderheid van de gevallen gebruikt, terwijl in de controlegroep juist het merendeel van de recepten wel werd gebruikt $(23 \%$ versus $72 \%, p<0.001$ ). Het herstel van de patiënten was gelijk in beide groepen. Patiënten waarbij een CRP test werd verricht waren meer tevreden met de geboden zorg dan de patiënten waarbij geen test werd verricht $(p<0.05)$. We concludeerden dat CRP gestuurd voorschrijven - inclusief het uitgestelde antibioticarecept - een bruikbare strategie is om het juiste recept op de juiste patiënt te richten, met een gunstige invloed op antibioticagebruik en patiënttevredenheid en zonder negatieve effecten op het herstel van de patiënt.

Hoofdstuk 11 toont een thematische analyse van semi-gestructureerde interviews die de meningen laat zien van huisartsen die zowel de CRP sneltest gebruikten (disease perspectief) én de communicatietraining volgden (illness perspectief) versus de meningen van huisartsen die geen van beide interventies gebruikten en dus gebruikelijke zorg leverden in de IMPAC ${ }^{3} T$ studie. We vroegen beide groepen welke voorkeur zij zouden hebben als ze één van beide interventies zouden moeten kiezen om hun consulten voor lageluchtweginfecties te optimaliseren. Vrijwel alle huisartsen uit de gebruikelijke zorggroep prefereerden de CRP sneltest ten opzichte van de communicatietraining. De huisartsen die al twee jaar beide interventies gebruikten gaven de prioriteit aan de communicatietraining, aangezien communicatieve vaardigheden bij alle patiënten met een lageluchtweginfectie toepasbaar zijn, terwijl de CRP sneltest slecht in een subgroep van patiënten te gebruiken is. Beide groepen benadrukten voorts de relevantie van een gecombineerde aanpak. De ervaringen en attitudes van huisartsen met specifieke interventies verdienen aandacht bij de verdere implementatie van deze interventies die gericht zijn op het veranderen van praktijkvoering bij een alledaagse aandoening.

In hoofdstuk 12 bespreken we de methodologische overwegingen van de studies (hoofdstuk 2-11) en bekijken we waarom de effecten plaatsvonden en hoe onze interventies verder verbeterd kunnen worden voor de dagelijkse praktijk. We presenteren zowel de kracht als de valkuilen van beide 
interventies. Tevens bespreken we de implicaties voor de praktijk en de mogelijke bedreigingen van antibioticareductie voor luchtweginfecties, met aanbevelingen voor toekomstig onderzoek. Bovenstaande wordt begeleid met een commentaar gericht op hoe de interventies in de dagelijkse praktijk gebruikt kunnen worden.

Concluderend kunnen we stellen dat zowel 'praten' als 'prikken' bijdragen aan een (kosten)effectief beleid van lageluchtweginfecties. De interventies zijn acceptabel en toepasbaar in de huisartspraktijk en kunnen zeer waarschijnlijk tevens bij andere aandoeningen worden gebruikt.

Hoofdstuk 13 brengt de onderzoeksbevindingen van de studies in dit proefschrift terug naar de praktijk. Het geeft kort en bondig weer wat de huisarts dient te bespreken en verder kan doen in een 10-minuten consult voor acute hoest. De beschrijving richt zich primair op het differentiëren tussen ernstige en onschuldige acute hoest, de arts-patiënt communicatie en informatie uitwisseling gedurende een alledaags consult in de huisartspraktijk. 



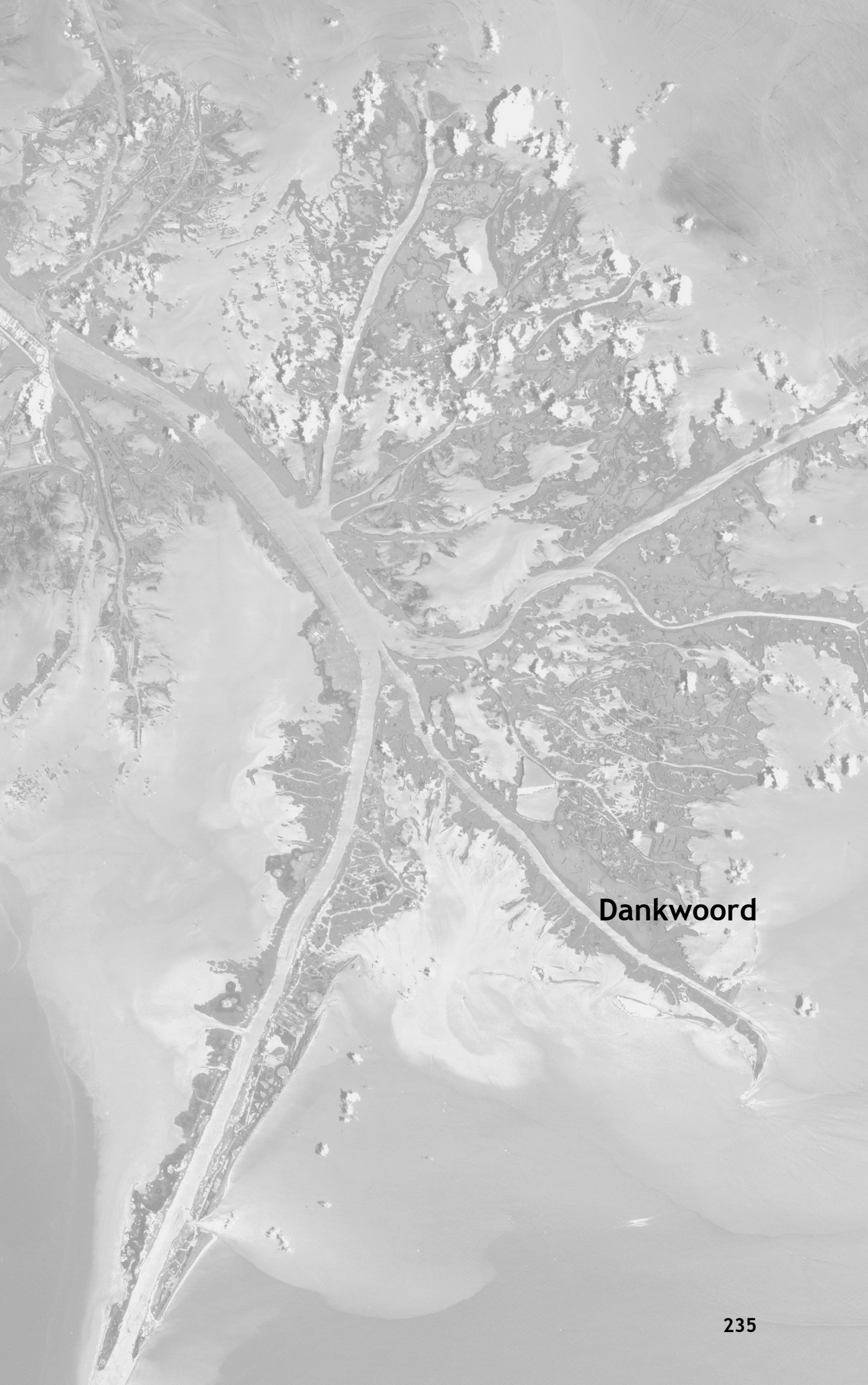




\section{Dankwoord}

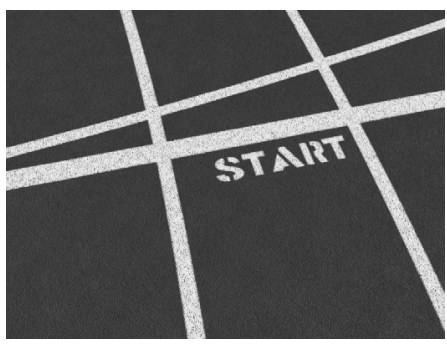

De gedachte aan wetenschappelijk onderzoek haalt nu niet gelijk het 'kinder-surprise-ei-effect' in de mens naar boven. Het feit dat je dit nu leest is daar een aardig voorbeeld van. Je hebt namelijk vast niet eerst de voorgaande dertien hoofdstukken vol verwachting opengeslagen en letter voor letter verslonden. Na het ontvangen van een proefschrift is de stap van kaft naar dankwoord immers snel gemaakt. Ik ben me bewust van deze hink-stap-sprong door een proefschrift en ik zal je daarom op de volgende pagina's een mooie reuzenslalom proberen voor te schotelen. De tocht voert langs de personen en plaatsen die ik tegenkwam tijdens de totstandkoming van dit proefschrift. ledereen die zijn naam hierna ziet verschijnen heeft op een of andere manier een steentje bijgedragen aan dit proefschrift. Gewild of ongewild, kiezelsteen of rotsblok, ik zal het uitleggen, en soms ook niet. In dat geval mag je graag je fantasie de vrije loop laten.

De weg die zou leiden tot dit proefschrift begon met een duurloopje door de Noorse heuvels, op een letterlijk hoogtepunt en een figuurlijk dieptepunt. Drie dagen daarvoor had ik met triathlonvriend Gijs Klerkx bijgepraat over onze toekomstplannen. Beiden hadden we de wedstrijdschoenen net aan de wilgen gehangen en we wilden allebei mogelijk een mooie combinatie aangaan; de opleiding geneeskunde combineren met wetenschappelijk onderzoek. Ik zou dat bij huisartsgeneeskunde gaan doen en Gijs bij de sportgeneeskunde. Het enthousiasme waarmee hij vertelde was aanstekelijk en we zagen het allebei helemaal zitten. Diezelfde nacht overleed Gijs onverwacht in zijn slaap. Toen ik het hoorde ben ik gaan hardlopen. Dat werkt het beste in situaties die niet te overzien zijn. Sport ordent de gedachten en de pijn in de benen verzacht pijn op andere plekken. Tijdens dat loopje op de biathlonbaan naar de hoogste top van de springschans van Holmenkollen heb ik me het spreekwoordelijke snot voor mijn waterige ogen gelopen en besloten om kansen die voorbij komen niet te laten schieten. Onderzoek doen was daar één van en ik had nooit gedacht dat die keuze zo'n schot in de roos zou zijn. En dit proefschrift is daarmee dus ook zeker een beetje voor jou Gijs.

Ik was destijds in Oslo voor de jaarlijkse GRIN bijeenkomst, hét jaarlijkse Europese luchtweginfectiecongres. De bijeenkomst was een fijne proloog voor wat een heel interessant traject zou gaan blijken en de GRIN bijeenkomst is sindsdien een jaarlijkse etappeplaats en hoogtepunt gebleven. En nu ik de eindsprint nader na de 403.749 letters die dit proefschrift tot nu toe telt (tel ze gerust na), is het tijd voor een persoonlijk woordje van dank aan de mensen die meefietsten. Naar aanleiding van een artikel dat uiteindelijk geplaatst werd in 
een prikkend internationaal tijdschrift, verscheen in een landelijke krant een nieuwsrubriek met de titel: "Geen namen, rugnummers!" Ofschoon ik het daarmee eens ben wat betreft publiceren, wil ik het in dit dankwoord toch liever anders doen. De Tour de France is tenslotte zo leuk als de renners die de ronde rijden. Daarom presenteer ik op pagina 239 en 241 een lijst van bontgekleurde ploegen - met enkel namen en geen rugnummers - die me hielpen om de laatste jaren tot een prettig ronddraaiend geheel te maken. Het is een lijst met enkel kopmannen en geen knechten en iedereen mag natuurlijk transfervrij naar een andere ploeg, want indelen in hokjes blijft arbitrair, maar het is wel zo overzichtelijk. Verder is het per definitie een incomplete lijst, maar de beste manier om iemand te onthouden is hem of haar eerst een keer vergeten, dus een plekje in het team van de vergeten renners is toch hopelijk een dankbare plek in dit dankwoord.

Team IMPAC ${ }^{3} \mathrm{~T}$ stond vanaf dag één als een huis. In de mooie bundeling van internationale krachten mocht ik vanaf de start mee in de slipstream tot ik zelf sterk genoeg was voor wat kopwerk. Geert-Jan, je bent de verpersoonlijking van de woorden pro \& motor. Als geen ander kun je stimuleren en faciliteren. En als perfecte ploegleider geef je precies op tijd aan wanneer er een gevaarlijke bocht komt of wanneer ik een demarrage mocht plaatsen. Je houdt mensen uit de wind wanneer het nodig is en juicht eigen initiatief toe wanneer het kan. Ik vind het dus helemaal niet zo gek dat er een plaats naar je vernoemd is in het fietsparadijs van de Ardennen. Ontzettend bedankt voor je bijzondere enthousiasme, je steun en je huisartsgeneeskundige blik op onderzoek en praktijk, die je al met me hebt willen delen vanaf onze eerste kennismaking.

Rogier, onze samenwerking begon onbewust in Wyck en bewust in datzelfde Oslo en dit boekje is het gevolg en vervolg van jouw onderzoek. Je geweldige betrokkenheid heeft ertoe geleid dat we niet één, maar zelfs twee gerandomiseerde trials konden doen in drie winters. Waar we begonnen als promovendus en dagelijks begeleider is het tegenwoordig eerder een goeddraaiend Limburgs-Brabants spitsenduo dat beurtelings wegdraaiende voorzetten met een tegendraadse kopbal effectief in een doel werkt. Ik had geen benul van ballen, noch van voorzetten, maar je hebt me het kunstje aardig geleerd en Puerto Rico was een gepast hoogtepunt om de resultaten van onze trials de wereld in te schieten. Blijt jammer dat ik je met squash niet kan verslaan, maar ge zijt in ieder geval de beste M\&M verslindende Brabander die ik ken. 


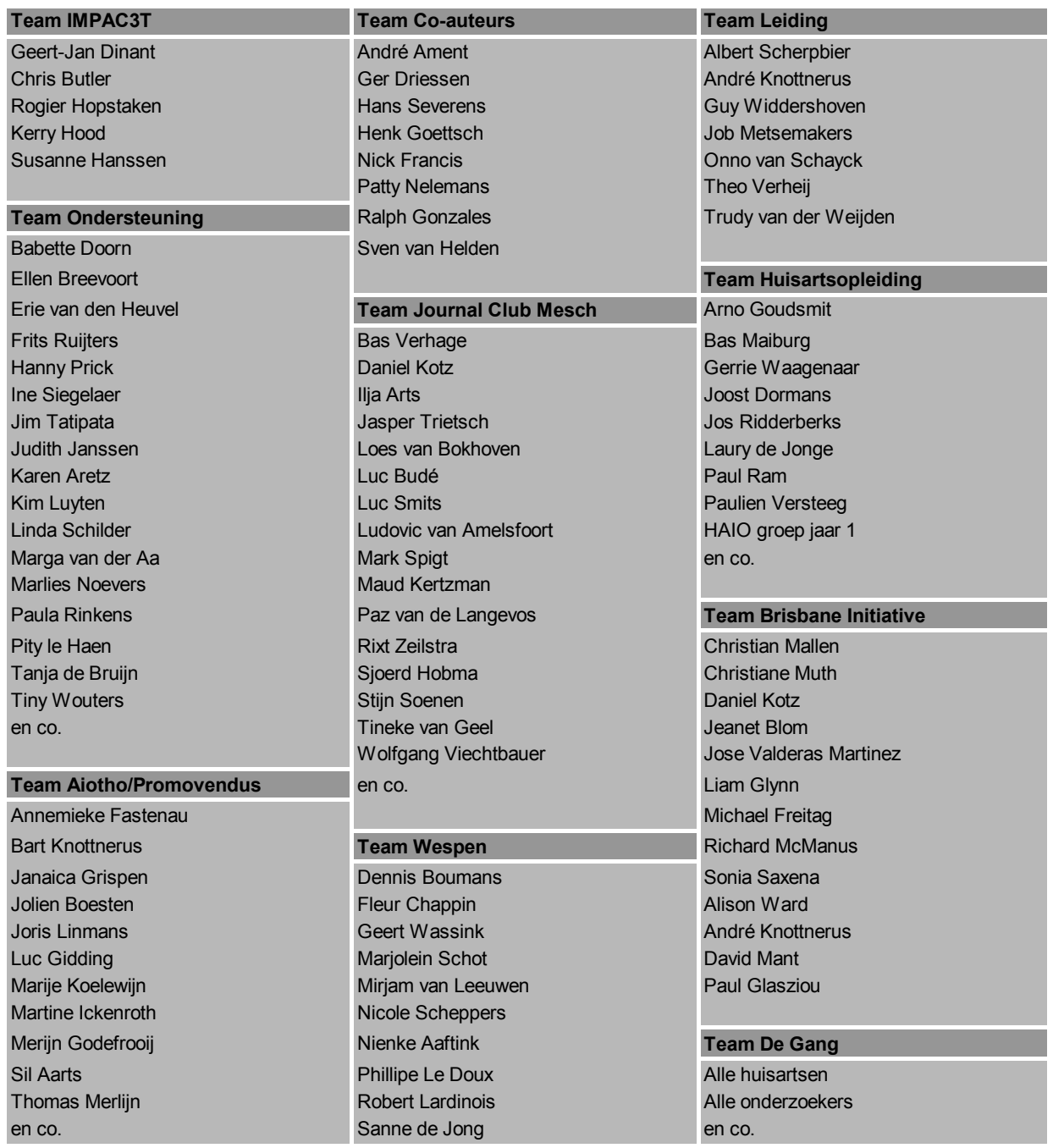


Susanne, een onderzoek zonder goede onderzoeksassistentie is als een volleybalploeg zonder spelverdeler. Jij weet dat, want niet alleen heb je de lengte van een spelverdeler, ook komen alle onderzoeksballen, hoe onmogelijk ook, op een of andere manier elke keer weer prachtig geplaatst terug dankzij jou. Veelzijdig en sociaal heb je de afgelopen jaren de IMPAC ${ }^{3} T$ en CAPRESA studies en mijn andere begeleidende hersenspinsels van alle gemakken en contacten voorzien. We werkten met 71 huisartsen en in elke praktijk was jouw naam voldoende om alle gegevens meteen met een glimlach te mogen ontvangen. Ik was nogal eens afwezig door een co-schap of later in de huisartspraktijk en dankzij jou hoefde ik me nooit zorgen te maken. Bedankt voor deze fijne samenwerking, en ik stel voor om over te gaan op winegums want ik ben nog misselijk van de dropjes.

To the British part of the team; our project was a true Dutch-Welsh collaboration from the start. It has been an honour to work with the Cardiff department and I have been amazed by the progress your department made throughout the years. You're a wonderful research team in common infections and your input in my studies was outstanding. A cycling team riding a team time trial is as weak as its slowest rider. I don't think we ever had one. The exchange of thoughts, ideas, and papers was fast, efficient, and very enjoyable above all.

Chris, as a world citizen with South-African roots, a Dutch wife and Canadian connections, you combine excellent international collaboration with perfect and personal mentorship. You remain unbeatable in scientific writing and attention for detail, which is why I'm inclined to rename 'track changes' into 'Chris changes' in my word processor. You truly sometimes make medical science merge with poetry. I'm hoping that these years were the start of an even closer collaboration in years to come. Baie dankie vir jou ondersteuning en die goeie samewerking die afgelope jare, ek het dit baie geniet. Lekker soos ' $n$ krekker!

Kerry, l've never met a statistician with such a great sense of humour and feeling for clinical relevance. And although I can't image that you think even faster than you speak, it actually always makes sense what you say, which is a joy. Ever since we watched rugby together in Maastricht after GRIN I'm addicted to watching these great matches (supporting Wales of course). My Welsh isn't up to standards yet, but here we go anyway: Diolch yn fawr am dy gefnogaeth a'r sgwrsiau braf a gawsom yn ystod ein gwaith gyda'n gilydd. Grêt bod ni wedi llwyddo i ddatrys a oes gan moch pengliniau :) Edrych ymalen i weithio gyda ti yn y dyfodol! 


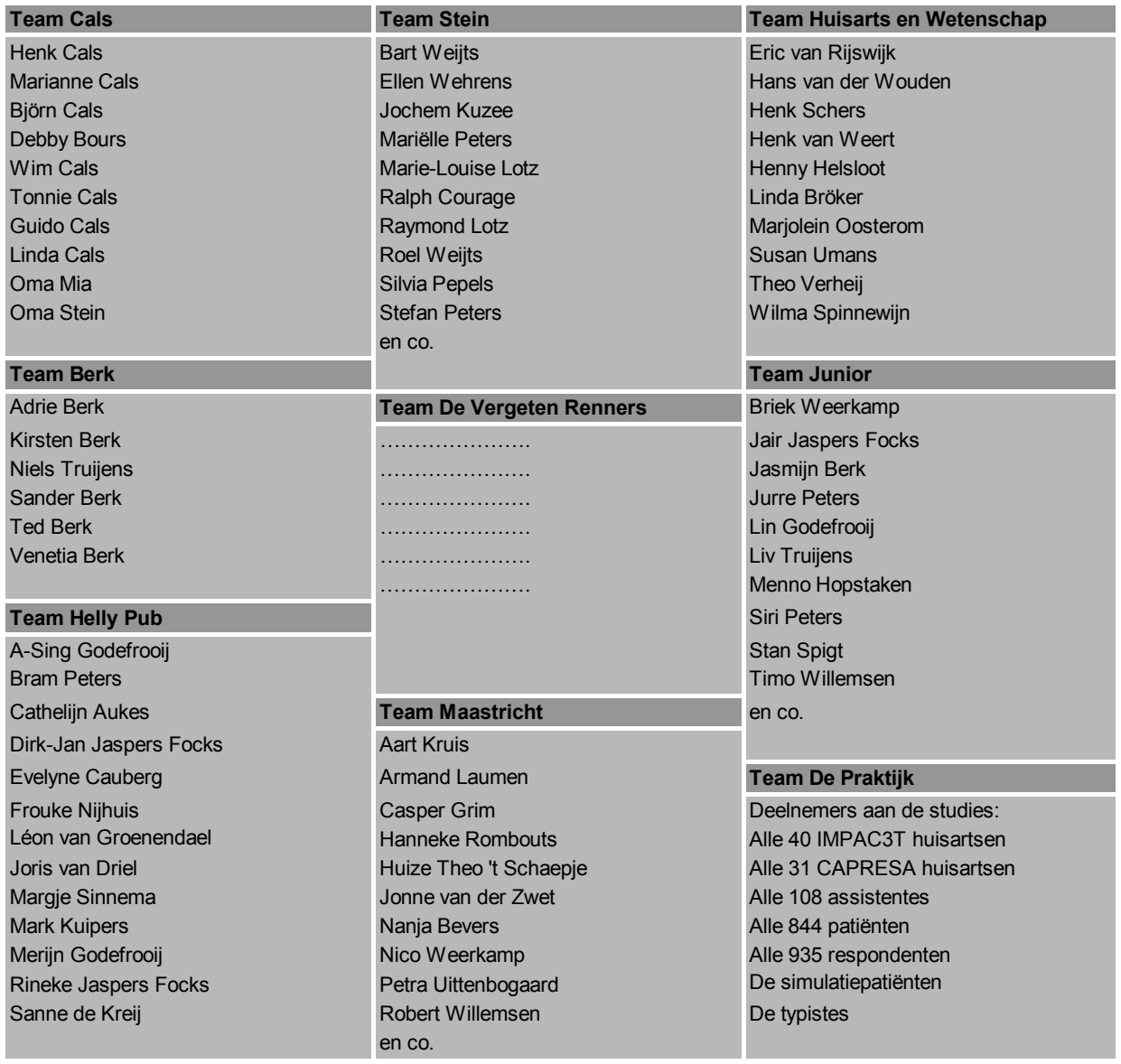

Writing in medicine is exciting and papers simply get better and better if you can rely on such a wonderful team of Co-authors. Thanks for our colourful collaboration! Nick, there were many similarities between our trials and it has been great to see them both end up in the BMJ. I enjoyed our coffee time conversations and our runs through Bute Park. Great to have you as a coauthor and I hope we can continue our mutual efforts and collaboration, both in research and in running.

Net als in de sport heeft ook het onderzoek scheidsrechters nodig. Beste Albert Scherpbier, André Knottnerus, Theo Verheij en Trudy van der Weijden, onze wegen kruisten elkaar al eerder en ik ben zeer verheugd dat jullie mijn manuscript als grand jury wilden beoordelen en hoop terdege dat onze wegen zich blijven kruisen (Team Leiding). André, terwijl onze kamers in Maastricht 
slechts 10 meter van elkaar verwijderd zijn, mocht ik je met veel plezier en bewondering in Oxford meemaken als voorzitter van de Brisbane Initiative bijeenkomst. Fellow BI members, it wasn't just the wonderful dining rooms and century-old student halls which gave our residential weeks a bit of Harry Potter magic. Our 2008 cohort is an inspiring group of GP-researchers and I'm honoured to be part of it. Many thanks to all of you and to the course leaders André, Alison, David and Paul for the great intervision, collaboration and discussions on the challenge of combining clinical work and research in general practice (Team Brisbane Initiative).

En natuurlijk hebben we in de wondere wereld van acronymen en afkortingen ook een naam voor deze combinatie: Aiotho zou niet misstaan als Japans automerk, noch als vechtsport naast Jiujitsu en Taekwondo, het is echter de naam voor huisartsen-in-opleiding die ook onderzoek doen. Een mooie combinatie binnen de huisartsgeneeskunst waar 1 plus 1 toch echt soms 3 wordt. Gaaf dat we inmiddels een nationaal netwerk hebben voor onze groep bezige bijen. Bart en Thomas, bedankt voor jullie voorgaande en verregaande inspanningen daarvoor. Ooit gaat het ons allemaal zeker lukken om 48 uur in een dag te proppen.

Toen ik als student-promovendus begon viel ik enigszins tussen de wal van de oude aiotho's en het schip van de nieuwe aiotho's, maar inmiddels is die oude wal een hele sterke met vaste voeten in de praktijk en varen we met de nieuwe club vrolijk vooruit (team Aiotho/Promovendus). Jolien, Martine, Joris en Merijn, en ook Marije, Tineke, Margje (ook CAPHRI!) en de andere (ex)aio's op de afdeling; mooi dat onze deuren op de vakgroep altijd open staan en dat de gangen zich perfect lenen voor onze discussies over zinvolle, zinhalfvolle en de zinmagere zaken.

De Afdeling Huisartsgeneeskunde is sowieso een prettige werkplek om te vertoeven. Ofschoon de mate van werkplezier omgekeerd evenredig is aan de smaak van de automatenkoffie, doet het eerste dat laatste toch snel vergeten. Het is een grote en leuke club mensen, waarmee je een tourpeleton ruim kunt vullen, onder de vakkundige leiding van koersdirecteur Job, en behorend bij de nog grotere CAPHRI club van Guy en Onno. Job, Onno en Guy, bedankt voor jullie steun en de creatie van rustig vaarwater en wind in de zeilen de afgelopen jaren. ledereen van de vakgroep huisartsgeneeskunde en de school CAPHRI (waaronder de teams Aiotho/Promovendus, Leiding en De Gang), hartelijk dank voor de leuke ontmoetingen in de wandelgangen en de ongepland langdurige gesprekken bij diezelfde koffieautomaat. Met echt elke vakgroepvraag van A tot $Z$ kun je sjiek, sjoen en sjarmant bij Ine terecht. Maar ook gekke getallen, piepende printers, beperkte budgetten of anarchistische agenda's; overal zijn er mensen die je voordat het überhaupt warm aanvoelt al uit de brand helpen (team Ondersteuning). Zelfs toen de hele afdeling na een verhit incident onverhoopt naar rookworst rook, gingen de herstelwerkzaamheden soepel door 
tot alles weer in tintelfrisse staat was opgeleverd. Onze onderzoeksgegevens waren toen gelukkig al allemaal ingevoerd en gecleand door Paula en Ger. Bedankt voor jullie getallengoochelgenot en syntaxplezier en sorry als ik soms wat hard van de datastapel rende met m'n uitleg. Dankzij jullie werk kon ik al vroeg gedegen analyse- en schrijfwerk doen. Het gebundelde resultaat ligt voor jullie. En ook de eindsprint naar de drukproeven hoefde ik niet alleen aan te trekken. Tiny, sowieso dorpsgenoot met de rollende $r$, maar vooral perfecte planner en lay-outer voor de puntjes op de i. Jouw werk zorgde voor een mooie kers op de toch al lekkere promotietaart.

Diezelfde spirit als op het onderzoeksgedeelte van de vakgroep heerst ook op de huisartsopleiding waar ik met veel plezier de eerste helft al heb mogen afronden (team Huisartsopleiding). HAIO groep jaar 1, we hadden een mooi jaar samen, maar toch excuses dat het Limburgs kwartiertje meestal Jochen's kwartiertje te laat was. In de praktijk in Ulestraten was ik wel altijd op tijd, behalve die tweede werkdag dan.... Jos, bedankt voor het geweldige eerste jaar van de opleiding die jij en je team me bezorgd hebben. Als co-assistent zetten Laury en jij me perfect in de startblokken en als HAIO mocht ik een mooie doorstart maken bij jou in Ulestraten en de Hagro in Meerssen. Waar mag ik ooit nog eens visites rijden in zo'n blitse babyblauwe Amazone?

Voordat ik als co-assistent aan dit traject begon, deed ik mijn eerste onderzoekservaring op als wetenschapsstudent bij de broze botten van de vakgroep chirurgie. Sven, bedankt voor je begeleiding en voor mijn allereerste publicatie. Tijdens het tellen van je fracturen was die onderzoeksvibe er opeens. Krap een jaar na onze samenwerking mocht ik zelf al studenten begeleiden, want op de vakgroep huisartsgeneeskunde zoemen er altijd wel wetenschapsstudenten rond (team WESP). Het vlijtige elftal dat ik heb mogen begeleiden heeft een belangrijke bijdrage geleverd aan dit proefschrift en ik ben er trots op dat jullie inmiddels allemaal co-auteur van een geaccepteerd artikel zijn geworden. Jullie waren de allerleukste én beste denktank die je je als promovendus kunt wensen.

Denktanken bestaan overigens ook met Michelin sterren. De Journal Club Mesch is inmiddels een initiatief waar menig onderzoeksgroep een punt aan zou willen zuigen, al was het maar voor de culinaire hoogstandjes die Mark elke keer weer uit de pan tovert. JCM-ers, bedankt voor de verhitte discussies en food for thought die elke avond oplevert (team Journal Club Mesch). Mark en Daniel, oprichters van de club, maar vooral geweldige collega's en (sport)vrienden, ik ben erg blij dat jullie paranimf willen zijn en de grote trek richting aula in pinguïnpak met me aandurven. We hebben urenlange discussies gevoerd over belangrijke thema's als onderzoek, Guinness en vrouwen en ik denk dat het nu toch echt tijd wordt voor een kookeiland in kamer 3.12 en een biertap in 3.21. Overgewicht is geen risico, want Huisartsgeneeskunde beweegt, sinds het hardloopvirus geleidelijk door de 
gangen waart. Zo is iedereen inmiddels gewend aan de blote benen van Sjoerd, Mark en mijzelf als we voor ons rondje Savelsbos gaan voor een inspirerende mengeling van modder, zweet en bladeren. Bedankt Grizzly maatjes voor de prettige intervisie op draftempo.

Volgens mij worden de beste onderzoeksideeën namelijk bedacht tijdens het sporten of in het café (bij voorkeur niet tegelijkertijd, maar wel in die volgorde). In het kader van samen is leuker dan alleen, hebben we het afgelopen jaar behoorlijk wat kilometers in Limburg, binnen- en buitenland, gedraafd en gepedaleerd en zijn er behoorlijk wat capucinnootjes en pilsjes weggespoeld met een fantastische club van wisselend pluimage (de één terrast wat meer dan de ander fietst, terwijl een ander weer meer loopt dan het terras lang kan zijn). De Teams Maastricht, Helly Pub en Stein stonden altijd klaar voor goede gesprekken, mooie rondjes door het heuvelland en vooral oeverloos geouwehoer, waarvoor meer dan dank. Binnenkort geef ik een rondje (drank of sport, naar keuze).

Pap en mam, jullie rol gaat natuurlijk wat verder terug dan de duur van een proefschrift. Al bijna dertig jaar zijn jullie de trouwste en beste supporters. Voorsprong begint bij de oorsprong, en daarna is het enkel een kwestie van vasthouden. En juist de afgelopen jaren ben ik ontzettend blij dat we zoveel leuke dingen samen meemaken. Dit proefschrift draag ik met veel plezier en liefde aan jullie op. Mam, het kan geen toeval zijn dat je meisjesnaam Vrolijk is. Laten we nog lang samen surfen op de geluidsgolven van de muziekfestivals, zoals we al doen vanaf het moment dat je me de eerste keer meenam naar Pinkpop 1994 waar we tijdens Rage Against The Machine een kleine aardbeving mee veroorzaakten. Pap, ik geniet altijd enorm van onze gesprekken, die we vroeger al hadden tijdens de schoolpauzes aan de keukentafel. Nieuwsgierigheid, kritisch redeneren en organisatietalent heb je me met de yoghurtlepel ingegoten en zo heb je toch echt onbewust de basis voor dit promotietraject gelegd. En Rowwen Hèze heeft zeker gelijk met dat ene liedje. Björn, wie wenst er nou geen grote broer die de afvalrace om commando te worden als een veelzijdige tienkamper doorstaat? Als fysiotherapeut heb je gouden handjes (lees ijzeren handen) en het lijkt me geweldig om ooit nog eens samen te werken in de praktijk. Maar ik besef dat ik je dan wel beter op de hoogte moet houden van mijn where-abouts. Ik zal daarom voortaan mijn GPS coördinaten dagelijks doormailen. Debby, de flair uit werelddorp Catsop die je inbrengt in ons gezin doen de buik- en wangspieren goed. We houden de pleisters en het verband altijd in de aanslag (team Cals).

Over dorpen gesproken; toen ik vroeger vertelde dat mijn vriendin in De Kwakel woonde, keken de meeste mensen alsof ze het in Duckstad hoorden donderen. Toch bestaat het echt, het is zelfs een leuk kwekersdorpje en ik mag er na negen jaar nog altijd graag komen bij de Berkjes, inmiddels schoonfamilie en nog sportgekker dan de Calsjes. Adrie en Ted, bij jullie is het altijd gastvrij en 
gezellig met een super G. Bedankt dat ik jullie jongste dochter mocht ontvoeren naar Maastricht. Kirsten, Niels, Sander en Venetia, ondanks dat we enigszins verspreid wonen, treffen we elkaar altijd chaotisch gezellig op de lepenlaan en met de kleine Liv en Jasmijn erbij wordt dat alleen nog maar leuker (team Berk). Want babies, peuters en kleuters zijn de meest doorgewinterde onderzoekertjes die er bestaan. Bij hen zijn nulhypotheses per definitie om aan te vechten (het liefst zo vaak mogelijk) en ik geniet van de fantastische trial and error momentjes die we meemaken met de letterlijk groeiende club onderzoekers-in-de-dop in Maastricht en omstreken (team Junior).

Birgit, inmiddels zwemmen, fietsen, lopen en lachen we al negen jaar samen. Jij bent voortdurend ter land, ter zee of in de lucht voor wedstrijden en trainingen en ik ren, spetter en zweef trots met je mee. Je legendarische telefoontjes hebben de voortgang van dit boekje zeker niet in de weg gezeten ("anders werk jij rustig door tot een uur of acht voor je naar huis komt, dan train ik nog even wat"). Verder ontdekte ik dankzij jou dat de combinatie van berg-, bos- en chloorlucht een prima omgeving is om je proefschrift af te schrijven en dat ik ideetjes moet inspreken op mijn mobiele telefoon om de (mentale) weg niet kwijt te raken tijdens onze fietstrainingen. Je vrolijkheid, kookkunsten en dolle dansjes maken elke dag op ons topstekkie in Wyck tot een feest (maar nu je je archeologische skills tijdelijk begraven hebt, moeten we misschien toch eens wat doen aan die botten in de kelder). Onze eerste 3003 dagen samen waren van 1000 en 1 pracht en ik loop nog graag een paar eeuwen met je door, misschien ooit wel met een rijtje vrolijk kwetterende en stuiterende rossigblonde Cals-Berkjes in ons kielzog. Je bent een schatje.

De eindstreep van dit dankwoord en het proefschrift is nu in zicht. Ik hoop op leuke foto's bij de finish en geen noodzaak tot een foto-finish. Ik heb enorm genoten van de tocht samen met jullie en ik hoop dat het plezier af te lezen is aan dit boekje in z'n geheel. En dan hoog tijd voor de cooling down. En die is al napratend met een koel drankje op z'n allerbest. Ik kijk er al naar uit!

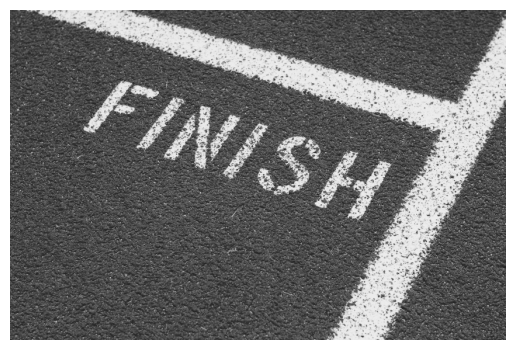










\section{International peer-reviewed publications}

1. Cals JW, Schot MJ, de Jong SA, Dinant GJ, Hopstaken RM. Testing C-reactive protein at the point of care to assist antibiotic prescribing for respiratory tract infections: a randomized controlled trial in family practice. Ann Fam Med 2009 accepted.

2. Cals JW, Hood K, Aaftink N, Hopstaken RM, Francis NA, Dinant GJ, Butler $\mathrm{CC}$. Predictors of patient-initiated reconsultation for lower respiratory tract infections in general practice. Br J Gen Pract 2009;59:761-4.

3. Cals JW, Butler CC, Dinant GJ. 'Experience talks': physician prioritisation of contrasting interventions to optimise management of acute cough in general practice. Implementation Science 2009;4:57.

4. Cals JW, Butler CC, Hopstaken RM, Hood K, Dinant GJ. Effect of point of care testing for $\mathrm{C}$ reactive protein and training in communication skills on antibiotic use in lower respiratory tract infections: cluster randomised trial. BMJ 2009;338:b1374.

5. Hopstaken RM, Cals JW, Dinant GJ. Accuracy of lipopolysaccharidebinding protein (LBP) and fibrinogen compared to C-reactive protein (CRP) in differentiating pneumonia from acute bronchitis in primary care. Prim Care Resp J 2009;18:227-30.

6. Cals JW. Comment on: The higher the number of daily doses of antibiotic treatment in lower respiratory tract infection the worse the compliance. J Antimicrob Chemother 2009; 63:1083-4.

7. Cals JW, Kotz D. Researcher identification: the right needle in the haystack. Lancet 2008;371:2152-3.

8. Cals JW, Hopstaken RM, Le Doux PH, Driessen GA, Nelemans PJ, Dinant GJ. Dose timing and patient compliance with two antibiotic treatment regimens for lower respiratory tract infections in primary care. Int $\mathrm{J}$ Antimicrob Agents 2008;31:531-6.

9. Cals JW, Boumans D, Lardinois RJ, Gonzales R, Hopstaken RM, Butler CC, Dinant GJ. Public beliefs on antibiotics and respiratory tract infections; an internet-based questionnaire study. Br J Gen Pract 2007;57:942-7. 
10. Cals JW, Scheppers NA, Hopstaken RM, Hood K, Dinant GJ, Goettsch H, Butler CC. Evidence based management of acute bronchitis; sustained competence of enhanced communication skills acquisition in general practice. Patient Educ Couns, 2007;68:270-8.

11. Cals JW, Hopstaken RM, Butler CC, Hood K, Severens JL, Dinant GJ. Improving Management of Patients with Acute Cough by C-reactive protein point of care testing and Communication Training (IMPAC ${ }^{3} \mathrm{~T}$ ); study protocol of a cluster randomised controlled trial. BMC Family Practice 2007;8:5.

12. Cals JW, Hopstaken RM. Lower respiratory tract infections: treating patients or diagnoses? J Fam Pract 2006;55:545-6.

13. Cals JW, Joyner P, Tuffley RJ, Dinant GJ. Vegemite and chocolate sprinkles: Dutch medical students in rural Australia. Med J Aust 2006;185: 661-3.

14. van Helden S, Cals JW, Kessels F, Brink P, Dinant GJ, Geusens P. Risk of new clinical fractures within 2 years following a fracture. Osteoporos Int 2006;17:348-54.

\section{Electronic letters}

1. Cals JW, Kotz D. An author identification system for vast coverage of researchers. Science 25-06-2009.

2. Cals JW. Prikken, of toch maar praten bij luchtweginfecties in de eerstelijn?, comment on: Bepaling van procalcitonine om ineffectief antibioticagebruik bij acute luchtweginfecties te verminderen" Ned Tijdschr Geneeskd. 2009;153:B131.

3. Cals JW. The double-Dutch program of combining vocational training and research, Fam Pract 02-12-2008.

4. van Amelsvoort LG, Cals JW, Spigt MG. Time to upgrade the original CONSORT statement. Ann Int Med, 04-04-2008.

5. Hopstaken RM, Cals JW, Dinant GJ. CRP helps to exclude pneumonia. BMJ, 29-06-2005. 


\section{Publications in national journals}

1. Cals JW, Hopstaken RM, Butler CC, Hood K, Hanssen S, Dinant GJ. Praten en prikken bij lageluchtweginfecties, training in communicatieve vaardigheden en de CRP sneltest. Huisarts en Wetenschap 2009; 52:576-83.

2. Cals JW, Hopstaken RM, Butler CC, Hood K, Hanssen S, Dinant GJ. Praten en prikken bij lageluchtweginfecties, training in communicatieve vaardigheden en de CRP sneltest. Huisarts Nu 2009;38:297-305.

3. Cals JW. De dokterstas als anker, Medisch Contact 26 maart 2009.

4. Hopstaken RM, Cals JW, Sneltest voor C-reactieve proteïne bij luchtweginfecties. Pat Care 2009:25-9.

5. Hopstaken RM, Cals JW, The practice guideline 'Influenza and influenza vaccination' (first revision) from the Dutch College of General Practitioners; a response from the perspective of general practice. Ned Tijdschr Geneeskd 2008;152:2108-10.

6. Cals JW, Lardinois RJ, Boumans D, Gonzales R, Hopstaken RM, Butler CC, Dinant GJ. Antibiotica en luchtweginfecties; wat weet de leek? Huisarts en Wetenschap 2008;51:190-4.

7. Cals JW, Scheppers NA, Hopstaken RM, Hood K, Goettsch H, Dinant GJ, Butler $\mathrm{CC}$. Een contextgebonden training in communicatieve vaardigheden bij lageluchtweginfecties voor huisartsen. Tijdschrift voor Medisch Onderwijs 2008;27:137-46.

8. Cals JW. Implementatie van prestatiepremies voor kwaliteit van zorg heeft geen invloed op intrinsieke motivatie van huisartsen - referaat. Ned Tijdschr Geneeskd 2007;151:2806.

9. Cals JW. Continuïteit van zorg lijkt hervatting van gebruik van statines te bevorderen - referaat. Ned Tijdschr Geneeskd 2007;151:2069.

10. Cals JW. Grotere kans op een recidieffractuur binnen twee jaar na een eerdere fractuur - referaat. Ned Tijdschr Geneeskd 2006;43:2399.

11. van Helden S, Geusens $P$, Cals JW. Incidentie en preventie van fracturen na een minimaal trauma. Ned Tijdschr Traumatologie 2005;13:32-6. 


\section{Contributions to books / Book chapters}

1. Cals JW, van Groenendael L, Dinant GJ. Huisartsgeneeskunde. In: Stilma JS, Borleffs JCC, van Deursen AMM, editors. Coschap over de grenzen. Houten: Prelum, 2009:189-97.

2. Cals JW, Hopstaken RM. Antibiotica bij acute bronchitis, baat het niet, dan schaadt het wel. In: Dinant GJ, Spigt MG, Knottnerus JA, editors. Practicum Huisartsgeneeskunde. Maarssen: Elsevier gezondheidszorg, 2008:121-9.

3. Hopstaken RM, Cals JW. Diagnostiek van lageluchtweginfecties. In: Dinant GJ, Spigt MG, Knottnerus JA, editors. Practicum Huisartsgeneeskunde. Maarssen: Elsevier gezondheidszorg, 2008:79-86.

\section{Awards and recognition}

1. Keynote distinguished paper presentation at the 2008 North American Primary Care Conference (NAPCRG) in Puerto Rico, United States.

2. Prize for best oral presentation of the $\mathbf{2 0 0 8}$ North American Primary Care Conference (NAPCRG) in Puerto Rico, United States.

3. Grant from the Netherlands Organisation for for Health Research and Development (ZonMW) for a position as a MD-medical research trainee (AGIKO) (2008).

4. Invitation for Brisbane Initiative program - an international leadership program for primary care in Oxford, United Kingdom (2008-2010).

5. Grant from the Royal Dutch Academy of Sciences (KNAW) for the development and organisation of the annual European GRIN conference (General Practice Respiratory Infection Network) in Maastricht (2007).

6. Nederlands Tijdschrift voor Geneeskunde award for best presentation at the Maastricht Medical Students Research Conference (MMSRC) in Maastricht (2005). 




\section{Curriculum Vitae}

Jochen Willo Lennert Cals was born on 10 March 1980 as son of Henk and Marianne Cals-Vrolijk and brother of Björn, in Stein, The Netherlands. He obtained his gymnasium diploma at College Sittard in 1998. After backpacking in New Zealand for one year (where he also worked as a pizza cook in the local pub 'The Tote' in Upper Hutt) and studying economics for one year at Maastricht University, he was allowed to enter medical school at that same university. He started to do triathlon in Stein in his youth and gradually progressed to an international level in his high school years. He was a five time national junior champion and member of the Dutch national triathlon team from 1995 until 2003. Before commencing clinical hospital

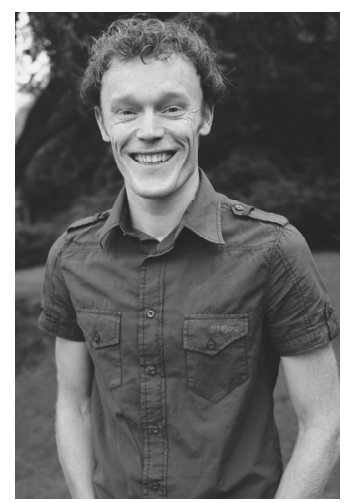
rotations, and ending his competitive triathlon career, he participated in the Ironman distance triathlon in the Franch Alps town of Embrun. Throughout his medical studies, and after having done two medical electives in Australia and Nepal himself, he got involved in the coordination and supervision of students undertaking primary health care medical electives in Australia. He is still coordinating this initiative. He obtained his master degree (with distinction) in 2004 and received his medical degree in 2007. From 2005 onwards, and after a research elective in osteoporosis, he was invited to combine clinical rotations as a medical student with research activities as a $\mathrm{PhD}$ student. This was the start of the respiratory tract infection projects presented in this thesis. In 2007, he was in the opportunity to chair the organisation of the annual European GRIN conference (General Practice Respiratory Infection Network) in Maastricht. In 2008, he was cordially invited to join the Brisbane Initiative, an international leadership course in primary care, hosted by Oxford University. After one year of full-time research at the Department of General Practice, he continued to combine his research activities with clinical work as a trainee general practitioner. He did his first year of vocational training in general practice at GP practice Ulestraten under the supervision of Jos Ridderbeks.

At present, Jochen is halfway through GP training and is combining clinical work with research at the Department of General Practice within the CAPHRI School for Public Health and Primary Care at Maastricht University as a ZonMW MD-medical researcher trainee. After his PhD defence he will continue his research activities as a CAPHRI postdoctoral research fellow, with a specific focus on common infections and patient centered clinical methods in general practice. He is a member of the editorial board of Huisarts \& Wetenschap, the official Dutch GP journal, since 2009.

Jochen is happily married to Birgit Berk, who graduated as an archeologist but currently a professional triathlete. Beyond medicine, he enjoys running and cycling in the wonderful hills around Maastricht, watching sports and art-house cinema, and going out for drinks (preferably a good pint of Guinness or a German Weißbier) with friends. 